Portland State University

PDXScholar

$10-2020$

\title{
Reducing Vehicle Miles Traveled, Encouraging Walk Trips, and Facilitating Efficient Trip Chains Through Polycentric Development
}

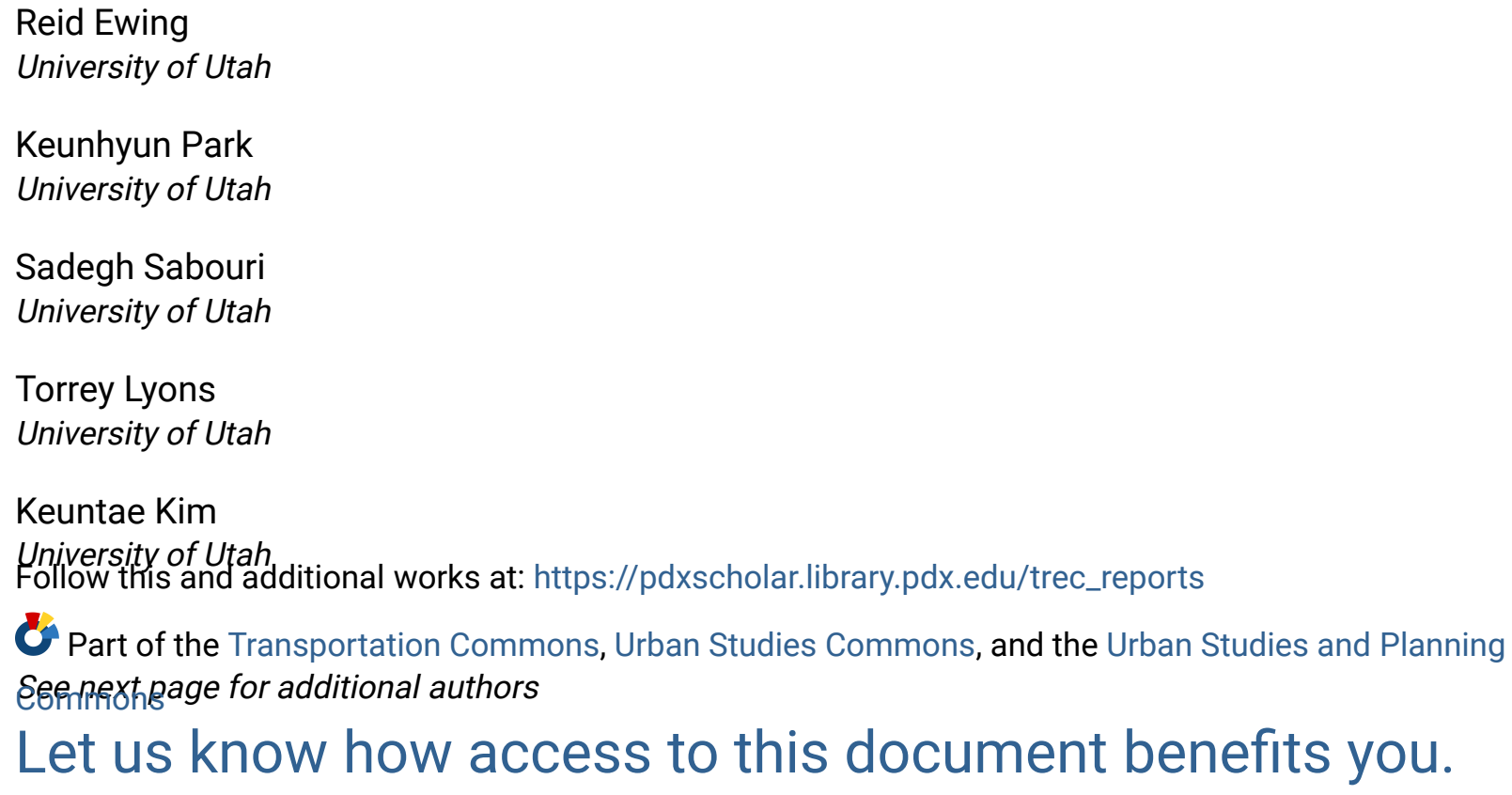

\section{Recommended Citation}

Ewing, R., Park, K., Sabouri, S., Lyons, T., Kim, K., Choi, D., Daly, K., Etminani Ghasrodashti, R., Kiani, F., Ameli, H, Tian, G., Gaspers, D., Hersey, J. Reducing Vehicle Miles Traveled (VMT), Encouraging Walk Trips, and Facilitating Efficient Trip Chains Through Polycentric Development. NITC-RR-1217. Portland, OR: Transportation Research and Education Center (TREC), 2020. https://dx.doi.org/10.15760/trec.255

This Report is brought to you for free and open access. It has been accepted for inclusion in TREC Final Reports by an authorized administrator of PDXScholar. Please contact us if we can make this document more accessible: pdxscholar@pdx.edu. 


\section{Authors}

Reid Ewing, Keunhyun Park, Sadegh Sabouri, Torrey Lyons, Keuntae Kim, Dong-ah Choi, Katherine Daly, and Roya Etminani Ghasrodashti 


\section{Reducing Vehicle Miles Traveled, Encourag- ing Walk Trips, and Facilitating Efficient Trip Chains Through Polycentric Development}

Reid Ewing, Ph.D.

Keunhyun Park, Sadegh Sabouri, Torrey Lyons, Keuntae Kim, Dong-ah Choi, Katherine Daly, Roya Etminani Ghasrodashti, Fatemeh Kiani, Hassan Ameli, Guang Tian, David Gaspers, and John Hersey 


\title{
Reducing Vehicle Miles Traveled, Encouraging Walk Trips, and Facilitating Efficient Trip Chains Through Polycentric Development
}

\author{
Final Report
}

NITC-RR-1217

by

Reid Ewing, Keunhyun Park, Sadegh Sabouri, Torrey Lyons, Keuntae Kim, Dong-ah Choi, Katherine Daly, Roya Etminani Ghasrodashti, Fatemeh Kiani, Hassan Ameli, Guang Tian, David Gaspers, and John Hersey

University of Utah

for

National Institute for Transportation and Communities (NITC)

P.O. Box 751

Portland, OR 97207
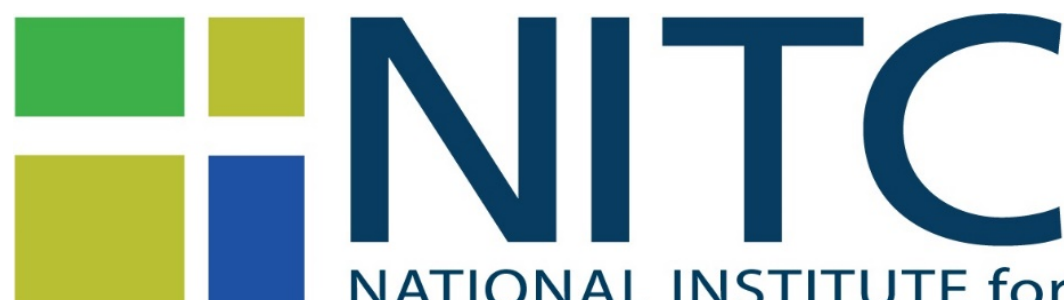

NATIONAL INSTITUTE for

TRANSPORTATION and COMMUNITIES

October 2020 


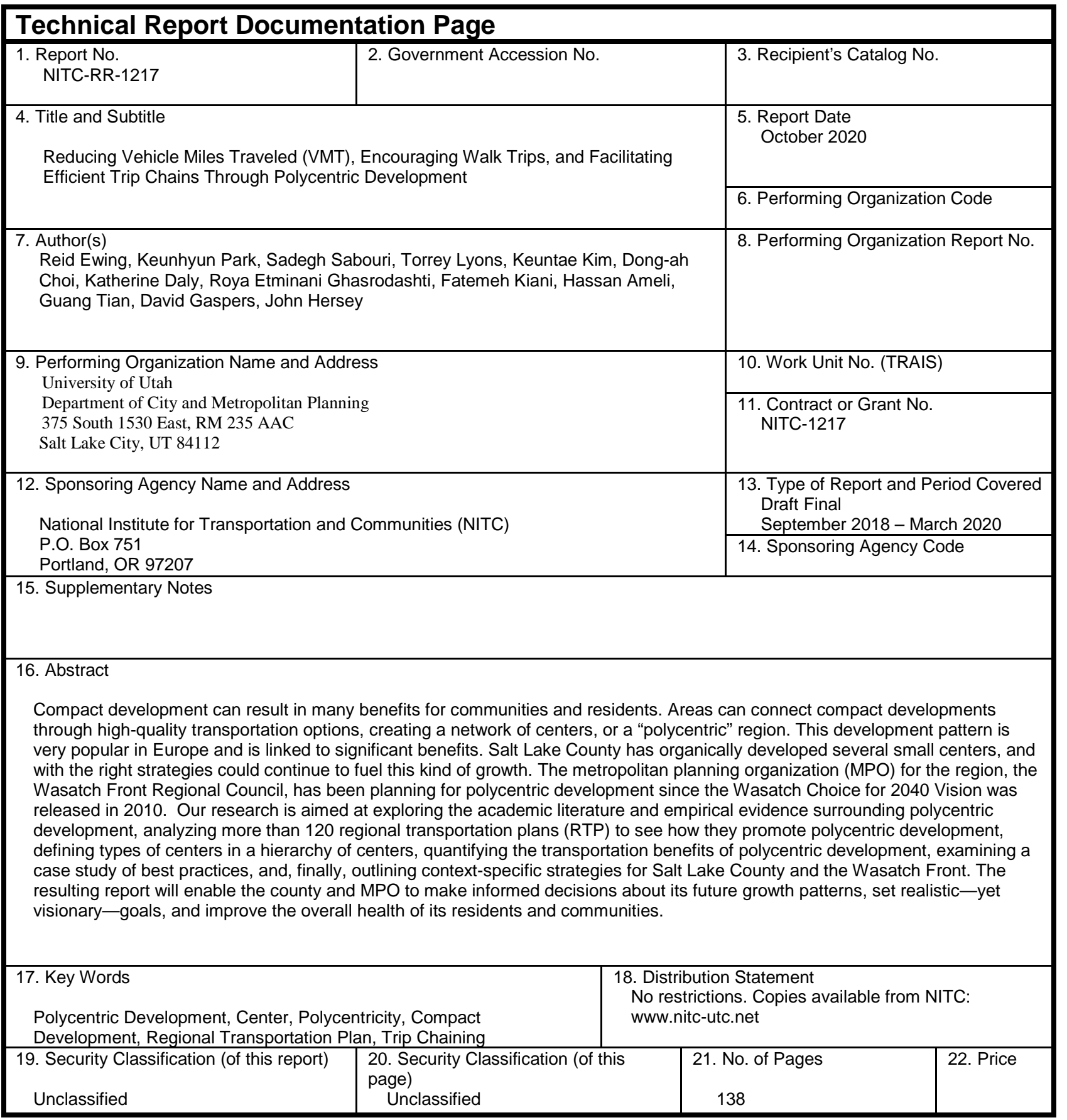




\section{ACKNOWLEDGEMENTS}

We would like to acknowledge partial support from the National Institute for Transportation and Communities (NITC; grant number 1217), a U.S. DOT University Transportation Center and the National Science Foundation (NSF; Grant number BCS123456), Utah Department of Transportation, Utah Transit Authority, Wasatch Front Regional Council, and Mountainland Association of Governments.

\section{DISCLAIMER}

The contents of this report reflect the views of the authors, who are solely responsible for the facts and the accuracy of the material and information presented herein. This document is disseminated under the sponsorship of the U.S. Department of Transportation University Transportation Centers Program in the interest of information exchange. The U.S. Government assumes no liability for the contents or use thereof. The contents do not necessarily reflect the official views of the U.S. Government. This report does not constitute a standard, specification, or regulation.

\section{RECOMMENDED CITATION}

Ewing, R., Park, K., Sabouri, S., Lyons, T., Kim, K., Choi, D., Daly, K., Etminani Ghasrodashti, R., Kiani, F., Ameli, H, Tian, G., Gaspers, D., Hersey, J. Reducing Vehicle Miles Traveled (VMT), Encouraging Walk Trips, and Facilitating Efficient Trip Chains Through Polycentric Development. NITC-RR-1217. Portland, OR: Transportation Research and Education Center (TREC), 2020. 


\section{TABLE OF CONTENTS}

EXECUTIVE SUMMARY

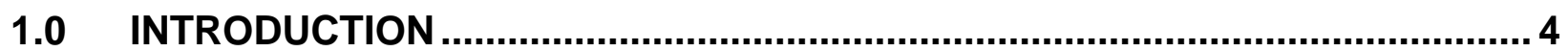

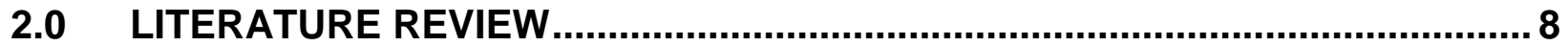

3.0 ANALYSIS OF REGIONAL TRANSPORTATION PLANS (RTP) AND DEFINITIONS OF CENTER TYPES ….............................................................. 10

3.1 DEFINITION AND CHARACTERISTICS OF CENTERS BY TYPE ................... 10

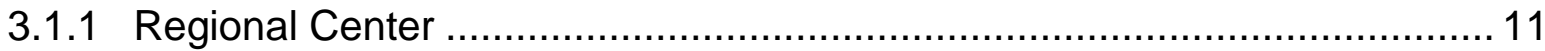

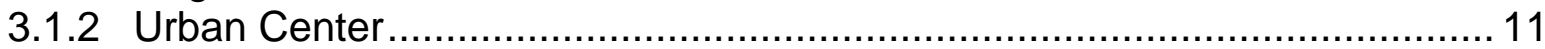

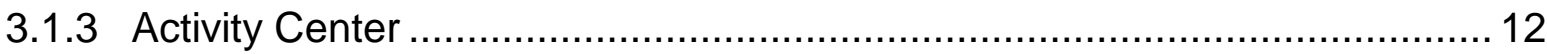

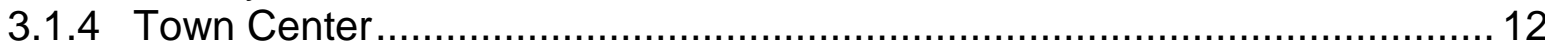

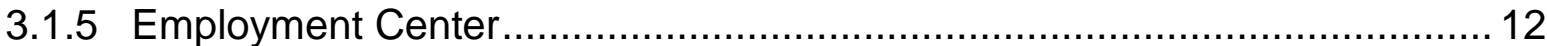

3.2 QUANTITATIVE CRITERIA FOR IDENTIFYING CENTERS........................ 13

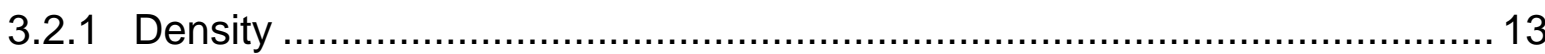

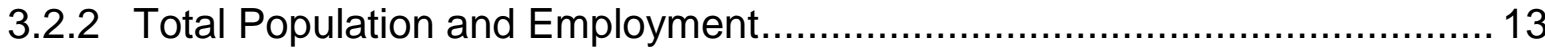

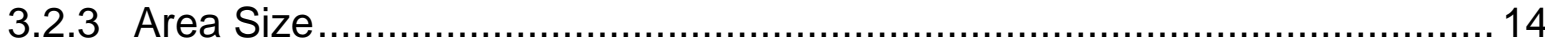

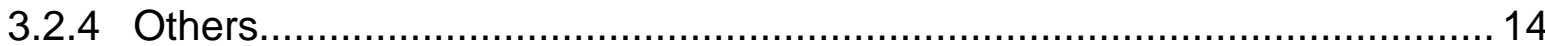

4.0 REVIEW OF SCENARIO PLANS TO IDENTIFY COMMON SCENARIO TYPES 15

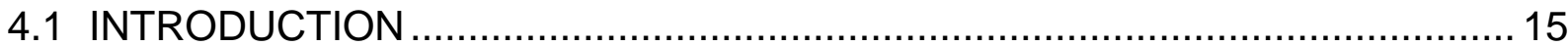

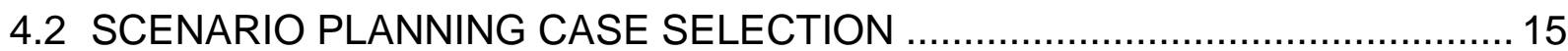

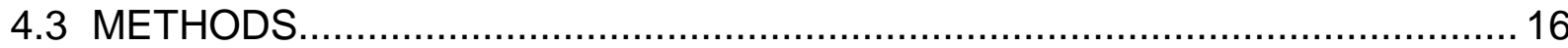

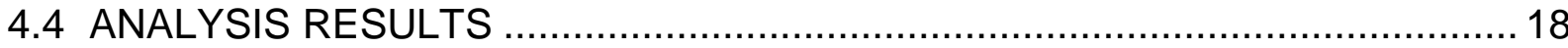

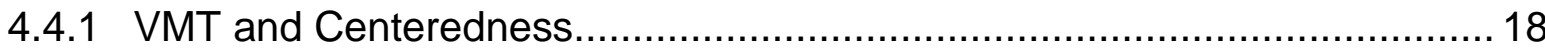

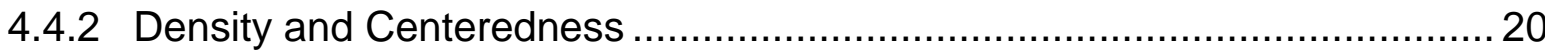

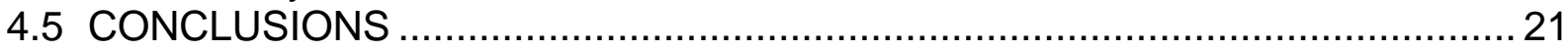

5.0 IDENTIFICATION OF CURRENT AND POTENTIAL CENTERS NATIONALLY

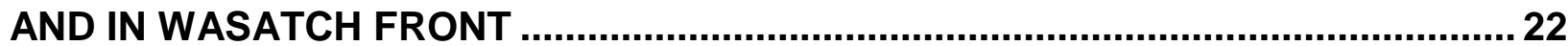

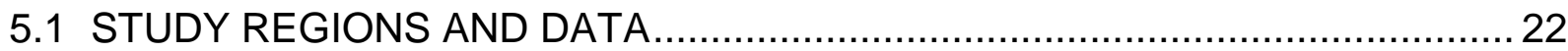

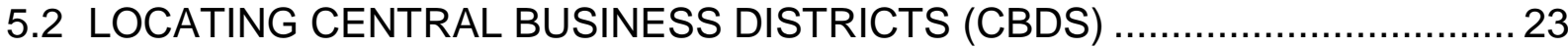

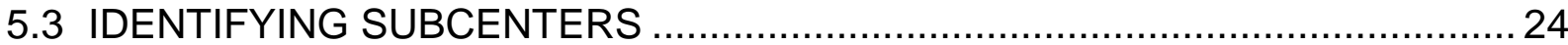

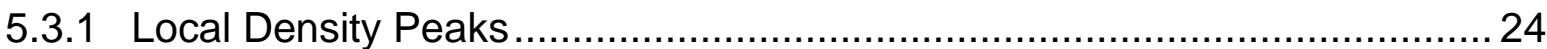

5.3.2 Mixed-Use Developments and Districts.............................................. 25

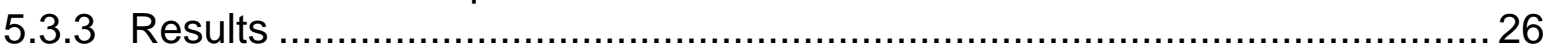

\subsection{ASSESSMENT OF CENTERS NATIONALLY FOR TRANSPORTATION}

IMPACTS

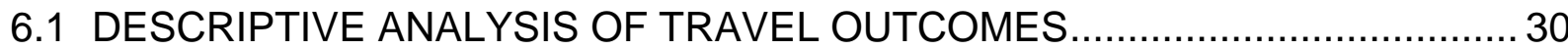

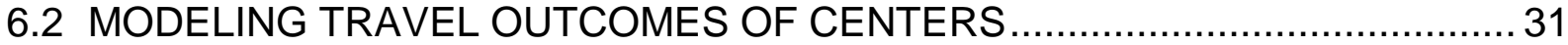

6.2.1 Methods: Propensity Score Matching ..................................................... 31

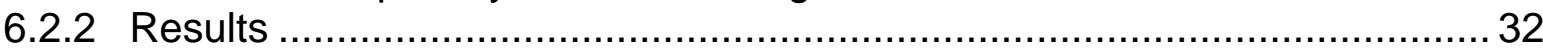

6.3 FINDING OPTIMAL VALUES OF D VARIABLES IN CENTERS: TRIP-LEVEL

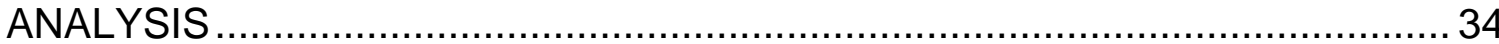

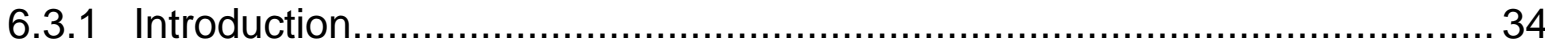


6.3.2 Data and Methods: Generalized Additive Model (GAM) .......................... 35

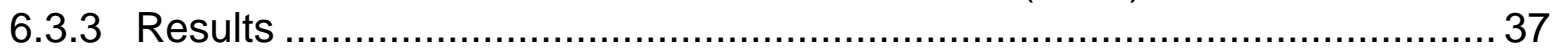

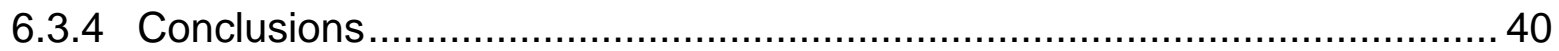

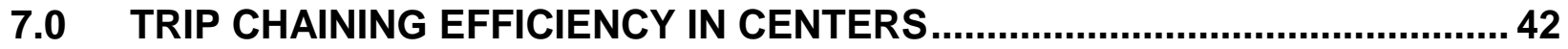

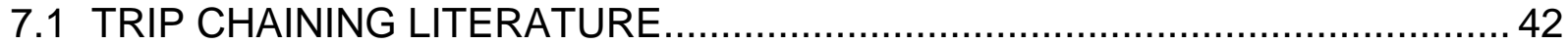

7.2 TRIP, MODE SHARE, AND TOUR PATTERNS ......................................... 45

7.3 METHODS: ONE-WAY ANALYSIS OF VARIANCE (ANOVA) ....................... 47

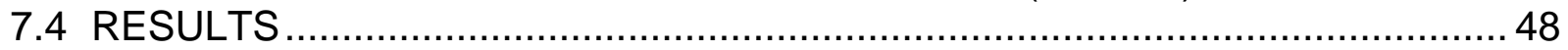

7.4.1 Tour Type 1: Within a Center ........................................................... 51

7.4.2 Tour Type 2: Hybrid (tours with trips both inside and outside a center)....... 51

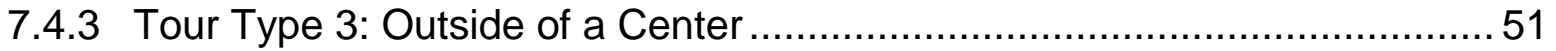

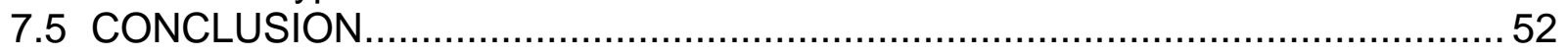

\subsection{CASE STUDY OF POLYCENTRIC DEVELOPMENT STRATEGIES IN}

PORTLAND, OR

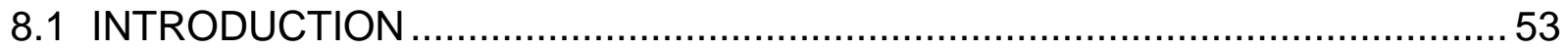

8.2 TOOLS AND STRATEGIES OF THE CITY OF PORTLAND .......................... 54

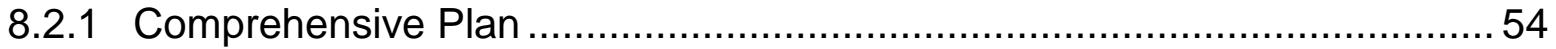

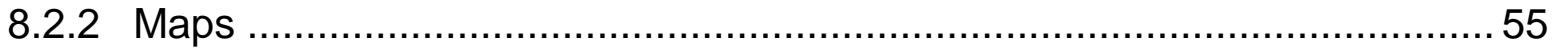

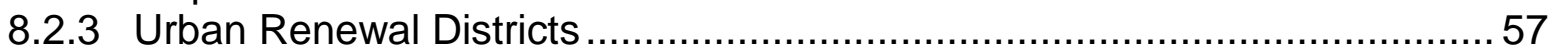

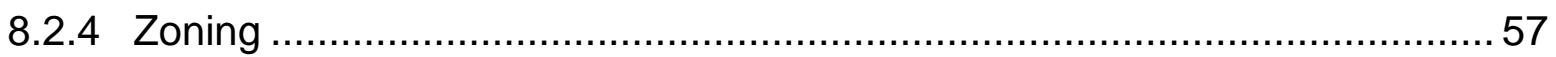

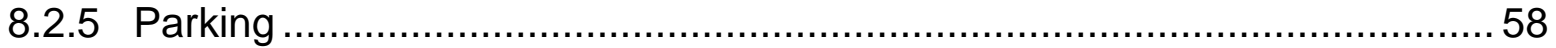

8.2.6 Transportation Demand Management Program Requirements .................. 58

8.3 TOOLS AND STRATEGIES FOR PORTLAND METRO (METROPOLITAN

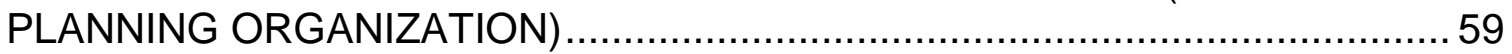

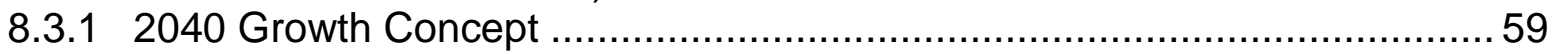

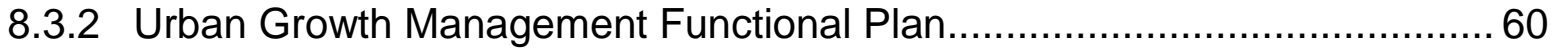

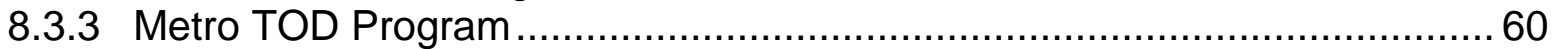

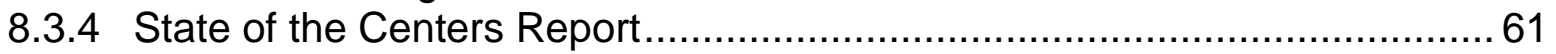

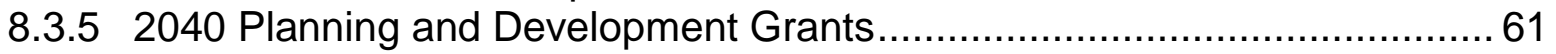

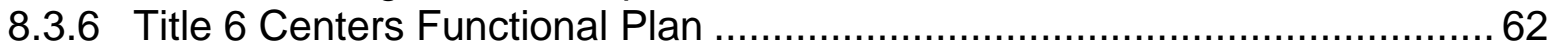

8.4 TOOLS AND STRATEGIES FOR TRIMET TRANSIT AGENCY .....................62

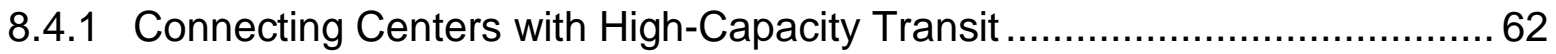

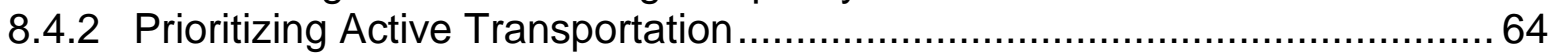

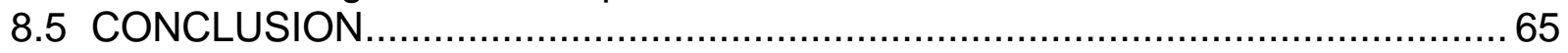

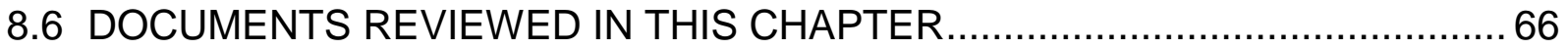

9.0 CASE STUDY OF POLYCENTRIC DEVELOPMENT STRATEGIES IN THE

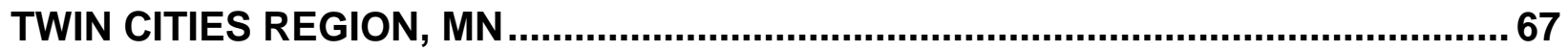

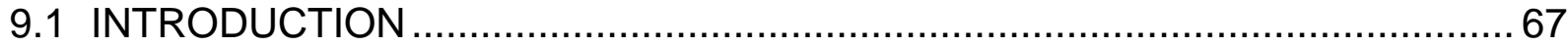

9.2 REGIONAL HISTORY OF POLYCENTRIC DEVELOPMENT .........................6 68

9.3 TOOLS AND STRATEGIES OF THE METROPOLITAN COUNCIL (MPO) AND

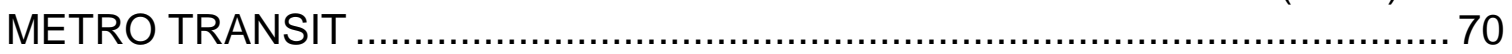

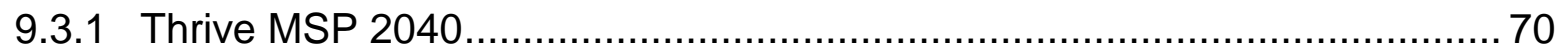

9.3.1.1 Metropolitan Urban Service and Rural Service Areas ....................................71

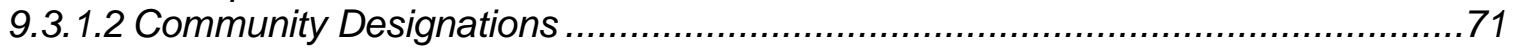

9.3.1.3 Minimum Average Density Thresholds ....................................................... 72 
9.3.1.4 Infill, Adaptive Reuse, and Redevelopment............................................. 73

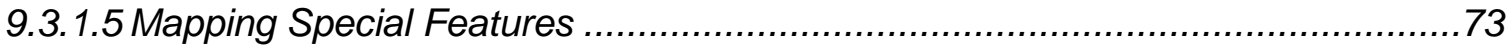

9.3.2 2040 Transportation Policy Plan.............................................. 74

9.3.2.1 Enhance Multimodal Access to Job Concentrations..................................... 74

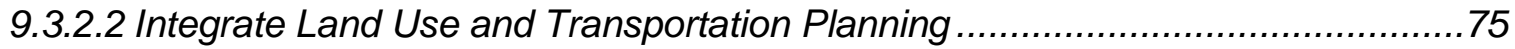

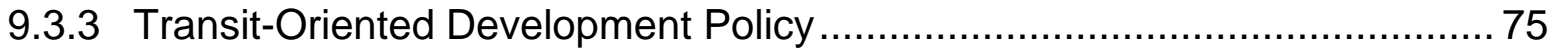

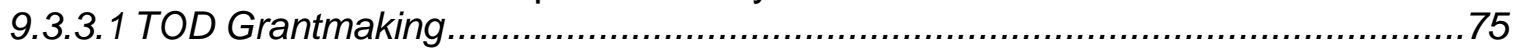

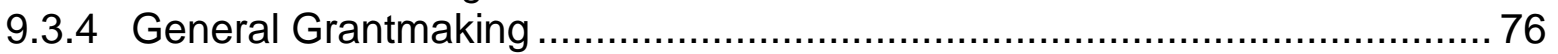

9.4 TOOLS AND STRATEGIES OF THE CITY OF MINNEAPOLIS ................... 76

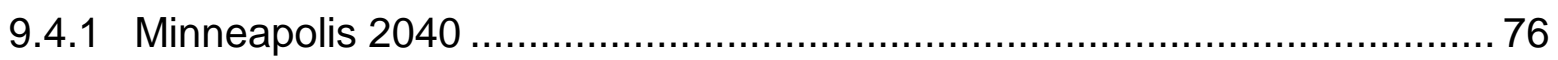

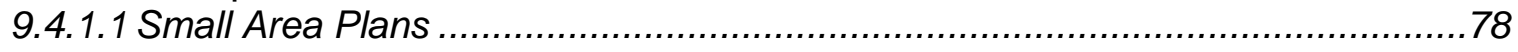

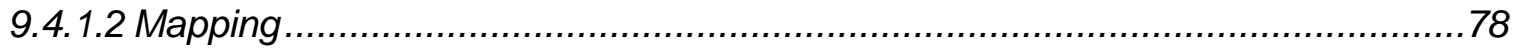

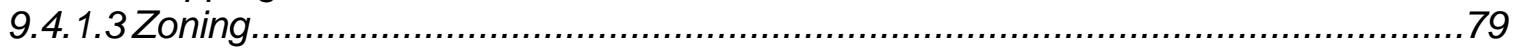

9.5 TOOLS AND STRATEGIES OF THE CITY OF ST. PAUL $\ldots \ldots \ldots \ldots \ldots \ldots \ldots \ldots \ldots . \ldots \ldots$

9.5.1 2040 Comprehensive Plan .......................................................... 80

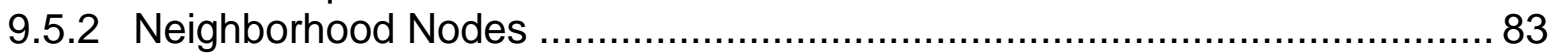

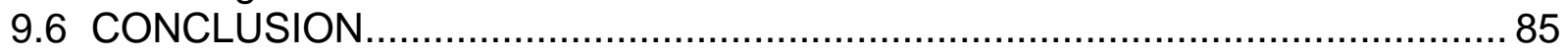

9.7 DOCUMENTS REVIEWED IN THIS CHAPTER $\ldots \ldots \ldots \ldots \ldots \ldots \ldots \ldots \ldots \ldots \ldots \ldots . . \ldots 6$

10.0 CASE STUDY OF POLYCENTRIC DEVELOPMENT STRATEGIES IN

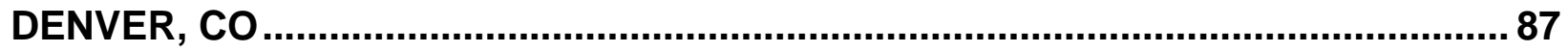

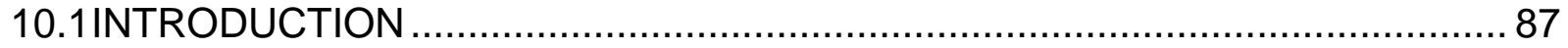

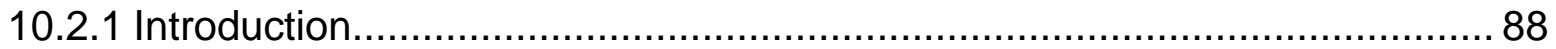

10.2.2 Metro Vision and the Promotion of Urban Centers .............................. 88

10.2.3 Metro Vision Mobility Initiatives ............................................ 90

10.2.4 DRCOG Programs and Initiatives Supporting Polycentric Development.... 92

10.2.4.1 FasTracks Commitment in Principle....................................................92

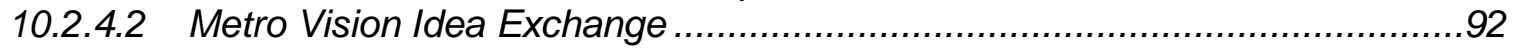

10.2.4.3 Transportation Improvement Program Criteria ......................................92

10.2.4.4 Transportation Improvement Program Station Area and Urban Center Plan

Funding 92

10.2.4.5 Transit-Oriented Development Reporting ...........................................93

10.2.4.6 Regional Scenario Analysis ............................................................93

10.3TOOLS AND STRATEGIES OF THE REGIONAL TRANSPORTATION DISTRICT

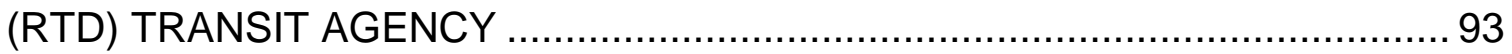

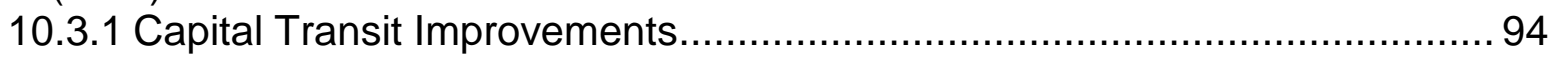

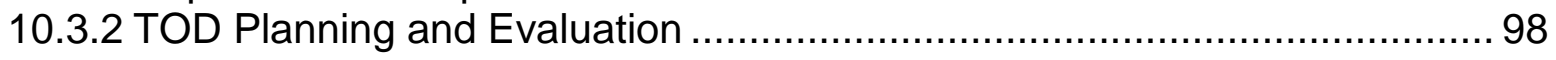

10.3.3 Future RTD TOD Policies .......................................................... 100

10.4TOOLS AND STRATEGIES OF THE CITY OF DENVER .......................... 101

10.4.1 Comprehensive Plan 2040 and Blueprint Denver............................... 101

10.4.2 Role of Centers in Visions, Goals, and Strategies ............................ 101

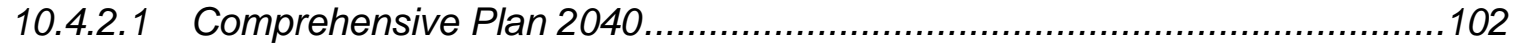

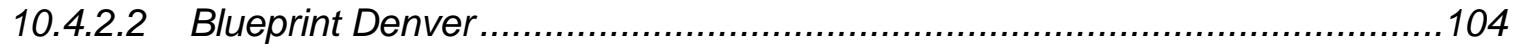

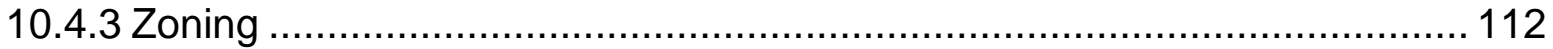

10.4.4 Transit-Oriented Denver: Denver's TOD Strategic Plan ...................... 113

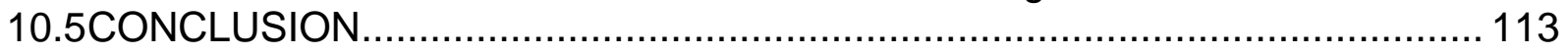

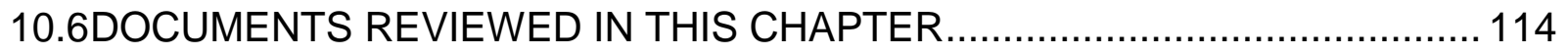




\subsection{CASE STUDY OF POLYCENTRIC DEVELOPMENT STRATEGIES IN}

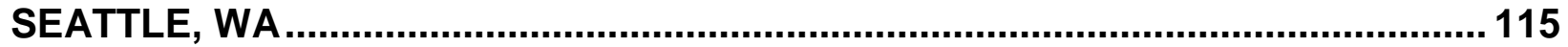

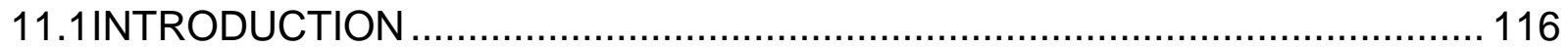

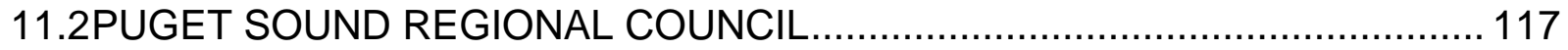

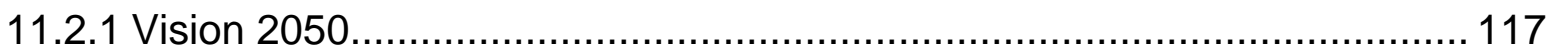

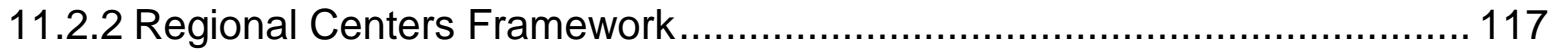

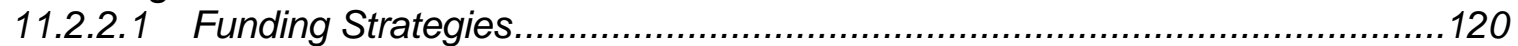

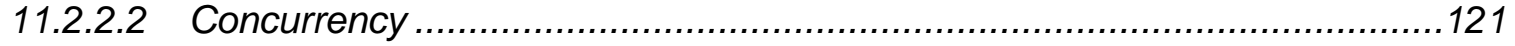

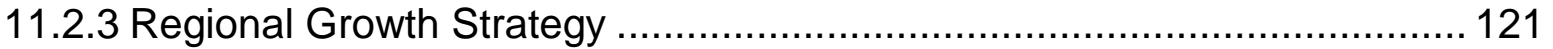

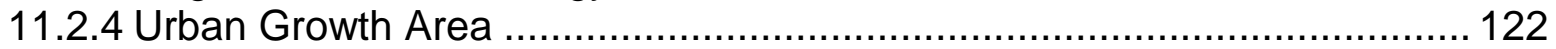

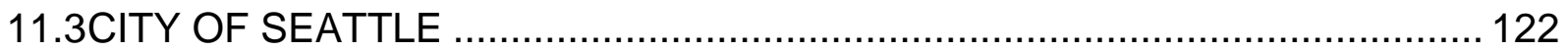

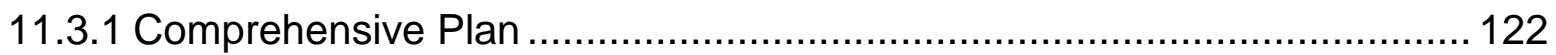

11.3.1.1 Urban Village Strategy ..................................................................122

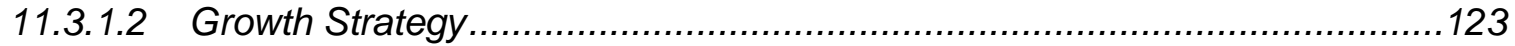

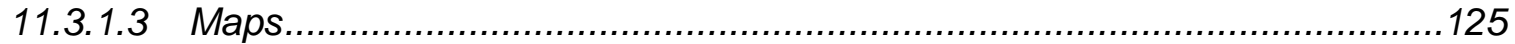

11.4SOUND TRANSIT - SEATTLE REGION'S HIGH-CAPACITY TRANSIT

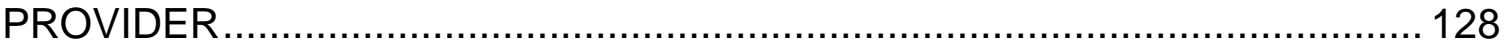

11.4.1 Sound Transit 3 - The Regional Transit System Plan............................. 129

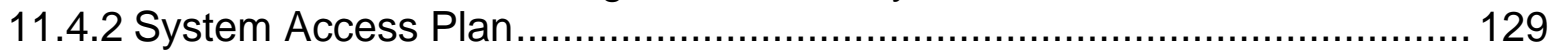

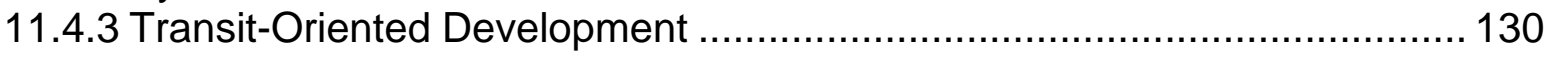

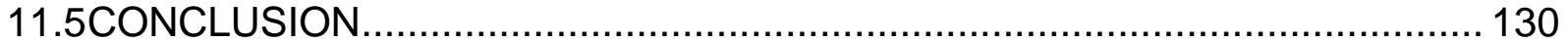

11.6DOCUMENTS REVIEWED IN THIS CHAPTER ....................................... 131

12.0 CONCLUSION: RECOMMENDATIONS FOR WASATCH FRONT ..................132

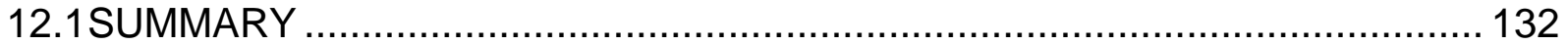

12.2RECOMMENDATIONS FOR THE WASATCH FRONT .............................. 134

12.2.1 Strategies for WFRC/MAG/Salt Lake County ....................................... 136

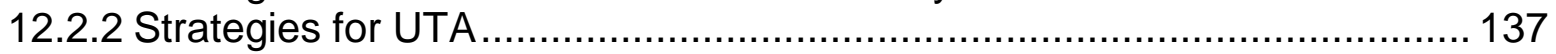

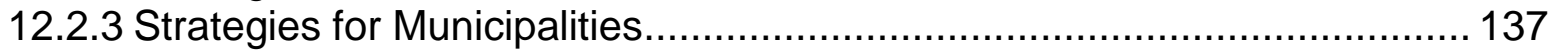

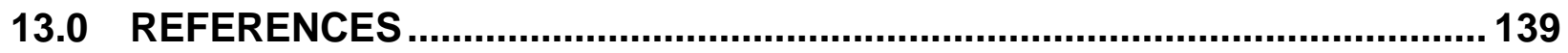

APPENDIX

\section{LIST OF TABLES}

Table 3.1: Types of centers in 126 RTPs sorted by the number of mentions ................ 10

Table 5.1: Household travel survey data in 28 regions.............................................. 22

Table 5.2: Number of centers identified in 28 regions ............................................. 29

Table 6.1: Descriptive statistics and t-test and chi-square results of household characteristics by center residency ........................................................... 30

Table 6.2: Descriptive statistics and t-test results of travel behaviors by center residency

Table 6.3: Descriptive statistics and t-test and chi-square results of household characteristics by center residency (after matching) 33 
Table 6.4: Descriptive statistics and t-test results of travel behaviors by center residency

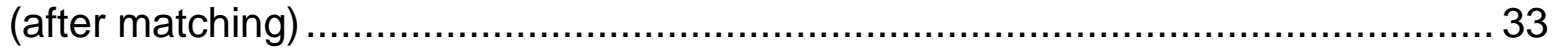

Table 6.5: Descriptive statistics of travel outcome and built environment variables ...... 35

Table 6.6: Two GAM models of mode choice and VMT .......................................... 37

Table 6.7: Patterns of travel outcomes with regard to D variables: from trip-level GAM

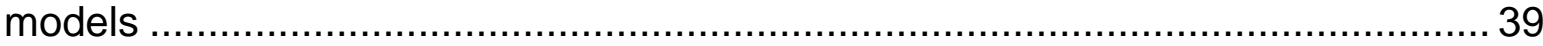

Table 6.8: Recommendations for optimal built environment characteristics of centers . 40

Table 7.1: Number of trips and tours in each region, with the maximum number recorded for an individual.......................................................................... 45

Table 7.2: Descriptive statistics of dependent variables for each of the tour types .......46 46

Table 7.3: The results of the ANOVA tests between tour types ............................... 49

Table 7.4: The results of the Tamhane post-hoc tests ......................................... 50

Table 7.5: Comparing the mean of walk trips between three types of trips for tour type 2

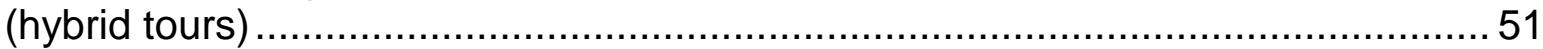

Table 8.1: Number of officials interviewed and documents reviewed ..........................5 53

Table 9.1: Number of officials interviewed and documents reviewed ..........................68

Table 9.2: Thrive MSP 2040 overall density expectations for new growth, development, and redevelopment. Source: Thrive MSP 2040.............................................. 73

Table 9.3: Residential land use density ranges. Source: St. Paul 2040 Comprehensive

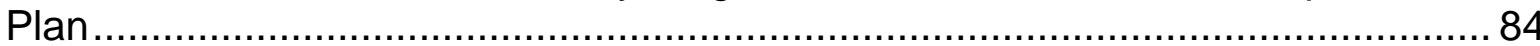

Table 9.4: Transit density goals. Source: St. Paul 2040 Comprehensive Plan............... 85

Table 10.1: The list of interviewed planners in Denver case study.............................. 87

Table 11.1: Number of officials interviewed and documents reviewed ..................... 117

Table 12.1: Current built environment condition of $D$ variables of 20 centers in the Wasatch Front, classified by the WC 2050 center designation (note: four centers were dropped because they don't overlap with any center in the WC 2050 map; see Appendix for more information) .................................................................... 134

Table 12.2: Recommendations for optimal built environment characteristics of centers from GAM analysis in Chapter 6 .......................................................... 134

Table 12.3: Density criteria by different centers types from other RTPs (see Chapter 3)

Table 12.4: Our recommendations on built environment characteristics by center type for the Wasatch Front.................................................................................. 135

Table A.1: Built environment measures (D Variables) of 22 centers in the Wasatch Front

\section{LIST OF FIGURES}

Figure 1.1: Three views of compact development and sprawl.................................... 5

Figure 1.2: Developing centers in Salt Lake County ............................................. 7

Figure 4.1: Urban footprints of four scenarios from the Cache Valley Council, Envision

Cache Valley final report and toolkit............................................................... 17

Figure 4.2: Percentage difference in VMT from the trend for 56 scenarios .................. 18 
Figure 4.3: Percentage difference in VMT from the trend for 56 scenarios by centricity (top) and development patterns (bottom) ......................................................... 19

Figure 4.4: Percentage difference in density (persons per developed acre) from the trend for 56 scenarios 20

Figure 4.5: A scatterplot of a percent difference in annual vehicle miles traveled (VMT) from trend and percent difference in development density from trend ..................2 21

Figure 5.1: Location of CBDs in Wasatch Front Region ........................................ 24

Figure 5.2: Davis/Weber counties: Centers using different methods (left) and in the Wasatch Choice 2050 (right)

Figure 5.3: Salt Lake County: Centers using different methods (left) and in the Wasatch Choice 2050 (right) 28

Figure 5.4: Utah County: Centers using different methods (left) and in the Wasatch Choice 2050 (right) 28

Figure 6.1: GAM plots between D variables and likelihood of walk mode choice (note: Red circles indicate potential optimal points to promote walking; Y-axis shows log odds of walk mode choice centered over driving, around zero)

Figure 6.2: GAM plots between D variables and likelihood of transit mode choice (note: Red circles indicate potential optimal points to promote transit use; Y-axis shows log odds of transit mode choice over driving, centered around zero)

Figure 6.3: GAM plots between D variables and VMT (Note: Red circles indicate potential optimal points to discourage driving; Y-axis shows predicted logtransformed VMT, centered around zero) ....

Figure 7.1: Histogram of the frequency of walk share within tours in type 3 (i.e., none of

the trips within a tour was inside a center) .................................................. 47

Figure 8.1: Comprehensive Plan Map (Portland, OR) ........................................... 55

Figure 8.2: Comprehensive Plan Centers Map (Portland, OR) .................................5 5

Figure 8.3: 2040 Growth Concept Map for Portland Metro ..........................................5 59

Figure 8.4: Southwest Service Enhancement Plan vision for future service (TriMet, OR)

Figure 9.1: Counties, major cities, and major roadways of the Twin Cities region. ....... 67

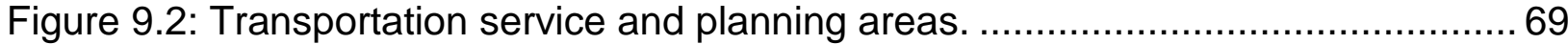

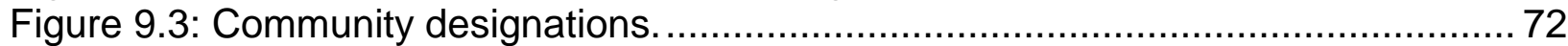

Figure 9.4: Minneapolis 2040 Future Land Use map ........................................... 79

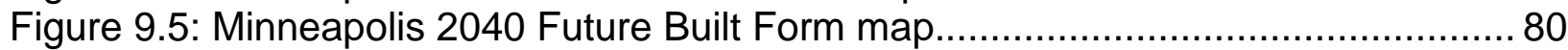

Figure 9.6: Opportunity Sites in the 2040 Comprehensive Plan............................... 82

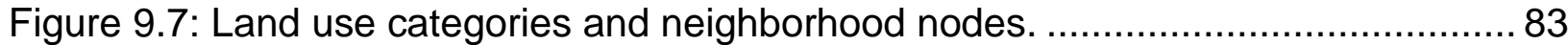

Figure 10.1: Urban Centers in the Denver Region ................................................ 90

Figure 10.2: Map of Funded and Planned FasTracks Projects ................................. 95

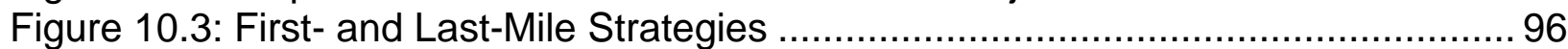

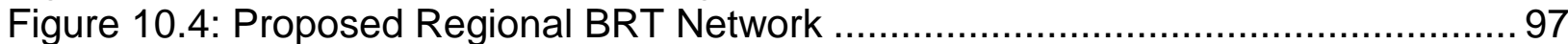

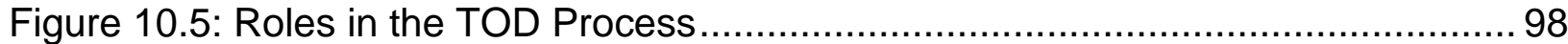

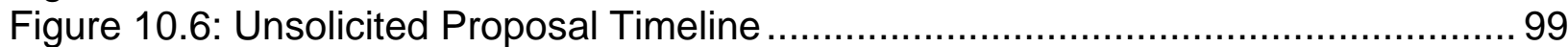

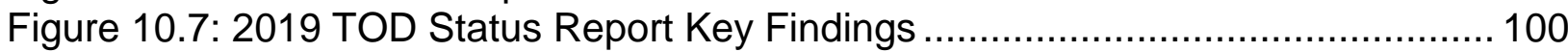

Figure 10.8: Comprehensive Plan 2040 Vision Elements ..................................... 102

Figure 10.9: Denver's vision for future places, Source: Blueprint Denver, 2019 ......... 105 


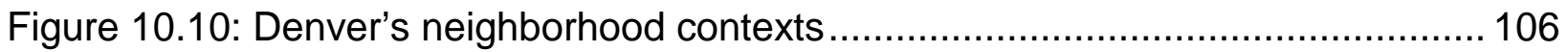

Figure 10.11: Denver's Growth Strategy ................................................................ 107

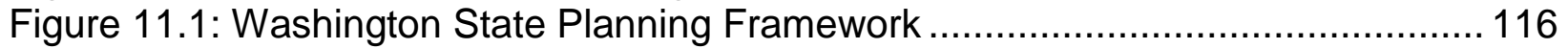

Figure 11.2: Regional centers hierarchy and criteria .......................................... 118

Figure 11.3: Regional growth and industrial centers map ..................................... 120

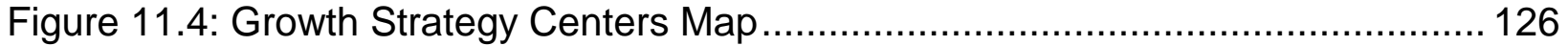

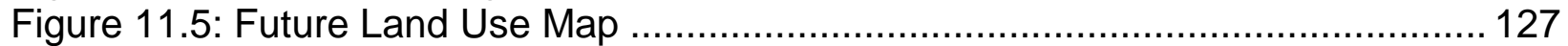

Figure 11.6: Sound Transit 3 plan map ................................................................ 128

Figure 11.7: Sound Transit 3 expansion planned fund expenditure .......................... 129

Figure A.1: Location of 22 centers in the Wasatch Front region (Part I) .....................A-2

Figure A.2: Location of 22 centers in the Wasatch Front region (Part II)....................A-3

Figure A.3: Location of 22 centers in the Wasatch Front region (Part III) ....................A-4 


\section{EXECUTIVE SUMMARY}

A "polycentric" region consists of a network of compact developments connected with each other through high-quality transportation options. Rather than continuing the expanse of low-density development radiating from an urban core, investments can be concentrated on central nodes and transit connections. Central to this shift is the increased influence of agglomeration economies and activity clusters on population and employment distribution and, thus, spatial development. As the antidote to sprawling suburbs, compact centers can encourage all the things sprawl discourages: public health, environmental sustainability, social cohesion, and economic diversity.

This development pattern is very popular in Europe and is linked to significant benefits. Salt Lake County has organically developed several small centers, and with the right strategies could continue to fuel this kind of growth. The metropolitan planning organization for the region, the Wasatch Front Regional Council, has been planning for polycentric development since the Wasatch Choice 2040 Vision was released in 2010.

This report first explores academic literature and empirical evidence on polycentric development (Chapter 2); analyzes 126 regional transportation plans (RTPs) on their definition and qualification of various types of centers (Chapter 3 ); reviews scenario planning projects in other regions to see how polycentric plans perform (Chapter 4); identifies centers in 28 U.S. regions as CBDs and subcenters (Chapter 5); analyzes transportation benefits of centers using comprehensive household travel survey datasets (Chapters 6 and 7); and conducts in-depth case studies of policy strategies aimed at polycentricity (Chapters 8 -11). In the concluding chapter, we summarize our findings and provide policy suggestions for the Wasatch Front region in Utah.

A comprehensive review of 126 regional transportation plans across the nation shows that the term "center" is used in connection with various geographic scales-region, city, sub-region, town, community, and village. Alternatively, the term "center" is also used to signify clusters of certain activities or functions - an area with a single concentrated use, such as an employment center, transit center, residential center, or entertainment center. Generally, a center is described as the densest part of an area, characterized by compact, mixed-use development, multiple transit options, and employment opportunities.

Only 25 of the 126 regional transportation plans we reviewed included any type of quantitative criteria for designating centers, and some of these indicators are overly broad. The quantitative criteria found in these 25 RTPs can be classified into four main areas-employment density, residential density, total population or employment, and area size. Other areas covered in only a few plans include land use mix, building design (e.g., floor area ratio), transit service, and street density. Synthesizing the quantitative criteria found in the 25 RTPs and the qualitative criteria found in all 126 plans, we 
articulated general guidelines for identifying five of the most common types of centersregional centers, urban centers, activity centers, town centers, and employment centers.

In Chapter 5, the identification of centers in selected regions was done in two steps. First, we identified the location of central business districts (CBD) in 28 U.S. regions using local spatial autocorrelation techniques. These techniques enabled us to identify the highest local peaks in terms of employment density as potential CBDs. Second, having identified CBDs, the location of potential employment subcenters was identified using Geographically Weighted Regression (GWR). Then, multistep criteria were applied to exclude unqualified candidates and find the final location of subcenters. As a result, a total of 23 centers as either CBDs or local density peaks were identified in the Wasatch Front region. The sites range in size from 78.6 acres to 956.4 acres. The locations of centers were validated against the centers designated in Wasatch Choice 2050. In the whole 28 regions, a total of 589 centers were identified (an average of 21 per region). Out of 79,670 households included in the travel surveys, 1,506 households live within centers and 78,164 households live outside centers.

Then, we compared travel outcomes between center households and non-center households. On average, households living in centers tend to make fewer and shorter automobile trips, take transit more, walk more, and bike less. After matching households having similar socio-demographic status using the propensity score matching method, center households tend to drive less ( 24.6 vs. 29.8 miles per day) and walk more (0.99 vs. 0.78 walk trips per day) than their counterparts outside centers. When a household in a suburban area moves into an existing center, or a center is newly developed, the average household is expected to have significantly shorter auto trips and more walk trips.

Using a non-linear regression model GAM, we tried to find optimal values maximizing transportation benefits of polycentric developments. By exploring the GAM plots, we could reach to recommendations for optimal built environment characteristics of centers. For successful centers, we recommend 10,000-25,000 activity density (16-40 per acre; may vary by center types), a minimum of 150 intersections/square mile, over $60 \%$ of four-way intersections, over 60 transit stops/square mile, and a minimum $30 \%$ of regional job accessibility within 30 minutes by transit.

In the next chapter, we focus mostly on trip chains or tours. A travel tour is a sequence of trips that begins and ends at home, also known as a home-to-home loop. In this regard, a simple tour contains only two trips (i.e., one stop if we exclude home), while a complex tour contains multiple stops, multiple trips, and can have different trip purposes. We investigate trip chaining efficiency using three different types of tours. Efficient trip chaining consists of tours that have short, walkable trips incorporated into them. We expand this definition to consider bike and transit trips as well since they are other sustainable modes of transportation. Hence, we consider a tour to be efficient if it comprises travel modes other than the personal automobile. The higher the proportion of walk, bike, or transit trips, the more efficient the trip chain. Also, the shorter the trips (even by automobile), the more efficient the trip chain. 
We find that tours associated with centers are more efficient than ones that are completely outside the centers. Same as the previous chapter, if our findings are correct, this would be the strongest evidence yet produced on the transportation benefits of polycentric development. Understanding individuals' trip chaining behavior can help planners design environments that promote active transportation while maximizing residents' access to the services and amenities, and minimizing their expenditure on mobility and travel time, as well as environment-related (e.g., pollution) and health-related (e.g., obesity) issues.

Finally, as a best practice in polycentric planning and development efforts, we conducted case studies of four regions with more or less polycentric policies. The strongest case study is the Portland region in Oregon. From interviews and document reviews for the City of Portland, Portland Metro (Portland's MPO), and TriMet (Portland's transit agency), we identified strategies that these entities are using to promote polycentric development. Many of the findings from the case study are incorporated into our recommendations for the Wasatch Front, discussed in the final section. 


\subsection{INTRODUCTION}

Since the early 20th century, the notion of "polycentricity" has been used to describe the urban landscape, but it is only recently that urban planners and policymakers have turned to polycentricity as a possible solution for more sustainable development (Davoudi, 2003; van Meeteren et al., 2016). In 1961, Gottman recognized the beginning of a new urban phenomenon-the monocentric city was expanding, interweaving multiple urban centers to create polycentric megalopolises (Champion, 2001). By the early 1990s, Garreau had fleshed out the notion of "edge cities," concentrations of business, shopping, and entertainment outside a traditional downtown in what had previously been residential or rural areas (ibid).

Scholars agree that the incidences of polycentric urban structures are increasing (Anas, Arnott, and Small, 1998; Kloosterman and Musterd, 2001; Parr, 2004; Hall and Pain, 2009; Vasanen, 2012), and that this development form is likely here to stay (Geppert, 2009; Garcia-López and Muñiz, 2010). Yet, as polycentricity has gained increasing recognition in both the literature and the field, the definition has become nebulous and vague (Kloosterman and Musterd, 2001; Davoudi, 2003; Hague and Kirk, 2003). Some attribute the diverse interpretations of polycentricity to the inherent complexity of urban space and the versatility of the term (Burger and Meijers, 2012). "The line between scattered development, a type of sprawl, and multicentered development, a type of compact development by most people's reckoning, is a fine one" (Ewing, 1997-see Figure 1). As a result, much of the literature has focused on attempting to define and operationalize polycentrism (Champion, 2001; Pessoa, 2009; Davoudi, 2003; GarciaLópez and Muñiz, 2010; Kloosterman and Musterd, 2001).

Notably, few scholars have explored the economic, social, and environmental costs and benefits of polycentric systems, despite the obvious supposition that the polycentric urban form would promote sustainable growth, social cohesion, and economic development (EC, 1999). A rare exception is Meijers and Burger (2010), who found that polycentricity - as opposed to monocentricity-is associated with higher labor productivity, though the literature is far from reaching consensus (Garcia-Lopez and Munez, 2010). We believe that a polycentric urban structure likely has the potential to encourage and support smart and sustainable growth. Rather than continuing the expanse of low-density development radiating from an urban core, cities could invest in central nodes and transit connections. The result would be centers-compact nodes servicing a wider area - spread across a region and connected through quality transit corridors. Centers can vary in scale-for example, rural areas have small town centers, metropolitan areas house regional centers and multiple city centers-but each would provide public services, housing, employment opportunities, and recreational experiences for the surrounding population, and each would be functionally connected to the other centers, creating a true polycentric network of places (Hall \& Pain, 2006; Green, 2007; Burger et al., 2011). 


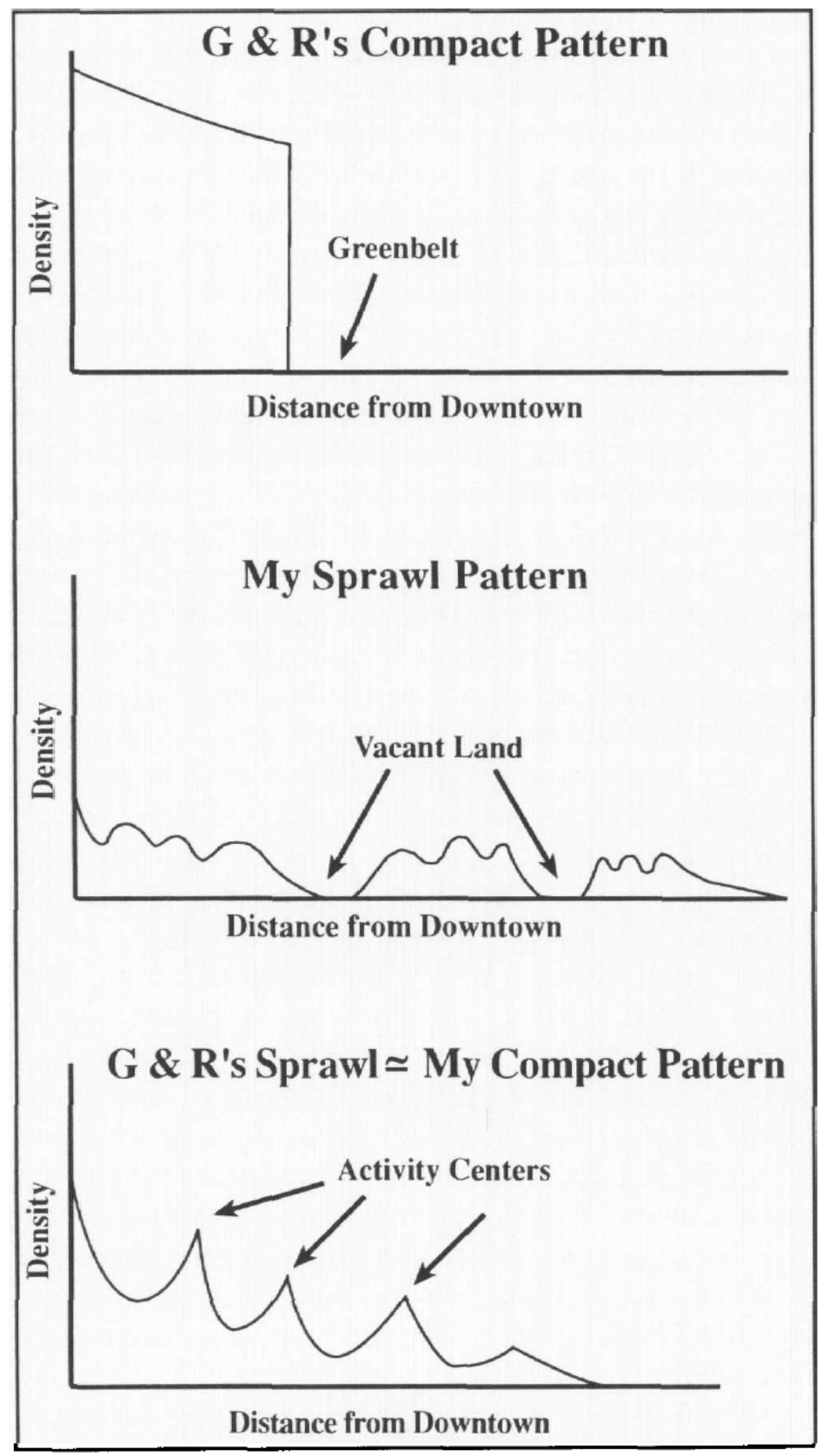

Figure 1.1: Three views of compact development and sprawl, in terms of urban density. G\&R stand for Peter Gordon and Harry Richardson. "My" refers to Ewing (Ewing, 1997).

Applying polycentricity to disparate scales has been done before, from the individual city all the way to the regional scale and everything in between (e.g., Roberts et al., 1999; Hall and Pain, 2006; Parr, 2004; Meijers, 2007; Waterhout et al., 2005; CEC, 1999). Typically, and traditionally, the term has been applied to inter-urban spatial structure, but recently the concept has been applied to the intra-urban scale as well (Davoudi, 2003). An inter-urban scale polycentricity is characterized by distinct cities connected in a network across a region (Dieleman and Faludi, 1998) while an intra-urban polycentric 
structure contains multiple subcenters within a single built-up area (Gordon et al., 1986).

At the root of intra-urban polycentric structure is compact development. If polycentric urban growth is going to be positive for our cities, it must be anchored by compact centers that are dense, diverse, and accessible. In his landmark article "Is Los Angeles Style Sprawl Desirable?", Ewing (1997) made a case for polycentric development as the antidote to sprawling suburbs. Compact centers could encourage all the things sprawl discourages: public health, environmental sustainability, and economic diversity.

To measure and define compact development, scholars and planners have developed compactness/sprawl indices with compact development at one end of a continuum and sprawl at the other. In the indices originally developed by Ewing et al. (2002) and updated by Ewing and Hamidi (2014), compact development has four dimensions: medium to high densities, mixed land uses, strong population and employment centers, and interconnected streets. Sprawling locations, on the other hand, lack all or most of these characteristics. Note that from the original indices to the present, strong centers have been shown to be a significant determinant to good travel outcomes.

The benefits of compact development are numerous, and many of these benefits are directly linked to transportation. The literature suggests that compact development is associated with increases in walking and transit use (Brown, Khattak, \& Rodriguez, 2008; Cao, Handy, and Mokhtarian, 2006; Cervero, 2001; De Bourdeaudhuij, Sallis, and Saelens, 2003; Frank and Pivo, 1994; Gallimore, Brown, and Werner, 2011; Hamidi and Ewing, 2014; Hamidi, Ewing, Preuss, and Dodds, 2015; Humpel, Owen, Iverson, Leslie, and Bauman, 2004; Moudon and Lee, 2003); reduced residential energy consumption (Ewing and Rong, 2008; Pitt, 2013); reduced pedestrian and motor vehicle fatalities (Ewing, Hamidi, and Grace, 2016); increased physical activity and reduced obesity (Atkinson, Sallis, Saelens, Cain, and Black, 2005; Cervero and Duncan, 2003; Doyle and Kelly-Schwartz, 2006; Durand, Andalib, Dunton, Wolch, and Pentz, 2011; Ewing et al., 2014; Forsyth, Hearst, Oakes, and Schmitz, 2008; Frank, Schmid, Sallis, Chapman and Saelens, 2005; Handy, Sallis, Weber, Maibach, and Hollander, 2008; MacDonald, Stokes, Cohen, Kofner, and Ridgeway, 2010; McCormack, Giles-Corti, and Bulsara, 2008; Rundle et al., 2007; Saelens, Sallis, Black, and Chen, 2003); reduced household transportation costs (Hamidi and Ewing, 2015); decreased crime (Colquhoun, 2004; Hillier, 2004; Landman, 2009); increased sense of community (Kim, 2007; Kim and Kaplan, 2004; Lund, 2002; Wood, Frank and Giles-Corti, 2010); increased upward social and economic mobility (Ewing, Hamidi, Grace, and Wei, 2016); increased social interaction and neighborliness (Brown \& Cropper, 2001; Lund, 2003; Podobnik, 2011; Wilkerson, Carlson, Yen, and Michael, 2012); increased social capital (Leyden, 2003; Rogers, Halstead, Gardner, and Carlson, 2011; Wood et al., 2008); reduced emergency response times (Trowbridge, Gurka, and O'Connor, 2009); increased innovation capacity (Hamidi, Zandiatashbar, and Bonakdar, 2018; Hamidi and Zandiatashbar, 2018); and increased life expectancy (Hamidi, Ewing, Tatalovich, Grace, and Berrigan, 2018). 
Clearly, the benefits of compact development are abundant, and the potential for polycentric development to share these benefits is intriguing. Salt Lake County is in a unique position to develop and invest in centers; several centers within the county have already begun to form organically (Figure 1.2). Armed with context-specific strategies and a deeper understanding of both polycentricity and compactness, Salt Lake County could thoughtfully and strategically develop centers within its communities that would help the county reach its goals of economic growth, community preservation, environmental sustainability, connected transportation networks, air quality improvement, and homelessness minimization. In fact, in the Wasatch Front Regional Council's (WFRC) RTP, 2015-2040, the region's development goals are said to be "largely dependent upon centered growth near transit lines" (2015).

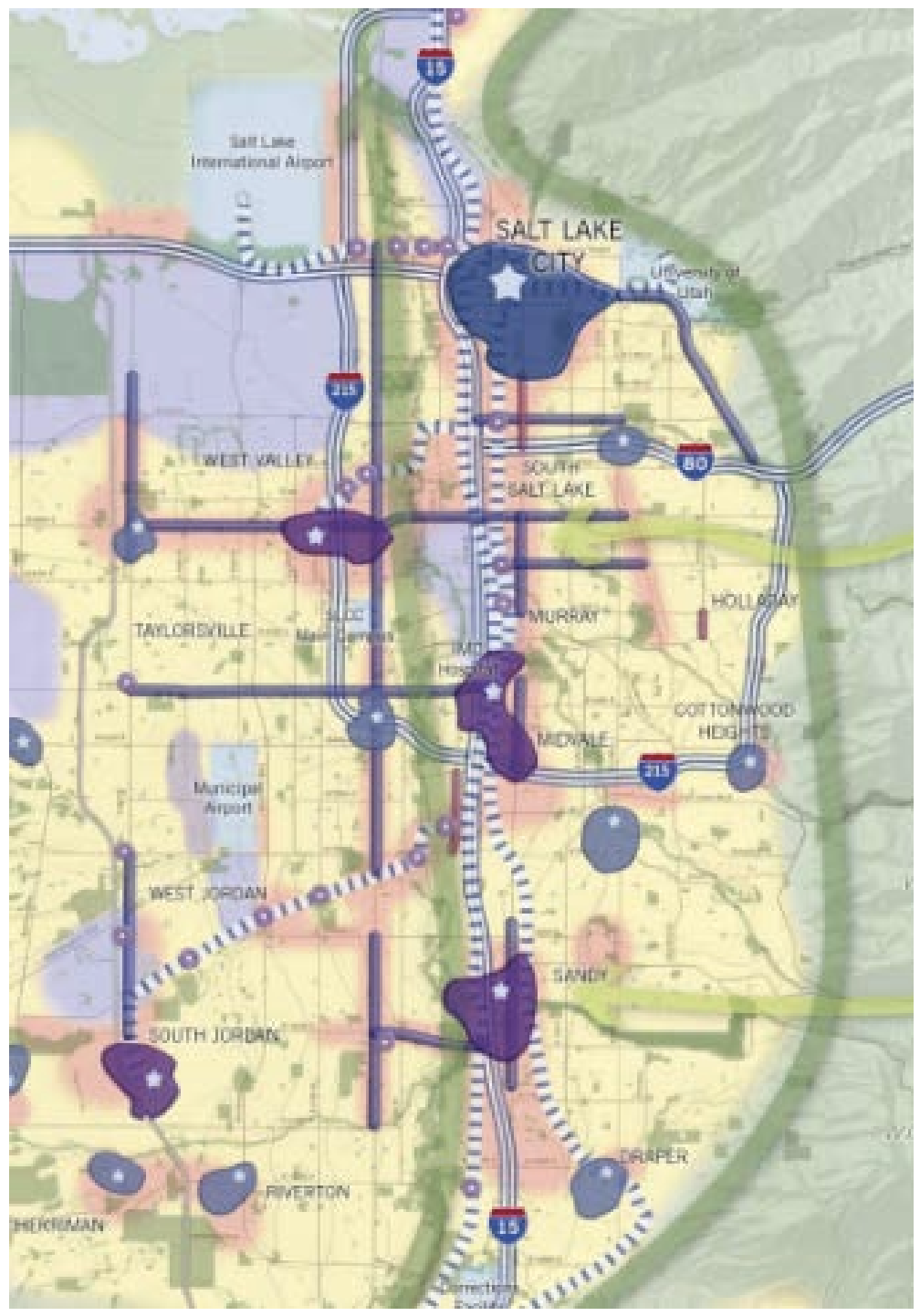

Figure 1.2: Developing centers in Salt Lake County 


\subsection{LITERATURE REVIEW}

Two broad axes of academic debate on polycentricity have revolved around 1) geographical scale and 2) functionality versus morphology (van Meeteren et al., 2016). Polycentricity has been examined at the intra-urban, inter-urban, and inter-regional scales (Davoudi, 2003). An intra-urban polycentric structure contains multiple subcenters within a single built-up area (Gordon et al., 1986), while inter-urban is characterized by distinct cities connected in a network across a region (Dieleman and Faludi, 1998). Intra-urban studies have focused largely on U.S. cities and inter-urban has been applied mostly to European settlements. Inter-regional polycentricity examines the effect across regions larger than a metropolitan area including concepts like the "mega-city" and "megapolitan" regions (Davoudi, 2003; Hall and Pain, 2009; Lang and Knox, 2009). The debate surrounding polycentricity as functional (based on activities and relationships) versus morphological construct (based on centering around nodal features) has also not been resolved (van Meeteren et al., 2016) and the more recent literature suggests that centers must have functional links between each other to be classified as polycentric (Vasanen, 2012). Suffice it to say, polycentricity has taken on different meanings and applications throughout the literature.

Homing in on the functional dimensions, several economic forces have been thought to explain polycentric development (Giuliano and Small, 1991; J. F. McDonald, 1987). Davoudi (2003) points out that decentralization of business activity, increased mobility, increased travel, demographic changes, and fragmentation of space rendered "the monocentric model increasingly irrelevant to the reality of urban growth patterns," thus making way for the development of polycentric areas. Central to this shift was the increased influence of agglomeration economies and activity clusters on population and employment distribution and, thus, spatial development (Davoudi, 2003; Scott, 1988; Porter, 2011; Krugman, 1993; McDonald, 1987). The correlation between population size and transportation costs was also theoretically demonstrated to cause subcenter creation (Fujita and Ogawa, 1982; McMillen and Smith, 2003). Gross employment density and the employment-population ratio were other measures used to identify subcenters (McDonald, 1987; Anderson and Bogart, 2003). But still, objective measures defining polycentricism are almost completely lacking in policy documents and plans (Jaume Masip-Tresserra, 2016).

There have been several studies that examine how polycentric development affects and is affected by transportation, commuting, mode choice, and trip generation. As early as the mid-1980s, the research found that in Los Angeles, polycentrism had been associated with shorter work trips, particularly intra-county trips in the more peripheral counties (Gordon, Richardson, and Wong, 1986). Contradictory to those findings, research done a few years later found that working in subcenters was associated with longer commute times than working in a central city (Dubin, 1991; Giuliano and Small, 1991) and higher rates of drive-alone automobile use in suburban centers (Cervero, 1991; Schwanen, Dieleman, and Dijst, 2001). Contrary to the co-location hypothesis, the idea that people will change their residencies or workplaces to be more proximate to employment, those working in subcenters were found to average higher rates of VMT, 
drive-alone automobile commuting, and insignificant levels of transit ridership because they often didn't work in the subcenter in which they lived (Cervero and Wu, 1997, 1998; Aguilera, 2005; Kim, 2008). In Europe, larger polycentric metropolises have also been found to correspond to longer commute distances (Schwanen, Dieleman, and Dijst, 2004). The most recent commuting research has focused on Asian cities and continues to reflect the complicated nature of polycentricity. One study found that polycentric development may be increasing commute times and relevant externalities (Hu, Sun, and Wang, 2018), while another found that a polycentric urban structure had shorter commute distances and lower CO2 emissions (Yang Liu et al., 2018).

The challenge with studying polycentricity, how it develops, and its effects remain to be lack of a clear and objective definition. And despite this lack of clarity, more than $75 \%$ of recent spatial plans for large metropolitan areas in OECD countries consider it as the best strategy for managing urban development while achieving sustainability, livability, and accessibility (van Meeteren et al., 2016). The following report will specify ways in which our region can refine policy strategies to promote the most successful forms of polycentric development as found in the empirical research. 


\subsection{ANALYSIS OF REGIONAL TRANSPORTATION PLANS (RTP) AND DEFINITIONS OF CENTER TYPES}

A review of 126 regional transportation plans from cities across the nation shows that the term "center" is used in connection with various geographic levels-region, city, subregion, town, community, and village. Generally, no matter the geographic level, the center is described as the densest part of an area, characterized by compact, mixeduse development, multiple transit options, and employment opportunities. These centers are nuclei, drawing people, goods, and activity towards them, thus generating and attracting trips.

Alternatively, the term "center" is used to signify clusters of certain activities or functions-an area with a single concentrated use, such as an employment center, transit center, residential center, or entertainment center. Unlike geographic-level centers, these types of centers are not necessarily dense or mixed use. For example, a city's central business district may be described as an employment or economic center; a sprawling subdivision may be considered a city's housing or population center; and the convergence of an airport and train station may constitute a city's transit center.

Among the surveyed plans, incidences of specific, quantitative definitions of "centers" are not common. Only 25 of the 126 plans included any type of quantitative indicator, and some of these indicators are overly broad. For example, the only quantitative criteria for a "community activity center" in Burlington, VT's, RTP is that the proportion of residential to non-residential land use mix should be approximately 60 to 40, while Murrietta, CA's, plan simply requires 22 dwelling units/acre to be a "town center." However, there are several plans that provide more comprehensive quantitative definitions of various centers. Baltimore, MD, for example, defines types of centers in terms of area, residential density, employment density, and the number of jobs. Having said that, there are a couple of regions that do not specifically talk about the centers in their RTPs, but they describe their centers in full detail on their websites. For instance, Seattle, WA, has different types of centers (i.e., urban growth centers, metro growth centers, industrial growth centers, and industrial employment centers) which all are described in detail (e.g., activity levels, size, market potential, role, and compatibility with Vision 2040) on its website.

\subsection{DEFINITION AND CHARACTERISTICS OF CENTERS BY TYPE}

Through these 126 RTPs, we have identified more than 20 types of centers. Table 1 shows these different types of centers with the number of times that each of them has been mentioned in plans. Among different types of centers, activity centers, employment centers, town centers, urban centers, and regional centers are the most repeated types of centers in the plans.

Table 3.1: Types of centers in 126 RTPs sorted by the number of mentions 


\begin{tabular}{lclc}
\hline Center Type & $\begin{array}{c}\text { Number of } \\
\text { mentions }\end{array}$ & Center Type & $\begin{array}{c}\text { Number of } \\
\text { mentions }\end{array}$ \\
\hline Activity Center & 994 & Metropolitan Center & 30 \\
\hline $\begin{array}{l}\text { Employment Center/ Industrial } \\
\text { Employment Center }\end{array}$ & 584 & $\begin{array}{l}\text { Industrial Center/Industrial } \\
\text { Growth Center }\end{array}$ & 29 \\
\hline Town Center & 369 & Neighborhood Activity Center & 24 \\
\hline Urban Center/ Urban Growth Center & 314 & Community Activity Center & 20 \\
\hline $\begin{array}{l}\text { Regional Center/Regional Core and } \\
\text { Employment Corridor/ Metro Growth }\end{array}$ & 186 & Government Centers & 20 \\
Center & & & \\
\hline Major Activity Center & 121 & Suburban Employment Center & 16 \\
\hline Community Center & 116 & Emerging Employment Center & 10 \\
\hline City Center & 89 & Rural Village Activity Center & 7 \\
\hline Major Employment Center & 81 & Community Commercial Center & 2 \\
\hline Mixed-Use Center & 52 & Center Planning Areas & 2 \\
\hline Village Center & 41 & $\begin{array}{l}\text { Sub-regional business, civic, } \\
\text { commercial and cultural centers }\end{array}$ & 1 \\
\hline Suburban Center & 31 & & \\
& & &
\end{tabular}

Synthesizing the quantitative criteria found in the 25 RTPs and the qualitative criteria found in all 126 plans, we articulate general guidelines for identifying five of the most common types of centers:

\subsubsection{Regional Center}

Regional centers are primary business, civic, commercial and cultural centers which serve the county and region with an intense diversity of land uses including homes, workplaces, universities, retail establishments, public facilities, entertainment venues, and medical centers. These centers are characterized by dense population, typically clustered in multistory buildings and economic vitality. They generally sit along other heavily traveled corridors, connecting them to other centers throughout the region. Enhanced transit service, often coordinated between multiple modes, ensures that residents, workers, and visitors enjoy high accessibility and mobility. Regional centers typically cover more than 100 acres, with floor-area ratios ranging from 3 to 5 . The term regional center, or regional core and employment corridor or metro growth center, has been used 186 times in these 126 RTPs.

\subsubsection{Urban Center}

Urban centers are described as mid- to high-density, pedestrian-, bicycle-, and transitfriendly, and mixed-use. These centers boast diverse populations and extensive employment opportunities. Intermodal transportation options ensure that residents, workers, and visitors have convenient access to retail, recreation, and employment. An urban center implies regional significance, and may include airports, universities, major employers, arenas, amusement parks, and performance venues. For some regions, urban centers are the highest-intensity areas. The best examples would be places such as downtown Los Angeles or high-intensity corridors such as Wilshire Boulevard. Urban 
centers are characterized by two- to four-story buildings, floor-area ratios between .75 and 4, roughly 20-120 dwelling units per acre, and around 300 jobs per acre. Urban center or urban growth center has been mentioned 314 times in the surveyed plans.

\subsubsection{Activity Center}

Activity center is the most frequently used type of center in the RTPs (repeated 994 times). As it was explained before, activity centers vary by scale and activity mix depending on location. They are places that contain a concentration of business, civic and cultural activities, creating conditions that facilitate interaction. Each activity center is unique with contextual and distinctive identities, derived from environmental features, a mix of uses, well-designed public spaces, parks, plazas, and high-quality urban design. In the commercial core of all urban activity centers, the first floor of the building is primarily commercial with storefront windows built to the back of a sidewalk. The building facade and type change frequently. Vertical mixed-use is strongly preferred. The pedestrian shed is made up of a variety of residential housing types. In historic neighborhoods, the activity center is anchored by historic buildings and new buildings in the pedestrian shed mimic historic building types and patterns. Since the quantitative criteria vary by the scale of an activity center (e.g., regional, community, and rural levels of activity centers), it is not practical to provide unique characteristics for this type of center.

\subsubsection{Town Center}

Town centers, which are mentioned 369 times in the RTPs, contain multiple land uses, some density, and transit options, but cater especially to pedestrians by providing walkable connections to surrounding neighborhoods. These centers are roughly onethird the density of urban centers. Though small, town centers will likely have the infrastructure necessary to handle future growth and adequately provide for the day-today needs of the surrounding neighborhoods. They function as the center of economic and civic activity, effectively the focal point of a community. Transit may be more limited than in regional and urban centers, but should include at least one high-capacity transit option. The town center provides some housing, often on the stories above retail establishments. Buildings typically stand two or more stories with condominiums or apartments over storefronts. The design and scale of the development in a town center encourage active living, with a comprehensive and interconnected network of walkable streets. Town centers cover between 100-640 acres, serve around 30,000-40,000 people, contain 10-50 housing units and 30-120 jobs per acre, and are between .5 and 1 mile in diameter.

\subsubsection{Employment Center}

Employment center is the second most mentioned (584 times) type of center in our survey of 126 plans. Employment centers include industrial and business parks that, due to their location (with limited surrounding residential development in the case of industrial) and associated infrastructure (including transportation), have been and are planned to be developed to support the attraction and retention of large-scale 
employment opportunities. Additionally, these areas will become the focus for the highest concentration of office employment in the city, increasing employment density and enhancing people's ability to walk or to take public transportation to their work destinations. Same as the activity center, the scale of an employment center varies from the regional employment center down to the suburban employment center. Typically, employment centers have an employment density of at least 1,000 workers per square mile and also have a greater employment density than population density.

\subsection{QUANTITATIVE CRITERIA FOR IDENTIFYING CENTERS}

The quantitative criteria found in the 25 RTPs with quantitative criteria can be classified into four main types-employment density, residential density, total population or employment, and area size. Other factors-covered in only a few plans-include land use mix, building design (floor area ratio), transit service, and street density.

\subsubsection{Density}

Among 25 RTPs, 10 plans have employment density criteria, which ranges from 320 jobs/acre for the urban center of Los Angeles. . to 1.25 jobs/acre for the regional activity center in Birmingham, AL. In two plans (Knoxville, TN, and Orlando, FL), the job density is set for retail and office separately. Little Rock, AK, requires its employment centers to have a greater employment density (minimum 1.56 jobs/acre) than population density. Instead of looking for either employment or population density, Austin, TX, uses activity density, the sum of population and employment per acre.

Fourteen plans use residential density criteria to identify centers. The range varies from almost $120 \mathrm{DU}$ (dwelling units)/acre for the downtown in Orlando, FL, and urban center in Los Angeles to 5-10 DU/acre for the growth corridors in Chattanooga, TN. Chattanooga uses the percentage of residential land uses in addition to housing density-30 to $70 \%$ of residential uses according to center types. The urban centers in Minneapolis, MN, have four subtypes with specific housing density criteria (from 10 to 50+ DU/acre) according to the serviced transit types (e.g., fixed or dedicated transitway, BRT, bus). Population density instead of housing density is used in Knoxville, TN-13.3 persons/acre in a mixed-use center and in Philadelphia, PA- six persons/acre in a rural center. Knoxville also has persons/employees per acre criteria which ranges from 11 in a community commercial center to 24 in a regional commercial center.

\subsubsection{Total Population and Employment}

Five plans require the specific number of total jobs for the center designation while three plans look at total population. For example, Spokane, WA, requires at least 2,300 jobs for an activity center, and the Wasatch Front (UT) plan states that a town center will serve tens of thousands of people within a two- to three-mile radius. In Milwaukee, WI, centers are defined by specific job types-an industrial center contains at least 3,500 industrial jobs; an office center, 3,500 office jobs; a retail center, 2,000 retail jobs; and general purpose centers, 3,500 total jobs. Same goes for Baltimore with the employment criteria of greater than 20,000 jobs (in 2030) for the employment centers to 
industrial centers with the threshold of 10,000 jobs. Baltimore also has government centers which are areas with at least 5,000 government employees. Birmingham's plan contains a more specific guideline-regional activity centers must have two large employers within one-quarter mile of each other, each providing at least 1,000 jobs.

Bakersfield/Kern, CA, use population criteria which ranges from 60,000 in a region-level center to 50-5,000 people in village centers. Instead of using population and employment separately, Austin has the target ratio of jobs to the population from 1:4 to $4: 1$.

\subsubsection{Area Size}

Four RTPs consider the total area and three consider the radius of the area when determining area size thresholds for center types. Austin requires at least 100 acres for a regional center, and Baltimore has the size restriction of up to 2, 3.5, and 6 miles for mixed-use, employment, and suburban employment centers, respectively. Minneapolis expects a half-mile radius or 10 minutes of a walk for its urban center, and even more specifically, Poughkeepsie, NY, describes the size of centers as "a convenient 10-15minute walking distance from surrounding residential blocks to a commercial core and potential transit stop."

\subsubsection{Others}

- Greensville, SC, and North Charleston, SC, plans consider the ratio of residential to non-residential land uses (60:40 for a community activity center).

- Floor area ratio (FAR) criteria for different types of centers are included in the Wasatch Front, Flagstaff, and Chattanooga RTPs. The Chattanooga plan has explained FAR criteria in detail for each type of center. For this region, FAR ranges from 3-5 for regional centers to $0.25-1$ for growth centers.

- Transit service is only included in the Austin and Minneapolis plans (e.g., highcapacity transit for regional centers; local transit for community centers).

- Street density is only shown in the Nashville plan as an approximate street spacing (750 to 1,500 feet for activity centers).

- Baltimore identifies centers based on 2030 population/employment estimates rather than current data. For instance, emerging employment centers require 15,000 jobs and $50 \%$ job growth between $2000-2030$. 


\subsection{REVIEW OF SCENARIO PLANS TO IDENTIFY COMMON SCENARIO TYPES}

\subsection{INTRODUCTION}

In a 2004 survey, Bartholomew identified 80 scenario planning projects completed between 1989 and 2003. Comparisons of scenario performance against the baseline scenario in a subset of 23 selected scenario plans showed that a typical compact growth pattern had the impact of reducing vehicle miles traveled (VMT) by lowering automobile use per capita and increasing use of public transportation modes. The degree of centeredness across scenarios was important in explaining variations in VMT and other quantitatively predicted outcomes of each scenario. Narrative descriptions and maps of each scenario in the scenario reports were used to identify centeredness of each scenario that can range from dispersed/sprawling development to compact and monocentric growth scenarios. The 2010 survey and analysis of 28 scenario planning projects completed between 2003 and 2010 updated and confirmed findings of the previous study by the Metropolitan Research Center.

Building on prior research and scenario planning cases by the MRC research team, this section aims to review scenario planning projects to assess the impacts of polycentric development on land use-transportation outcomes. Due to advances in data management and predictive modeling approaches, scenario planning has increasingly gained popularity, and many scenario planning projects have been completed since 2010. While revisiting the existing 80 scenario planning projects, we will review the recent scenario planning projects to evaluate the common types of scenario plansranging from compact development scenarios with a few major centers to scenarios of dispersed development with many minor centers

\subsection{SCENARIO PLANNING CASE SELECTION}

To address the question of how the degree of polycentricity affects predicted outcomes of each scenario, we need to accumulate a large sample of recent regional scenario planning projects. To achieve this goal, the research team employed a combination of methods from two-phase, open-ended surveys to internet searches by keyword ("scenario planning," "scenario plans," "scenario planning projects," etc.). In this study, the internet keyword search was used to identify recent scenario planning projects completed after 2010. Along with the previously studied 80 scenario planning projects, 31 additional scenario planning projects were identified and included as a part of the initial data pool.

Based on the initial data pool, we next collected the detailed information on measures used for predicted scenario outcomes. Adopting the criteria used in the previous studies, we esablished three criteria to select the final dataset of scenario planning projects: (a) are at a regional scale, (b) have consistent scenario outcomes such as population, employment, transportation, land use consumption, and environmental 
impact projections, and (c) provide comprehensive descriptions and visualization of centers across each scenario. Particularly, the degree of polycentricity is our key measure, and we first looked at scenario planning documents to check whether they mentioned centers in crafting scenarios, estimating scenario outcomes, and visualizing locations of centers in their documents. Only a few scenario planning projects were found to visualize and include a description of centers in their documents. After applying all these criteria, we were able to identify 15 scenario planning projects. These 15 scenario projects contain 75 scenarios, including 19 trend scenarios. Most scenario planning projects tested three to five scenarios including a baseline/trend scenario, which means that two to four alternative scenarios will be compared against the corresponding trend scenario in terms of the degree of polycentricity and its impacts on relevant scenario planning outcomes.

\subsection{METHODS}

As with the 2004 and 2010 studies by the research team, this study also uses metaanalysis. Meta-analysis is "the statistical analysis of a large collection of results from individual studies to integrate the findings (Glass, 1976, p.3)." This statistical method allows us to compare the outcomes of different scenario planning projects and evaluate the performance of each scenario in terms of the degree of centeredness, which is our key variable. To conduct a meta-analysis, the subject studies must be empirical and conceptually comparable to ones that can be encoded like datasets in quantitative research methods (Lipsey and Wilson, 2001). Although scenario planning outcomes and narrative descriptions or visualization of centers are simulated results, these findings are based on quantitative models that are empirically derived, which in turn satisfies the conditions for conducting a meta-analysis.

For the 15 scenario projects, the research team collected the following data based on variables and policy categories described by Bartholomew and Ewing (2008 and 2010):

- Centeredness factors

o Centeredness dummy variable: Does a scenario planning project clearly explain the definitions of centers and visualize how centers are allocated in each scenario?

o Center hierarchy: Does a scenario planning project provide a hierarchy of centers?

o Patterns of centeredness in each scenario: monocentricity/polycentricity

o Development patterns: dispersed/compact/corridor

- Density factors: population density and development density (persons per developed acres)

- Demographic factors: population growth rate between the base and the target years

- Transportation outcome: daily vehicle miles traveled (VMT) in target year

- Economic outcome: employment growth rate between base and target years

- Environment outcome: CO2 emission change between base and target years 
The literature suggests that centeredness can be important in explaining variations in different scenario outcomes, especially variations in VMT (Ewing et al., 2003). However, due to lack of numeric data for measuring the degree of centeredness, this study also relied on narrative descriptions and scenario maps in the scenario planning documents to create categorical and dichotomous dummy variables on the degree of centeredness. A typical example of narrative and visual descriptions of centers in scenarios is Envision Cache Valley, Utah. The Envision Cache Valley project was initiated by the Cache Valley Regional Council to explore challenges associated with the growth of the Cache Valley region and devise long-term visions and strategies (Cache Valley Regional Council, 2008). Four different scenarios including a trend scenario were crafted. As we see in Figure 4.1, the scenarios B and C present polycentric growth patterns, whereas new growth seems to occur within existing major centers in the baseline and scenario D.
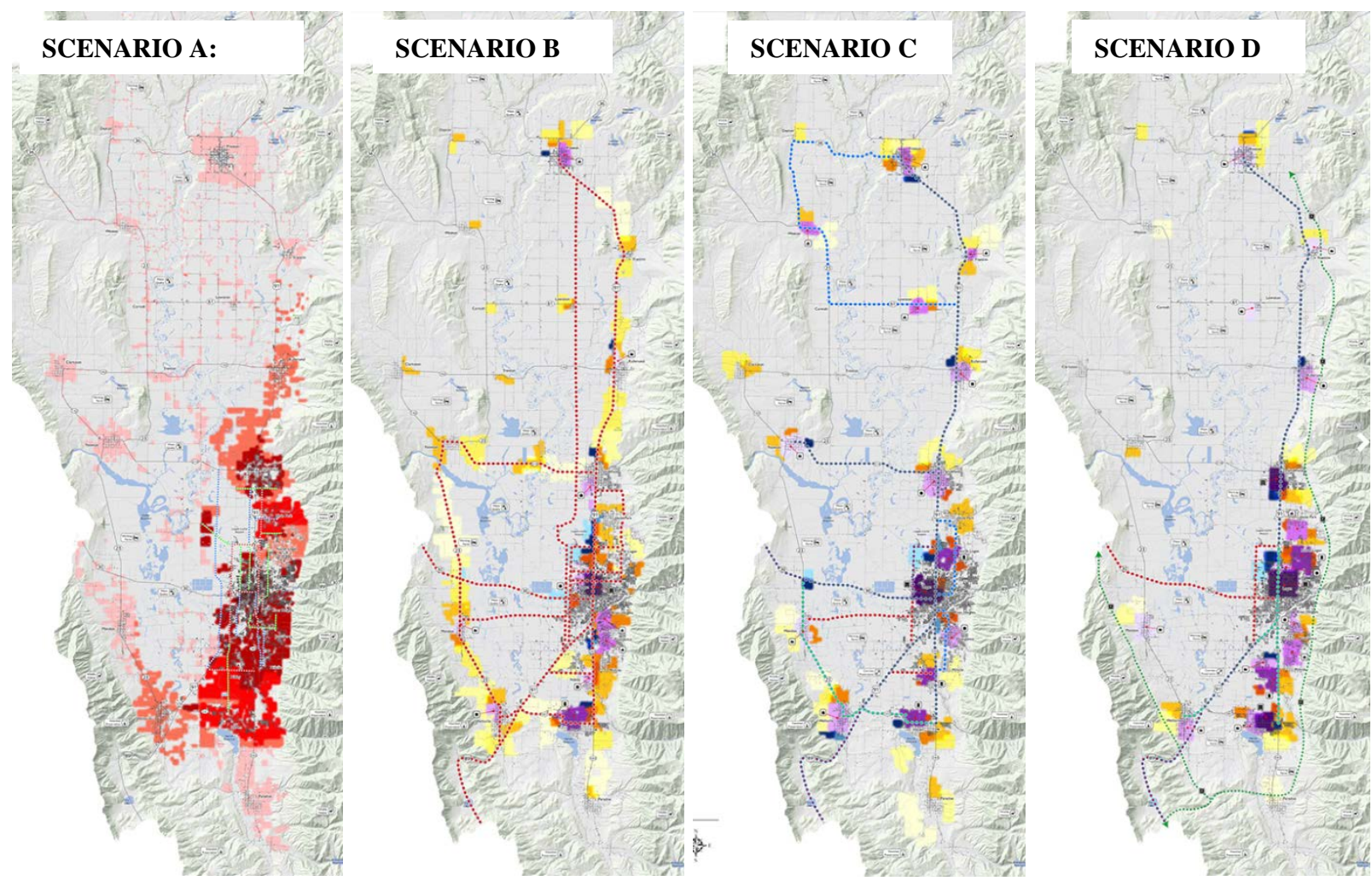

Figure 4.1: Urban footprints of four scenarios from the Cache Valley Council, Envision Cache Valley final report and toolkit (Cache Valley Regional Council, 2008)

Compared to scenarios $\mathrm{B}$ and $\mathrm{C}$, it would be accurate to say that the baseline scenario and scenario D may have monocentric growth patterns. As for development patterns, the baseline scenario consumes undeveloped land to expand urban boundaries, so its development pattern would be a dispersed one. Along with the polycentric center pattern, the narrative description of the scenario $B$ and its map indicate that new growth will occur near major transportation corridors, so the development pattern of scenario B will be "corridor." Lastly, scenario C presents an example of a "compact" development pattern because the narrative description of the scenario suggests new growth will 
occur within the traditional towns and small cities through mixed-use and infill development. Based on these rating processes, the research team identified 75 scenarios in the 15 scenario planning projects for analysis in the next section.

\subsection{ANALYSIS RESULTS}

\subsubsection{VMT and Centeredness}

Figure 4.2 shows the percentage difference in regional daily VMT for each alternative planning scenario when compared to the trend scenario. Each bar stands for a different planning scenario. Due to the highly positive percentage value in the "Build Out" and "Wise Growth Build Out" scenarios of the Lansing County Regional 2035 Transportation Plan, the median regional daily VMT across scenario planning projects is about $1.8 \%$ less than their trend scenarios. Among 15 scenario projects, the Central Ohio insight 2050 and Vision Dixie, St. George Utah project show the largest VMT reduction effect in alternative scenarios than their trend scenarios.

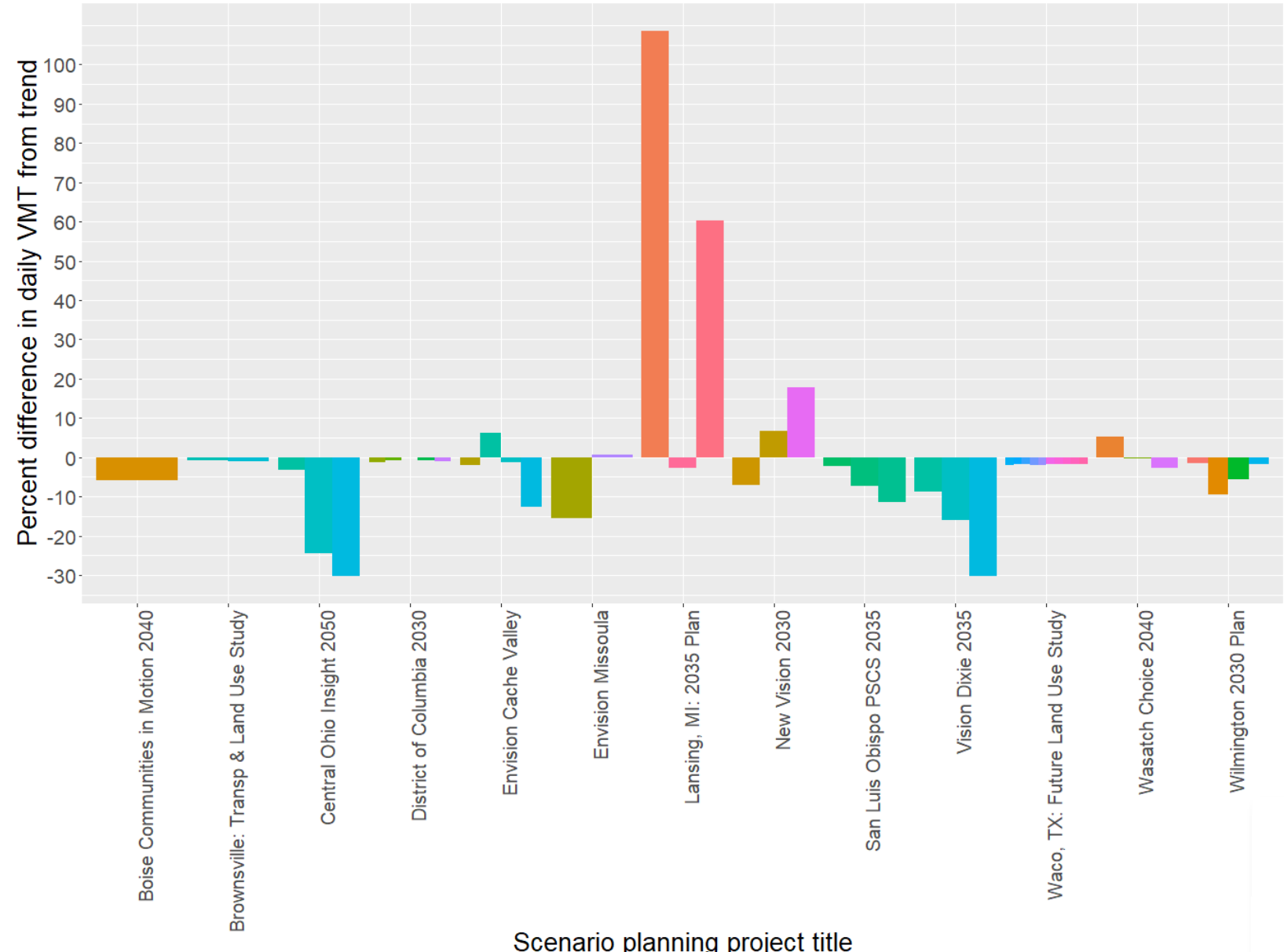

Figure 4.2: Percentage difference in VMT from the trend for 56 scenarios

Figure 4.3 shows the percentage difference in VMT depending on the degree of polycentricity (monocentric vs. polycentric) and development patterns (compact vs. corridor vs. dispersed). The monocentric planning scenarios tend to have larger impacts 
on reducing daily VMT compared to the trend scenario by $12.2 \%$ on average. In terms of how new growth is allocated in the region, the alternative scenarios showing the compact development pattern have the largest impact on reducing regional daily VMT by $4.8 \%$ from the trend.

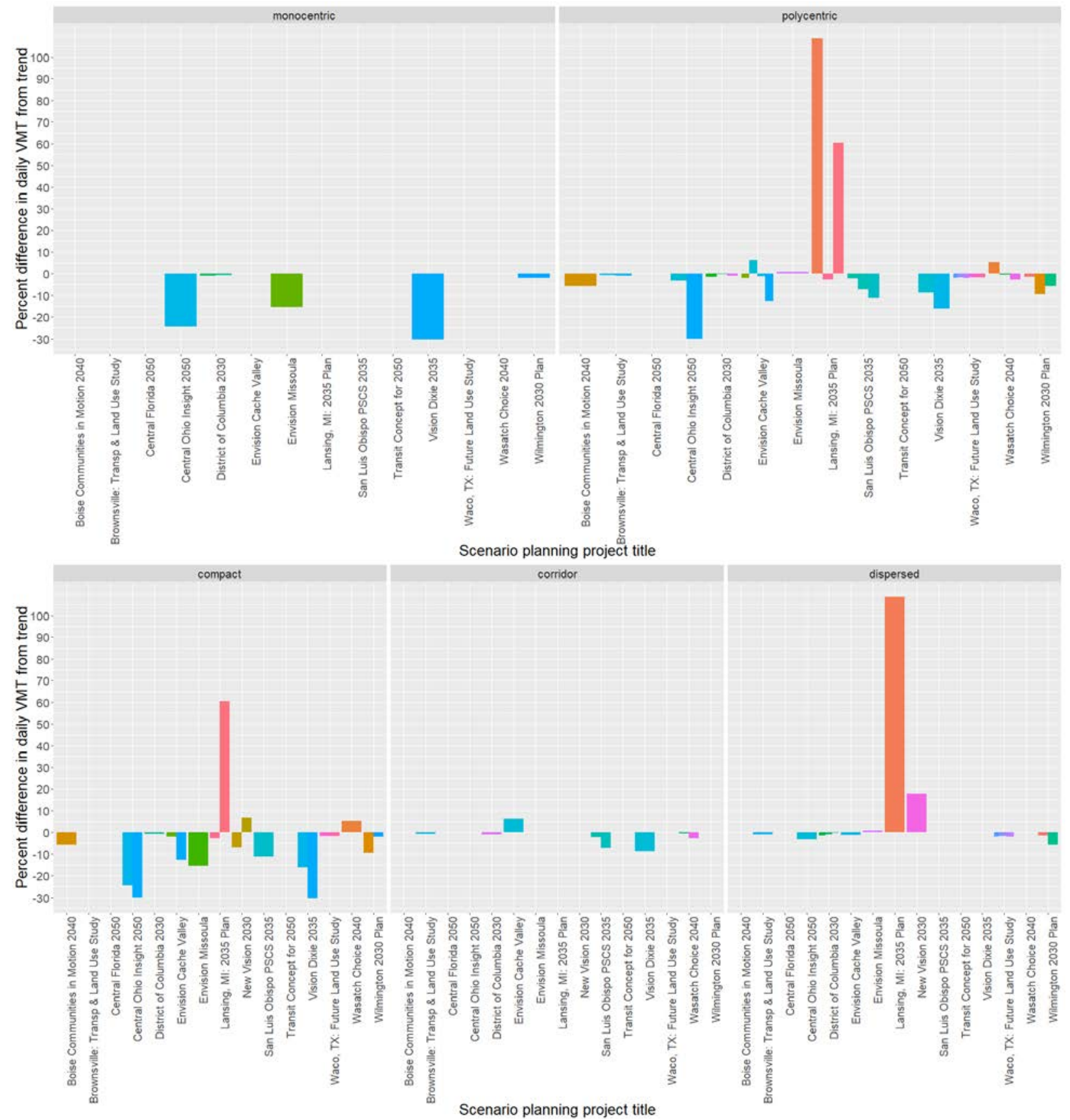

Figure 4.3: Percentage difference in VMT from the trend for 56 scenarios by centricity (top) and development patterns (bottom) 


\subsubsection{Density and Centeredness}

Persons per developed acres can be calculated by using the total acres of development land and the total population in the target year. Figure 4.4 shows the percentage difference in persons per developed acre for 56 scenarios from the trend. Except for two alternative scenarios in the New Vision 2030 and Wasatch Choice 2040, most alternative scenarios encourage compact development by adopting higher development density than the trend.

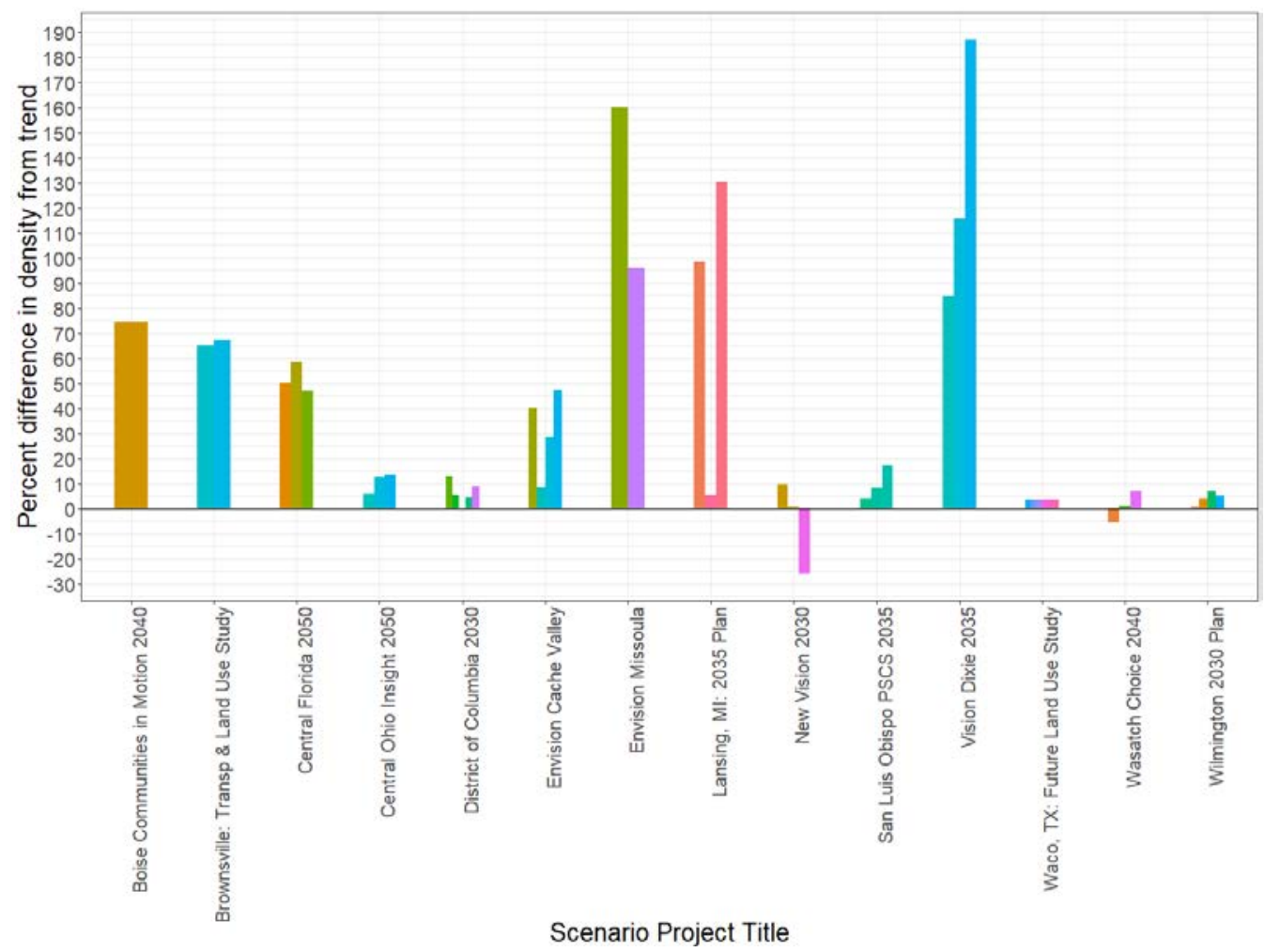

Figure 4.4: Percentage difference in density (persons per developed acre) from the trend for 56 scenarios

The density and annual vehicle miles traveled (VMT) difference from the trend in terms of centricity for each alternative scenario (53 scenarios from 15 scenario planning projects) are shown as a scatter plot in Figure 4.5. The scatter plot shows the negative relationship between the two variables; the higher the density is, the less annual VMT will be. The negative relationship between VMT and density holds valid in both monocentric and polycentric growth patterns. For monocentric scenarios, the red spot in the lower-left corner shows the Scenario C ("Focused Growth") in the Ohio Insight 2050. The reason a strong drop in annual VMT with a slightly high development density are that it seeks growth in infill and redevelopment in existing cities and towns, suggesting highly compact development patterns.

For polycentric scenarios, the overall decreasing trendline seems to be led by one blue point on the right slightly below the trendline, which represents Scenario $C$ of the "Vision Dixie." However, removing that blue point from the alternative scenario data sample 
does not change the slope of the trendline, suggesting the negative relationship between annual VMT and development density hold valid across polycentric scenarios. Finally, the scatter of points around the regression line in Figure 4.5 also suggests that there may be other factors affecting this relationship.

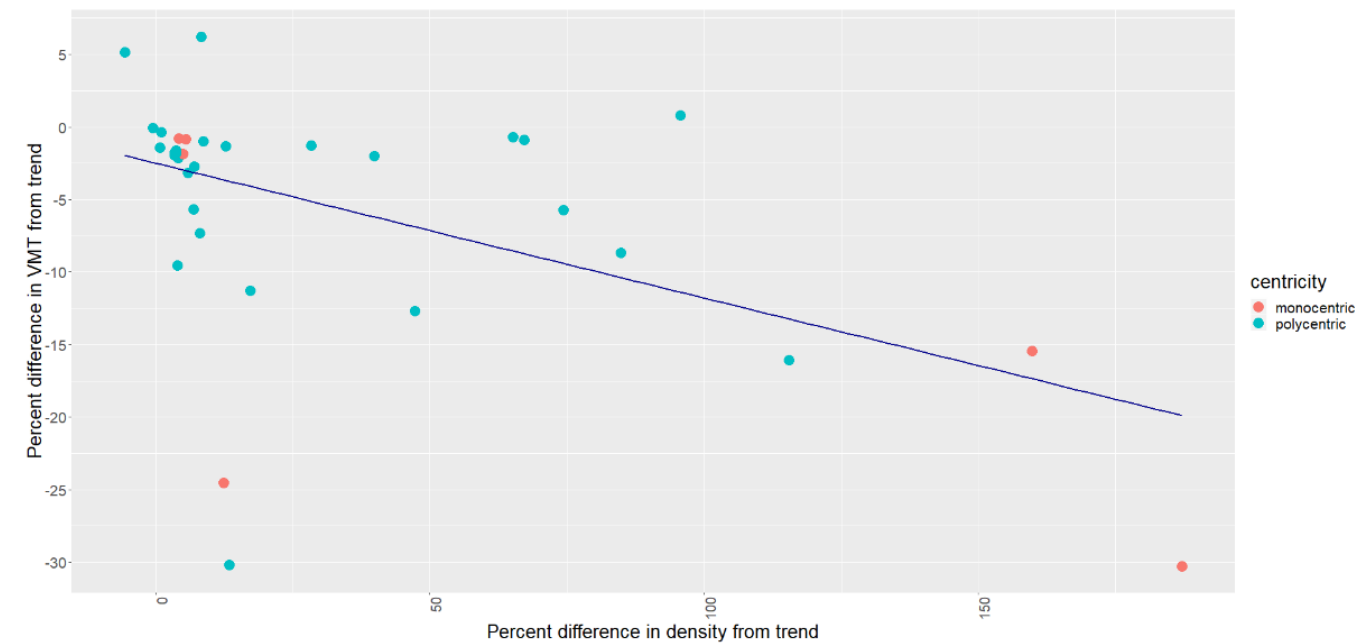

Figure 4.5: A scatterplot of a percent difference in annual vehicle miles traveled (VMT) from trend and percent difference in development density from trend

\subsection{CONCLUSIONS}

In this chapter, we reviewed scenario planning projects that have been established in the U.S. over the past three decades in terms of polycentric and monocentric development patterns shown in alternative scenarios. Fifty-three alternative scenarios from fifteen scenario planning projects were identified as scenarios that clearly showed their polycentric or monocentric development patterns through maps or texts. Through meta-analysis of a sample of those scenario planning projects, this chapter shows that (1) both monocentric and polycentric development scenarios have positive impacts on reducing annual vehicle miles traveled compared to the baseline (trend) scenario, and; (2) both monocentric and polycentric alternative scenarios show positive effects on VMT reduction as the development density increases, but alternative scenarios seeking the monocentric development pattern are more likely to reduce annual VMT as the development density increases.

From the scatter and bar charts, we could reach recommendations that, for significant VMT reduction, monocentric rather than polycentric development scenarios show better scenario performance. This suggests that compact development patterns with a few strong centers have an advantage. 


\subsection{IDENTIFICATION OF CURRENT AND POTENTIAL CENTERS NATIONALLY AND IN WASATCH FRONT}

The identification of centers was done in multiple steps. First, we identified the location of central business districts (CBDs) in 28 U.S. regions using local spatial autocorrelation techniques. These techniques enabled us to identify the highest local peaks in terms of employment density as potential CBDs. Then we applied multistep criteria to exclude unqualified candidates and find the final CBD locations. Having identified CBDs, the locations of potential employment subcenters were identified as positive residuals of a density function using Geographically Weighted Regression (GWR). Again, multistep criteria were applied to exclude unqualified candidates and find the final location of centers.

\subsection{STUDY REGIONS AND DATA}

This study identifies the location of CBDs and centers for 28 regions in the U.S. (Table 5.1). For the 28 regions, the MRC has collected regional household travel survey data from MPOs, so we can explain travel outcomes of residents living in centers, compared with those living outside centers.

For the 28 regions, we acquired household travel surveys conducted after 2004. While conducted by various metropolitan planning organizations (MPOs) or state departments of transportation (DOTs), the regional household travel surveys have quite similar structure and questions, akin to U.S. DOT's National Household Travel Survey (NHTS). To gather comprehensive data on travel and transportation patterns, the survey data consistently include, but are not limited to, household demographic information, vehicle information, and data about one-way trips taken during a designated 24-hour period on a weekday, including travel time, mode of transportation, and purpose of trip information. The survey data have exact $X Y$ coordinates so we could geocode the precise locations of households and the precise origins and destinations of trips. The regional survey data were acquired from individual MPOs or state DOTs with confidentiality agreements. The pooled dataset consists of 745,275 trips produced by 79,670 households in 28 regions (Table 5.1).

Table 5.1: Household travel survey data in 28 regions

\begin{tabular}{llccc}
\hline No. & Region & Survey year & $\begin{array}{c}\text { Households } \\
\text { in the } \\
\text { surveys }\end{array}$ & $\begin{array}{c}\text { Trips } \\
\text { in the } \\
\text { surveys }\end{array}$ \\
\hline 1 & Albany, NY & 2009 & 1,447 & 12,583 \\
\hline 2 & Atlanta, GA & 2011 & 9,574 & 93,678 \\
\hline 3 & Burlington, NC & 2009 & 594 & 4,982 \\
\hline 4 & Dallas, TX & 2009 & 2,869 & 27,056 \\
\hline 5 & Denver, CO & 2010 & 5,551 & 55,056 \\
\hline 6 & Eugene, OR & 2009 & 1,674 & 16,377 \\
\hline 7 & Greensboro, NC & 2009 & 1966 & 17,030 \\
\hline 8 & Hampton Roads-Norfolk, VA & 2009 & 1,954 & 16,462 \\
\hline
\end{tabular}




\begin{tabular}{clccc}
\hline 9 & Houston, TX & 2008 & 5,276 & 59,268 \\
\hline 10 & Indianapolis, IN & 2009 & 3,777 & 37,467 \\
\hline 11 & Kansas City, KS-MO & 2004 & 3,022 & 31,779 \\
\hline 12 & Madison, WI & 2009 & 138 & 1,316 \\
\hline 13 & Miami, FL & 2009 & 1,402 & 11,327 \\
\hline 14 & Minneapolis-St. Paul, MN-WI & 2010 & 8,234 & 68,005 \\
\hline 15 & Orlando, FL & 2009 & 866 & 7,315 \\
\hline 16 & Palm Beach, FL & 2009 & 944 & 7,166 \\
\hline 17 & Phoenix, AZ & 2008 & 4,314 & 37,815 \\
\hline 18 & Portland, OR & 2011 & 4,509 & 47,211 \\
\hline 19 & Provo-Orem, UT & 2012 & 1,464 & 19,255 \\
\hline 20 & Richmond, VA & 2009 & 612 & 5,123 \\
\hline 21 & Rochester, NY & 2011 & 3,438 & 23,036 \\
\hline 22 & Salem, OR & 2010 & 1,668 & 16,231 \\
\hline 23 & Salt Lake City, UT & 2012 & 3,490 & 39,029 \\
\hline 24 & San Antonio, TX & 2007 & 1,563 & 14,952 \\
\hline 25 & Seattle, WA & 2014 & 4,954 & 40,315 \\
\hline 26 & Syracuse, NY & 2009 & 652 & 5,735 \\
\hline 27 & Tampa, FL & 2009 & 2,259 & 17,538 \\
\hline 28 & Winston-Salem, NC & 2009 & 1,459 & 12,168 \\
\hline & Total & & 79,670 & 745,275 \\
\hline
\end{tabular}

For employment data, required to compute employment density, we relied on Longitudinal Employer-Household Dynamics (LEHD) data. The LEHD database is assembled by the U.S. Census Bureau, is available from 2002 to 2015 at the census block level, and can be aggregated to any larger geography, in this case, census block groups. In this study, LEHD data were downloaded and processed for the year 2015. The data were aggregated up to census block groups to generate total employment by a two-digit North American Industry Classification System (NAICS) code for each block group in 28 regions. Also, to obtain the total population at the census block group level in 2015, we used the five-year range (2012-2016) of the American Community Survey (ACS) because one-year ACS is not available at the block group level.

\subsection{LOCATING CENTRAL BUSINESS DISTRICTS (CBDS)}

To find CBDs among census block groups in each region, we used a spatial statistics technique, Local Moran's I. Local Moran's I is an indicator of the extent of significant spatial clustering related to the variable of interest (in this case, employment density) around each observation and can be used to locate hotspot block groups in an MSA in terms of the employment density. The formula for calculating Local Moron's I is:

$\mathrm{I}_{\mathrm{i}}=\frac{\left(x_{i}-\bar{x}\right)}{\sum_{i=1}^{n}\left(x_{i}-\bar{x}\right)^{2} / n} \sum_{j=1}^{n} w_{i j}\left(x_{j}-\bar{x}\right)$

Where $I_{i}$ is the Local Moran's I value, $\mathrm{x}$ is the employment density, $\mathrm{W}_{\mathrm{ij}}$ is the matrix of spatial weights, and $n$ is the sample size (Anselin, 1995).

We ran the Moran's I analysis at the block group level for 28 regions using LEHD employment data. The cluster census block group(s) with the highest Moran's I value were considered as a candidate for the CBD location. 
We then applied our second criterion to minimize error and exclude cases that were not CBDs even though they had the highest cluster of employment density. The reason behind this exclusion criterion is that there usually are clusters of block groups containing large organizations such as hospitals, malls, and university campuses. We excluded them from the analysis by considering the CBD as an area with no more than $75 \%$ in any population serving sectors (retail, entertainment, health, education, and personal services). The CBD locations were verified in comparison with the 1983 Census shapefile of CBDs of 247 MSAs (Hamidi, in press).

As a result, in the Wasatch Front region, three CBDs - one in Ogden, one in Salt Lake City, and one in Provo - were identified (Figure 5.1).

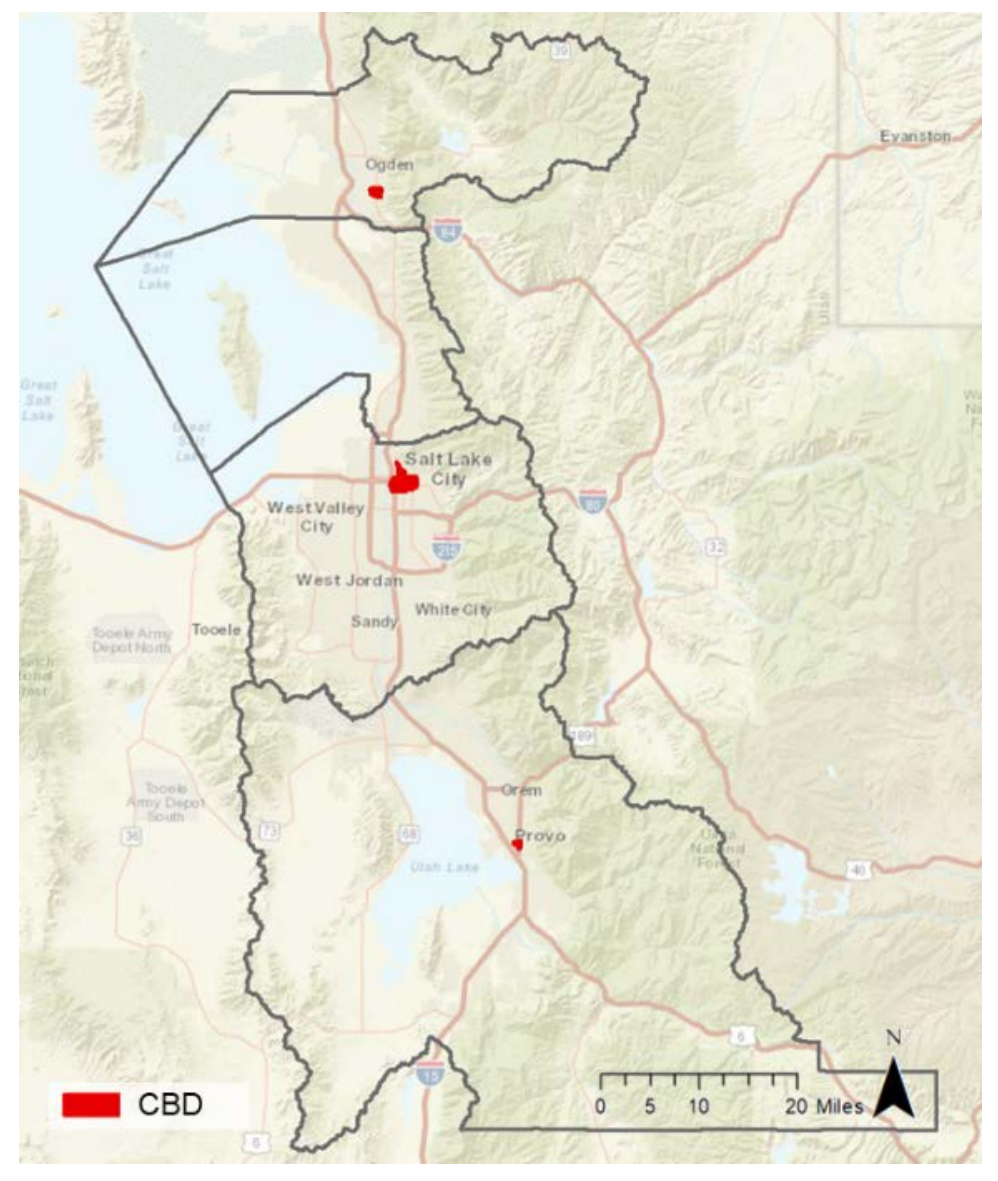

Figure 5.1: Location of CBDs in Wasatch Front Region

\subsection{IDENTIFYING SUBCENTERS}

\subsubsection{Local Density Peaks}

The spatial structure of metropolitan areas primarily depends on the location and distribution of employment subcenters within them. Employment subcenters are clusters of activities outside the traditional central business district large enough to influence real estate and, hence, the spatial form of nearby areas (Giuliano et al., 2008). Cervero 
describes them as "secondary office and retail centers within their respective metropolitan markets" (Cervero, 1989). These subcenters are identified as positive residuals of a density function using Geographically Weighted Regression (GWR).

GWR is the most common nonparametric method used in polycentricity studies and proposed by McMillen (2001). GWR identifies candidate subcenters as positive residuals of a nonparametric regression of the natural logarithm of employment density on distance from the CBD. GWR is more objective and less sensitive to the unit of measurement than other methods, and thus it can be applied and generalized to various metropolitan areas. The major advantage of GWR over a local spatial autocorrelation approach is that GWR takes into account the distance from the CBD in addition to the employment density. So, GWR qualifies local peaks that are far from the CBD even if they are not as dense as areas closer to the CBD.

The GWR method estimates an employment density surface using only neighboring observations for any block group while giving more weight to the closer observations. Our dependent variable is the employment density of a block group; the independent variable is the distance of the block group population centroid from the CBD. We used the population centroid rather than the geographic centroid as it better represents the spatial concentration of population in block groups. We obtained population centroid shapefiles from the census website.

In our GWR analysis, we used the adaptive kernel type with 30 number of neighbors. The clusters of one or more block groups with the highest positive residuals ( 2.5 times greater than predicted values) were considered as our subcenter candidates. Using a similar procedure as for the CBD analysis, we excluded cases containing large employment firms such as hospitals, shopping malls, and universities with more than $75 \%$ of the block group employment. We also excluded potential candidates if the ratio of employment to population was less than 1 or greater than 15 , thereby requiring centers to have a mix of uses. If several block groups meeting the above criteria were adjacent to each other, they were merged into one center.

As a result, a total of 20 local density peaks were identified in the Wasatch Front region - eight in Salt Lake, four in Davis, three in Weber, and five in Utah County. An area in downtown Provo overlaps with the Provo CBD. The sites range in size from 78.6 acres to 956.4 acres.

\subsubsection{Mixed-Use Developments and Districts}

As an entirely different approach to identify centers, we surveyed local planners. Over the years, the Metropolitan Research Center has collected mixed-use districts (MXD) locations in 32 regions, where we also have household travel data and related built environmental data. MXDs are a signature feature of smart growth, New Urbanism, and other contemporary land use movements aimed at reducing the private automobile's dominance in suburban America. Thus, we see MXDs as potential employment and population centers. 
To identify MXDs in the 32 regions, the team used a bottom-up, expert-based process in which planners with the different municipalities were queried about MXDs within their boundaries. Using this approach, a definition of an MXD was read or emailed to local planners, and they were asked to name, identify the boundaries, and list the uses contained within such areas.

"A mixed-use development or district consists of two or more land uses between which trips can be made using local streets, without having to use major streets. The uses may include residential, retail, office, and/or entertainment. There may be walk trips between the uses."

As a result, a total of 28 MXDs were identified in the Wasatch Front region - 23 in Salt Lake County, two in Davis County, two in Utah County, and one in Weber County. The sites range in size from 6.5 acres to 992.0 acres.

\subsubsection{Results}

To validate the results of each method, we compared them with the centers designated in Wasatch Choice for 2050 Vision. This is a test of face validity. The vision for the region, developed by the Wasatch Front Regional Council, our MPO, is one of multiple centers in a polycentric pattern. This helps us understand which of the two methods better explains the current and potential centers in this region, as perceived by public officials in the region. In Salt Lake County, we may have only one major center, downtown Salt Lake City, but we have already identified 22 mixed-use developments/districts that might be classified as subcenters and might form the nuclei for future major centers. We have also identified 20 minor employment centers, using Moran's I and GWR, that might form the nuclei for future major centers. For example, the neighborhood of Sugarhouse is identified as a subcenter by both methods, as is suburban Sandy's City Center.

Below three figures show side-by-side comparisons between locations of centers identified with the two different methods and those identified in the Wasatch Choice for 2050 Vision (Figures 5.2 through 5.4). Overall, the local density peaks using GWR align more closely with the WC2050 centers than do the MXDs from planner surveys, especially in Davis, Weber, and Utah counties. Out of 20 centers identified using GWR, 17 centers overlap with designated centers in the WC 2050 - eight urban centers, eight town centers, and one neighborhood center. Thus, we believe that the local density peaks, when combined with CBDs, are more valid indicators of centers. 


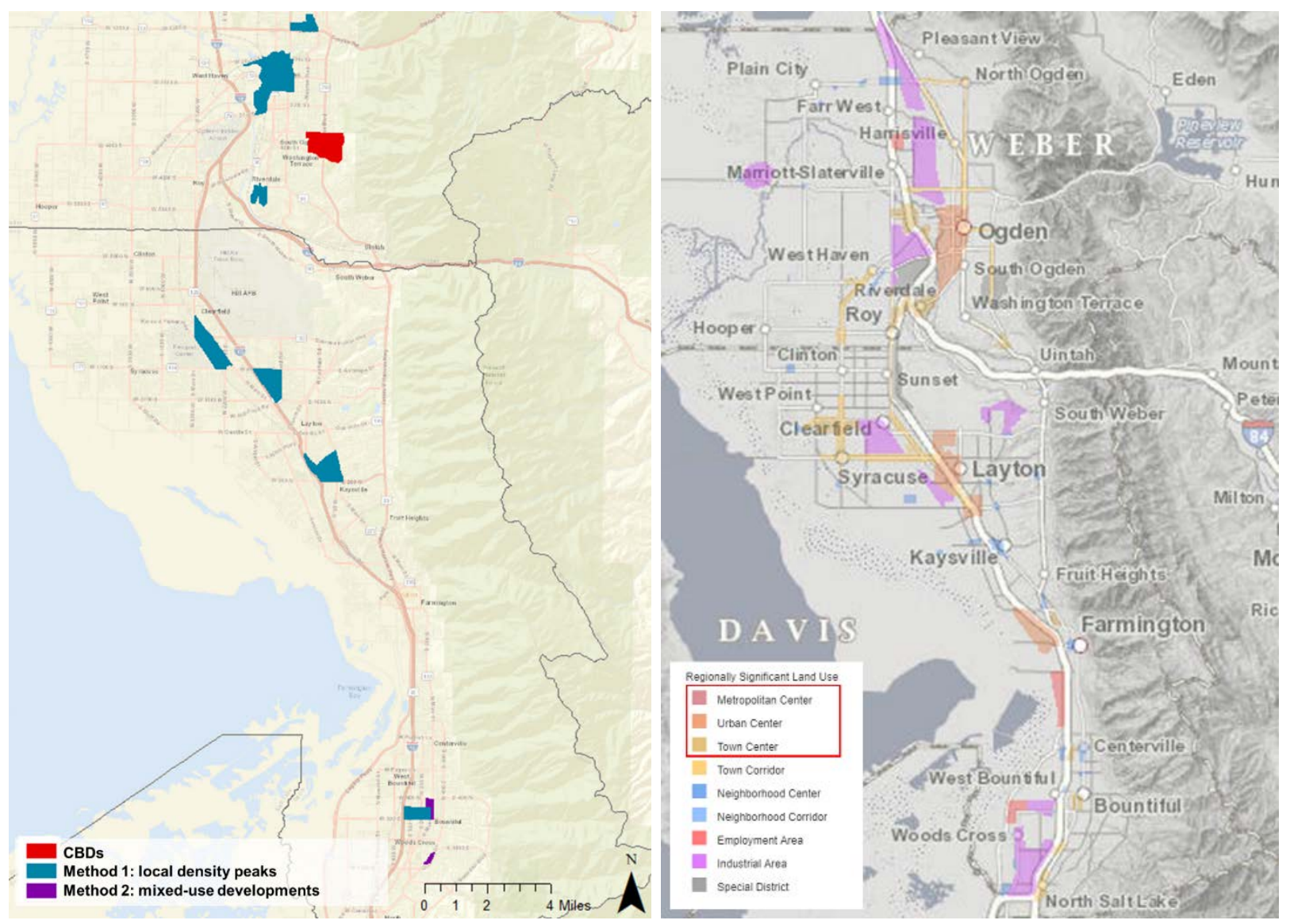

Figure 5.2: Davis/Weber counties: Centers using different methods (left) and in the Wasatch Choice 2050 (right) 

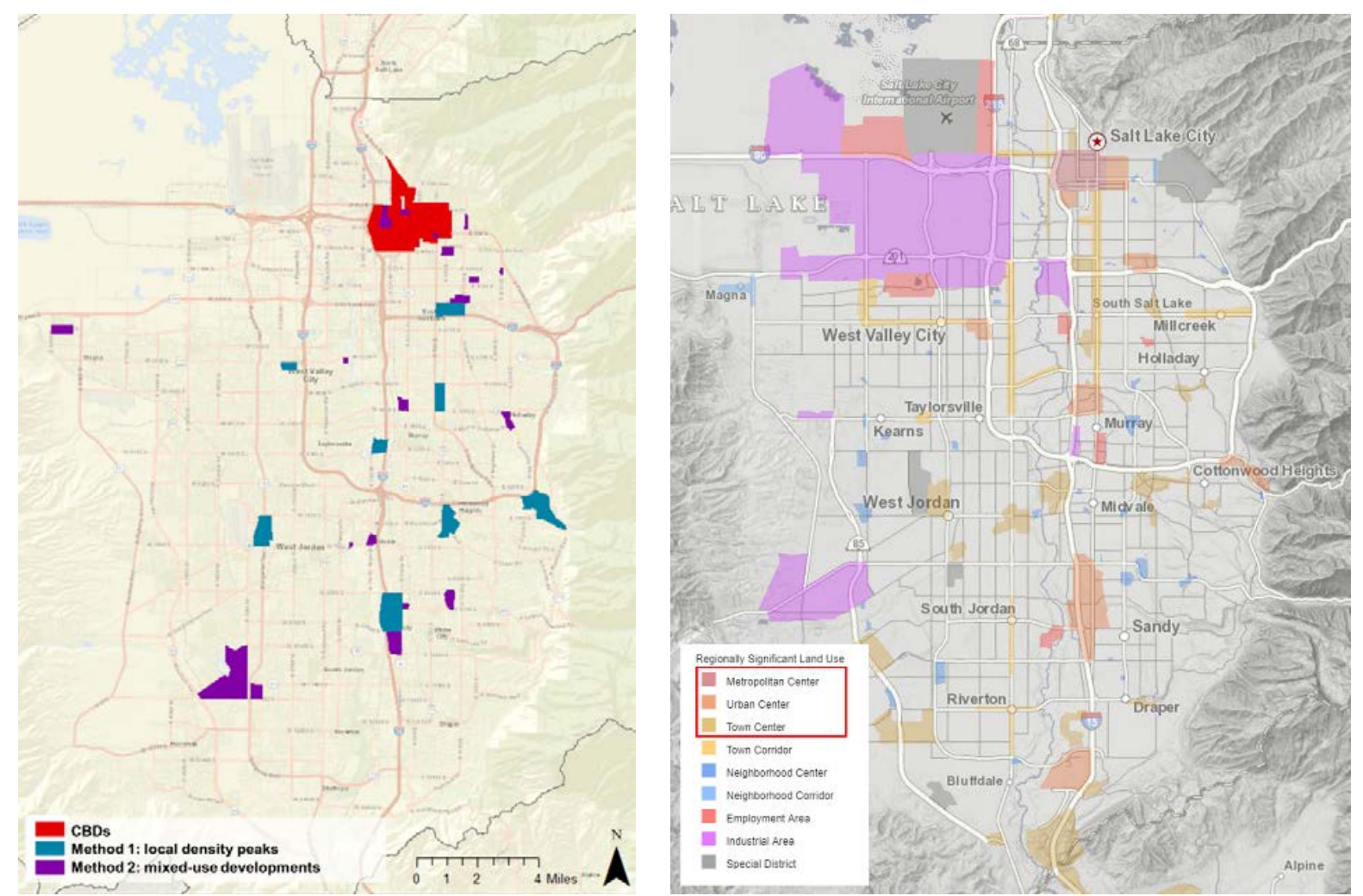

Figure 5.3: Salt Lake County: Centers using different methods (left) and in the Wasatch Choice 2050 (right)
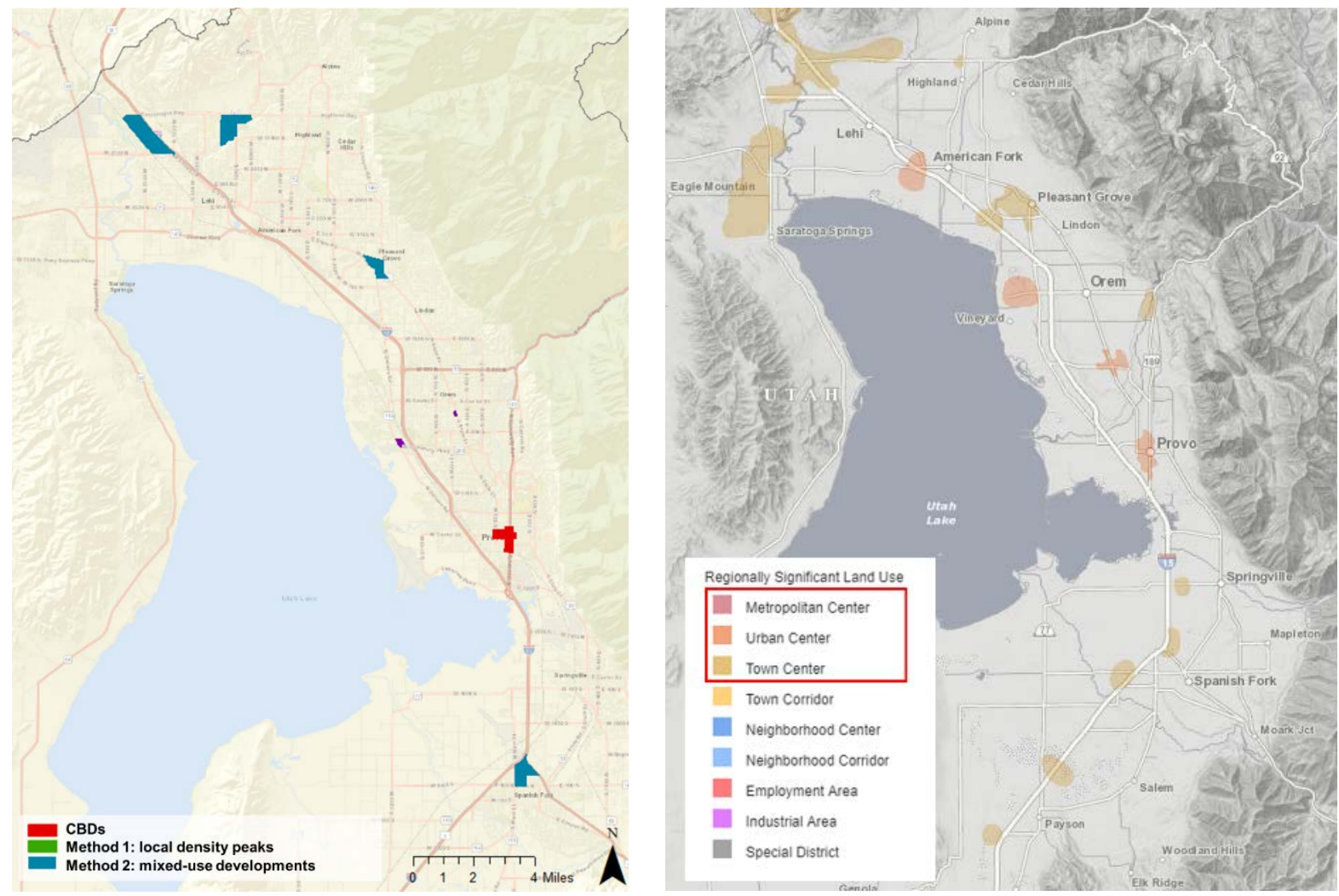

Figure 5.4: Utah County: Centers using different methods (left) and in the Wasatch Choice 2050 (right) 
Using the GWR methods, a total of 589 centers were identified in 28 U.S. regions (Table 5.2). The final centers include both CBDs and local density peaks. When a local density peak is within a CBD boundary, we consider it part of the CBD to avoid doublecounting. The number of centers in each region varies from one (Salem, OR) to 76 (Dallas, TX), with an average of 21 per region. Out of 79,670 households included in the travel surveys, 1,506 households live within centers and 78,164 households live outside centers. In the next chapter, we explore the transportation benefits of living in centers, in comparison with residents living outside of centers, using the extensive household travel survey database.

Table 5.2: Number of centers identified in 28 regions

\begin{tabular}{llccc} 
No. & Region & $\begin{array}{c}\text { Number of } \\
\text { centers }\end{array}$ & $\begin{array}{c}\text { Surveyed } \\
\text { households } \\
\text { living within } \\
\text { centers }\end{array}$ & $\begin{array}{c}\text { Surveyed } \\
\text { households } \\
\text { living outside of } \\
\text { centers }\end{array}$ \\
\hline 1 & Albany, NY & 7 & 20 & 1,427 \\
\hline 2 & Atlanta, GA & 50 & 217 & 9,357 \\
\hline 3 & Burlington, NC & 2 & 23 & 571 \\
\hline 4 & Dallas, TX & 76 & 50 & 2,819 \\
\hline 5 & Denver, CO & 30 & 109 & 5,442 \\
\hline 6 & Eugene, OR & 3 & 27 & 1,647 \\
\hline 7 & Greensboro, NC & 3 & 13 & 1,953 \\
\hline 8 & Hampton Roads-Norfolk, VA & 26 & 43 & 1,911 \\
\hline 9 & Houston, TX & 45 & 63 & 5,213 \\
\hline 10 & Indianapolis, IN & 23 & 58 & 3,719 \\
\hline 11 & Kansas City, KS-MO & 30 & 75 & 2,947 \\
\hline 12 & Madison, WI & 6 & 1 & 137 \\
\hline 13 & Miami, FL & 29 & 26 & 1,376 \\
\hline 14 & Minneapolis-St. Paul, MN-WI & 42 & 158 & 8,076 \\
\hline 15 & Orlando, FL & 12 & 11 & 855 \\
\hline 16 & Palm Beach, FL & 13 & 12 & 932 \\
\hline 17 & Phoenix, AZ & 37 & 49 & 4,265 \\
\hline 18 & Portland, OR & 15 & 81 & 4,428 \\
\hline 19 & Provo-Orem, UT & 5 & 14 & 1,450 \\
\hline 20 & Richmond, VA & 11 & 11 & 601 \\
\hline 21 & Rochester, NY & 10 & 56 & 3,382 \\
\hline 22 & Salem, OR & 1 & 26 & 1,642 \\
\hline 23 & Salt Lake City, UT & 17 & 54 & 3,436 \\
\hline 24 & San Antonio, TX & 12 & 18 & 1,545 \\
\hline 25 & Seattle, WA & 44 & 247 & 4,707 \\
\hline 26 & Syracuse, NY & 2 & 3 & 649 \\
\hline 27 & Tampa, FL & 33 & 30 & 1,448 \\
\hline 28 & Winston-Salem, NC & 5 & 11 & $\mathbf{7 8 6 4}$ \\
\hline & Total & 589 & 1,506 & \\
\hline & & & 39 & \\
\hline
\end{tabular}




\subsection{ASSESSMENT OF CENTERS NATIONALLY FOR TRANSPORTATION IMPACTS}

We used a database that consists of household travel data for 28 regions. For each of these households and trips, we have precise $X Y$ coordinates and know the trip purpose and travel mode for all trips. Therefore, we can identify households living within centers and outside of centers. We expect to find that households living in centers generate fewer automobile trips and less VMT on trips and make more walk and transit trips than those in nearby suburban sprawl. If our expectations are correct, this would be the strongest evidence yet produced on the transportation benefits of polycentric development.

\subsection{DESCRIPTIVE ANALYSIS OF TRAVEL OUTCOMES}

On average, households living in centers tend to be smaller, have a fewer number of workers and vehicles, and be less affluent (Table 6.1). An average household within a center has 2.05 persons, 1.04 workers, and 0.86 vehicles per capita, and earns $\$ 63,910$ annually. On the other hand, an average non-center household has 2.46 persons, 1.20 employees, and 0.90 cars per capita, and earns $\$ 70,947$ annually. And only $49 \%$ of households live in single-family detached housing, significantly lower than $79 \%$ in noncenter households. T-test results and chi-square statistic show that the differences are all statistically significant.

Table 6.1: Descriptive statistics and t-test and chi-square results of household characteristics by center residency

\begin{tabular}{|c|c|c|c|c|c|c|}
\hline & $\begin{array}{c}\text { Sample } \\
\text { househol } \\
\text { ds }\end{array}$ & $\begin{array}{l}\text { Household } \\
\text { size }\end{array}$ & $\begin{array}{l}\text { Number } \\
\text { of } \\
\text { workers }\end{array}$ & $\begin{array}{l}\text { Vehicl } \\
\text { e per } \\
\text { capita }\end{array}$ & $\begin{array}{c}\text { Income } \\
\text { (\$1000; } \\
\text { adjusted for } \\
2013 \text { dollars) }\end{array}$ & $\begin{array}{c}\% \text { of single- } \\
\text { family } \\
\text { detached } \\
\text { housing }\end{array}$ \\
\hline $\begin{array}{l}\text { Households } \\
\text { living } \\
\text { within a center }\end{array}$ & 1,506 & 2.05 & 1.04 & 0.86 & 63.91 & 48.87 \\
\hline $\begin{array}{l}\text { Households } \\
\text { living outside a } \\
\text { center }\end{array}$ & 78,164 & 2.46 & 1.20 & 0.90 & 70.95 & 78.58 \\
\hline $\begin{array}{l}\text { T-statistic or } \\
x^{2} \text { statistic } \\
\text { (p-value) }\end{array}$ & - & $\begin{array}{c}13.23 \\
(<.001)\end{array}$ & $\begin{array}{c}8.12 \\
(<.001)\end{array}$ & $\begin{array}{l}3.00 \\
(.003)\end{array}$ & $\begin{array}{c}5.40 \\
(<.001)\end{array}$ & $\begin{array}{l}759.05 \\
(<.001)\end{array}$ \\
\hline
\end{tabular}

Then, we compared travel outcomes including VMT and trip frequency of automobile trips, transit trips, walk trips, and bike trips between center households and non-center households (Table 6.2). On average, households living in centers tend to make fewer and shorter auto trips, take transit more often, walk more, and bike less. T-test results show that the differences are all statistically significant for all travel outcomes at the 0.05 significance level. Most centers are walkable and well-served by transit, so their residents might have less need for bike travel. 
Table 6.2: Descriptive statistics and t-test results of travel behaviors by center residency

\begin{tabular}{lccccc}
\hline & VMT & Auto trips & Transit trips & Walk trips & Bike trips \\
\hline $\begin{array}{l}\text { Households living } \\
\text { within a center }\end{array}$ & 24.57 & 6.50 & 0.25 & 1.00 & 0.06 \\
\hline $\begin{array}{l}\text { Households living } \\
\text { outside a center }\end{array}$ & 31.80 & 8.03 & 0.20 & 0.78 & 0.11 \\
\hline $\begin{array}{l}\text { T-statistic } \\
\text { (p-value) }\end{array}$ & $\begin{array}{c}10.15 \\
(<0.001)\end{array}$ & $\begin{array}{c}10.08 \\
(<0.001)\end{array}$ & $\begin{array}{c}-2.42 \\
(0.02)\end{array}$ & $\begin{array}{c}-4.00 \\
(<.001)\end{array}$ & $\begin{array}{c}5.34 \\
(<.001)\end{array}$ \\
\hline
\end{tabular}

Residential self-selection theory says, however, that the households living in centers might live there because they want to take transit or walk more and want to be less auto-dependent. Therefore, the observed differences in travel outcomes between the two groups are confounded by residential self-selection. Statistically, this generates a biased estimate of treatment effect. The results from difference-of-means tests call for more sophisticated approaches, controlling for the different household characteristics between centers and outside areas. Thus, we used propensity score matching, which will be discussed in the next section.

\subsection{MODELING TRAVEL OUTCOMES OF CENTERS}

\subsubsection{Methods: Propensity Score Matching}

Treatment selection bias is a common problem in non-randomized studies (Dehejia and Wahba, 2002). Propensity Score Matching (PSM) is a quasi-experimental research design used to attain unbiased cause-effect estimates in non-randomized studies (Rosenbaum and Rubin, 1985). With its natural weighting scheme, PSM is particularly helpful for studies that have a high dimensionality of observable characteristics for which deciding an appropriate weighting approach and appropriate dimensions for matching subjects can be difficult (Dehejia and Wahba, 2002). Propensity scores represent the likelihood of a subject receiving a treatment of a policy or intervention based on a set of pre-test covariates (Rosenbaum and Rubin, 1985; Rubin and Thomas, 2000). The score can help to match each treated subject with an untreated subject and create a control group from the pool of untreated subjects that share a similar distribution of baseline characteristics with the treated group. The matched sample subjects are comparable with the treated subjects based on their background co-variates, but they differ in that they have not received the treatment. Thus, by creating this control group, PSM approximates a randomized study (Caliendo and Kopeinig,2008). A propensity score can be estimated with any model that can predict the probability of a subject's receiving a treatment using treatment assignment as the dependent variable and the potential confounders as the independent variables. Logistic regression, probit regression, and discriminant analysis are the most widely used methods for estimating propensity scores (Thoemmes and Kim, 2011). It is important that all possible confounders are included in estimating propensity scores. Excluding any confounder can lead to a biased result and bring the credibility of the study results into question. 
Determining the appropriate method for creating pairs of treated and untreated subjects entails the decision of tradeoff between the precision of estimated treatment effect and elimination of bias. Among the different methods of matching (1:1, one to many or many to many), 1:1 matching is the most widely used where a treated subject is matched with an untreated subject in the control group with most similar propensity scores (Austin, 2009). For determining the range of scores that can be deemed similar for matching the treated and untreated subjects, nearest neighborhood matching with a specified caliper width is commonly used (Austin, 2009; Rubin and Thomas, 2000; Stuart, 2010).

PSM has not been applied widely in urban planning research until very recently. Since 2000, the application of PSM has risen in quasi-experimental studies. Sutton (2014) applied the technique to the assessment of commercial corridors and downtown shopping areas with and without business improvement districts in New York City. Sutton matched BIDs to non-BID census tracts based on observed pre-BID attributes known to affect BID adoption (retail density, assessed property value, and many other variables). This exercise produced a credible control group of non-BID census tracts that have a high probability of BID adoption but have not done so. In Sutton's case, each BID tract was matched with two "nearest neighbor" non-BID tracts with the closest propensity scores to create a matched trio. Sutton's primary finding is that both sales and employment declined for existing independent neighborhood retailers within BIDs relative to comparable non-BID areas.

Freeman and Rohe (2000) adopted propensity score matching to compare the neighborhoods that received assisted housing with those that did not. The purpose was to investigate the impact of assisted housing on neighborhood racial transition. Perdomo-Calvo (2007) employed PSM to compare selling prices of buildings in two areas of Bogota considering areas with BRT (bus rapid transit) service as the treatment group and areas without BRT service as the control group. Like other disciplines, the use of PSM has also gained much popularity in transportation research for treating the problem of self-selection bias and determining the true effect of the treatment. Nasri et al. (2018) used PSM in their analysis of mode choice in TOD (transit-oriented development) areas to estimate the effect of self-selection. Park et al. (2017) applied PSM comparing the travel behavior of households living in TOD station areas with those living in TAD (transit-adjacent development) or hybrid areas and concluded that living in a TOD truly influences people's travel choices. Tyndall (2018) compared the mode choice in areas with bus service vs areas without bus service applying PSM to avoid the bias incurred with the endogenous selection of route location. Boer et al. (2007), Cao and Schonar (2014), Cao and Fan (2012), Cao et al. (2010), Mishra et al. (2015) also applied PSM in travel behavior research.

\subsubsection{Results}

Descriptive statistics show that households living in centers tend to be smaller, have fewer workers and fewer vehicles per capita, are less affluent, and are more likely to live in non-single-family-detached housing (see Table 6.1). The households living outside of centers might live there because they are more auto-oriented, a phenomenon we referred to as residential self-selection. Therefore, the true difference in travel outcomes 
between centers and non-centers is estimated here by matching samples having similar socio-demographic status using propensity score matching.

With the five explanatory variables_household size, number of workers, vehicles per capita, household income, and single-family house -household pairs in centers and non-centers were matched. The PSM generates 1,498 household pairs $(2,996$ households in total). This number differs from the 1,506 households shown in Table 5.2 because not all households living in centers could be matched.

After matching, whether the chosen residents in one type of area are systematically different from those in another type was evaluated. If they are different in terms of demographics, self-selection is still a concern. Unlike unmatched samples where all demographic variables are significantly different between pair groups, t-test and chisquare results for matched samples show that residents in centers and non-centers do not differ in terms of all five covariates used in the PSM (see Table 6.3).

Table 6.3: Descriptive statistics and t-test and chi-square results of household characteristics by center residency (after matching)

\begin{tabular}{lcccccc}
\hline & $\begin{array}{c}\text { Sample } \\
\text { household } \\
\text { s }\end{array}$ & $\begin{array}{c}\text { Househol } \\
\text { d size }\end{array}$ & $\begin{array}{c}\text { Number } \\
\text { of } \\
\text { workers }\end{array}$ & $\begin{array}{c}\text { Vehicl } \\
\text { e per } \\
\text { capita }\end{array}$ & $\begin{array}{c}\text { Income } \\
\mathbf{( \$ 1 0 0 0 ;} \\
\text { adjusted for } \\
\mathbf{2 0 1 3} \text { dollars) }\end{array}$ & $\begin{array}{c}\text { \% of single- } \\
\text { family } \\
\text { detached } \\
\text { housing }\end{array}$ \\
\hline $\begin{array}{l}\text { Households } \\
\text { living } \\
\text { within a center }\end{array}$ & 1,498 & 2.01 & 1.03 & 0.86 & 63.91 & 49.07 \\
\hline $\begin{array}{l}\text { Households } \\
\text { living outside } \mathbf{a} \\
\text { center }\end{array}$ & 1,498 & 2.05 & 1.04 & 0.86 & 63.88 & 49.60 \\
\hline $\begin{array}{l}\text { T-statistic or } \\
\text { र2 statistic } \\
\text { (p-value) }\end{array}$ & - & -1.05 & -0.39 & -0.04 & 0.02 & 0.07 \\
\hline
\end{tabular}

Once the matching was complete, a difference-of-means test, or t-test, was used to check the statistical difference between household travel behaviors in centers and those outside of centers (see Table 6.4). Households in centers walk more (0.99 walk trips per day) than non-center households do ( 0.78 walk trips per day), and the difference is statistically significant at .001 significance level. Regarding VMT, after matching (i.e., controlling for demographic factors), center households drive 24.6 miles per day, 5.2 miles less than non-center households (29.8 miles). On the other hand, there are no statistically significant differences in the number of automobile trips, transit trips and bike trips between center and non-center households after matching.

Table 6.4: Descriptive statistics and t-test results of travel behaviors by center residency (after matching)

\begin{tabular}{lccccc}
\hline & VMT & Auto trips & Transit trips & Walk trips & Bike trips \\
\hline $\begin{array}{l}\text { Households living } \\
\text { within a center }\end{array}$ & 24.58 & 6.52 & 0.25 & 0.99 & 0.06 \\
\hline $\begin{array}{l}\text { Households living } \\
\text { outside a center }\end{array}$ & 29.78 & 6.66 & 0.30 & 0.78 & 0.06 \\
\hline
\end{tabular}




\begin{tabular}{lccccc}
\hline T-statistic & 5.38 & 0.84 & 1.35 & -2.94 & 0.20 \\
(p-value) & $(<.001)$ & $(0.40)$ & $(0.18)$ & $(0.003)$ & $(0.844)$ \\
\hline
\end{tabular}

These findings show that when a household in a suburban area moves into an existing center, or a city develops a new center by increasing its employment density and other D variables, the average household is expected to have significantly less VMT and significantly more walk trips.

\subsection{FINDING OPTIMAL VALUES OF D VARIABLES IN CENTERS: TRIP-LEVEL ANALYSIS}

\subsubsection{Introduction}

In travel behavior studies, the influence of the built environment has often been identified along with the five principal dimensions known as the 5Ds-Density, Diversity, Design, Destination accessibility, and Distance to transit (Cervero \& Kockelman, 1997; Ewing \& Cervero, 2001; Ewing et al., 2009). Using the five dimensions as measures of the built environment will provide a valuable framework to navigate and encapsulate the influences of complex built environment attributes on travel outcomes.

The impact of the built environment on moderating the travel demand is the subject of more than 200 empirical studies. In principle, higher D variables (except distance to transit, which should be lower) will result in a mode shift from auto trips to more sustainable modes of transportation such as walk, bike, and transit (Ewing \& Cervero, 2001; Reilly \& Landis, 2002; Frank et al., 2007; Ewing \& Cervero, 2010).

By compiling more than 50 studies, Ewing and Cervero (2001) showed that mode choice is most affected by local land use patterns. Consistent with the prior work, Ewing and Cervero (2010) found that destination accessibility and street network design have the greatest impact on auto use and, therefore, VMT (vehicle miles traveled); proximity to transit, street network design, and then land use diversity have the greatest impact on transit use; and walking is highly associated with land use diversity, intersection density, and the number of destinations within walking distance among $D$ variables.

As was explained in chapters 3 and 5 of this report, centers are usually described as the densest parts of a region, characterized by compact, mixed-use development, wellconnected, multiple transit options, and employment opportunities. This description is more vivid for centers at higher levels such as regional centers and urban centers. Hence, centers have a great potential to attract and generate trips and absorb a great portion of the economy of a region.

Ostensibly, centers are associated with higher levels of $D$ variables (or a lower level of distance to transit), and one would presume to see higher trip generation by non-auto modes in these areas. In this section, we will investigate how built environment variables - controlling for socio-demographic variables - will impact different modes of travel. We will use a generalized additive model (GAM) to identify non-linear relationships between different travel mode choices and $D$ variables within centers. The 
results will provide practical implications and guidelines for planning and developing centers, especially in regional transportation plans (RTPS).

\subsubsection{Data and Methods: Generalized Additive Model (GAM)}

The objective of this section is to find optimal values of each D variable to maximize the transportation benefits of centers. In most cases, a built environment variable is not linearly related to travel behavior. For example, the influence of doubling residential density from 20 to 40 (persons/acre) on walk mode share may be different fromprobably bigger than-the influence of the same rate of change from 200 to 400 (persons/acre). The latter may have rather negative impacts on walking if it leads to overcrowding and degraded walkability.

We use a database that consists of household travel data for 28 regions. For each of these households and trips, we have precise $X Y$ coordinates and know the trip purpose and travel mode for all trips. Therefore, we can identify trip ends-trip origins and destinations-within centers. We also dropped bike and other modes since they only account for limited mode share-1.65\% and 1.56\%, respectively-within the centers. Within 589 centers found previously using spatial autocorrelation and GWR techniques (see Table 5.2; note that six centers have no trip ends at all, so were dropped), we identified 163,487 trip ends-19\% walking, 7\% transit use, and 73\% driving. Then, built environment characteristics of centers were assigned to each trip end. Descriptive statistics for travel outcomes and $D$ variables are presented in Table 6.5. Note that the sample size for VMT is smaller than other trip measures because for that variable, we only included automobile trips having known travel distance.

Table 6.5: Descriptive statistics of travel outcome and built environment variables

\begin{tabular}{lrrrrr}
\hline Variables & N & Mean & S.D. & Min. & Max. \\
\hline Trip/traveler attributes & & & & & \\
\hline Walk trip (1= yes, 0=no) & 163,487 & 0.19 & 0.40 & 0 & 1 \\
\hline Transit trip (1=yes, 0=no) & 163,487 & 0.07 & 0.26 & 0 & 1 \\
\hline Auto trip (1=yes, 0=no) & 163,487 & 0.73 & 0.44 & 0 & 1 \\
\hline Vehicle miles traveled (VMT) & 118,988 & 6.54 & 7.78 & 0 & 99.00 \\
\hline Senior (over 65 years old) (1=yes, 0=no) & 163,487 & 0.16 & 0.37 & 0 & 1 \\
\hline $\begin{array}{l}\text { Child (less than 15 years old) (1=yes, } \\
\text { O=no) }\end{array}$ & 163,487 & 0.06 & 0.25 & 0 & 1 \\
\hline Driver license (1=yes, 0=no) & 163,487 & 0.59 & 0.49 & 0 & 1 \\
\hline Worker (1=yes, 0=no) & 163,487 & 0.65 & 0.48 & 0 & 1 \\
\hline $\begin{array}{l}\text { Trip purpose: home-based work (1=yes, } \\
\text { 0=no) }\end{array}$ & 163,487 & 0.16 & 0.37 & 0 & 1 \\
\hline $\begin{array}{l}\text { Trip purpose: home-based other (1=yes, } \\
\text { 0=no) }\end{array}$ & 163,487 & 0.32 & 0.47 & 0 & 1 \\
\hline $\begin{array}{l}\text { Trip purpose: non-home-based (1=yes, } \\
\text { 0=no) }\end{array}$ & 163,487 & 0.51 & 0.50 & 0 & 1 \\
\hline Center-level walk mode share (\%) & 583 & 6.21 & 10.01 & 0 & 100.00 \\
\hline Center-level transit mode share (\%) & 583 & 1.74 & 3.37 & 0 & 23.09 \\
\hline Center-level auto mode share (\%) & 583 & 92.05 & 11.77 & 0 & 100.00 \\
\hline
\end{tabular}




\begin{tabular}{lrrrrr}
\hline Center-level VMT & 583 & 6.35 & 3.13 & 0 & 31.67 \\
\hline Built environment attributes & & & & & \\
\hline Activity density ((pop + emp)/sq.mi.) & 583 & 11,084 & 10,800 & 2.26 & 92,435 \\
\hline Job-pop balance (a) $^{(a)}$ & 583 & 0.28 & 0.22 & 0.01 & 0.99 \\
\hline Entropy index $^{(\text {b) }}$ & 583 & 0.74 & 0.21 & 0.05 & 1.00 \\
\hline Intersection density (\# intersection/sq.mi.) & 583 & 129.34 & 80.92 & 10.86 & 730.65 \\
\hline Percentage of four-way intersections & 583 & 38.71 & 16.02 & 5.49 & 86.79 \\
\hline Transit stop density (\# stops/sq.mi.) & 583 & 31.85 & 42.86 & 0.00 & 361.54 \\
\hline $\begin{array}{l}\text { Percentage of regional employment within } \\
\text { 10 minutes by car }\end{array}$ & 583 & 7.05 & 10.26 & 0.00 & 79.34 \\
\hline $\begin{array}{l}\text { Percentage of regional employment within } \\
\text { 30 minutes by transit }\end{array}$ & 583 & 18.42 & 20.07 & 0.00 & 91.15
\end{tabular}

(a) JOBPOP $=1-$ [ABS(employment -0.2 * population $) /($ employment +0.2 * population $)]$, where $A B S$ is absolute value of expression in parentheses (Ewing et al., 2015). The value 0.2, representing a balance of employment and population, was found through trial and error to maximize the explanatory power of the variable.

(b) The entropy calculation is ENTROPY $=-$ [residential share * In(residential share) + commercial share * $\ln ($ commercial share $)+$ public share * $\ln ($ public share $)] / \ln (3)$, where $\ln$ is the natural logarithm.

Table 6.5 shows highly skewed distributions of $\mathrm{D}$ variables. For example, activity density ranges from 2.26 to 92,435 with an average of 11,084 ; transit stop density varies between 0 and 361.54, with an average of 31.85. The existence of extreme values can affect the results of our correlational analyses by lowering the predictive power of a model. Also, these outliers may be less relevant to the practical application of our models. Thus, we replaced outliers-identified as values below $5 \%$ percentile or above $95 \%$ percentile - with the $5^{\text {th }}$ and $95^{\text {th }}$ percentile values, a process called winsorization (Ghosh and Vogt, 2012; Yang et al., 2011). For example, the maximum value of activity density is dropped from 92,435 to 33,703 , the $95^{\text {th }}$ percentile of the original variable.

We use generalized additive models (GAM) to reveal a non-linear relationship between each D variable and travel outcome. The GAM is a generalized linear model in which the linear predictor depends on local smooth functions of some predictor variables (Hastie and Tibshirani, 1990). For example, a regression might be estimated between the two variables for some restricted range of values for each variable and the process is repeated across the range of each variable, while controlling for other explanatory variables. The series of local estimates are then aggregated by drawing a line to summarize the relationship between the two variables (Hothorn and Everitt, 2014).

A GAM can be written as:

$Y=a+s_{1}\left(x_{1}\right)+s_{2}\left(x_{2}\right)+\cdots+s_{n}\left(x_{n}\right)+\varepsilon$

where $\mathrm{a}$ is an intercept and $\mathrm{s}$ is a smooth function, estimated from the data. 
For smooth functions, different types of functions can be used such as local linear regression or splines. Generally, splines have better mathematical properties and are most often used in GAM fitting. Unlike traditional linear regression such as GLM (generalized linear model), an analyst cannot interpret coefficients or express the estimated curve by a formula. Instead, a GAM model enables us to visualize the fit by plotting, and thus is appropriate for exploratory analyses about the functional nature of response. The gam function ( $m g c v$ package) in R 3.6.0 was used to generate the GAM models. This enables us to see whether the $D$ variables are non-linearly related to travel outcomes such as mode share or vehicle use and where the tipping points maximizing sustainable travel behaviors are.

We ran two GAM models for mode choice and VMT. Mode choice is a categorical variable with three options-walking, transit, and automobile modes-and thus, modeled with a multinomial logistic model (reference category: automobile). VMT, a continuous variable, is log-transformed to deal with the right-skewed distribution and modeled with a Gaussian GAM model. We tested three models for VMT-a Gaussian with an original VMT variable, a Gaussian with a log-transformed VMT, and a gamma model—and found that the Gaussian model with a log-transformed VMT has significantly lower AIC (Akaike information criterion) and deviance values, thus providing the best model fit.

\subsubsection{Results}

Using GAM can help to relax the assumption of linearity between independent variables and a dependent variable. Table 6.6 shows two GAM models. All trip and traveler attributes-age factors, driver license, trip purpose, and employment status- but for employment status in the transit mode model are associated with the outcome variables at a statistical significance level $(p<.001)$. The "edf" in the model is the estimated degrees of freedom-- essentially, the larger the number, the more wiggly the fitted model (i.e., a more complex spline). Values of around 1 tend to be close to a linear form. P-values of the smoothed variables - in this case, D variables-indicate a test of the null hypothesis of a linear relationship instead of a nonlinear relationship. Thus, the models show that all $D$ variables have some degree of nonlinear relationship to travel outcomes. Two models explain $55.5 \%$ and $13.6 \%$ of the deviance in the data, respectively.

Table 6.6: Two GAM models of mode choice and VMT

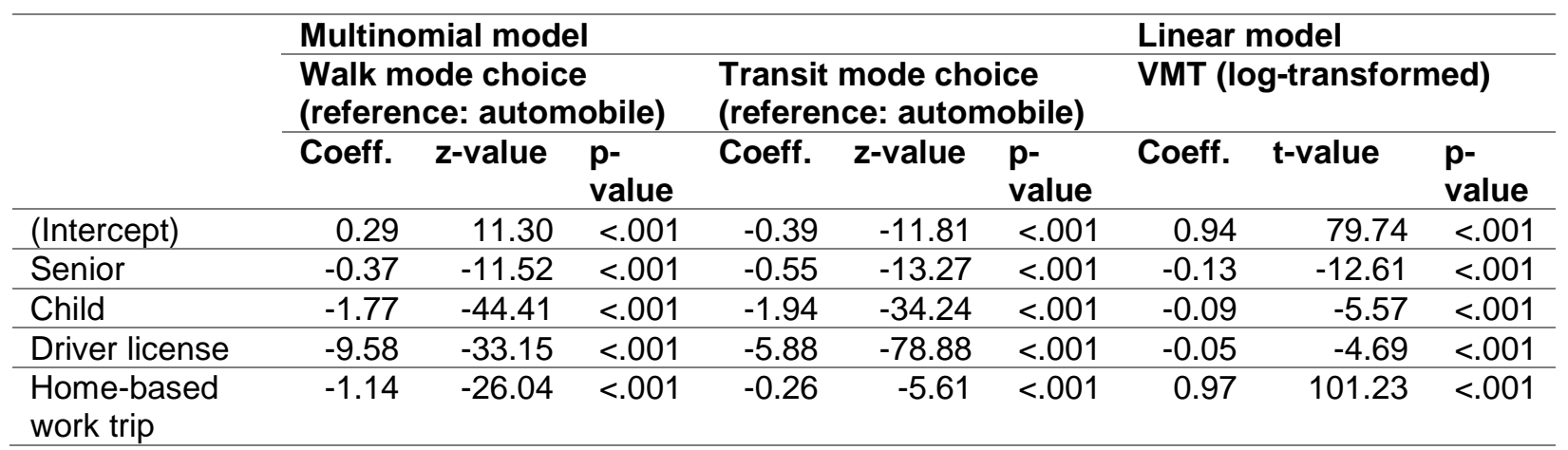




\begin{tabular}{|c|c|c|c|c|c|c|c|c|c|}
\hline $\begin{array}{l}\text { Home-based } \\
\text { other trip }\end{array}$ & -0.85 & -34.38 & $<.001$ & -1.61 & -44.93 & $<.001$ & 0.39 & 51.19 & $<.001$ \\
\hline \multirow[t]{2}{*}{ Worker } & 0.59 & 21.81 & $<.001$ & -0.01 & -0.19 & 0.85 & 0.06 & 6.83 & $<.001$ \\
\hline & edf & $\begin{array}{r}\text { X2- } \\
\text { value }\end{array}$ & $\begin{array}{c}p- \\
\text { value }\end{array}$ & edf & $\begin{array}{r}\text { X2- } \\
\text { value }\end{array}$ & $\begin{array}{l}p \text { - } \\
\text { value }\end{array}$ & edf & F-value & $\begin{array}{l}p- \\
\text { value }\end{array}$ \\
\hline s(actden) & 8.18 & 464.66 & $<.001$ & 8.43 & 108.46 & $<.001$ & 8.90 & 33.63 & $<.001$ \\
\hline s(jobpop) & 8.52 & 335.02 & $<.001$ & 7.37 & 159.16 & $<.001$ & 8.45 & 71.12 & $<.001$ \\
\hline s(entropy) & 8.61 & 150.74 & $<.001$ & 6.88 & 109.38 & $<.001$ & 8.94 & 4.16 & $<.001$ \\
\hline s(pct4way) & 8.03 & 435.48 & $<.001$ & 8.45 & 96.86 & $<.001$ & 8.93 & 50.38 & $<.001$ \\
\hline s(intden) & 8.64 & 229.61 & $<.001$ & 8.49 & 153.77 & $<.001$ & 8.92 & 45.58 & $<.001$ \\
\hline s(transitden) & 8.48 & 227.99 & $<.001$ & 8.73 & 349.77 & $<.001$ & 8.46 & 89.28 & $<.001$ \\
\hline s(pctemp10a) & 8.25 & 200.13 & $<.001$ & 8.46 & 198.54 & $<.001$ & 8.88 & 32.64 & $<.001$ \\
\hline s(pctemp30t) & 8.74 & 151.78 & $<.001$ & 8.52 & 103.12 & $<.001$ & 8.54 & 30.35 & $<.001$ \\
\hline & \multicolumn{6}{|c|}{$\begin{array}{l}N=163,461 \\
\text { Deviance explained }=55.4 \% \\
\text { REML }=-65,927\end{array}$} & \multicolumn{3}{|c|}{$\begin{array}{l}\mathrm{N}=118,988 \\
\text { Deviance explained }= \\
13.6 \% \\
\mathrm{GCV}=1.349\end{array}$} \\
\hline
\end{tabular}

Figures 6.1 to 6.3 show GAM plots with $95 \%$ confidence intervals. Then we summarize the patterns in Table 6.8. When controlling for other trip-related and $D$ variables, the likelihood of walk mode choice over driving becomes maximized at over 35,000 activity density (secondarily at around 22,000), over 175 intersection density, and 30-90 transit stop density. The likelihood of riding transit over driving becomes highest at 20,000 activity density, 160 intersection density, and 60-100 transit stop density. Lastly, VMT is likely to be minimized at 20,000 activity density, 230 intersection density, over $65 \%$ fourway intersections, 70 transit stop density, and over $40 \%$ of regional job accessibility in 30 minutes by transit, when controlling for other effects.
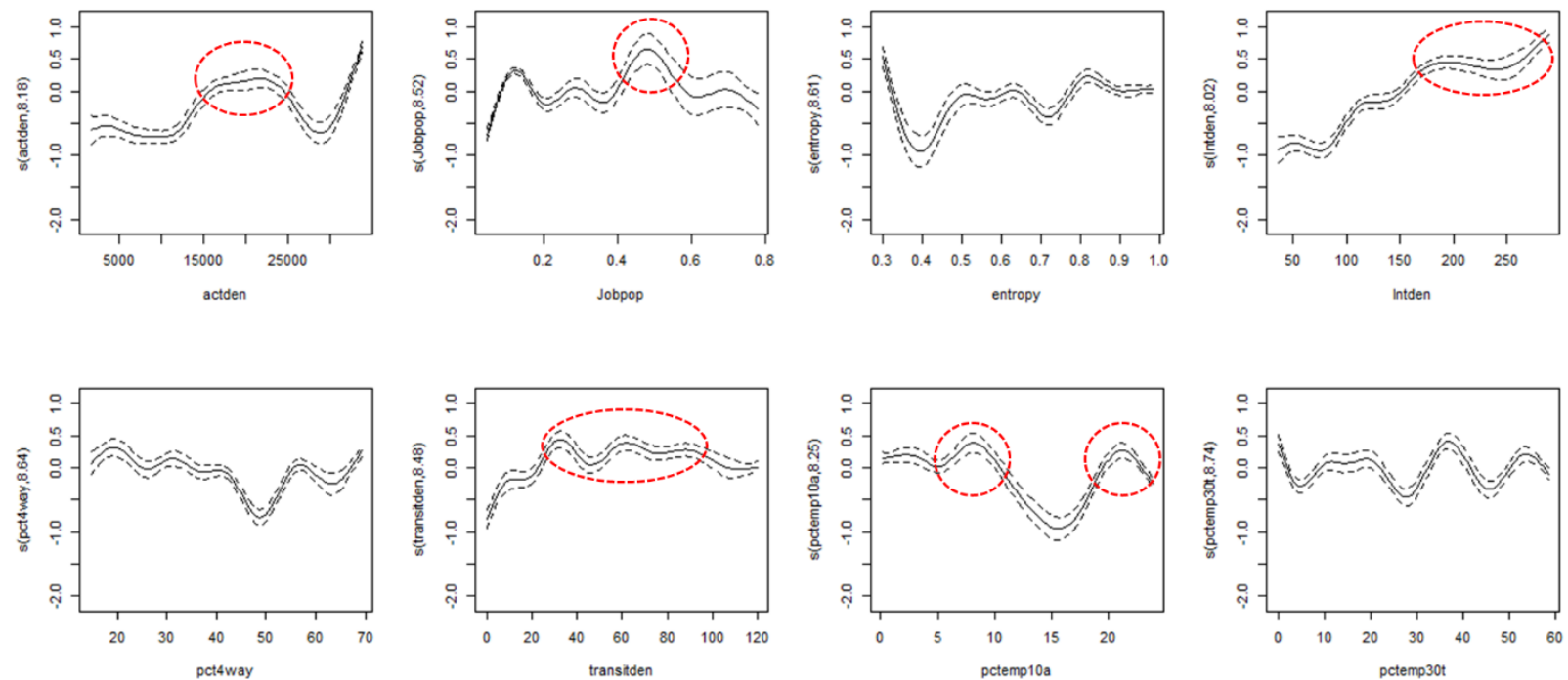

Figure 6.1: GAM plots between D variables and likelihood of walk mode choice (note: Red circles indicate potential optimal points to promote walking; Y-axis shows log odds of walk mode choice centered over driving, around zero) 

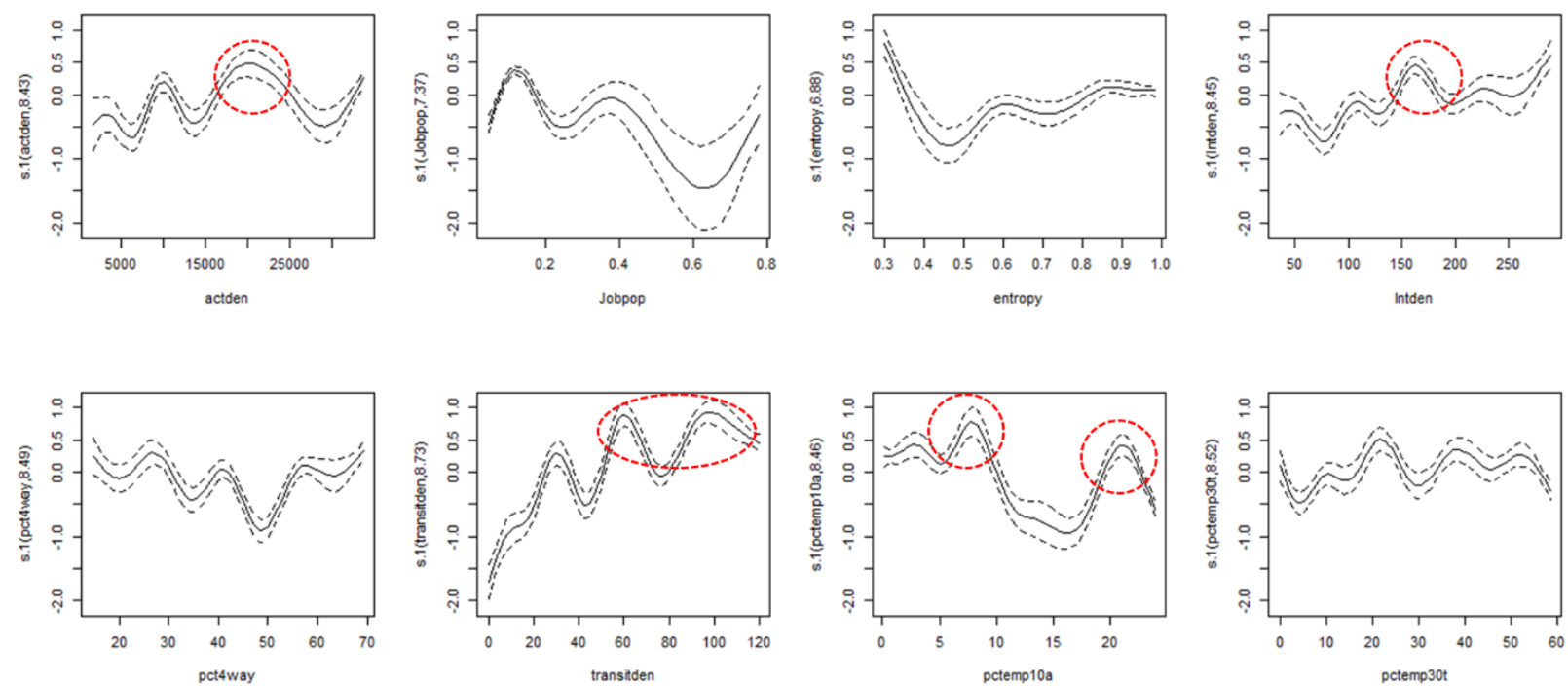

Figure 6.2: GAM plots between D variables and likelihood of transit mode choice (note: Red circles indicate potential optimal points to promote transit use; Y-axis shows log odds of transit mode choice over driving, centered around zero)
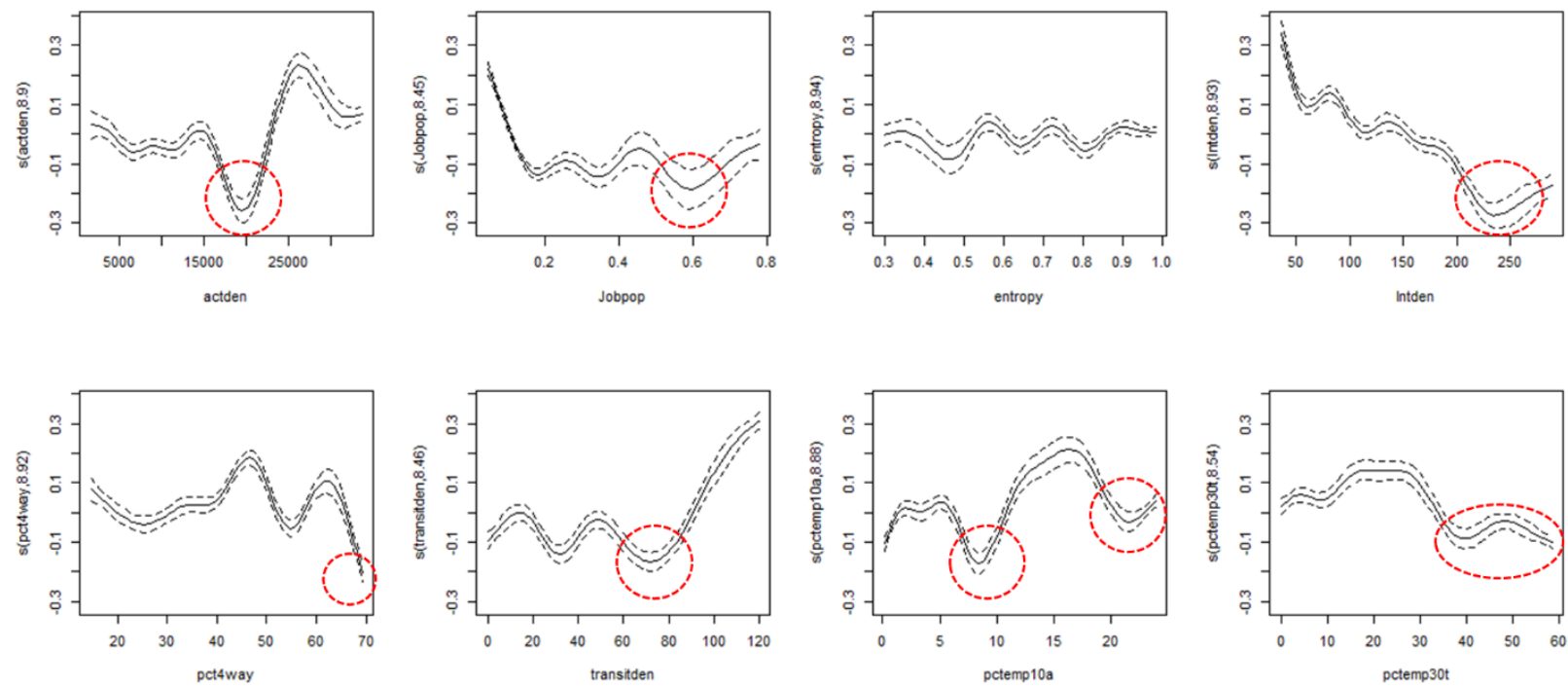

Figure 6.3: GAM plots between D variables and VMT (Note: Red circles indicate potential optimal points to discourage driving; Y-axis shows predicted log-transformed VMT, centered around zero)

Table 6.7: Patterns of travel outcomes with regard to D variables: from trip-level GAM models

\begin{tabular}{llll}
\hline & $\begin{array}{l}\text { Walking } \\
\text { (reference: } \\
\text { automobile) }\end{array}$ & $\begin{array}{l}\text { Transit use } \\
\text { (reference: } \\
\text { automobile) }\end{array}$ & VMT \\
\hline $\begin{array}{l}\text { Activity density } \\
\text { ((pop + emp)/sq.mi.) }\end{array}$ & $\begin{array}{l}\text { - High at between } \\
15,000 \text { and 25,000 }\end{array}$ & $\begin{array}{l}\text { - Maximum at around } \\
20,000\end{array}$ & $\begin{array}{l}\text { - Minimum at around } \\
\text { - Also high at 10,000 }\end{array}$ \\
\hline
\end{tabular}




\begin{tabular}{|c|c|c|c|}
\hline & $\begin{array}{l}\text { - Maximized at over } \\
35,000\end{array}$ & & \\
\hline $\begin{array}{l}\text { Intersection density } \\
\text { (\# intersection/sq.mi.) }\end{array}$ & $\begin{array}{l}\text { - Generally, the higher } \\
\text { the better } \\
\text { - High at over } 175\end{array}$ & $\begin{array}{l}\text { - Maximum at } 160 \text { and } \\
\text { after } 250\end{array}$ & $\begin{array}{l}\text { - Generally, the higher } \\
\text { the better } \\
\text { - Minimum at } 230-240\end{array}$ \\
\hline $\begin{array}{l}\text { Percentage of four- } \\
\text { way intersections }\end{array}$ & $\begin{array}{l}\text { - V-shape (maximized } \\
\text { below } 30 \% \text { or over } \\
55 \% \text { ) }\end{array}$ & $\begin{array}{l}\text { - V-shape (maximized } \\
\text { below } 25 \% \text { or over } \\
55 \% \text { ) }\end{array}$ & $\begin{array}{l}\text { - Minimized at over } \\
65 \% \\
\text { - Also low at } 55 \% \text { and } \\
\text { around } 25 \%\end{array}$ \\
\hline $\begin{array}{l}\text { Transit stop density } \\
\text { (\# stops/sq.mi.) }\end{array}$ & $\begin{array}{l}\text { - Maximum at between } \\
30 \text { and } 90\end{array}$ & $\begin{array}{l}\text { - Maximum at } 60 \text { and } \\
100 \\
\text { - Also high at } 30\end{array}$ & $\begin{array}{l}\text { - Minimum at between } \\
60 \text { and } 80 \\
\text { - Also low at } 30\end{array}$ \\
\hline $\begin{array}{l}\text { Percentage of } \\
\text { regional employment } \\
\text { within } 30 \text { minutes by } \\
\text { transit }\end{array}$ & - No clear pattern & - No clear pattern & $\begin{array}{l}\text { - Minimum at over } 40 \% \\
\text { - Generally, the higher } \\
\text { the better over } 30 \%\end{array}$ \\
\hline
\end{tabular}

Optimal values of $D$ variables may be related to the second highest (or second lowest for VMT) likelihood of the specific travel outcome, if it would be more feasible to be realized. For example, in Figure 6.1, while the probability of walking becomes maximized at over 35,000 activity density, 15,000-25,000 activity density also shows such a strong association with walk mode choice and thus may be optimal.

\subsubsection{Conclusions}

In this chapter, we used a non-traditional statistical model-GAM-to explore non-linear relationships between $D$ variables and travel outcomes, hence to find optimal values maximizing transportation benefits of polycentric developments. By relaxing the assumption of linearity between independent variables and a dependent variable, GAM plots show the tipping points of individual built environment variables maximizing the likelihood of walk/transit mode choice or minimizing VMT.

From GAM plots, we could reach recommendations for desired built environment characteristics of centers (see Table 6.9). For successful centers, we recommend 10,000-25,000 activity density (16-40 per acre; may vary by center types), a minimum of 150 intersections/square mile, over $60 \%$ of four-way intersections, over 60 transit stops/square mile, and a minimum $30 \%$ of regional job access within 30 minutes by transit. Note that one of the land use diversity variables, entropy, is not strongly associated with any travel outcome in centers, and thus we have no specific suggestion. In the literature. However, the entropy index is found to encourage walking and transit use and discourage vehicle use (Ewing and Cervero, 2010; Ewing et al., 2015).

Table 6.8: Recommendations for optimal built environment characteristics of centers

\begin{tabular}{ll}
\hline Built environment variables & Recommendations \\
\hline Activity density ((pop + emp)/sq.mi.) & $10,000-25,000$ (according to a center type) \\
\hline Job-pop balance & No recommendation \\
\hline Entropy index & No recommendation \\
\hline
\end{tabular}




\begin{tabular}{ll}
\hline $\begin{array}{l}\text { Intersection density (\# } \\
\text { intersection/sq.mi.) }\end{array}$ & Minimum 150 \\
\hline Percentage of four-way intersections & Minimum $60 \%$ \\
\hline Transit stop density (\# stops/sq.mi.) & Minimum 60 (recommended: $60-100)$ \\
\hline $\begin{array}{l}\text { Percentage of regional employment } \\
\text { within } 10 \text { minutes by car }\end{array}$ & No recommendation \\
\hline $\begin{array}{l}\text { Percentage of regional employment } \\
\text { within } \mathbf{3 0} \text { minutes by transit }\end{array}$ & Minimum $30 \%$ \\
\hline
\end{tabular}




\subsection{TRIP CHAINING EFFICIENCY IN CENTERS}

In the previous chapter, we assessed the transportation impacts of centers at the household level, and we found that households that live in centers have more walk trips and lower VMT. In this chapter, we will focus mostly on trip chains, which are also called travel tours. A travel tour is a sequence of trips that begins and ends at home, also known as a home-to-home loop. In this regard, a simple tour contains only two trips (i.e., one stop if we exclude home), while a complex tour contains multiple stops, multiple trips, and can have different trip purposes.

In this chapter, we investigate trip chaining efficiency using three different types of tours, which will be explained in detail in the following section. Harding et al. (2015) define efficient trip chaining as tours that have short, walkable trips incorporated into them. We expand this definition to consider bike and transit trips as well since they are other sustainable modes of transportation. Hence, we consider a tour to be efficient if it comprises travel modes other than the personal automobile. The higher the proportion of walk, bike, or transit trips, the more efficient the trip chain. Also, the shorter the trips (even by automobile), the more efficient the trip chain.

We expect to find that tours associated with centers are more efficient than ones that are completely outside the centers. Same as the previous chapter, if our expectations are correct this would be the strongest evidence yet produced on the transportation benefits of polycentric development. Understanding individuals' trip chaining behavior can help planners design environments that promote active transportation while maximizing residents' access to the services and amenities, and minimizing their expenditure on mobility and travel time as well as environment-related (e.g., pollution) and health-related (e.g., obesity) issues.

\subsection{TRIP CHAINING LITERATURE}

In Chapter 2 of this report, we summarized the literature on polycentricity and polycentric development. Since the literature on trip chaining is only related to this chapter, we have decided to describe it here and not to integrate it into Chapter 2.

Household members have both individual and common needs that are met through activities. Many of the activities are outside the home, and so involve travel. Household members cooperate in the organization of trips to meet their collective needs (Ewing et al., 1994; Ewing, 1997). Household members have the ability to defer or advance the times of certain discretionary activities and may also have a choice of activity sites. They can reduce overall travel by scheduling activities as part of trip tours or chains.

By previous estimates, between $40 \%$ and $60 \%$ of all trips taken by household members are part of multistop tours. Conservatively, the ability to link trips in tours cuts overall household travel by $15-22 \%$ relative to separate trips for the same purposes (Ewing et al., 1994; Ewing, 1997). The flexibility of the automobile makes it all possible. 
Household travel patterns are a function of accessibility (the D variables outlined above). The proximity of out-of-home activities to one's place of residence (so-called residential accessibility) affects the length, mode and, arguably, even the frequency of home-based trips. The second type of accessibility gets less attention in the literature but is also important. Destination accessibility (proximity of out-of-home activities to one another) affects travelers' ability to link trips efficiently into tours or, better still, complete more than one activity at a single stop. "...a shop which is close to a decision-maker's place of employment may be quite accessible (as indicated by the frequency of use) even though it may be quite distant from the decision-maker's place of residence" (Ewing et al., 1994; Ewing, 1997). Centers are the ultimate in destination accessibility.

The literature suggests that trips as the basic unit of analysis for the traditional four-step travel demand model should not be analyzed in isolation and the new trend in transport models is towards tour and activity-based models (Shiftan et al., 2003; Pendyala and Ye, 2005; Frank et al., 2008; Daisy et al., 2018). In contrast to individual trips, tourbased modeling "more closely matches the ways in which travel decisions are actually made, and so is more likely to capture true behavioral causality (as opposed to spurious correlations)" (Frank et al., 2008).

Obviously, individuals think about the modes they want to use for an entire tour (including the first destination, intermediate stops, and return trips) before they leave their home. An individual will not use his car to go to his work and then use transit to go back home. In addition, earlier studies suggest that individuals tend to optimize (mostly in terms of cost and time) their entire activity patterns rather than just considering separate trip choices (Bhat and Koppelmann, 1999; Bowman and Ben-Akiva, 2001).

Hence, failure to account for the dependency of trips within a tour can result in a biased understanding of true travel behavior. Because of that, we see growing attention to activity and tour-based modeling and during the past few decades, numerous studies have shed light on the important factors that affect tour frequency, the complexity of a tour, as well as the interconnection between activities, tours, and modes of travel (e.g., see Noland and Thomas, 2007; Bradley et al., 2009; Yang et al., 2010; Wang, 2014).

Most of the studies have confirmed that for individuals who choose complex tours, the personal vehicle is the preferred mode of travel due to its greater flexibility and convenience in trip chaining, while for short distance tours walk is the preferred mode (Strathman and Dueker, 1990; Primerano et al., 2008; de Nazelle et al., 2010; Daisy, Millward and Liu, 2018). By complex tours, as we explained in the previous section, we mean tours that have at least two intermediate stops. An intermediate stop occurs when a person participates in an activity at a location other than the home location.

However, some studies suggest that this conclusion cannot be drawn for all metropolitan areas around the world. For instance, by analyzing household travel surveys in 1980, 1990, and 2000 in Osaka, Japan, Susilo and Kitamura (2008) realized that auto commuters are more likely to make simple home-based work tours in this metropolitan area. But the number of tours that they generate is higher. Transit commuters, on the other hand, have a reverse travel behavior, meaning that they try to 
combine more visits into each tour or trip chain. Another interesting conclusion of their paper is that the commute trip length has more impact on transit commuters' behaviors than those of auto commuters.

By analyzing both simple and complex tours, Ho and Molly (2013) found that public transport use is promoted in a cluster of activity centers where people can do social, shopping, and personal business all in close proximity. They believe that the nature of the transit-involved tours is different from the ones undertaken by car. This is because public transport activities are linked to tours being in close proximity and reachable by walking. Moreover, they found out that land use mix at workplaces reduces the number of car trips in a tour since it allows workers to do multiple activities near their workplaces via walking.

Harding et al. (2015) investigated trip chaining efficiency among different types of tours. They found that multiple purposes at a single destination (MPSD) tours are positively correlated with the land use diversity and development density. Also, locations that provide better transit accessibility are more likely to result in efficient trip chaining (i.e., generate more walk trips on a tour). They also concluded that both MPSD and single purpose, single destination (SPSD) short tours have higher combined transit and walk mode shares. In terms of the built environment criteria, a higher level of land use mix and density lead to a higher prevalence of short SPSD tours which are mostly made on foot. Finally, they argued that the coordination between land use and transit provision can result in having more efficient trip chaining.

In principle, studies have found that the built environment can play a huge role in promoting the use of sustainable modes of travel within a tour. Studies conducted by Frank et al. (2008) and Lee et al. (2017) are two of the few studies that control for many built environment variables, and they found that density, diversity, and street connectivity have a positive impact on the number of walk, bike and transit trips within each tour. In the latter study, same as Susilo and Kitamura (2008), the authors found that transit trips for short-distance travel were likely to involve more trips within a tour (i.e., higher chain length).

Existing literature reports the potential effect choice of compact, mixed, and wellconnected urban forms on trip chaining efficiency and mode, yet empirical evidence is limited. The two main issues with the literature are, first, mixed results in terms of the relationships between tour patterns and the built environment. Second, although some research considered the effect of built environment characteristics or the so-called $D$ variables (albeit, not all of them in a single study), we could not find any study that focuses on centers. Centers, as we defined in the earlier chapters of this report, are areas that are dense, diverse, well-connected, and transit-served, with a high concentration of jobs. So, previous studies implicitly consider areas that meet some of the criteria of a center. However, they do not distinguish trips and tours that are generated inside a center versus ones generated outside a center and ones with some of the trips inside and the rest outside a center. 


\subsection{TRIP, MODE SHARE, AND TOUR PATTERNS}

Our dataset consists of almost a million trips made by individuals in 28 regions. However, for some of the trips, the $\mathrm{XY}$ coordinates are not reported by the individuals mostly because of the issues related to privacy. Since our unit of analysis is the tour, we needed to have the $\mathrm{XY}$ coordinates of all trips and stops. Therefore, we removed a tour completely if we did not have the location of even one single stop associated with that tour. On the other hand, not all of the tours started and ended at home. So, we needed to remove them as well. After filtering disqualified tours, the resulting pooled dataset consists of 678,932 trips in 235,291 simple and complex tours. Table 7.1 shows the total and maximum numbers of trips and tours in each region

Table 7.1: Number of trips and tours in each region, with the maximum number recorded for an individual

\begin{tabular}{|c|c|c|c|c|}
\hline Region & \# of trips & \# of tours & $\begin{array}{l}\text { Max \# tours } \\
\text { per person }\end{array}$ & $\begin{array}{l}\text { Max \# trips } \\
\text { within a tour }\end{array}$ \\
\hline Albany, NY & 10,630 & 3,892 & 7 & 16 \\
\hline Atlanta, GA & 81,714 & 27,467 & 8 & 24 \\
\hline Burlington, NC & 4,251 & 1,515 & 6 & 12 \\
\hline Dallas, TX & 23,685 & 8,503 & 7 & 18 \\
\hline Denver, CO & 53,298 & 17,373 & 7 & 32 \\
\hline Eugene, OR & 16,165 & 5,075 & 6 & 22 \\
\hline Greensboro, NC & 14,947 & 5,260 & 6 & 11 \\
\hline Hampton Roads-Norfolk, VA & 14,316 & 5,244 & 8 & 11 \\
\hline Houston, TX & 55,802 & 19,959 & 9 & 21 \\
\hline Indianapolis, IN & 36,357 & 11,909 & 6 & 21 \\
\hline Kansas City, MO & 29,582 & 10,387 & 8 & 21 \\
\hline Madison, WI & 1,071 & 390 & 6 & 8 \\
\hline Miami, FL & 9,759 & 3,649 & 7 & 12 \\
\hline Minneapolis-St. Paul, MN-WI & 74,157 & 25,802 & 5 & 11 \\
\hline Orlando, FL & 64 & 23 & 3 & 6 \\
\hline Palm Beach, FL & 4,959 & 1,875 & 9 & 10 \\
\hline Phoenix, AZ & 31,413 & 11,873 & 8 & 13 \\
\hline Portland, OR & 46,344 & 14,185 & 9 & 25 \\
\hline Provo, UT & 16,617 & 6,155 & 9 & 15 \\
\hline Richmond, VA & 4,431 & 1,621 & 7 & 11 \\
\hline Rochester, NY & 21,116 & 7,486 & 9 & 16 \\
\hline Salem, OR & 15,838 & 5,307 & 7 & 36 \\
\hline Salt Lake City, UT & 39,339 & 14,331 & 12 & 31 \\
\hline San Antonio, TX & 14,278 & 5,252 & 7 & 29 \\
\hline Seattle, WA & 42,961 & 15,043 & 12 & 18 \\
\hline Syracuse, NY & 4,925 & 1,752 & 5 & 12 \\
\hline Tampa, FL & 137 & 51 & 3 & 5 \\
\hline Winston-Salem, NC & 10,776 & 3,863 & 6 & 27 \\
\hline
\end{tabular}


In order to compare trip chaining efficiency, we have created three types of tours: 1 ) tours that fall entirely within a center; in other words, all trips in a tour were generated inside a center; 2) some of the trips within a tour were generated inside a center and the rest outside, which we call hybrid tours; and 3) tours that do not have a single trip/stop inside a center. Table 7.2 shows the share of travel modes, VMT per trip (calculated by dividing total VMT of a tour by the number of trips within a tour), and chain length or the number of trips within each tour.

Table 7.2: Descriptive statistics of dependent variables for each of the tour types

\begin{tabular}{|c|c|c|c|}
\hline $\begin{array}{l}\text { Dependent } \\
\text { Variable }\end{array}$ & Tour type $^{*}$ & Mean & Std. Deviation \\
\hline \multirow[t]{3}{*}{ Walk share } & Type 1: Within a center & 0.512 & 0.471 \\
\hline & Type 2: Hybrid & 0.068 & 0.197 \\
\hline & Type 3: Outside of a center & 0.074 & 0.248 \\
\hline \multirow[t]{3}{*}{ Bike share } & Type 1: Within a center & 0.036 & 0.182 \\
\hline & Type 2: Hybrid & 0.014 & 0.112 \\
\hline & Type 3: Outside of a center & 0.013 & 0.109 \\
\hline \multirow[t]{3}{*}{ Transit share } & Type 1: Within a center & 0.059 & 0.197 \\
\hline & Type 2: Hybrid & 0.042 & 0.157 \\
\hline & Type 3: Outside of a center & 0.012 & 0.097 \\
\hline \multirow[t]{3}{*}{ Auto share } & Type 1: Within a center & 0.374 & 0.471 \\
\hline & Type 2: Hybrid & 0.860 & 0.318 \\
\hline & Type 3: Outside of a center & 0.867 & 0.325 \\
\hline \multirow[t]{3}{*}{ VMT per Trip } & Type 1: Within a center & 0.586 & 1.709 \\
\hline & Type 2: Hybrid & 2.125 & 2.8356 \\
\hline & Type 3: Outside of a center & 2.210 & 3.260 \\
\hline \multirow[t]{3}{*}{ Chain Length } & Type 1: Within a center & 2.598 & 1.315 \\
\hline & Type 2: Hybrid & 3.716 & 2.098 \\
\hline & Type 3: Outside of a center & 2.687 & 1.223 \\
\hline
\end{tabular}

${ }^{*}$ Number of Observations in each tour type: Type $1=2,414$, Type $2=45,622$, Type $3=187,255$, Total $=$ 235,291

As Table 7.2 shows, type 1 (tours entirely within centers) has the highest walk, bike, and transit shares, and the lowest auto share, VMT per trip, and chain length compared to types 2 and 3. Note that type 2 (hybrid tours) has higher bike and transit mode shares and a lower auto share and VMT per trip compared to type 3 (tours entirely outside centers). The walk share for tour type 2 is marginally lower compared to type 3 , which we will discuss in the next section. In the meantime, the average number of trips associated with tour type 2 is higher than both types 1 and 3 , suggesting that these tours are more complex because they involve travel from inside to outside centers or vice versa. Judging by this table, trip chaining or tours are more efficient in type 1 than type 2, and least efficient for type 3 with $87 \%$ personal auto trips. However, we need to 
test these results since we are not sure whether we have reached these conclusions by chance or there are statistically significant differences between the shares of walk, bike, transit, and auto trips for these three types of tours.

\subsection{METHODS: ONE-WAY ANALYSIS OF VARIANCE (ANOVA)}

The appropriate statistical approach to test significant differences between the means of our three unrelated types of tours is a one-way analysis of variance (ANOVA). In our study, we violate one of the basic assumptions of ANOVA. That is, the dependent variable should be approximately normally distributed for each group of the independent variable (here, tour type). Our dependent variables here are walk, bike, transit, car mode shares, average VMT per trip, and chain length in each tour. As expected, our data is not normally distributed. Depending on the group, this non-normality might be more pronounced. For instance, Figure 7.1 shows a highly skewed distribution of the walk shares for each tour in type 3 (tours made outside of a center). For many of the tours, a zero percentage of walk share has been recorded.

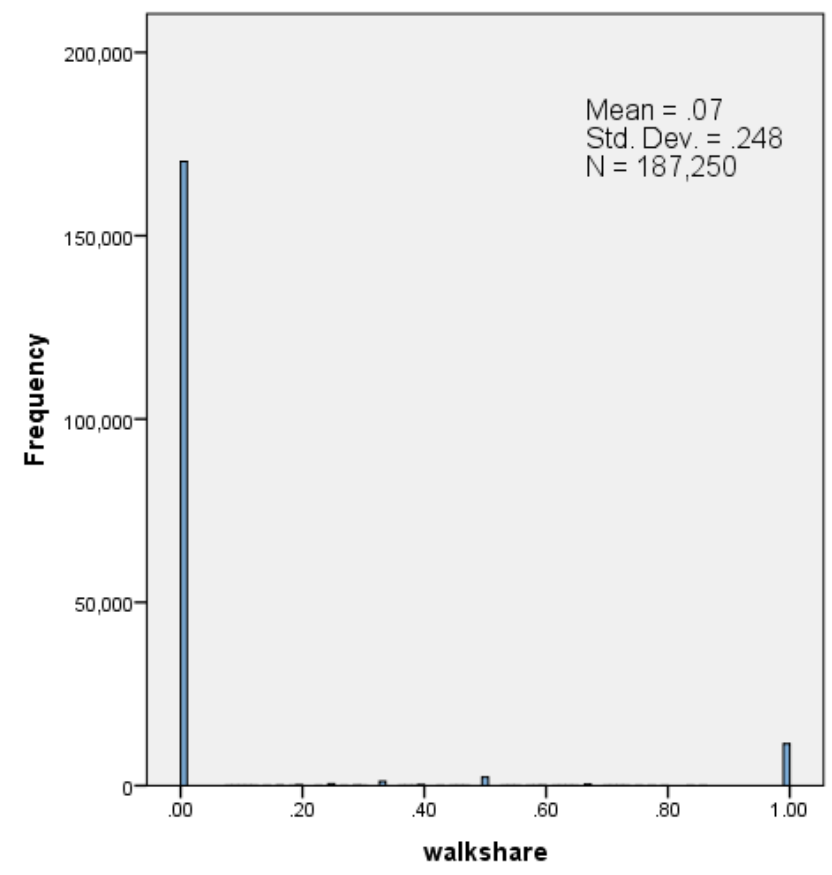

Figure 7.1: Histogram of the frequency of walk share within tours in type 3 (i.e., none of the trips within a tour was inside a center)

However, it has been argued that many statistical tests are robust in the presence of violations of the normality assumption when the sample size is large enough based on the central limit theorem. By robustness, we mean that these tests maintain their statistical properties even when assumptions are not entirely met. In fact, Fagerland (2012) found that non-parametric tests are most useful for small sample studies. As a rule of thumb, when we say a small sample size, we mean group size of no more than 20. For studies with a large sample size, parametric tests (focusing heavily on t-tests 
and their corresponding confidence intervals) "can and should be used even for heavily skewed data" (Fagerland, 2012).

Since our study consists of three tour types with thousands of tours within each of them, it is safe to use parametric tests; in this case, ANOVA. To determine whether differences in means among groups are significant, ANOVA calculates an F-statistic. A large F-statistic is evidence against the null hypothesis since it indicates that there is a greater difference between groups than within groups (Bingham and Fry, 2010).

\subsection{RESULTS}

Tables 7.3 shows the results of the ANOVA tests between tour types for each of the mode shares, average VMT per trip, and chain length. By looking at the last two columns, we can conclude that the F-statistics are extremely large and, hence, all differences are statistically significant. So, we can reject the null hypothesis and conclude that the variation among group means is more than one would expect to see by chance.

Having said that, since our sample size $(n)$ is quite large, one would expect to see a huge F-statistics for each of the ANOVA tests. The F-statistic is the ratio of betweengroup variance to the within-group variance. The within-group variance is the residual sum of squares (between observations and group means) averaged by the number of samples. Because this is an average, this does not change much as we increase the number of samples. However, the between-group variance is the sum of squares between the groups multiplied by the number of observations in the group, then averaged by the number of groups. Because of that multiplication, this will increase as $n$ increases.

Hence, as we have more and more samples, the numerator in the ratio gets bigger and bigger, so the $F$ statistic increases, even if we are sampling from the same population of observations. Because of that, we have computed the effect sizes to determine how meaningful the differences are (i.e., practical significance). Eta-squared $\left(\eta^{2}\right)$ and Cohen's $f$ are two of the well-known effect size measures used for ANOVA tests in this chapter. Eta-squared (also known as the correlation ratio or $R^{2}$ ) is defined as the between-group sums of squares divided by the total sums of squares (Kotrlik and Williams, 2003). In behavioral sciences, the values of $0.01,0.06$, and 0.14 for etasquared are used to represent small, medium, and large effect sizes, respectively (Cohen, 1988).

Cohen's $f$, on the other hand, is defined as the square root of eta-squared divided by one minus eta-squared $\left(\sqrt{\frac{\eta^{2}}{1-\eta 2}}\right)$. Cohen's $f$ can take on values between zero, when the population means are all equal, and an indefinitely large number as the standard deviation of means increases relative to the average standard deviation within each group. Cohen (1988) has suggested that the values of $0.10,0.25$, and 0.40 represent small, medium, and large effect sizes, respectively. 
As it is shown in the last two columns of table 7.3, the practical significance between our groups in three of the ANOVA tests (i.e., bike share, transit share, and VMT per trip) is small, while for the walk and auto shares, the values are close to medium effect size. Lastly, for the chain length, we see a medium to large effect size. It is worth reiterating that all of these tests are statistically significant. What this means is that although for some ANOVAs we see small differences (small effect sizes) between trip chains that are completely inside a center, both inside and outside a center, and completely outside a center, these differences are not due to chance and the results derived from tables 7.3 and 7.4 (which will be explained shortly) are highly generalizable.

Another problem associated with the F-statistic in ANOVA is that it cannot show which specific tour types are statistically significantly different from each other since it is an omnibus test statistic. In other words, Table 7.3 only tells us that at least two tour types (for each of the dependent variables) are different. Since we have three unrelated tour types in our study, determining which of these tour types differ from each other is important. Therefore, we need to use a post hoc test.

Table 7.3: The results of the ANOVA tests between tour types

\begin{tabular}{|c|c|c|c|c|c|c|c|c|}
\hline Mode & $\begin{array}{l}\text { Between } \\
\text { vs. } \\
\text { Within }\end{array}$ & $\begin{array}{l}\text { Sum of } \\
\text { Squares }\end{array}$ & df & $\begin{array}{l}\text { Mean } \\
\text { Square }\end{array}$ & $\mathbf{F}$ & Sig. & $\eta^{2}$ & $\underset{f}{\text { Cohen's }}$ \\
\hline \multirow[t]{3}{*}{$\begin{array}{l}\text { Walk } \\
\text { share }\end{array}$} & $\begin{array}{l}\text { Between } \\
\text { Groups }\end{array}$ & 462.34 & 2 & 231.17 & 3927.23 & $<.001$ & 0.032 & \multirow{3}{*}{$\begin{array}{l}\text { medium } \\
\text { t size }\end{array}$} \\
\hline & $\begin{array}{l}\text { Within } \\
\text { Groups }\end{array}$ & 13849.57 & 235283 & .06 & & & \multirow{2}{*}{$\begin{array}{l}\text { small to medium } \\
\text { effect size }\end{array}$} & \\
\hline & Total & 14311.91 & 235285 & & & & & \\
\hline \multirow[t]{3}{*}{$\begin{array}{l}\text { Bike } \\
\text { share }\end{array}$} & $\begin{array}{l}\text { Between } \\
\text { Groups }\end{array}$ & 1.37 & 2 & .69 & 56.28 & $<.001$ & \multirow{3}{*}{\multicolumn{2}{|c|}{$\begin{array}{c}<0.001 \quad 0.022 \\
\text { very small effect } \\
\text { size }\end{array}$}} \\
\hline & $\begin{array}{l}\text { Within } \\
\text { Groups }\end{array}$ & 2872.62 & 235288 & .01 & & & & \\
\hline & Total & 2873.99 & 235290 & & & & & \\
\hline \multirow[t]{3}{*}{$\begin{array}{l}\text { Transit } \\
\text { share }\end{array}$} & $\begin{array}{l}\text { Between } \\
\text { Groups }\end{array}$ & 36.58 & 2 & 18.29 & 1434.81 & $<.001$ & \multirow{3}{*}{$\begin{array}{l}0.012 \\
\text { small } \epsilon\end{array}$} & 0.11 \\
\hline & $\begin{array}{l}\text { Within } \\
\text { Groups }\end{array}$ & 2999.38 & 235286 & .01 & & & & \\
\hline & Total & 3035.96 & 235288 & & & & & \\
\hline \multirow[t]{3}{*}{$\begin{array}{l}\text { Auto } \\
\text { share }\end{array}$} & $\begin{array}{l}\text { Between } \\
\text { Groups }\end{array}$ & 578.92 & 2 & 289.46 & 2727.58 & $<.001$ & \multirow{3}{*}{\multicolumn{2}{|c|}{$\begin{array}{l}0.023 \quad 0.152 \\
\text { small to medium } \\
\text { effect size }\end{array}$}} \\
\hline & $\begin{array}{l}\text { Within } \\
\text { Groups }\end{array}$ & 24964.16 & 235239 & .11 & & & & \\
\hline & Total & 25543.07 & 235241 & & & & & \\
\hline \multirow{3}{*}{$\begin{array}{l}\text { VMT } \\
\text { per } \\
\text { Trip }\end{array}$} & $\begin{array}{l}\text { Between } \\
\text { Groups }\end{array}$ & 6437.48 & 2 & 3218.74 & 320.38 & $<.001$ & \multirow{3}{*}{$\begin{array}{l}0.003 \\
\text { small } \mathrm{E}\end{array}$} & 0.052 \\
\hline & $\begin{array}{l}\text { Within } \\
\text { Groups }\end{array}$ & 2363346.43 & 235239 & 10.05 & & & & ect size \\
\hline & Total & 2369783.91 & 235241 & & & & & \\
\hline \multirow[t]{2}{*}{$\begin{array}{l}\text { Chain } \\
\text { Length }\end{array}$} & $\begin{array}{l}\text { Between } \\
\text { Groups }\end{array}$ & 39048.65 & 2 & 19524.33 & 9469.83 & $<.001$ & \multirow[t]{2}{*}{0.075} & 0.284 \\
\hline & $\begin{array}{l}\text { Within } \\
\text { Groups }\end{array}$ & 484989.39 & 235233 & 2.06 & & & & $\begin{array}{l}\text { to large } \\
\text { size }\end{array}$ \\
\hline
\end{tabular}




\section{Total $\quad 524038.04 \quad 235235$}

In ANOVA, post hoc tests (also known as multiple comparisons tests) are divided into two categories. Tests in the first category (e.g., Bonferroni, Tukey, and Duncan) assume that the variances in groups (here, tour types) are equal. In other words, these tests assume homogeneity of variance. Tests in the second category (e.g., Tamhane and Games-Howell) do not assume equal variances. In order to be sure which of these two types of tests are suitable for our dataset, we used a homogeneity of variances test, known as the Levene statistic. The result of this test, which we do not report here for the sake of brevity, suggests that mode shares and VMT per trip in our three different tour types do not have equal variances. Hence, we use Tamhane (in the second category) for our multiple comparisons tests.

Table 7.4 shows the results of the Tamhane post hoc tests. All of the comparisons are statistically significant. Hence, we are highly confident that the means of mode shares, average VMT per trip, and chain length for each tour type are different from the other types and this result has not been produced by chance. In what follows, we will interpret this table for each of the tour types.

Table 7.4: The results of the Tamhane post-hoc tests

\begin{tabular}{|c|c|c|c|c|c|}
\hline \multicolumn{3}{|c|}{ Dependent Variable } & \multirow{2}{*}{$\begin{array}{l}\text { Mean Difference } \\
(\mathrm{I}-\mathrm{J})\end{array}$} & \multirow[t]{2}{*}{ Std. Error } & \multirow[t]{2}{*}{ Sig. } \\
\hline & Type I & Type J & & & \\
\hline \multirow{3}{*}{$\begin{array}{l}\text { Walk } \\
\text { share }\end{array}$} & Within a center & Hybrid & 0.444 & 0.010 & $<.001$ \\
\hline & Within a center & Outside of a center & 0.438 & 0.010 & $<.001$ \\
\hline & Hybrid & Outside of a center & -0.006 & 0.001 & $<.001$ \\
\hline \multirow[t]{3}{*}{ Bike share } & Within a center & Hybrid & 0.021 & 0.004 & $<.001$ \\
\hline & Within a center & Outside of a center & 0.023 & 0.004 & $<.001$ \\
\hline & Hybrid & Outside of a center & 0.002 & 0.001 & .005 \\
\hline \multirow{3}{*}{$\begin{array}{l}\text { Transit } \\
\text { share }\end{array}$} & Within a center & Hybrid & 0.017 & 0.004 & $<.001$ \\
\hline & Within a center & Outside of a center & 0.047 & 0.004 & $<.001$ \\
\hline & Hybrid & Outside of a center & 0.030 & 0.001 & $<.001$ \\
\hline \multirow{3}{*}{$\begin{array}{l}\text { Auto } \\
\text { share }\end{array}$} & Within a center & Hybrid & -0.486 & 0.010 & $<.001$ \\
\hline & Within a center & Outside of a center & -0.493 & 0.010 & $<.001$ \\
\hline & Hybrid & Outside of a center & -0.007 & 0.002 & $<.001$ \\
\hline \multirow{3}{*}{$\begin{array}{l}\text { VMT per } \\
\text { Trip }\end{array}$} & Within a center & Hybrid & -1.540 & 0.037 & $<.001$ \\
\hline & Within a center & Outside of a center & -1.624 & 0.036 & $<.001$ \\
\hline & Hybrid & Outside of a center & -0.085 & 0.015 & $<.001$ \\
\hline \multirow{3}{*}{$\begin{array}{l}\text { Chain } \\
\text { Length }\end{array}$} & Within a center & Hybrid & -1.118 & 0.029 & $<.001$ \\
\hline & Within a center & Outside of a center & -0.089 & 0.027 & .003 \\
\hline & Hybrid & Outside of a center & 1.030 & 0.010 & $<.001$ \\
\hline
\end{tabular}




\subsubsection{Tour Type 1: Within a Center}

According to Table 7.4, the most efficient tours are the ones that were generated within a center since we have the highest means of walk, bike, and transit shares for this tour type compared to the other two types. On the other hand, these tours are associated with lower auto share, and fewer VMT per trip and chain length as well. Interestingly, the differences of means in walk and auto shares are quite large. The mean of walk share is about $44 \%$ higher, and the mean of auto share is about $49 \%$ lower for tour type 1 (within a center) compared to tour types 2 (hybrid) and 3 (outside of a center). These results clearly depict the transportation benefits of centers and polycentric development.

\subsubsection{Tour Type 2: Hybrid (tours with trips both inside and outside a center)}

Based on Tables 7.2 and 7.4, the means of bike and transit shares are higher for this type of tour compared to tour type 3 . On the other hand, the means of auto share and VMT per trip are slightly lower compared to tour type 3 , and these differences are statistically significant, at least partially due to the large sample size. The comparison of chain length shows that this type of tour is more complex than both tour types 1 and 3 . This makes sense because individuals are typically traveling from home outside centers to activities inside centers, conducting their business inside centers, and then traveling back to home. In terms of walk share, the result might seem to be contradictory since the mean walk share is lower for tour type 2 compared to tour type 3. However, Table 7.5 sheds light on a different aspect of trips for tour type 2 .

Table 7.5: Comparing the mean of walk trips between three types of trips for tour type 2 (hybrid tours)

\begin{tabular}{llll}
\hline Trip type & Mean & $\mathbf{N}$ & Std. Deviation \\
& & & \\
\hline None of the trip ends are within a center & 0.09 & 53449 & .288 \\
\hline Either the origin or destination is inside a center & 0.03 & 98942 & .184 \\
\hline Both trip ends are inside a center & 0.48 & 17144 & .500 \\
\hline Total & 0.10 & 169535 & .297 \\
\hline
\end{tabular}

According to Table 7.5, among tours that are hybrid, the mean value of walk trips is substantially higher when both ends of trips are inside a center, compared to the trips that are not inside a center or only one end (i.e., either the origin or destination) is inside a center. So, these results tell us that individuals are mostly inclined to use their vehicles (auto share $=86 \%$ ) or transit (transit share $=4 \%$ ) to reach a center and once they are inside of it, the chance of walking is exceptionally high (if the next stop is also inside of the center) since almost half of the trips are made by walking.

\subsubsection{Tour Type 3: Outside of a Center}

Tours occurred entirely outside of a center show the lowest bike and transit shares, and the highest auto share and VMT per trip. In other words, these tours are highly auto- 
dependent, and sustainable modes of transportation are discouraged. Although it is not reported here, we created another set of tour types where tour type 1 was tours made by individuals who live inside a center, tour type 2 was tours made by individuals who live outside a center but had at least one trip inside a center, and tour type 3 was tours made by individuals who live outside a center and do not have one single trip end inside a center. As expected, we found the same results that we reported in this section. Tours made by individuals who live outside a center and do not have a trip inside a center are associated with more VMT and auto share, while maintaining extremely low walk, bike, and transit shares compared to tour types 1 and 2.

To recapitulate, tour type 3 is the least efficient type of tour compared to tour types 1 and 2. By moving toward polycentric development and encouraging people to either live or work or shop inside centers, we can promote active transportation and transit use, and alleviate the costs and issues associated with auto-dependent neighborhoods. These neighborhoods, as we explained in the previous chapters, are mostly characterized by lower density, diversity, street design, and destination accessibility and higher distance to transit.

\subsection{CONCLUSION}

This chapter used a parametric test (i.e., ANOVA) to assess trip chaining or tour efficiency for three distinct types of tours; tours that are entirely inside a center, tours that are both inside and outside a center, and tours that are entirely outside a center. Our results lend credence to the hypothesis that tours within a center are associated with higher walk, bike, and transit mode shares and, at the same time, lower car shares. Even tours associated with trips both inside and outside a center (i.e., type 2-hybrid) have incorporated more sustainable modes of travel compared to the tours that were generated entirely outside a center. However, for bike and transit shares, the differences or effect sizes are small, but enough to be significant.

In principle, we argue that if the goal is vehicular travel reduction, development patterns can have a significant effect on individuals' travel behavior. Placing the same individuals in more accessible residential locations would cut down significantly on their vehicular travel. Hence, as our empirical findings suggest, centers may promote active transportation as well as transit use. Encouraging individuals to use these modes of travel will have great environment-, health-, and community-related benefits.

Implications for land planning are more complex than merely pedestrianizing or transitizing the suburbs. Planners and policymakers who hope to increase walking, biking, and transit use should concentrate growth in compact commercial cores of residential areas, while transit agencies should consider trends like chained trip-making and focus transit service on central places. This will facilitate efficient automobile trips and tours. The more sprawling the area, the more important this becomes. 


\subsection{CASE STUDY OF POLYCENTRIC DEVELOPMENT STRATEGIES IN PORTLAND, OR}

\subsection{INTRODUCTION}

The Portland region in Oregon has long been renowned for its progressive planning policies targeted at constraining sprawl and directing growth in a polycentric development pattern. This has not always been the case, however. In the 1970s, the region was experiencing significant growth, and much of this growth was directed outward in a typical suburban fashion. Along with this type of growth and development came the associated congestion concerns. Transportation planners were combating congestion by creating more and more roadway capacity, as was the status quo of the time. Later in the 1970s, a "freeway revolt" began to gain political momentum and was even supported by the mayor of Portland (Dueker, Edner, and Rabiega, 1987). In response, a task force was created by the Oregon governor to evaluate alternatives to highway expansion, including introducing light rail transit to the region. This effort culminated in LUTRAQ: Making the Land Use, Transportation, and Air Quality Connection plan that was commissioned by 1000 Friends of Oregon. The plan identified the need to look to transit as the best option for reducing congestion and facilitating polycentric development.

Several factors have contributed to Portland's reputation as a leader in progressive planning, but few are as influential as the unique role of their metropolitan planning organization (MPO). Portland Metro, the region's MPO and governmental body, was granted land use authority by a state ballot measure, which effectively created a regional government with policy and decision-making power that is unlike any other in the U.S. Related to this is the urban growth boundary that was implemented in 1977 to limit sprawl and direct growth within the already developed urban area. The responsibility for defining, maintaining, and reassessing the urban growth boundary was placed on the MPO, and that responsibility remains an important function of Metro to this day.

This case study utilizes interviews and document review to identify policies, programs, tools, and strategies used by the Portland region to facilitate polycentric development patterns. We organize this study based on the three agencies that have the largest influence on the polycentric policy. We interviewed planners from the City of Portland, Metro, and TriMet (Portland's transit agency) to initially identify the ways that these entities are promoting polycentric development. After the interviews, the planners provided supporting documentation that we carefully reviewed to highlight further how the region is planning to focus growth in centers. Hundreds of pages of documents were reviewed. Table 8.1 outlines our efforts.

Table 8.1: Number of officials interviewed and documents reviewed

\begin{tabular}{lcc}
\hline Organization & Officials Interviewed & Documents Reviewed \\
\hline City of Portland & One & Four \\
\hline
\end{tabular}


One

\subsection{TOOLS AND STRATEGIES OF THE CITY OF PORTLAND}

\subsubsection{Comprehensive Plan}

The main document guiding and identifying the City of Portland's planning is the 2035 Comprehensive Plan. The plan was updated in July of 2018 and is intended to "coordinate policies and actions across City bureaus as well as with regional and state agencies." The plan provides a framework for the ways Portland hopes to channel future growth in an effective and sustainable fashion. One of the most important components of this strategy is the channeling of growth to established centers. The comprehensive plan has nearly 200 references to centers, and the majority of the document is dedicated to defining and planning for development of various types of centers and corridors within the city.

The comprehensive plan defines nine specific policies pertinent to centers:

- Policy 3.12 Role of centers. Enhance centers as anchors of complete neighborhoods that include concentrations of commercial and public services, housing, employment, gathering places, and green spaces.

- Policy 3.13 Variety of centers. Plan for a range of centers across the city to enhance local, equitable access to services, and expand housing opportunities.

- Policy 3.14 Housing in centers. Provide housing capacity for enough population to support a broad range of commercial services, focusing higher-density housing within a half-mile of the center core.

- Policy 3.15 Investments in centers. Encourage public and private investment in infrastructure, economic development, and community services in centers to ensure that all centers will support the populations they serve.

- Policy 3.16 Government services. Encourage the placement of services in centers, including schools and colleges, health services, community centers, daycare, parks and plazas, library services, and justice services.

- Policy 3.17 Arts and culture. Ensure that land use plans and infrastructure investments allow for and incorporate arts, culture, and performance arts as central components of centers.

- Policy 3.18 Accessibility. Design centers to be compact, safe, attractive, and accessible places, where the street environment makes access by transit, walking, biking, and mobility devices such as wheelchairs, safe and attractive for people of all ages and abilities. 
- Policy 3.19 Center connections. Connect centers to each other and to other key local and regional destinations, such as schools, parks, and employment areas, by pedestrian trails and sidewalks, bicycle sharing, bicycle routes, frequent and convenient transit, and electric vehicle charging stations. Prepare and adopt future street plans for centers that currently have poor street connectivity, especially where large commercial parcels are planned to receive significant additional housing density.

- Policy 3.20 Green infrastructure in centers. Integrate nature and green infrastructure into centers and enhance public views and connections to the surrounding natural features.

\subsubsection{Maps}

Another tool used by the City of Portland to facilitate polycentric development is mapping. The Comprehensive Plan Map (CPM) is the planning guide for defining future land uses and development in Portland. The CPM represents the "preferred scenario" from a scenario planning process. Figure 8.1 depicts the Comprehensive Plan Map.

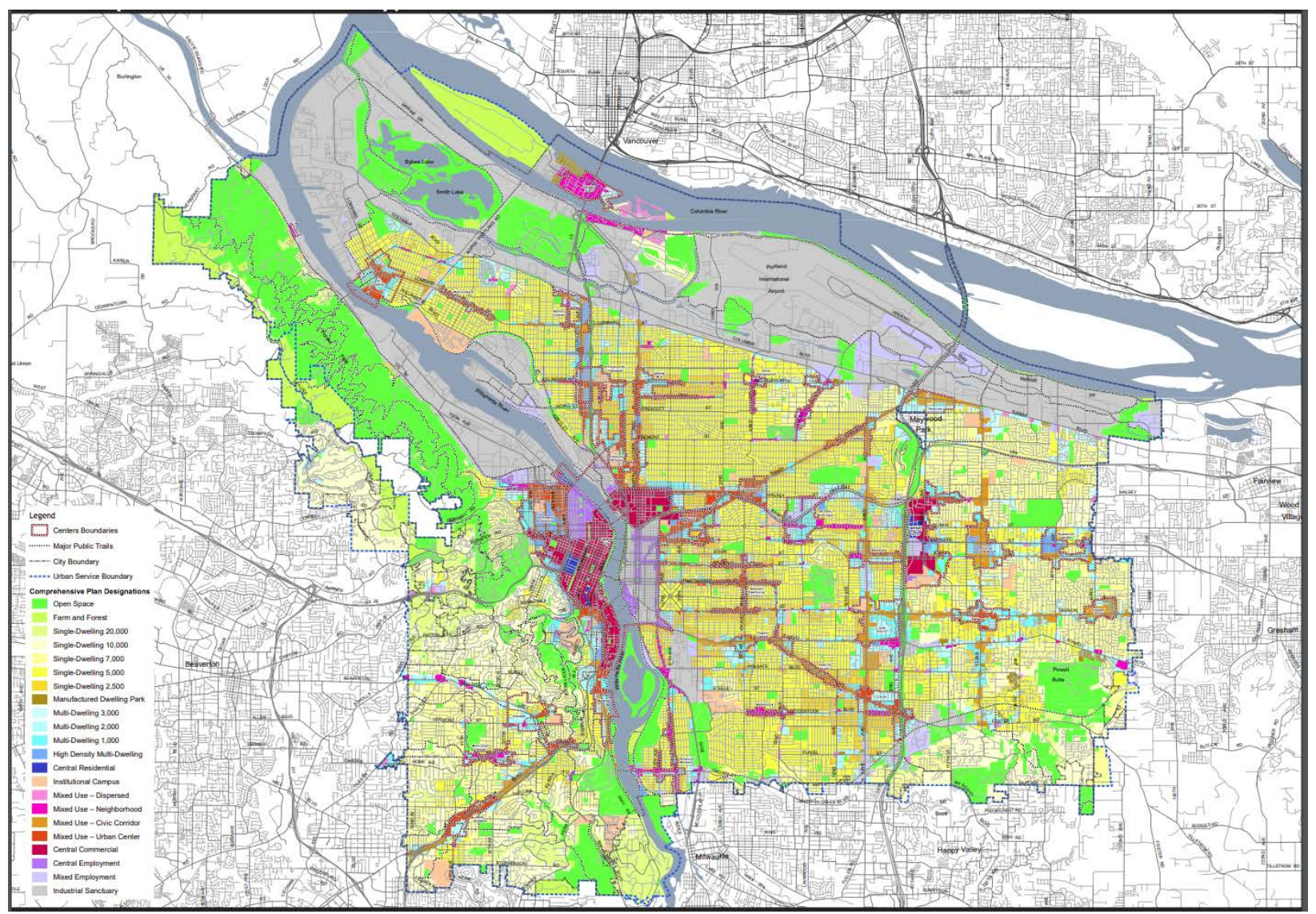

Figure 8.1: Comprehensive Plan Map (Portland, OR)

The CPM calls for zones that are primarily mixed use and high density. The map identifies areas for six different levels of multifamily housing density, as well as areas for 
five different levels of intensity of mixed-use development. The comprehensive plan also provides a map of existing and future centers based on the preferred scenario from the scenario planning process.
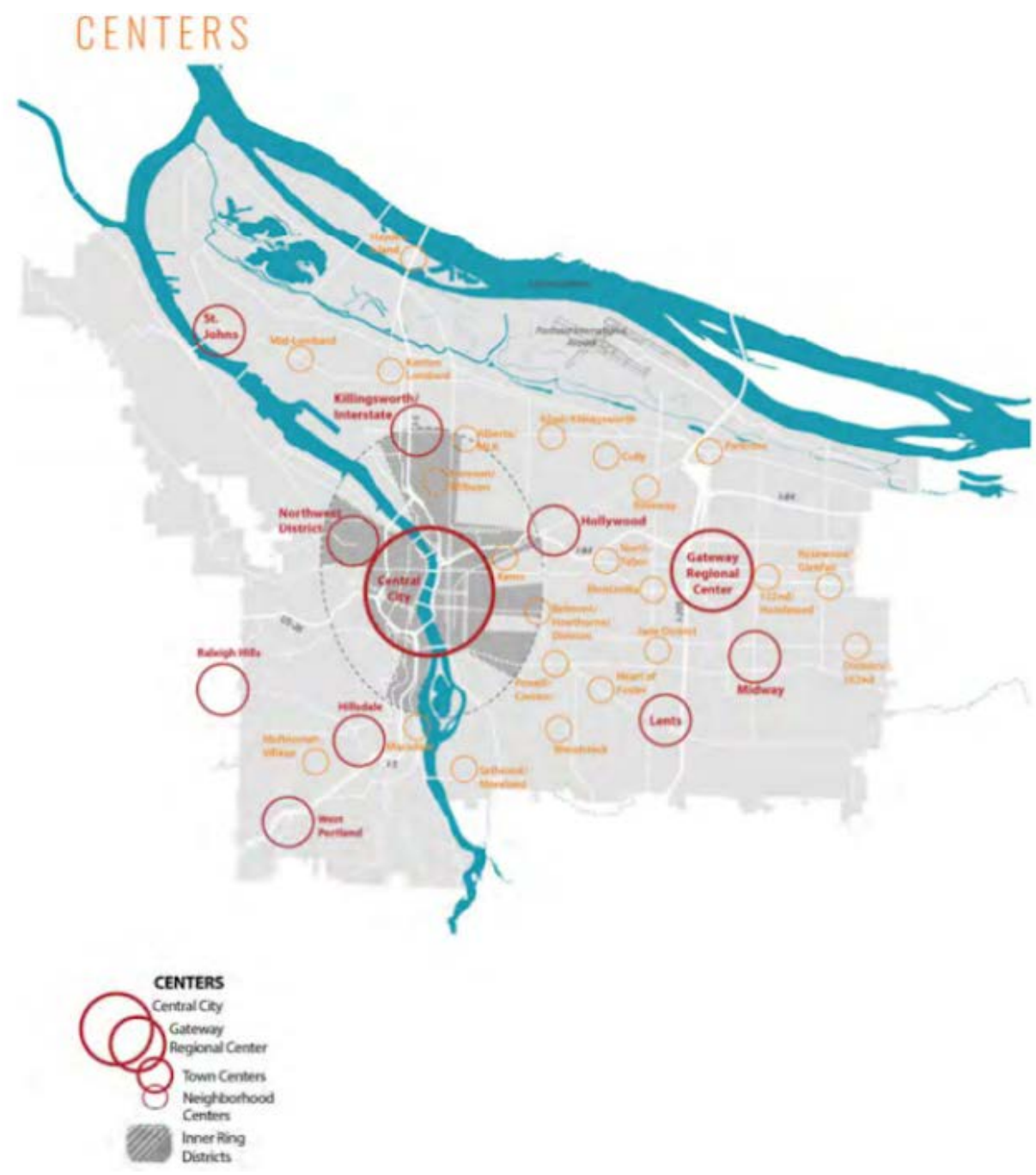

Figure 8.2: Comprehensive Plan Centers Map (Portland, OR)

The centers map identifies 33 current and future centers within Portland. The centers are also ordered within an established hierarchy. Portland defines this hierarchy in the following way, declining in prominence, respectively: central city; regional center; town center; and neighborhood center. The comprehensive plan explains that the role of the central city within the context of the hierarchy of centers is to remain the "Region's premier center for jobs, services, and civic and cultural institutions that support the entire city and region." The central city is intended to provide a model urban center that constitutes the largest center for employment in the region coupled with the densest housing opportunities. Additionally, the central city acts as a multimodal transportation hub that optimizes regional access as well as the movement of people within and through the center. Finally, an additional essential function of the central city is to 
provide public spaces, including the Willamette River waterfront, as places of social activity for residents of the center as well as those of the surrounding areas.

The Gateway Regional Center is Portland's only center with this designation, although other regional centers exist outside Portland's municipal boundaries. The regional center is similar to the central city in that it is intended to provide a major center for employment, high-density housing, and community services. One distinction between the Gateway Regional Center and the central city is that Gateway serves East Portland, whereas the central city lies on the west side of the Willamette River. Like the central city, the regional center also serves as a multimodal transportation hub providing highcapacity transit as well as good freeway accessibility and easy access to Portland International Airport. Finally, public space is also prioritized in the regional center to provide vibrant environments for business and social activity.

Town centers and neighborhood centers are similarly slated to provide dense housing opportunities, multimodal transportation hubs, and lively public spaces. The language within the comprehensive plan describing roles of these different categories of centers with respect to transportation, housing, and public spaces is very similar. There is little mention of quantitative distinctions between the categories, with quantifiable prescriptive goals for housing availability being the only quantified measures provided in the plan.

\subsubsection{Urban Renewal Districts}

In an explicit effort to combat trends of increasing income inequality in the region, the comprehensive plan includes urban renewal districts as a strategy for promoting equitable economic development. Urban renewal districts are specific areas designated within a city to address urban blight and poor economic conditions. Typically, urban renewal districts use the investment of city funds to turn around neighborhoods or even smaller geographies to a point where property values stop declining, and economic conditions become more favorable for business development. The primary benefits of urban renewal plans are supposed to be reaped by existing residents and businesses of that area. Urban renewal plans should achieve their goal of equitable economic development by revitalizing neighborhoods, expanding housing choices, creating jobs and businesses, providing new transportation opportunities, and limiting gentrification and displacement.

\subsubsection{Zoning}

Zoning is the preeminent tool used by planners to direct development patterns. The City of Portland uses its Zoning Code in tandem with the Zoning Map to control current and future land uses. As mentioned above, the Zoning Map designates a variety of mixeduse, commercial, and residential zones that allow adequate density to guide development intensity into centers. Single-family residential of varying intensity (lot size) is still allowed within the code and map, but these zones are required to be far from centers where infrastructure investment will be limited, saving those resources for more intensively developed areas. The majority of land use designations, however, allow for 
dense multifamily dwelling residential development, mixed-use development, and highintensity commercial development. Providing zones with high allowances for intensity gives planners the ability to direct growth to already designated centers, limiting sprawl and consumptive development patterns.

\subsubsection{Parking}

Parking is often a contentious issue when new development is being discussed. As contentious as it might be, however, parking can also be an effective tool for planners to manage the impacts of changes to the built environment on transportation systems.

The comprehensive plan contains a section on parking management which outlines seven distinct policies that are aimed at achieving climate, health, livability, and prosperity goals. The plan claims that "Providing too much and/or underpriced parking can lead to more driving and less walking, cycling, and transit use; inefficient land use patterns; and sprawl." As such, the goal of parking policies is primarily to reduce demand, and secondarily to reduce the supply of parking in an effort to increase the attractiveness of other modes of transportation.

The plan's parking policy recognizes that street space is public space and urges that this fact be consistently considered. The policy begs the question of whether parking is, indeed, the highest and best use of public space. The parking policies also promote the use of market-based parking pricing systems in which parking prices accurately represent demand spatially and temporally. The comprehensive plan's parking policies also advocate the redevelopment of surface parking lots within centers in order to achieve higher densities. Similarly, Policy 9.58, which addresses off-street parking, suggests that the construction of new parking structures should be limited, with consideration of proximity to transit a primary factor in determining whether new parking structures should be allowed.

\subsubsection{Transportation Demand Management Program Requirements}

Transportation demand management (TDM) describes strategies used by planners to reduce demand for travel or parking, or to redistribute demand in space or time. That is, to move travel or parking demand from places or times where demand is high to places or times where demand is lower. The City of Portland seeks to create programs and policies that provide incentives for alternative modes of transportation in a cost-effective manner. One way that the comprehensive plan proposes achieving the goals of TDM is by improving outreach using transportation management associations (TMAs). TMAs are non-profit membership organizations that consist of employers, property managers, and developers who work collectively to address transportation issues by using TDM strategies such as carpooling matching programs and flexible work hours. The policy used by the City of Portland that seems to have the most potential to effect polycentric development, however, is the mandate that new developments implement and operate TDM programs in order to be permitted and advance to construction. The mandate of such programs ensures that new development will have reduced impacts on congestion and vehicle trip generation through the facilitation of alternative modes of transportation. 


\subsection{TOOLS AND STRATEGIES FOR PORTLAND METRO (METROPOLITAN PLANNING ORGANIZATION)}

\subsubsection{Growth Concept}

Portland Metro's 2040 Growth Concept was approved in 1995 for the purpose of establishing a framework for the region's development pattern. The concept dictates where growth should be concentrated, emphasizing centers and maximizing the efficient use of space. The Growth Concept is the result of a collaborative public engagement process involving thousands of stakeholders. Through this process, goals were established and resulting policies created. The policy that pertains most to polycentric development demands "compact development that uses land and money efficiently." The concept establishes urban design principles to achieve polycentric development, identifying a central city, regional centers, town centers, neighborhood centers, station communities, and main streets as the typologies for polycentric development. Much like the hierarchy of centers laid out by the City of Portland's comprehensive plan, the growth concept facilitates polycentric development by setting goals and design principles.

In conjunction with the 2040 Growth Concept, Metro has created the 2040 Growth Concept Map, depicted below. The map differs from the Comprehensive Plan Map and the Centers Map in that it illustrates boundaries for different types of development patterns and typologies. The map portrays different types of polycentric development like regional centers, station communities, and town centers.

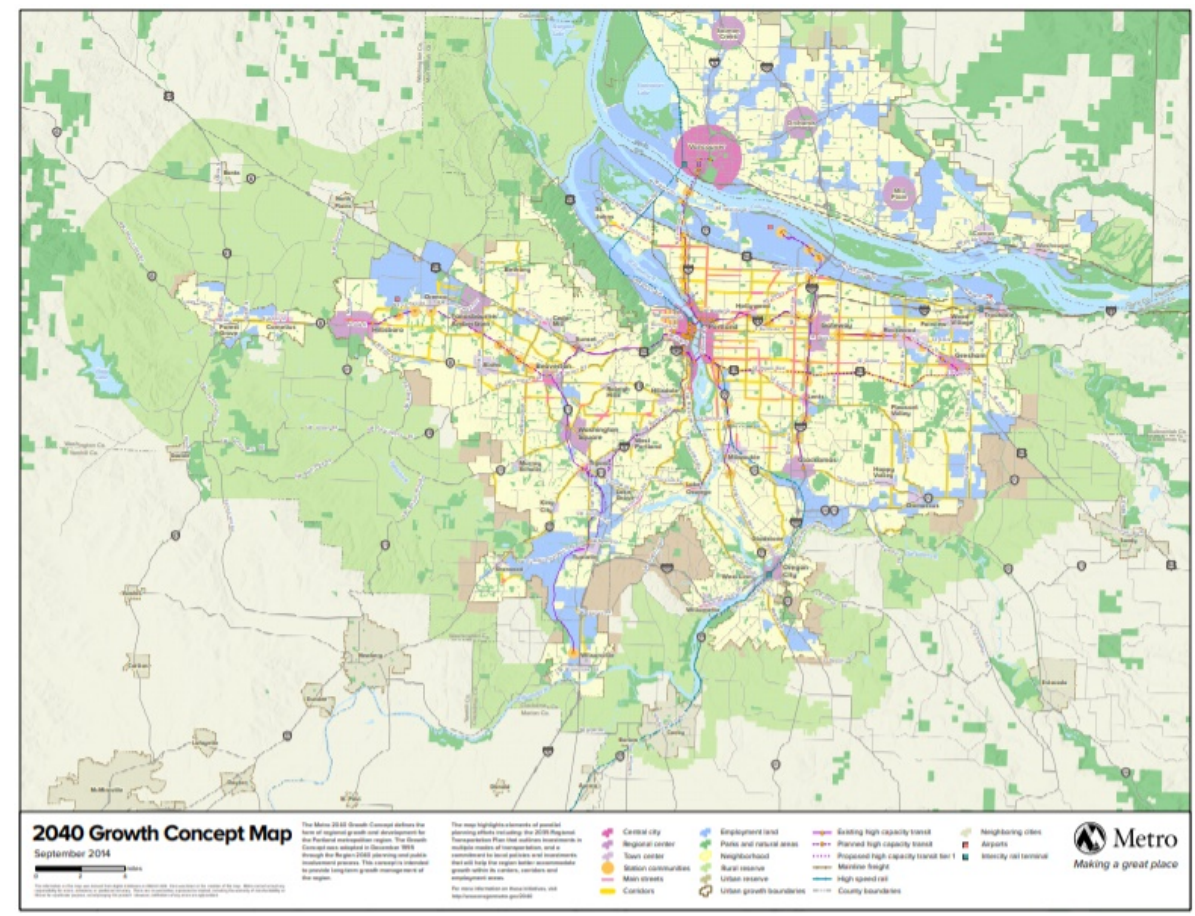

Figure 8.3: 2040 Growth Concept Map for Portland Metro 


\subsubsection{Urban Growth Management Functional Plan}

The Urban Growth Management Functional Plan (UGMFP) is an effort by Portland Metro to provide guidance to municipalities and coordinate policy that can collectively achieve regional growth goals. In particular, the functional plan recommends changes to ordinances and comprehensive plans. Unlike regional efforts typical of much of the rest of the U.S., the functional plan has teeth. By this, we mean that the guidelines set forth by the UGMFP are not voluntary, but rather municipalities that neglect adopting changes to their comprehensive plans in accordance with the direction of the functional plan are subject to a conflict resolution and mediation process.

One way that the UGMFP directs centered growth is by affecting housing capacity. Where many cities use maximum housing densities to influence growth patterns, the functional plan instead calls for minimum housing densities. Although the plan allows for reductions in minimums given certain circumstances, the requirement for establishment of minimum densities in zoning ordinances is non-negotiable. In a parallel effort to direct cities to facilitate denser polycentric development, the functional plan also requires the allowance of a minimum of one accessory dwelling unit for each detached single-family dwelling unit in any zone that allows single-family housing. In essence, this doubles the potential housing capacity of what is typically the least dense style of housing development.

The UGMFP also creates requirements for consideration of regional funds and investment in centers. In order to be eligible for regional investment in a center, a city or county must establish a boundary for the center. Additionally, the city must perform a comprehensive assessment of the center including a market analysis, assessment of regulatory barriers to mixed-use, pedestrian friendly and transit supportive development, and an analysis of the development code with respect to these same things.

While not binding, the UGMFP recommends actual quantified objectives for activity levels within centers. The plan defines recommended numbers of residents and workers per square mile for each center type. In addition, the functional plan recommends specific levels and types of mixed use as well as mixes of housing types.

\subsubsection{Metro TOD Program}

Transit-oriented development (TOD) represents the epitome of coordinated land use and transportation planning. Pedestrian-friendly, mixed-use development that is oriented to transit stations allows for denser housing options that have limited impacts on the surrounding transportation system by supporting alternatives to automobile travel and internal capture. The Portland region has been a leader in supporting TOD, and Metro's Transit-Oriented Strategic Plan is a perfect example of this leadership.

The TOD program's main function is to provide modest grants for projects near transit to incentivize denser development than would otherwise be built by developers. When transit-oriented or adjacent projects qualify, the TOD program provides funding and support to increase the density of these projects by, ordinarily, increasing the height of 
buildings. Funding amounts are based on the projected increase that such density would have on transit ridership. The estimated increase in fare box recovery is then offered to developers, granted they are willing to increase the number of housing units in the development by the amount stipulated by Metro. This portion of the program is intended to increase density in desirable areas as well as to provide market examples for such levels of density. The program currently spends just under \$3 million annually on TOD capital projects.

Another facet of the TOD program is land acquisition. Metro has purchased and held land around transit stations with the intention of promoting TOD in the future. This practice of land banking allows Metro to hold onto land and prevent lower utilization from occurring prior to the point in time when the market will support more intensive TOD development. In coordination with Metro, TriMet also maintains an inventory of land for this purpose. The land acquisition by Metro alone has amounted to over $\$ 8$ million in investment from the TOD program.

\subsubsection{State of the Centers Report}

The State of the Centers Report is an effort by Metro to quantify the progress being made in the region to concentrate growth in centers. The report contains a plethora of data and figures which describe in detail how the designated centers have changed over time. According to the report, "The State of the Centers report helps measure progress in creating the type of centers envisioned in the 2040 Growth Concept and to illustrate the kind of investments that contribute to a successful center."

The State of the Centers Report defines six different types of centers and identifies actual centers within the region, assigning each to one of the six designations. The report identifies, by name, one central city center, eight regional centers, and 32 town centers. For each of these centers, Metro has collected and analyzed data from 2011 to 2017 on demographics, employment, mode share, housing, and business activity. These data are available for all 41 centers in the region on an interactive webpage that was made available in 2017.

\subsubsection{Planning and Development Grants}

Another example of tangible ways in which Portland Metro helps to facilitate polycentric development is through 2040 Planning and Development Grants. This program provides grants to local governments to plan for development that is aligned with the 2040 Growth Concept. The program was implemented in 2006 and has offered \$22 million in grants since its inception. Grants from the program are intended for local governments to use in six specific categories of planning: urban reserve and new urban area planning; strategy or policy development; investment strategies and financial tools; area-specific redevelopment planning; site-specific development or redevelopment; and equitable housing projects and policies. An important facet of the program, noted by a Metro planner we interviewed, is the fact that these funds are only available for planning within identified centers. Allocating funds for planning in centers, thus making these 
places readier for development, will further help the region channel growth into a polycentric pattern.

\subsubsection{Title 6 Centers Functional Plan}

The Centers Functional Plan is a strategy that was first implemented in 2002 by Portland Metro with the intention of helping cities within the region promote and grow their centers. This plan is a component (Title 6) of the Urban Growth Management Functional Plan, but it should not be confused with Title VI of the 1964 Civil Rights Act. Initially, this program requested that cities develop their own plans to either grow their existing centers or to develop new centers in a way that conforms to the broader comprehensive plan. Unfortunately, however, the effectiveness of this program was hindered by the fact that there were no mechanisms to incentivize the creation of centers plans by cities. According to a planner from Portland Metro, after first institution of the plan, cities did not follow up with the MPO or follow through with their plans. An additional impediment to the success of the strategy, said the planner we interviewed, the MPO did not provide funding that would increase local capacity to add this task to their already strained agendas. In 2010, the program was updated, becoming incentivebased. The updated program allows the MPO to link high-capacity transit funding to the existence of a centers plan. Cities that have centers plans in place are eligible for additional funding for high-capacity transit.

\subsection{TOOLS AND STRATEGIES FOR TRIMET TRANSIT AGENCY}

Although cities, counties, and the regional government in the Portland region are responsible for policy making that facilitates polycentric development, this goal would not be possible without a supportive transit system. Polycentric development requires high-quality transit connections between centers, and a coordinated effort between TriMet, the City of Portland, and Portland Metro has catalyzed the region's polycentric growth. This coordination includes the development of new capital projects and fixedguideway transit lines, the concentration of resources in specifically designated corridors in the form of high-frequency service, and the acquisition and retention of critical real estate. Portland has also prioritized transit funding over freeway funding, as illustrated by the use of funds for MAX light rail lines rather than the Mount Hood Freeway and the Western Bypass.

\subsubsection{Connecting Centers with High-Capacity Transit}

Arguably the most important contribution of TriMet to the region's efforts in promoting polycentric development is its part in connecting centers through corridors with highquality alternatives to auto travel. The planners we interviewed at TriMet described a collaborative process with Portland Metro in service planning as well as capital development. The best example of this collaborative endeavor is the Southwest Corridor Plan led by Metro, and TriMet's corresponding Southwest Service Enhancement Plan. The Southwest Corridor Plan is a response to a growing need in this portion of the region to address transportation and economic development concerns. The area has experienced growth in population and employment, but this has 
also created problems with congestion and unsafe conditions for active transportation users. Metro has led the effort to bring local leaders, planners, and the public together to create a plan that will increase the livability and economic vitality of the region while also enhancing transportation options. A major part of this plan involves the design and implementation of a new light rail line to alleviate congestion and provide a viable alternative to auto travel.

Like the process of the Southwest Corridor Plan, TriMet's Southwest Service Enhancement Plan (SWEP) brings together municipalities, counties, business groups, and residents of the area to help design a light rail line as well as other service improvements and active transportation amenities. In the near term, the plan is meant to improve bus service and bus stops to enhance the attractiveness of transit in its current form. According to TriMet, "The plan aligns future improvements with current and projected needs by recommending better transit connections, improved frequency, safer pedestrian facilities, and increased access to jobs and community services." Most notably, the plan identifies near-term service enhancements of limited cost, long-term service expansion, and improvements to walk and bike environments. Three explicit goals of the plan are to increase transit access to employment, contribute to the community and economic development, and foster continued growth of the area's burgeoning sectors like health care, research, and education. Through this process of community outreach and collaboration with city and county governments, TriMet has created a vision for future service in the Southwest Corridor. Below, Figure 8.4 is a representation of that vision. 


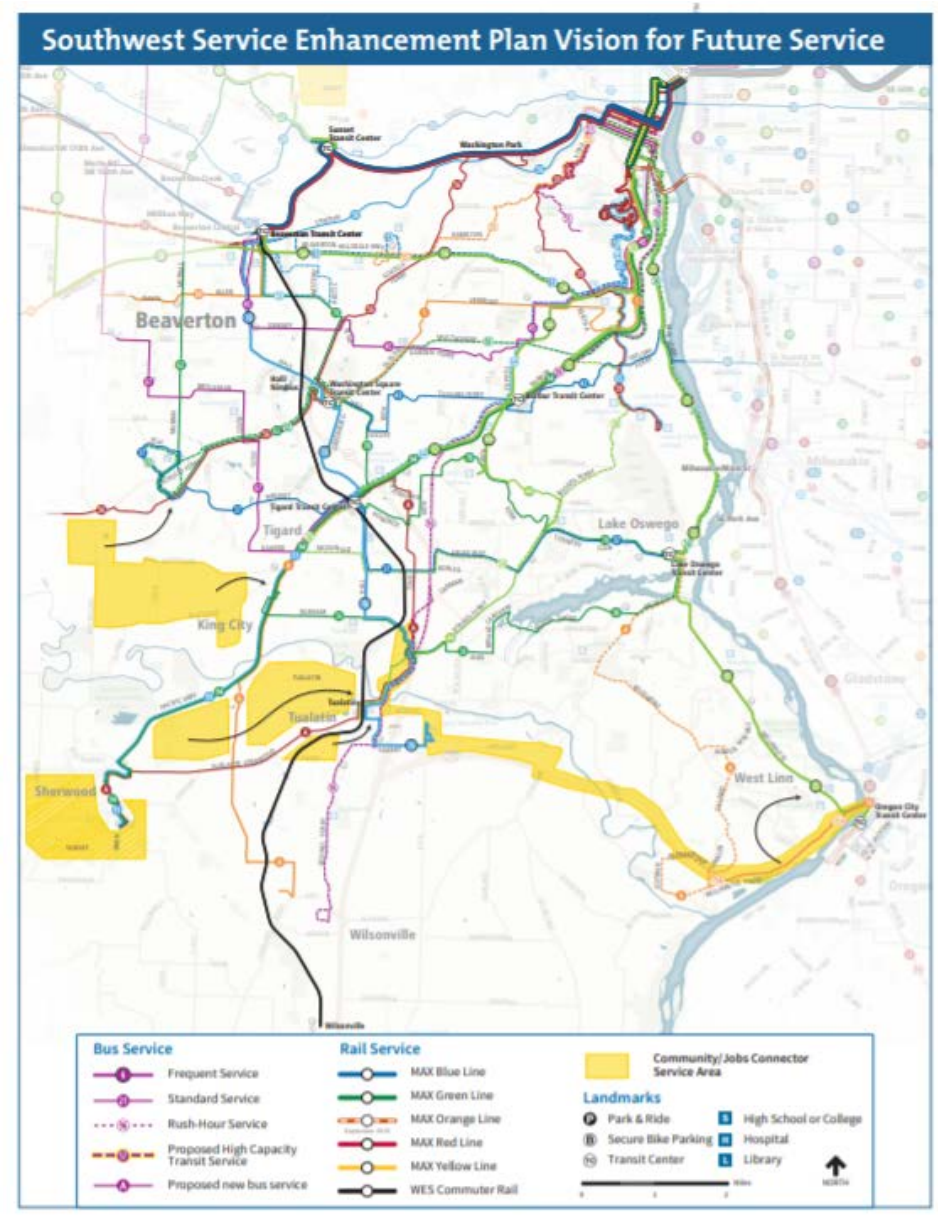

Figure 8.4: Southwest Service Enhancement Plan vision for future service (TriMet, OR)

\subsubsection{Prioritizing Active Transportation}

In addition to connecting centers with high-quality transit, TriMet is also contributing to improving other transportation amenities for pedestrians and bikes. TriMet recognizes that an essential element of transit ridership expansion is creating an environment that is safe and convenient for active transportation modes, as transit trips start with walking or bicycling. The Southwest Service Enhancement Plan (SWEP) recognizes four priorities for enhancing the active transportation environment.

First, the plan prioritizes safe crossings for pedestrians, particularly near transit stations. SWEP recognizes the desire of cities to address congestion issues by widening roads and increasing capacity, but suggests that this practice is at odds with the need to promote alternative modes. This is because widening roads creates an unsafe environment for pedestrians and bikes, and subsequently degrades the transit experience as well. To demonstrate the agency's commitment to improving the pedestrian and bike environment, a TriMet planner we interviewed highlighted the fact that TriMet now includes plans for active transportation infrastructure when they acquire rights of way for transit projects. 
The next priority named in the plan is an extension of the first, stating that it is essential to shorten crossing distances for pedestrians. TriMet urges cities, counties, and the Oregon Department of Transportation to revisit design standards for streets that require minimum widths that create long crossing distances and inhospitable environments for pedestrians.

Another priority is the construction of bus stop landing pads. SWEP claims that these pads are helpful for connecting pedestrians, bikes, and mobility devices to the transit system by creating a more appealing space than uneven or muddy surfaces that might exist between sidewalks and curbs. They also suggest that the pads create the opportunity to make further bus stop improvements like shelters, particularly at highridership stops.

Finally, the plan urges cities and counties to extend the reach (bikeshed) of transit by creating new bike paths and bike lanes in a pattern that connects well to transit lines. TriMet also commits to providing adequate bike parking so that bikes can be stored safely when transit riders do not wish to take their bikes with them for the transit trip. These efforts by TriMet to improve transit service and active transportation opportunities in the Southwest Corridor demonstrate how the agency collaborates with regional entities to connect centers and effectively facilitate a polycentric development pattern.

\subsection{CONCLUSION}

This case study depicts a region at the forefront of polycentric development policy. We see that the MPO, City, and transit authority each occupy distinct policy niches while also contributing to a larger regional effort to promote polycentric development. One unique quality of this region is the land use authority given to Portland Metro. This gives the MPO greater power than such an organization typically has; most MPOs are limited to transportation planning and spending. The relative strength that derives from the MPO's ability to contribute to regional land use planning creates a situation in which strategies to limit sprawl and promote centered development are developed at the regional scale and implemented at multiple (i.e. City, neighborhood, transit corridor) scales. This chapter outlines a set of policies utilized by multiple planning agencies for promoting centered development in the Portland, OR region. We see that the region's reputation for leadership regional planning extends to polycentric development as well. Each agency that we interviewed described innovative policies that they are using to guide centered development. The empirical work of this report indicates that the region has achieved a polycentric development pattern, and this comes as no surprise given the extent of the policy efforts detailed in this chapter.

In the Portland region we see an extraordinary case of collaborative regional government working to coordinate land use and transportation planning. When interviewing our informants, it was clear that each agency was very aware of both how their work fit within the larger context of regional efforts, as well as the specifics of what their peer agencies were doing simultaneously. The higher-level regional perspective, however, was best articulated by the officials that we spoke to from the MPO. These officials could describe the policy frameworks, much of which are quite unique to this 
region, that govern the regional planning process and the implementation of shared goals like polycentric development. However, the smaller scale actors like the City of Portland and TriMet play important roles within their geographic extents as well as beyond.

\subsection{DOCUMENTS REVIEWED IN THIS CHAPTER}

- City of Portland (2011). Comprehensive Plan Goals and Policies. Retrieved from https://www.portlandonline.com/bps/Comp_Plan_Nov2011.pdf

- City of Portland (2013). Portland Zoning. Retrieved from https://www.portlandmaps.com/bps/zoning/\#/about/

- City of Portland (2020). Zoning Code. Retrieved from https://www.portlandoregon.gov/bps/31612

- Oregon Metro (2014). 2040 Growth Concept Map. Retrieved from https://www.oregonmetro.gov/sites/default/files/2016/10/18/2040GrowthConcept.pdf

- Oregon Metro (2010). Urban Growth Management Functional Plan. Retrieved from https://www.oregonmetro.gov/sites/default/files/2018/04/16/urban-growth-management-functionalplan-04162018.pdf

- Oregon Metro (2019). Transit-Oriented Development Investment Criteria. Retrieved from https://www.oregonmetro.gov/sites/default/files/2019/02/05/Revised-Investment-Criteria-2-5-19. pdf

- Oregon Metro (2011). State of the Centers Investing in Our Communities. Retrieved from https://www.oregonmetro.gov/sites/default/files/2015/02/25/2011_state_of_the_centers_0.pdf

- TriMet (2015). The Future of Transit Southwest Service Enhancement Plan Final Report. Retrieved from https://trimet.org/future/pdf/southwest-final-report.pdf 


\subsection{CASE STUDY OF POLYCENTRIC DEVELOPMENT STRATEGIES IN THE TWIN CITIES REGION, MN}

\section{$9.1 \quad$ INTRODUCTION}

The Twin Cities region in Minnesota is comprised of seven counties where an estimated 3.2 million people live. This bustling region is anchored by Minneapolis, the state's most populous city, and St. Paul, the state's capitol and second-most populous city (see Figure 9.1). These cities contain the region's largest concentrations of residences and workplaces within their boundaries and are often thought of as a significant part of what makes the region polycentric.

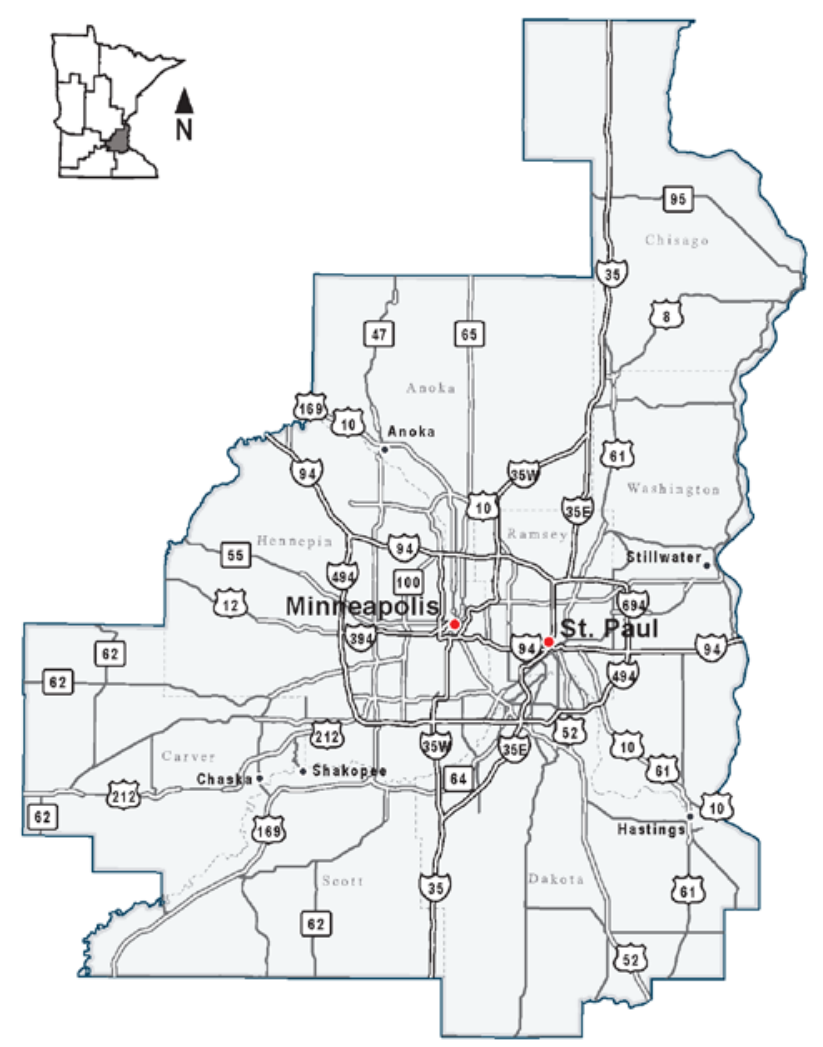

Figure 9.1: Counties, major cities, and major roadways of the Twin Cities region. Source: dot.state.mn.us

This case study utilizes interviews and document review to identify strategies used within the Twin Cities region to facilitate polycentric development patterns that contain sprawl and facilitate access to regional goods and services. Because our findings indicate the importance of prior planning practices in shaping current regional development patterns, we begin the study with a review of key events in the region's planning history. We then identify and describe the policies, programs, tools, and approaches that currently support polycentric development. Table 9.1 shows the number of interviewees and documents reviewed. 
Table 9.1: Number of officials interviewed and documents reviewed

\begin{tabular}{lcc}
\hline Organization & Officials Interviewed & Documents Reviewed \\
\hline Metropolitan Council & One & Nine \\
\hline City of Saint Paul & Two & One \\
\hline City of Minneapolis & One & One \\
\hline
\end{tabular}

We interviewed planners from the City of Minneapolis, the City of St. Paul, and the Metropolitan Council (of which the regional transit authority Metro Transit is an operating division) to identify the means by which these entities promote centered development with their partners. We made efforts to contact planners working with Ramsey and Hennepin Counties, but did not receive responses to our inquiries. Planners we spoke with also provided supporting documents that we carefully reviewed to better understand how the region is planning to focus growth in centers. Finally, we reviewed hundreds of pages of documents to fill in any gaps remaining from our interviews.

\subsection{REGIONAL HISTORY OF POLYCENTRIC DEVELOPMENT}

The Federal-Aid Highway Act of 1962 was a watershed moment for planners nationwide, as it required areas of the country with populations greater than 50,000 to form metropolitan planning organizations (MPOs). In the Twin Cities region, this led to the 1962 Joint Program for Land-Use Transportation Planning, which emphasized a coordinated, regional approach to transit and regional land use planning that laid the groundwork for the region's new MPO. The Minnesota Legislature created the Metropolitan Council five years later and gave it responsibilities for planning and coordinating the region's growth and setting policies to deal with regional issues. The establishment of the Metropolitan Council led to public transit improvements, a reversal of declining ridership, and service modernization and expansion.

The population of the Twin Cities region reached 1.9 million in 1970. An analysis of travel behavior sampled that year revealed that the majority of the region's residents conducted their daily business within five miles of their homes. This finding brought attention to the existing public transit system, which was designed primarily to move people to and from Minneapolis and St. Paul and therefore did not serve these shorter trips. Not only was the current system insufficient for meeting complex regional travel patterns, planners recognized that it was inequitable. They noted that those without private transportation were "limited in their choice of housing location" to areas served by transit. The 1973-74 oil crisis-and the attendant lines at gas stations-amplified these concerns by illuminating the downside of the region's auto-dependent suburbs.

These factors led the Metropolitan Council to create two regional plans that supported polycentric development. In 1975, the Council adopted the region's first guided growth plan, which included a chapter on a new development framework. The framework consisted of five development designations that were applied to land within the region with the intention of combatting sprawl and efficiently providing services. The result was a combination of infill and polycentric development policy (Figure 9.2). It identified firstring suburbs as "developing areas" toward which to channel future growth as well as 
"freestanding growth centers" whose boundaries required protection from outward creep into surrounding "rural areas."

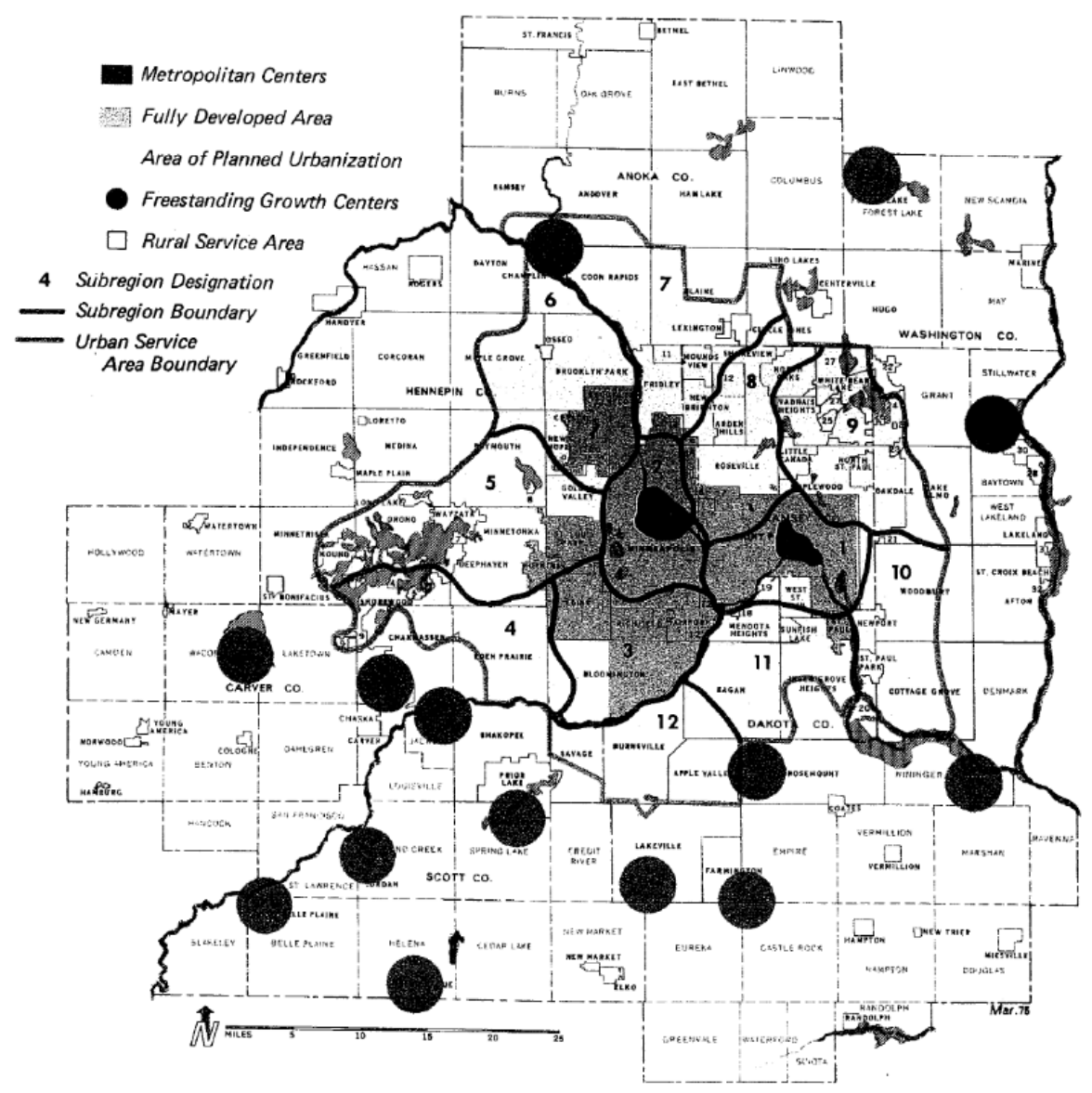

Figure 9.2: Transportation service and planning areas. Source: 1976 Transportation Policy Plan.

The following year, the Council unveiled a complementary approach to transit service in its Transportation Policy Plan, which divided each of the Twin Cities and their adjacent suburbs into 12 "subregions." Each subregion was imagined as a proto transit-oriented development (TOD). Subregions would offer all of the "basic necessities for daily living" and be designated as transit service areas. Transit service would provide access to activities and opportunities within each subregion, as well as express service to either Minneapolis or St. Paul. In an effort to minimize costs, the Council also discouraged transit service between subregions prior to 1990, effectively—if not explicitly_promoting the creation of centers in each of these subregions.

The legislature imbued the Council's plans with authority by passing the 1976 Metropolitan Land Planning Act (Minn. Stat. 473.145), which gave the Council power to provide technical assistance, distribute planning grants, and review comprehensive plans. Henceforth, municipalities and townships within the region were required to undergo a process known today as "conformance." To this day, communities must submit their comprehensive plans to the Council for review of three factors: compatibility with the plans of neighboring municipalities, consistency with adopted Council policies, 
and conformance with metropolitan system plans (e.g., transportation, water resources, housing, etc.). This review process remains an integral component of how the Council promotes centered development.

During the 1990s, the population of the Twin Cities region grew more than in any previous decade. Developers anticipating this growth and seeing an opportunity broke ground on the largest mall in the U.S. during the summer of 1989. The Mall of America would be located in the first-ring suburb of Bloomington, which had been classified as part of subregion 3 in the 1976 Transportation Policy Plan. Patrons would arrive via the recently completed Interstate 494, part of a beltway that encircled the Twin Cities. Some planners at the Metropolitan Council saw the construction of Mall of America in this location as an acknowledgement that large communities had developed in the suburbs, pulling the region's centers of gravity outward. Meanwhile, congestion grew $500 \%$ between 1980 and 2000 on the region's highway system.

Two years after the Mall of America opened in 1992, the Minnesota Legislature consolidated planning, services, and operations into one agency: the Metropolitan Council. In addition to having the authority to review comprehensive plans, the Council now had operational control over regional wastewater systems and the transit authority, which would be renamed Metro Transit in 1998. The passage of the Metropolitan Livable Communities Act in 1995 was a legislative effort to provide the Council with financial tools to implement their regional development guides, which had begun to reference the need to coordinate land use and transportation and include strategies for strengthening transitway corridor potential.

Planners interviewed for this study agreed that planning for polycentric development has not been an explicit priority for several decades. That approach is seen as part of the region's "legacy," and as such has become, at least to one planner we interviewed, "more organic than policy directed." Rather than dictate a region-wide polycentric development policy, the Metropolitan Council, Metro Transit, and the Cities of Minneapolis and St. Paul are partnering and coordinating with communities to develop local interventions that capitalize on their existing infrastructure and unique features. The resulting strategies emphasize the link between land use and transportation and focus on promoting growth both within the larger centers of Minneapolis and St. Paul and at smaller geographies throughout the region. Fine-grained interventions such as transit-oriented development, corridor planning, and planning around "neighborhood nodes" or "job concentrations" are rarely framed in terms of centers or polycentric development, but still contribute to centered development.

\subsection{TOOLS AND STRATEGIES OF THE METROPOLITAN COUNCIL (MPO) AND METRO TRANSIT}

\subsubsection{Thrive MSP 2040}

Minnesota Statute 473.146 dictates that the Metropolitan Council must produce a "comprehensive development guide" for the "coordinated, orderly, and economical development" of the Twin Cities region at least once a decade, following updates to 
long-term forecasts that incorporate data from the most recent Decennial Census. The Council adopted its current development guide, Thrive MSP 2040, in May of 2014. Although polycentric development is not an explicit goal, it is emphasized throughout the document. More nudge than mandate, the guide encourages local communities to direct dense, mixed-use development to job concentrations and nodes along corridors and identify local centers where this type of development may be fostered. In service of this goal, Thrive MSP 2040 references "centers" more than 100 times and describes the following policies, strategies, and tools supportive of polycentric development.

\subsubsection{Metropolitan Urban Service and Rural Service Areas}

The Council categorizes land within the Twin Cities region as part of either the Metropolitan Urban Service Area (MUSA) or the Rural Service Area (RSA). The MSA constitutes about half of the land in the region and hosts more than $90 \%$ of the population. The Council invests in communities within the MUSA by providing regional wastewater services, regional highways, transit service, the regional parks system, and other programs that support redevelopment. In return, the Council expects these jurisdictions to plan for and build the higher levels of development that economically support those regional services. Conversely, in the RSA, the Council discourages higher development densities to ensure the orderly development of the region, promote the efficient use of regional investments, and protect agricultural land, water resources, and the rural landscape. Density thresholds are assigned at a finer grain using community designations, which are described below.

\subsubsection{Community Designations}

The legacy of the Council's 1975 development framework is evident in its ongoing practice of using community designations to facilitate the application of regional policies. There are currently nine designations - five for the MUSA and four for the RSAassigned to cities and townships within the Twin Cities on the basis of "existing development patterns, common challenges, and shared opportunities." The primary function of these community designations could be read as a centering policy. Thrive MSP 2040 describes this as "guid[ing] regional growth and development to areas that have urban infrastructure in place and the capacity to accommodate development and redevelopment." Figure 9.3 illustrates how this practice concentrates growth around the major centers of Minneapolis and St. Paul. 


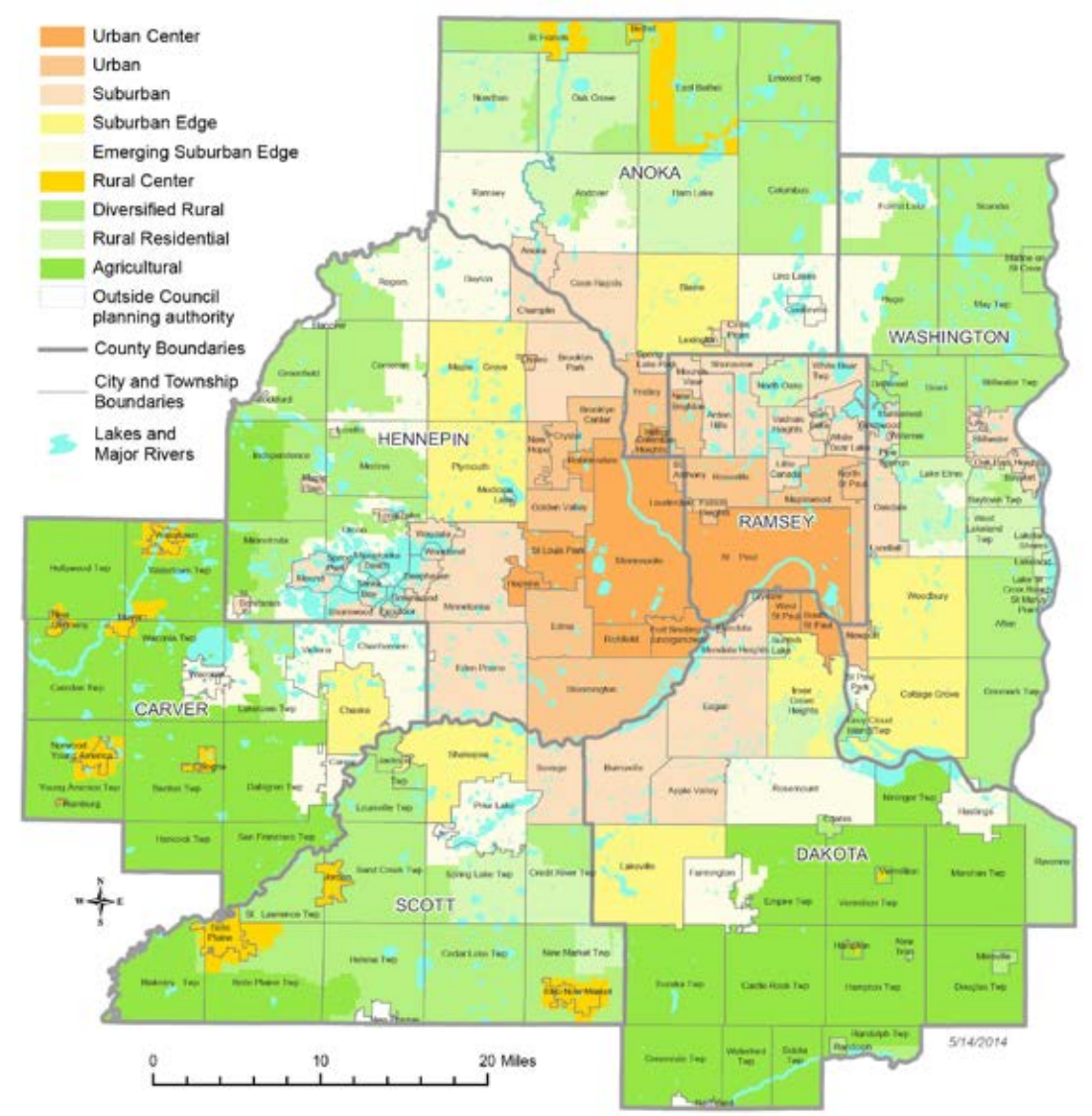

Figure 9.3: Community designations. Source: Thrive MSP 2040.

From the Council's community designations flow two principal strategies that contribute to centered development: density thresholds and identifying infill and redevelopment opportunities.

\subsubsection{Minimum Average Density Thresholds}

Community designations provide the Council with a rule of thumb for determining minimum average density thresholds for cities and townships. Each community is then empowered to determine precisely how and where to promote density (provided their plans align with regional policy) to meet this threshold. Thrive MSP 2040 states explicitly that this flexible approach to density expectations is designed to honor the uniqueness of individual communities and their values. Preservation of community identity and agency, therefore, is prioritized over a regionwide mandate of polycentric development.

There are notable exceptions to this approach. For example, the region's 11 communities designated as "urban centers"-including the cities of Minneapolis and St. Paul-must plan for forecasted population and household growth at average densities of at least 20 units per acre for new development and redevelopment (See table 9.2). They also are expected to target opportunities for more intensive development near regional transit investments in accordance with the 2040 Transportation Policy Plan. 
Table 9.2: Thrive MSP 2040 overall density expectations for new growth, development, and redevelopment. Source: Thrive MSP 2040.

\begin{tabular}{lc}
\hline \multicolumn{2}{l}{ Metropolitan Urban Service Area: Minimum Average Net Density } \\
\hline Urban Center & 20 units/acre \\
\hline Urban & 10 units/acre \\
\hline Suburban & 5 units/acre \\
\hline Suburban Edge & $3-5$ units/acre \\
\hline Emerging Suburban Edge & $3-5$ units/acre \\
\hline Rural Service Area: Maximum Allowed Density, except Rural Centers \\
\hline Rural Center & $3-5$ units/acre minimum \\
\hline Rural Residential & $1-2.5$ acre lots existing, 1 unit/10 acres where possible \\
\hline Diversified Rural & 4 units/40 acres \\
\hline Agricultural & 1 units/40 acres \\
\hline
\end{tabular}

\subsubsection{Infill, Adaptive Reuse, and Redevelopment}

Regional opportunities for infill, adaptive reuse, and redevelopment (IAR\&R) are also targeted using the Council's system of community designations. Thrive MSP 2040 explicitly encourages IAR\&R in three of its nine service areas: urban center, urban, and suburban. All of these service areas are within the MUSA and together are designed to "result in a denser, more compact region, minimizing the loss of agricultural land, reducing travel distances, and enhancing the ability of the region to support transit."

To support this effort, the Council compiles locally identified priority sites for development and redevelopment into a regional inventory of development priorities. They also analyze the market readiness of these sites and develop investment and redevelopment strategies customized to the needs of different types of strong and weak markets with local and regional partners. Lastly, the Council uses its authority to streamline redevelopment processes and "equalize the playing field" between redevelopment, infill development, and greenfield development sites."

\subsubsection{Mapping Special Features}

To tailor interventions to smaller geographies, the Council has identified and mapped eight place-based features with distinct policy implications for planners. Guided by policies listed at the beginning of this section, the Council explicitly sets expectations and offers incentives for centered, diverse development around two special features: station areas on existing and planned transitways and job concentrations.

The Council's 2040 Transportation Policy Plan (TPP) defines expectations for transitsupportive land use near station areas on existing and planned transitways, including 
higher levels of residential density, a mix of housing affordability, and well-connected development patterns. The Council provides technical assistance and grant opportunities to support transit-oriented development in station areas, as well as proactively working to preserve housing affordability and protect housing options for existing low-income residents. This is discussed further in the section on the Council's transit-oriented development policy.

The job concentration special features are employment areas with at least 7,000 jobs at a minimum density of at least 10 jobs per acre. The Council actively promotes centered development at this type of special feature by focusing expansion of bus service and transitway investment to and within existing and emerging job concentrations. Furthermore, they explicitly encourage employers and communities who "value transit access for their workforce" or "aspire to higher levels of transit service for job access" to either locate within or build toward the thresholds of job concentrations. To accommodate changes in development patterns, the Council monitors relevant activity and annually identifies new job concentrations.

\subsubsection{Transportation Policy Plan}

As operators of Metro Transit, the regional transit authority, the Metropolitan Council prepares transportation plans on behalf of the Twin Cities region. The most recent of these is the 2040 Transportation Policy Plan (TPP), which builds upon themes expressed in Thrive MSP 2040. Two of the TPP's goals relate to centered development: enhance multimodal access to job concentrations and integrate land use and transportation planning.

\subsubsection{Enhance Multimodal Access to Job Concentrations}

People are the lifeblood of communities and their ability to access a place is what makes centers thrive. Metro Transit plays a crucial role in promoting centered development by enhancing multimodal access to job concentration, transit corridors, and other activity centers throughout the Twin Cities Region. Multiple strategies articulated in the TPP support this aim, most notably:

- Strategy C4. Regional transportation partners will promote multimodal travel options and alternatives to single-occupant vehicle travel and highway congestion through a variety of travel demand management initiatives, with a focus on major job, activity, and industrial and manufacturing concentrations on congested highway corridors and corridors served by regional transit service.

- Strategy D3. The Council and its partners will invest in regional transit and bicycle systems that improve connections to jobs and opportunity, promote economic development, and attract and retain businesses and workers in the region on the established transit corridors.

These and other strategies have resulted in plans to expand the region's transit network. The Council and Metro Transit will develop four additional light rail lines and 
three new arterial bus rapid transit lines through 2040. Additional investment of at least $\$ 2.4$ billion is anticipated to support improvements along new corridors in the later years of the TPP.

\subsubsection{Integrate Land Use and Transportation Planning}

Both the TPP and Thrive MSP 2040 exhort local governments to plan for more dense, diverse development in job concentrations and nodes along transportation corridors. This goal is articulated as "leveraging transportation investments to guide land use" and includes two strategies that clearly support centered development:

- Strategy F2. Local governments should plan for increased density and a diversification of uses in job concentrations, nodes along corridors, and local centers to maximize the effectiveness of the transportation system.

- Strategy F4. Local governments will identify opportunities for and adopt guiding land use policies that support future growth around transit stations and near highfrequency transit service. The Council will work with local governments in this effort by providing technical assistance and coordinating the implementation of transit-oriented development. The Council will also prioritize investments in transit expansion in areas where infrastructure and development patterns supporting a successful transit system are either in place or committed in the planning or development process.

\subsubsection{Transit-Oriented Development Policy}

The Metropolitan Council's TOD Policy vigorously supports the development of transitoriented development, defined as "moderate- to higher-density development located within easy walking distance of a major transit stop that typically includes a mix of uses." Enacted in 2013, the policy supports the overarching goal to "foster efficient and economic growth for a prosperous metropolitan region" for all of its residents. A strategic action plan adopted the same year laid the groundwork for the policy and defines next steps in terms of the following six tools: collaboration, technical resources, communication and education, TOD planning, TOD development, and TOD funding. To advance TOD regionwide, the Council engages in two key activities, providing funding for TOD and prioritizing TOD on the land it owns through joint development, which are described below. The TOD Office also produces a wealth of documents related to TODs, including an annual report, studies of different TODs, and guides for developers and members of the public that reflect best practices in TOD planning and design.

\subsubsection{TOD Grantmaking}

Grantmaking is a widespread and effective means of incentivizing preferred development patterns. To motivate developers and communities to build within established and emerging station areas, the Council created the Livable Communities TOD grant category (LCA-TOD) in 2011 with an initial allocation of \$26.2 million. TOD projects are expected to diversify uses and provide a higher concentration of amenities 
in a compact built environment within transit station areas contributing to high-quality, pedestrian-oriented streets and public spaces encouraging the use of transit service. Eligible projects lie within a half or a quarter mile of different light rail and commuter rail lines. Projects located within a half mile of stations on certain rail lines that are not included in the Livable Communities TOD grant are eligible for TOD PreDevelopment and Zoning Implementation grants.

LCA-TOD is not the only pot of money that has supported TOD in the Twin Cities region. TOD funding sources have included: the $\$ 20$ million Corridors of Opportunity Housing/TOD Loan Program, Department of Employment and Economic Development Transit Improvement Area Loan Fund, Developer Working Capital, and the Greater Metropolitan Housing Corporation. Hennepin County, where Minneapolis is located, began its own TOD Program in 2003 and has since awarded more than \$29 million in general obligation bonding and levy funding to both urban and suburban projects. Funds from this program have assisted projects along key Hennepin County transit corridors such as Hiawatha, Central Corridor, Southwest, Bottineau, and other high-frequency and express bus routes. Together, these six grant programs represent a significant investment in compact, transit-centered development regionwide.

\subsubsection{General Grantmaking}

Aside from the TOD grantmaking program, the Metropolitan Council administers the Livable Communities Demonstration Account (LCDA) grant to incentivize centered development. The LCDA grant funds innovative (re)development projects that efficiently link housing, jobs, services and transit. To date, 243 LCDA grants totaling more than $\$ 130$ million have funded projects in 67 cities within the Twin Cities region. The Council encourages applicants to develop projects that increase connectivity, contribute to housing diversity (in terms of density, type, etc.), and catalyze additional "efficient" development. To increase the quality of projects submitted to this (and other) programs, the Council sponsors optional design workshops where prospective applicants receive input on site planning and design from expert panels.

\subsection{TOOLS AND STRATEGIES OF THE CITY OF MINNEAPOLIS}

\subsubsection{Minneapolis 2040}

On October of 2019, the Minneapolis City Council adopted a resolution to approve its comprehensive plan, Minneapolis 2040. A planner we spoke with from the City of Minneapolis described the new plan as a departure from the past 20 years of planning in the city, which had promoted polycentric development in what were known as "lobby centers." Confusion about what was and was not permitted within these centers was never resolved and continued over the decades. Rather than try to rehabilitate a concept that had lacked clarity from the outset, city planners "wanted to hit the reset button." As a result, centers remain on Minneapolis' planning maps, but corridors are the focus. The planner we interviewed elaborated that the emphasis on corridors allowed the City to be "more explicit about inviting new, higher-density development on streets that have frequent bus service." Moreover, he continued, "from an overall 
coordinating land use and transportation standpoint, it makes sense to build where good transportation options exist."

Because Minneapolis 2040 is required to conform with Thrive MSP 2040, it echoes many of the ideas and interventions that support centered development in the Council's vision document. This is perhaps most evident in Minneapolis 2040's focus on increasing housing densities near transit and job centers, but also applies to proposed expansions of active transportation infrastructure and investments to corridors. All of these efforts serve to create local centers within municipal boundaries and are described in the list of policies below. It is important to remember that Minneapolis as a whole may still be considered a center-the Council assigned it the "urban center" community designation-so the city is also working to increase densities citywide. This effort is addressed in a later section on zoning.

\section{Policy 1: Increase the supply of housing and its diversity of location and types. Strategies:}

- Allow the highest-density housing in and near downtown.

- Allow multifamily housing on public transit routes, with higher densities along high-frequency routes and near METRO stations.

\section{Policy 4: Improve access to goods and services via walking, biking and transit. Strategies:}

- Increase access to commercial goods and services by allowing multifamily housing on select public transit routes, with higher densities along high-frequency routes and near METRO stations; and by expanding opportunities for commercial activity particularly on certain corridors, while requiring commercial activity in key locations.

- Increase access to commercial goods and services by allowing the highestdensity housing in and near downtown, while requiring commercial activity in key locations.

Policy 38: Create more affordable housing near transit and job centers. Strategies:

- Maximize opportunities to create affordable housing, including senior housing and multigenerational housing, near transit stations and along high-frequency transit corridors.

- Identify and pursue opportunities to acquire and assemble vacant and for-sale properties for affordable housing near transit stations and along transit corridors. 
- Improve coordination within the City enterprise and with outside jurisdictions to identify opportunities to increase housing density and affordability along transit corridors and near job centers.

- Promote a diversity of housing options throughout the city, especially in places near job employment opportunities, commercial goods and services, and educational institutions.

- Support education and housing stability by encouraging the development of larger, family-supportive housing units (with at least two bedrooms) in close proximity to Minneapolis Public Schools and along Minneapolis Walking Routes for Youth.

These three policies and their associated strategies clearly articulate how the City of Minneapolis plans to promote centered development within municipal boundaries. First, encourage the construction of higher-density development along high-frequency transit routes and in station areas. Second, continue to build density in the city's downtown. Finally, ensure there is diverse and plentiful housing available at job centers, activity centers, and transit routes and stations.

\subsubsection{Small Area Plans}

In addition to the three policies described above, Minneapolis 2040 uses small area plans to support centered development at finer geographies. The comprehensive plan includes small area plans for three corridors, three light rail station areas, and a handful of additional business centers and neighborhoods. The most significant aspects of these plans are their allowances with regard to density and expansion of mixed-use commercial activity.

\subsubsection{Mapping}

Minneapolis 2040 includes the Future Land Use and Built Form Maps. These two maps are the primary tools for implementing the land use and built form policies of the comprehensive plan. The Future Land Use Map assigns every parcel in Minneapolis one of 11 land use categories, including those that align with centers, such as "corridor mixed use," "destination mixed use," and "public, office, and institutional." Figure 9.4 exhibits Minneapolis' clear corridor planning strategy, in which corridors emanate from a dense central business district. The Future Build Form map specifies height, bulk, and setback standards among other regulations that are discussed in greater detail in the following section on zoning. The maps, along with other policies in the plan, will be used to make decisions on development proposals and to shape regulations over the life of the document. 


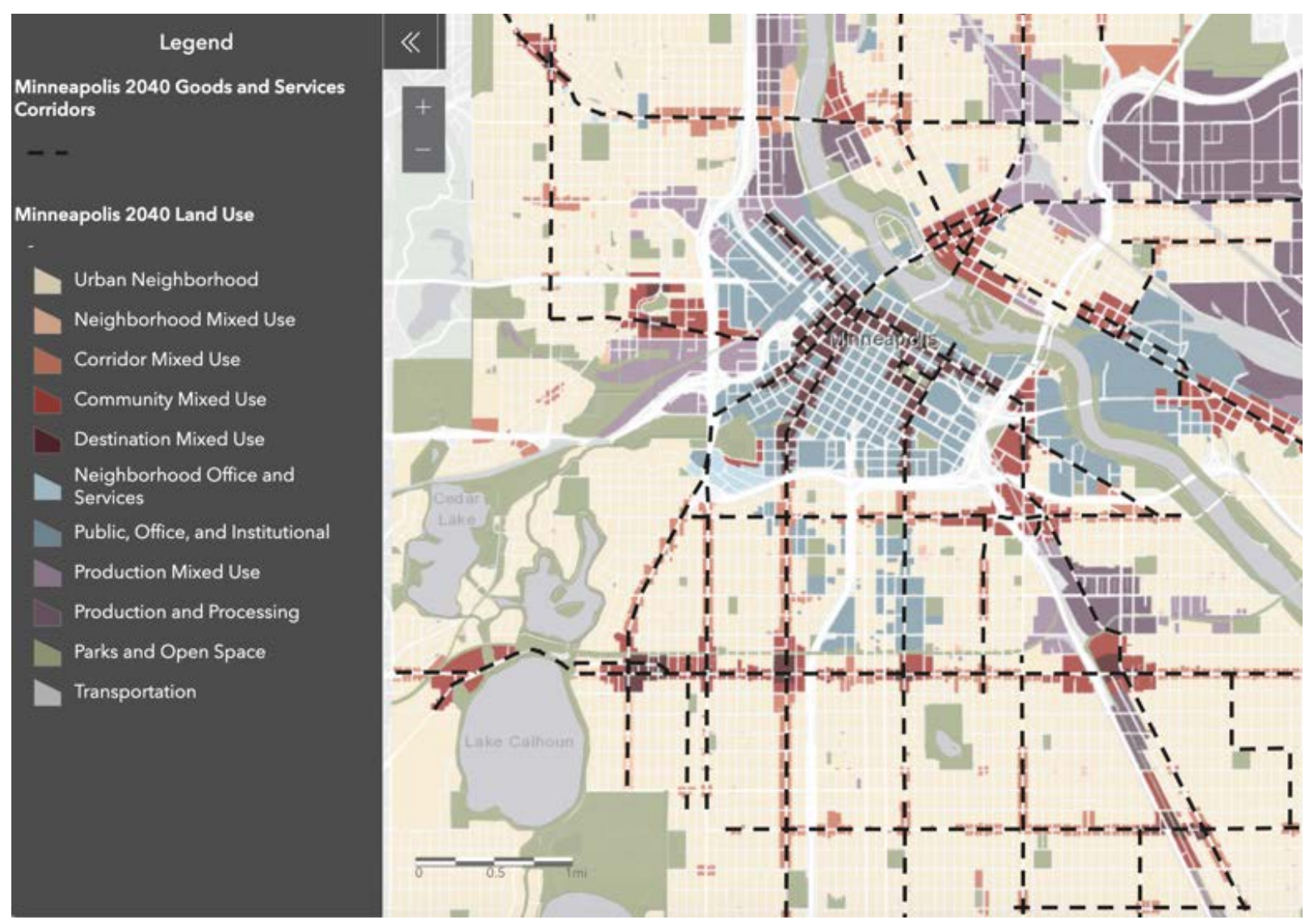

Figure 9.4: Minneapolis 2040 Future Land Use map

\subsubsection{Zoning}

The City of Minneapolis recently made headlines by eliminating single-family zoning. A planner with Minneapolis described this decision as driven by "moral" and "practical" considerations. Single-family zoning was historically used to segregate Minneapolis and exclude people of color from desirable areas. Moreover, Minneapolis is facing its "own version of the affordable housing crisis." The effects of this change are anticipated to promote centered development in two ways: "capturing a higher share of the regional development within the boundaries of Minneapolis" and directing the "vast majority of new housing construction [to] larger, multifamily development in centers and on major streets." Figure 9.5 illustrates how densities are highest in Minneapolis' city center and generally decrease according to how far parcels are from this area. The exceptions are along corridors and around transit stations. For example, the 'Corridor 6' category seen in red allows six building stories as of right. The 'Transit 10' category allowing up to 10 building stories as of right. Both of these categories have minimum building heights of two stories. 


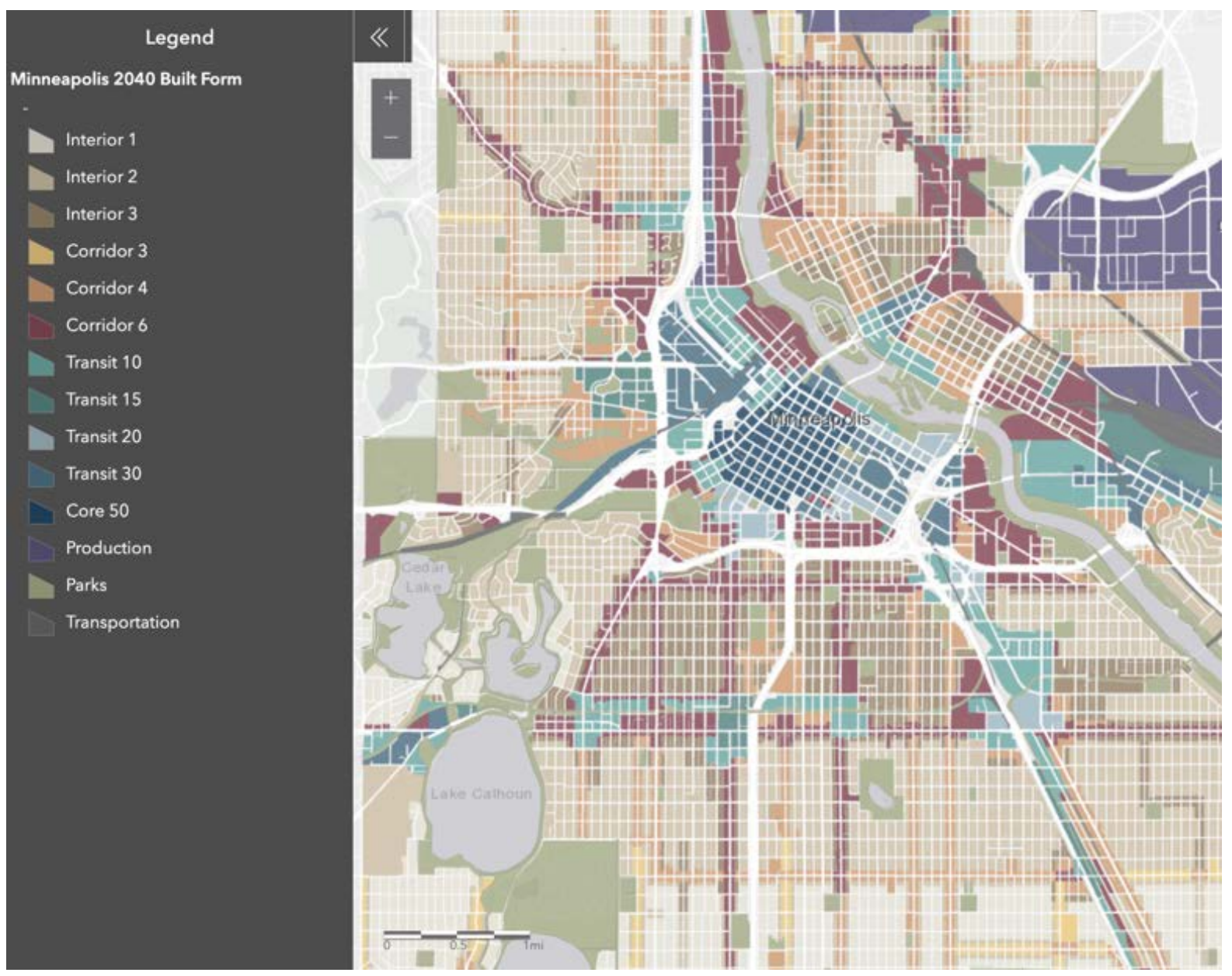

Figure 9.5: Minneapolis 2040 Future Built Form map. Source: Minneapolis 2040

\subsection{TOOLS AND STRATEGIES OF THE CITY OF ST. PAUL}

\subsubsection{Comprehensive Plan}

The 2040 Comprehensive Plan is St. Paul's "blueprint" for guiding development in the city over the next two decades. St. Paul has promoted centered development through prior comprehensive plans, and this plan is no exception. In fact, one of the City's 10 core values, which undergird the 2040 Comprehensive Plan, is "growth and prosperity through density."

Although centered development remains central to the new comprehensive plan, the strategies are new. The 2030 comprehensive plan had included "neighborhood centers" as a means of promoting polycentric development, but planners moved away from that concept in favor of promoting developments around nodes and corridors. According to our interviews, their inspiration came largely from the "20-minute neighborhoods" concept pioneered in Portland, OR, around 2008. The aim is to provide many daily services and amenities within a 20-minute walk from the vast majority of residences. The City of Cincinnati's node-based comprehensive plan, which includes a hierarchy of 
centers, provided another source of ideas. The focus on walkability also reflects what members of the public shared during outreach for the 2040 Comprehensive Plan. "We heard clearly," a planner with the City of St. Paul told us, "that people want to walk to things and have access to services, amenities like libraries, restaurants, retail."

The Land Use Chapter in the 2040 Comprehensive Plan describe most of St. Paul's interventions that support polycentric development. The aim of creating dense areas served by multiple transit modes is clear from the chapter's outset and are articulated in its goals. There are eight total goals, the first two of which pertain to centered development:

- Goal 1: Economic and population growth focused around transit

- Goal 2: Neighborhood Nodes that support daily needs within walking distance

Generally, the citywide goals are to increase density and land use diversity at Neighborhood Nodes, focus investment along transit corridors and promote high-quality urban design. Mixed-use clusters anchoring neighborhoods provide convenient access to local services and employment and promote vibrancy, which supports walking and reduces the amount of driving needed to satisfy daily needs. The following policies apply across the city regardless of land use category:

- Policy LU-1: Encourage transit-supportive density and direct the majority of growth to areas with the highest existing or planned transit capacity.

- Policy LU-2: Pursue redevelopment of Opportunity Sites (generally sites larger than one acre identified as having potential for redevelopment) as higher-density, mixed-use development or employment centers with increased full-time living wage job intensity, and the appropriate location for community services that are completely absent in the surrounding area. Figure 9.6 illustrates how many of these sites cluster along arterial corridors or near downtown. 


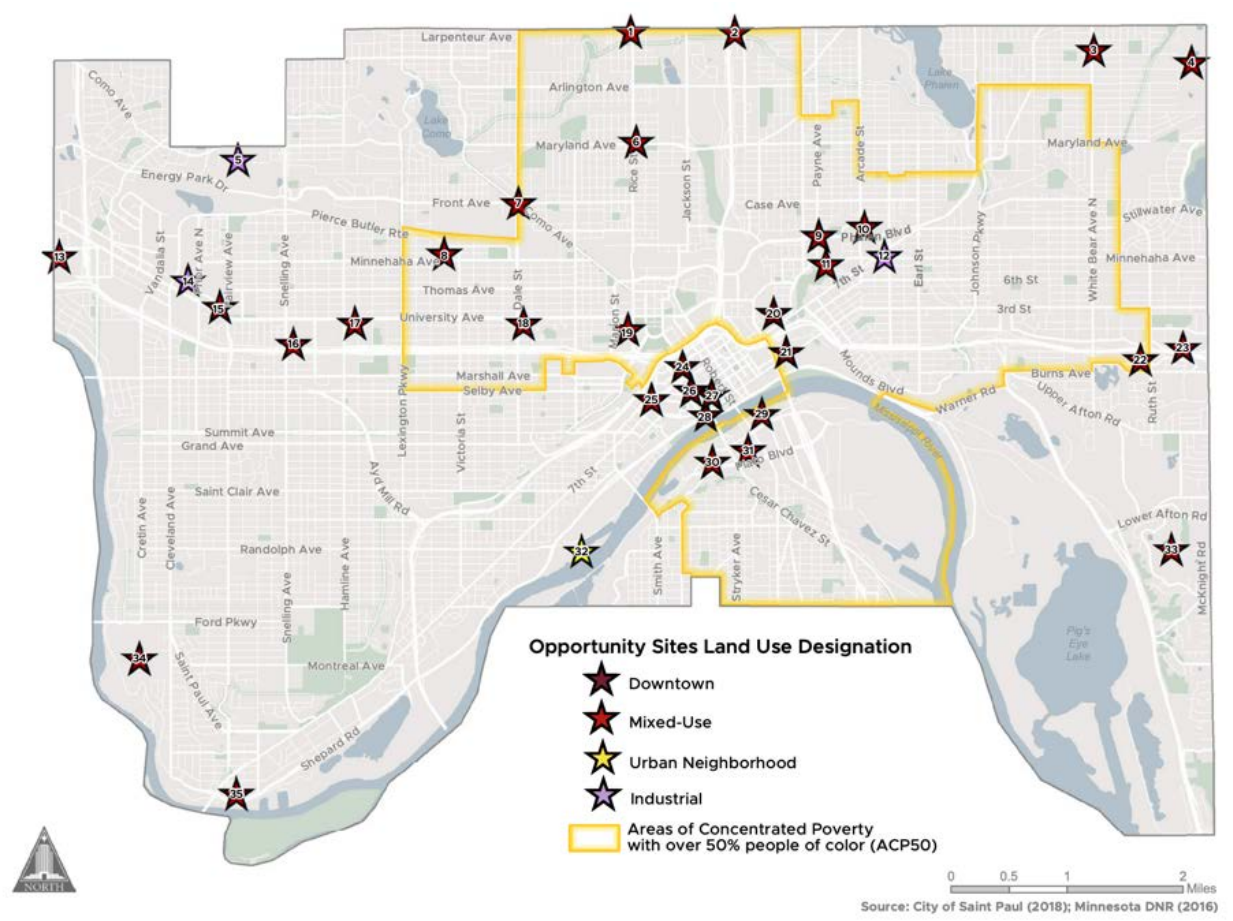

Figure 9.6: Opportunity Sites in the 2040 Comprehensive Plan. Source: St. Paul 2040 Comprehensive Plan.

Policy LU-6: Foster equitable and sustainable economic growth.

o Strategies that simultaneously support this policy and promote centered development include:

o Proactively directing new development to high-priority geographies, such as Neighborhood Nodes, ACP50 Areas and Opportunity Sites;

o Encouraging cultural and arts-based businesses and business districts, such as Little Mekong, Little Africa, Rondo and the Creative Enterprise Zone; and

o Building and expanding neighborhood economic and cultural assets through the development of the local micro-economies of our Neighborhood Nodes.

- Policies LU-13-15: Improve off-street parking efficiency.

o LU-13: Support strategies, as context and technology allow, to improve off-street parking efficiency, such as shared parking agreements, district ramps, car-sharing, electric vehicle charging and reduced parking overall.

o LU-14. Reduce the amount of land devoted to off-street parking in order to use land more efficiently, accommodate increases in density on valuable 
urban land, and promote the use of transit and other non-car mobility modes.

o LU-15. Ensure that stand-alone parking uses are limited, and that structured parking is mixed use and/or convertible to other uses.

These four policies and their supporting strategies support centered development in three important ways. Like the City of Minneapolis, St. Paul's priority is to support higher-density development around transit, particularly areas with higher capacity. St. Paul also strives to concentrate development around emerging centers at smaller geographies within the city, such as at Neighborhood Nodes, Opportunity Sites, and business and arts districts. Finally, the city supports dense development by minimizing land devoted to off-street parking.

\subsubsection{Neighborhood Nodes}

Like the Minneapolis 2040 Comprehensive Plan, land use policy in St. Paul concentrates growth downtown and supports development along corridors (Figure 9.7). A unique feature of St. Paul's plan is the identification of 72 Neighborhood Nodes, toward which the city will direct growth. Neighborhood Nodes may be neighborhood centers, transit station areas, or urban villages, and have often developed adjacent to major intersections or at former streetcar stops. As such, many of these nodes are situated either in the already-dense downtown area or along transportation corridors.

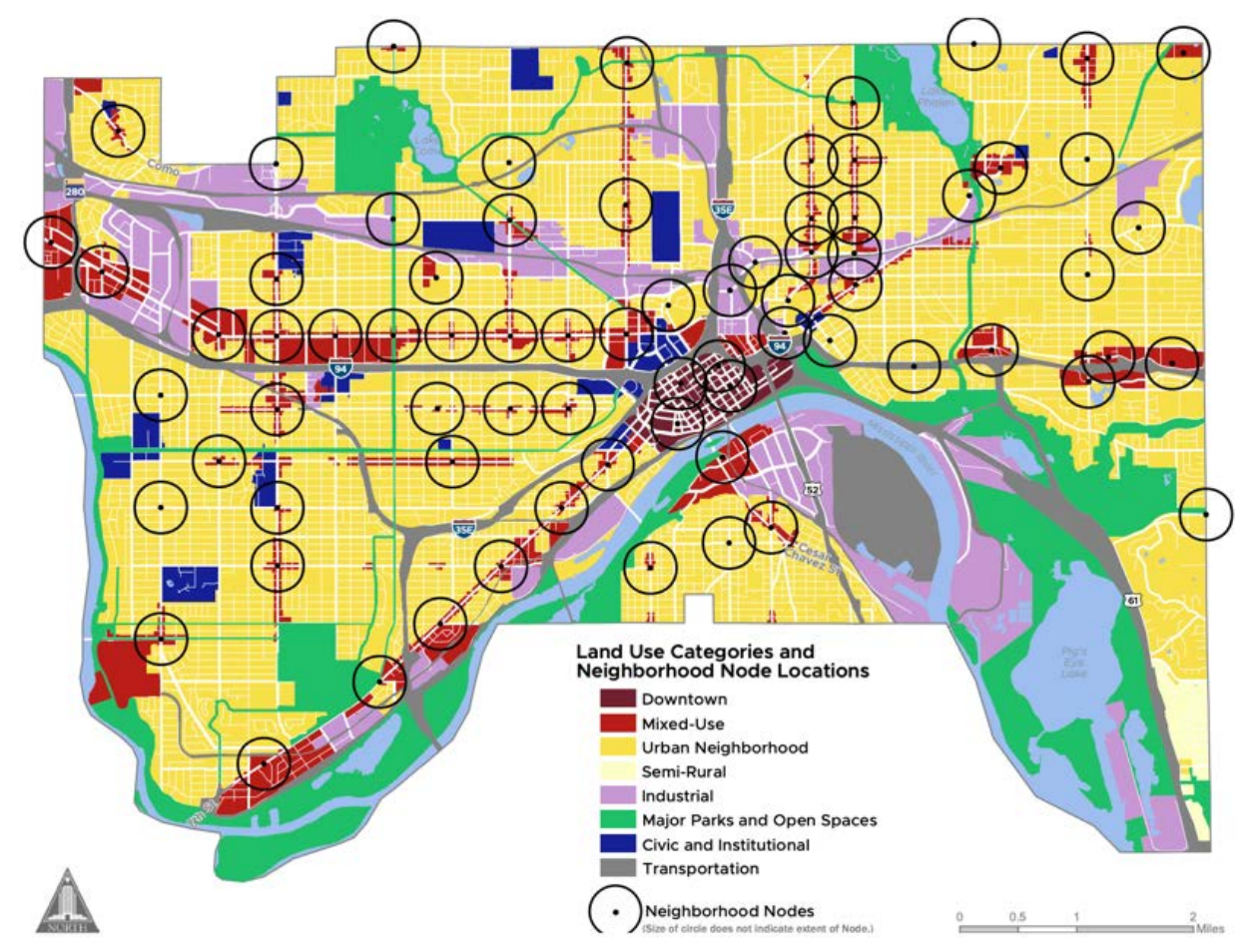

Figure 9.7: Land use categories and neighborhood nodes. Source: St. Paul 2040 Comprehensive Plan. 
An important feature of Neighborhood Nodes is that, with the exception of those that lie within the downtown area, they allow for higher development density averages than those permitted by the surrounding land use designations. For example, in St. Paul's mixed-use areas, the goal for new density averaged across that land use type is between 15-17 units per acre. The density goal for Neighborhood Nodes within mixeduse areas, however, is between 20-200 units per acre. See Table 9.3 for more information about density ranges. Note that density ranges represent a goal for new development averaged across the generalized future land use type. Individual projects may exceed targeted goals.

Table 9.3: Residential land use density ranges. Source: St. Paul 2040 Comprehensive Plan

\begin{tabular}{lcc}
\hline Land Use Type & Base Range & At Neighborhood Node \\
\hline Downtown & \multicolumn{2}{c}{$30-300$ units/acre } \\
\hline Mixed-Use & $15-75$ units/acre & $20-200$ units/acre \\
\hline Urban Neighborhood & $7-30$ units/acre & $15-55$ units/acre \\
\hline Semi-Rural & $2-15$ units/acre & n/a \\
\hline $\begin{array}{l}\text { Citywide* } \\
\text { * Metropolitan Council's requirement for communities with the urban core designation. All of Saint Paul } \\
\text { falls within this category }\end{array}$
\end{tabular}

The process of designating a Neighborhood Node involves layers of analysis and robust community feedback. Analysis includes reviewing historic land use maps for persistent commercial nodes and mixed uses, reviewing current zoning designations, evaluating proximity to transit, comparing amenities proximate to potential nodes, and identifying public anchors such as schools, parks and libraries. A final analysis ensured that, generally, there would be a Neighborhood Node within a 20-minute (or less) walk of any residence in Saint Paul.

- Policy LU-30: Focus growth at Neighborhood Nodes using the following principles:

o Increase density toward the center of the node and transition in scale to surrounding land uses.

o Prioritize pedestrian-friendly urban design and infrastructure that emphasizes pedestrian safety.

o Cluster neighborhood amenities to create a vibrant critical mass.

o Improve access to jobs by prioritizing development with high job density.

- Policy LU-31: Invest in Neighborhood Nodes to achieve development that enables people to meet their daily needs within walking distance and improves equitable access to amenities, retail and services.

Together, these two policies provide a detailed and thoughtful blueprint of how to create a center within a municipality that provides access to all of the goods, services, and activities necessary for everyday life. In addition to supporting higher densities within 
each node, these policies encourage growth at nodes with high job densities and prescribe the clustering of amenities. They also strongly emphasize the importance of making these centers accessible and friendly to pedestrians, whose travel patterns support and reinforce compact development.

In addtion to Neighborhood Nodes, The 2040 Comprehensive Plan acknowledges that the Metropolitan Council is primarily responsible for promoting transit-oriented development (TOD), and so largely steers away from detailed TOD policy. However, it does support the Council's efforts by introducing the concept of TOD in the Land Use chapter and establishing a set of transit density goals. These goals include minimum average and target average densities for new development targeted by distance from transit (either half or quarter mile) and transit type (fixed rail, bus rapid transit, arterial bus rapid transit, and high-frequency transit (see Table 9.4). St. Paul sets the highest density goals for half-mile areas around fixed rail and bus rapid transitways.

Table 9.4: Transit density goals. Source: St. Paul 2040 Comprehensive Plan

\begin{tabular}{llcc}
\hline Distance from transit & Transit type & Min (units/acre) & Target (units/acre)** $^{*}$ \\
\hline \multirow{2}{*}{$1 / 2$ mile } & Fixed rail transitway & 50 & $75-150$ \\
\cline { 2 - 4 } & Bus rapid transitway & 25 & $40-75$ \\
\multirow{2}{*}{$1 / 4$ mile } & Arterial bus rapid transit & 15 & $20-60$ \\
\cline { 2 - 4 } & High-frequency transit & 10 & $15-60$ \\
\hline
\end{tabular}

${ }^{*}$ Minimum represents an average goal for new development.

** Individual projects may exceed target goals.

\subsection{CONCLUSION}

Our interviews and subsequent document review revealed an evolution of development paradigms in the Twin Cities region. In the decade after it was created, the Metropolitan Council had an explicit focus on polycentric development. Promoting development in urban, suburban, and rural centers was seen as a way to enhance mobility, accessibility, security, and equity for residents regionwide. Although this no longer guides decision making, its historic legacy has had lasting effects on the built environment.

Under the new paradigm, support remains strong for increasing density within the major metropolitan centers of Minneapolis and St. Paul. However, the coordinated effort to create regional centers has given way to a general strategy of transit-oriented development. Each entity we interviewed has their own, often overlapping, strategy for promoting density along high-capacity transit lines. These strategies are tailored according to geographic scale (e.g. neighborhood intersection or regional corridor) and to the transportation mode best suited to that geography (e.g. walking or lightrail). The relative persistence of historical polycentric planning practices and the impacts of the new, transit-oriented approach to development remain topics for future study. 


\subsection{DOCUMENTS REVIEWED IN THIS CHAPTER}

- City of Minneapolis Department of Community Planning and Economic Development. (2019). Minneapolis 2040 - The City's Comprehensive Plan. Retrieved from https://minneapolis2040.com/media/1488/pdf minneapolis2040.pdf

- City of Saint Paul. (2019). Saint Paul For All: 2040 Comprehensive Plan. Retrieved from https://www.stpaul.gov/sites/default/files/Media\%20Root/Planning\%20\%26\%20Economic\%2 ODevelopment/Saint-Paul-For-All-2040-Comprehensive-Plan.pdf

- Metropolitan Council. (2019). 2019 Transportation Planning and Programming Guide: For the Twin Cities Metropolitan Area. Retrieved from: https://metrocouncil.org/CouncilMeetings/Committees/Transportation-Advisory-Board-TAB/TAB-Technical-AdvisoryCommittee/TAC-Planning-Committee/2019/TAC-Planning-5-09-19/5-b-Info-item-attPlanning-and-Programming-Guide.aspx

- Metropolitan Council. (2015). 2040 Transportation Policy Plan. Retrieved from https://metrocouncil.org/Transportation/Planning-2/Key-Transportation-PlanningDocuments/Transportation-Policy-Plan/The-Adopted-2040-TPP-(1)/Final-2040Transportation-Policy-Plan/2040-TPP-Complete.aspx

- Metropolitan Council. (2014). Handbook for Transit-Oriented Development Grants, Liveable Communities Program. Retrieved from https://metrocouncil.org/Communities/Services/Livable-Communities-Grants/TransitOriented-Development/TOD/LCA-TOD-Handbook.aspx

- Metropolitan Council. (2014). Thrive MSP 2040: One Vision, One Metropolitan Region. Retrieved from https://metrocouncil.org/Planning/Publications-And-Resources/Thrive-MSP2040-Plan-(1)/ThriveMSP2040.aspx

- Metropolitan Council. (2014). Transit Oriented Development Policy. Retrieved from https://metrocouncil.org/Communities/Planning/TOD/Files/TOD-Policy.aspx

- Metropolitan Council. (2004). 2030 Regional Development Framework. Retrieved from https://metrocouncil.org/Planning/Publications-And-Resources/2030-REGIONALDEVELOPMENT-FRAMEWORK-(1)/2030-Regional-Development-Framework.aspx

- Metropolitan Council. (2003). Comparison of Framework 2030 to Regional Blueprint (1996).

- Metropolitan Council. (1986). Metropolitan Development and Investment Framework.

- Metropolitan Council. (1976). 1976 Transportation Policy Plan. 


\subsection{CASE STUDY OF POLYCENTRIC DEVELOPMENT STRATEGIES IN DENVER, CO}

\subsection{INTRODUCTION}

The Denver region has 40-plus years of experience with smart growth through policies and strategies that focus on the benefits of compact, mixed-use development across the Colorado Front Range. Through the Denver Regional Council of Governments (DRCOG), a nonprofit, voluntary association of local governments, the region has a strong shared sense of its future. While DRCOG is a public agency, it is not a unit of government nor does it have statutory authority to require local governments to be members or to follow its plans. It does play several important roles, including serving as a regional planning commission under Colorado law and as the designated metropolitan planning organization (MPO) for the Denver region. This polycentric development case study was conducted by interviewing planners at the City and County of Denver, DRCOG and the Regional Transportation District (RTD). We asked planners to provide us with the supporting documents and tools to facilitate the growth of centers in Denver. We then combined the highlighted parts of the interviews with the reviewed official plans and policies. Table 10.1 represents the list of interviewed planners.

Table 10.1: The list of interviewed planners in Denver case study

\begin{tabular}{|c|c|c|c|}
\hline \multicolumn{2}{|c|}{ Organization } & $\begin{array}{c}\text { Number/Departments } \\
\text { of Interviewees }\end{array}$ & Reviewed documents \\
\hline MPO & $\begin{array}{l}\text { Denver Regional } \\
\text { Council of } \\
\text { Governments } \\
\text { (DRCOG) }\end{array}$ & $\begin{array}{l}\text { Two/ Regional Planning } \\
\text { and Development }\end{array}$ & $\begin{array}{l}\text { Metro Vision 2020, Metro Vision } 2035 \text { Growth and } \\
\text { Development Supplement, } 2040 \text { Metro Vision } \\
\text { Regional Transportation Plan, Community } \\
\text { Mobility Planning and Implementation Set-Aside } \\
\text { FY } 2020 \text { and FY 2021 Projects } \\
\text { Eligibility Rules and Selection Process }\end{array}$ \\
\hline $\begin{array}{l}\text { City of } \\
\text { Denver }\end{array}$ & $\begin{array}{l}\text { City and County of } \\
\text { Denver, } \\
\text { Community } \\
\text { Planning and } \\
\text { Development }\end{array}$ & $\begin{array}{l}\text { One/ Community } \\
\text { Planning and } \\
\text { Development }\end{array}$ & $\begin{array}{l}\text { Comprehensive Plan } 2040 \text { Denver's Plan for the } \\
\text { Future, Blueprint } \\
\text { Denver 2019, Denver Zoning Code 2019, Transit } \\
\text { Oriented Denver: Strategic Oriented Development } \\
\text { Strategic Plan } 2014\end{array}$ \\
\hline $\begin{array}{l}\text { Transit } \\
\text { Agency }\end{array}$ & $\begin{array}{l}\text { Regional } \\
\text { Transportation } \\
\text { District (RTD) }\end{array}$ & $\begin{array}{l}\text { One/ Community } \\
\text { Planning and } \\
\text { Development }\end{array}$ & $\begin{array}{l}\text { RTD Transit Oriented Development Design } \\
\text { Criteria 2012, First and Last Mile Strategic Plan } \\
\text { 2019, } 2018 \text { TOD Status Report }\end{array}$ \\
\hline
\end{tabular}




\subsection{TOOLS AND STRATEGIES OF THE DENVER REGIONAL COUNCIL OF GOVERNMENT}

\subsubsection{Introduction}

Growth management was a prevalent discussion amongst communities along the Colorado Front Range during the 1990s as the Denver region began to see significant growth, sprawling land use consumption and worsening air quality. Although Colorado did not pass any top-down state legislation mandating growth management, the Denver Regional Council of Governments (DRCOG) did orchestrate two key growth management documents that still frame the smart growth conversation in the Denver region today. The Mile High Compact is an intergovernmental agreement created in 2000 and now signed by 46 Denver-area communities that affirms the commitment to a shared regional vision. The binding agreement commits communities to adopt a comprehensive land use plan and use growth management tools such as zoning regulations, urban growth boundaries and development codes.

The first regional plan that articulated that shared vision was Metro Vision 2020, which focused on a two-pronged approach of managing the extent of urban development (through voluntary urban growth boundaries or areas) and intensification of existing urban areas (through growth in centers). The urban growth boundary/area (UGB/A) has been an important program in shaping growth and development in the region's longrange plans. The UGB/A reflects a bottom-up approach to growth management that starts with local governments and relies heavily on voluntary collaboration among communities. Urban centers are locally designated by communities and regionally recognized by DRCOG in Metro Vision with the intent to accommodate a significant share of new housing and job growth.

\subsubsection{Metro Vision and the Promotion of Urban Centers}

Since its initial adoption in 1997 Metro Vision has gone through multiple updates, most recently in 2017 with the DRCOG Board's unanimous adoption of Metro Vision 2040. This most recent plan shows a significant shift in the regional plan's overall approach to a more thematic approach that stresses outcomes opposed to previous plans' more rigid topic-based plan elements. The plan is organized through five unique themes, each tied to a set of outcomes and measures to track plan progress. The most relevant theme to this chapter's discussion is "An Efficient and Predictable Development Pattern." Centers are a key approach to achieving "an efficient and predictable development pattern," as one of the theme's outcomes is that "new urban development occurs in an orderly and a compact pattern within regionally designated growth areas" and another is that "connected urban centers and multimodal corridors throughout the region accommodate a growing share of the region's housing and employment." Figure 10.1 shows the location of these centers in Denver region. 
The context of Metro Vision 2040 includes continued strong regional population growth. The plan predicts growth in population of 1.3 million people from now to 2040 . That is a 40 percent increase resulting in a total population of around 4.3 million, with over 1 million over the age of 60 . The plan also expects employment growth from 1.8 million jobs to 2.6 million jobs by 2040. To accommodate this growth, Metro Vision provides a framework for how and where development should occur, aspiring that a significant amount of the region's growth occurs in centers. The plan targets centers to have 25 percent of all housing and 50 percent of all jobs by 2040 (total housing and jobs, not just new housing and jobs) which currently have about 12 percent of all housing and 35 percent of all jobs.

Metro Vision 2040 recognizes 105 locally identified centers across the region that vary in terms of size, context, and location. Many centers are located on existing or planned RTD rail lines. These centers are each in a different place of its development cycle ranging from centers that are only in planning stages, to emerging centers with significant development activity and existing centers that are largely built-out and serving its communities as a hub of activity and mobility. For example, Eastlake is a yet-to-be developed, but planned, urban center in Thornton that the North Metro rail line will begin serving in late 2020. The $38^{\text {th }}$ and Blake Station in Denver is an emerging urban center that is rapidly developing along the RTD A line that connects downtown Denver with Denver International Airport. Southglenn is an urban center in Centennial on the site of a former mall that is largely built out and provides a more walkable, urban environment that the city is working to connect to the lower-density housing in nearby neighborhoods. 


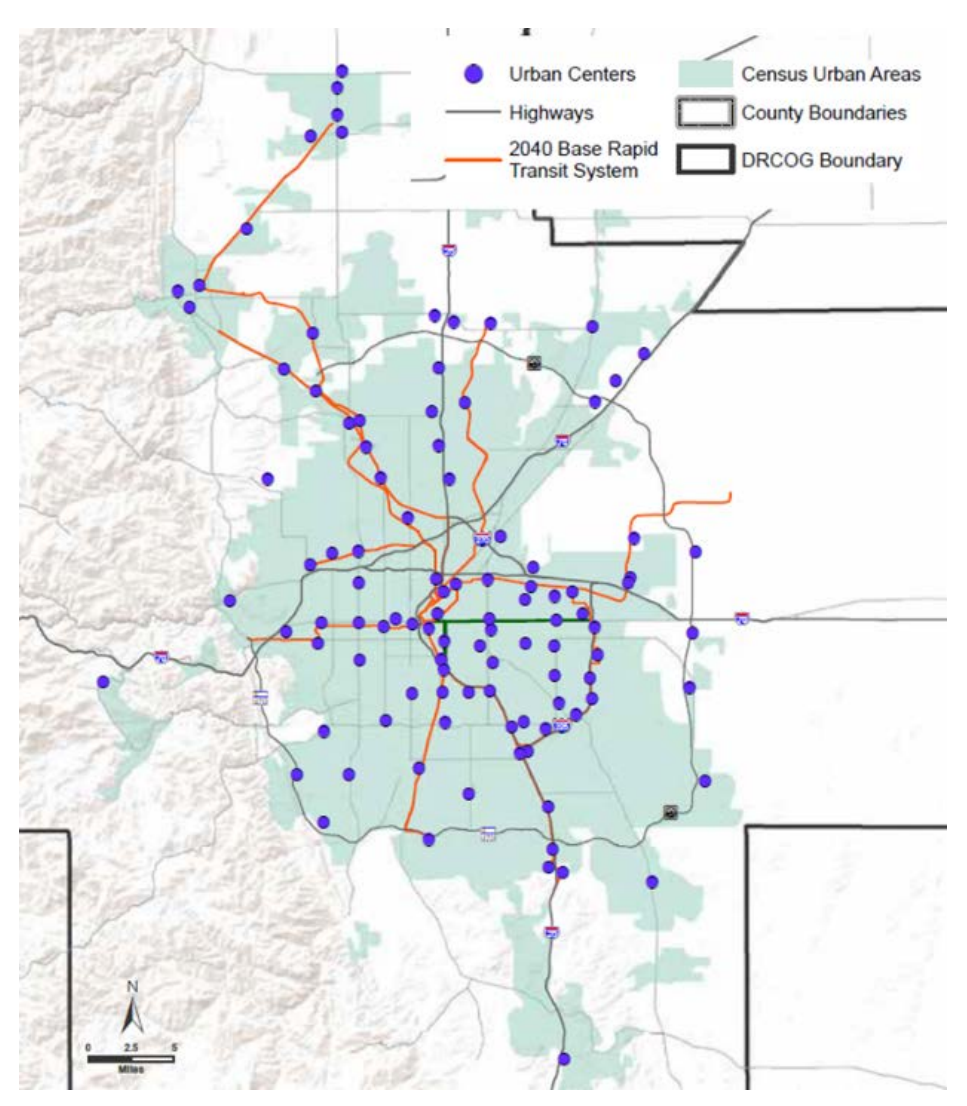

Figure 10.1: Urban Centers in the Denver Region

To achieve the Metro Vision's desired outcomes related to urban centers, the plan offers strategic implementation measures local jurisdictions can pursue, including:

- Seek opportunities for public/private partnerships to leverage resources and implement infrastructure improvements or other catalytic projects in urban centers.

- Adopt policies and development regulations that support higher-density, mixeduse development, pedestrian activity and accessible public spaces within urban centers.

\subsubsection{Metro Vision Mobility Initiatives}

A connected multimodal region is an overarching theme of Metro Vision 2040. The RTD FasTracks program serves as the backbone of the region's multimodal transportation system and is the impetus for many of the region's planned and emerging urban centers. After voters approved FasTracks in 2004, DRCOG supported station-area planning/urban center planning through Transportation Improvement Program (TIP) funding, specifically the Station Area Master Plan/Urban Centers set-aside, which funded many of the region's station areas and urban center planning since the late2000s. 
The Metro Vision 2040 plan suggests transportation system investment initiatives available for use by regional partners and local jurisdictions. This structure places DRCOG in a position of leadership and a critical funding partner with the regional partners and local jurisdictions responsible for delivering projects that expand mobility options that increase access to urban centers throughout the region. Example mobility initiatives include:

- Expand travel demand management services and strategies.

- Work with partners to expand the regional travel demand management program consisting of outreach, promotion, trip-planning and marketing activities to shift commute choices to non-single-occupant vehicle modes, including carpools, vanpools, transit, bicycling and walking, as well as telework and alternative work schedules. Continue and expand marketing consisting of advertising campaigns and events such as Bike to Work Day and Walk and Bike to School Day.

- Conduct activities to inform and promote the use of travel demand management strategies and services by transportation management associations/organizations and local travel demand management providers, such as ride-sharing, vanpools, carpools and school carpools.

- Improve the region's comprehensive transit system, including the timely completion of the FasTracks program.

- Adopt Transportation Improvement Program project selection policies that consider all transportation users.

- Coordinate with Denver Regional Mobility and Access Council and transit operators to increase transportation for vulnerable populations, such as older adults, people with disabilities and low-income populations.

- Implement parking supply and pricing mechanisms, such as shared, unbundled, managed and priced parking in locally defined activity centers to manage parking availability and provide incentives for walking, bicycling, carpooling and transit use.

- Fund first- and final-mile bicycle and pedestrian facilities and connections to transit such as sidewalks, bicycle facilities, bike-sharing, wayfinding, bicycle parking, shelters and car-sharing at transit stations.

- Expand mobility options within urban centers and other locally defined activity centers. 


\subsubsection{DRCOG Programs and Initiatives Supporting Polycentric Development}

To achieve the goals of Metro Vision, DRCOG has long-running programmatic, policy, and research efforts. Many of these endeavors support a polycentric development pattern across the region.

\subsubsection{FasTracks Commitment in Principle}

As part of its original 2004 FasTracks approval, DRCOG established a "commitment in principle" to direct $\$ 60$ million of Transportation Improvement Program (TIP) funding to FasTracks during the construction period. In the multiple TIP processes since then, DRCOG has honored its "commitment in principle." This DRCOG funding functions as a program of corridor-controlled set-asides (RTD FasTracks funded seven new rail corridors and extended others) with the intent to meet localized needs to support the buildout of a transit system. Funded projects assist jurisdictions in meeting Metro Vision goals that assist in achieving a polycentric development pattern.

\subsubsection{Metro Vision Idea Exchange}

Metro Vision Idea Exchanges allow land use and transportation planners, local government staff, the region's residents and other stakeholders to share information and ideas of importance to the Denver region. These forums identify areas of local and regional success worth continuing, as well as emerging and ongoing challenges that require action. DRCOG hosts four to six Idea Exchanges each year. Topics range from transportation accessibility and housing market trends to water planning and public health policy. These exchanges began in 2008 as a TOD Planners Idea Exchange to help local jurisdictions share knowledge about transit-oriented development and resolve key challenges as RTD was planning, designing and building the FasTrack corridors.

\subsubsection{Transportation Improvement Program Criteria}

Since FasTracks was approved in 2004, multiple DRCOG TIP cycles have rewarded projects that support centers development. The TIP scoring criteria contained a scored element related to the "implementation of Metro Vision and a strategic corridor focus," which provides points for projects that are related to Urban Centers and Rapid Transit Stations through the 2016-2021 cycle. With the change to a regional/sub-regional TIP for 2020-2023, projects being evaluated for the regional share were scored on how the project demonstrated consistency with and contributes to the transportation-focused Metro Vision objectives.

\subsubsection{Transportation Improvement Program Station Area and Urban Center Plan Funding}

Many station area and urban center plans have been funded specifically through the Station Area Master Plan/ Urban Centers (STAMP/UC) TIP set-aside. This pot of funding is intended to further implement the fiscally constrained rapid transit system at 
existing or future rapid transit station locations or further implement urban centers identified in the Metro Vision.

\subsubsection{Transit-Oriented Development Reporting}

DRCOG has been providing quantitative and qualitative data behind TOD development over the past two decades. The initial 2009 "Who is TOD in Metro Denver?" study, conducted by National Research Center Inc. on behalf of DRCOG, was the first original research in the region to benchmark people's attitudes, perceptions and behaviors related to transit. As FastTracks began to open new rail lines and higher-density development around rail stations became normalized in the region, the report was renamed "Perspectives on Transit in the Denver Region" but retained its goal to help local and regional stakeholders understand if, and how, the region's residents and businesses are increasing their orientation toward transit as it affects mobility, quality of life and economic opportunities. The report measures how preferences change over time related to how transit use and TOD affect the ability of the region to achieve targets established in Metro Vision.

\subsubsection{Regional Scenario Analysis}

DRCOG has been testing the regional benefits of a center-based growth strategy since the initial Metro Vision 2020 plan. By evaluating multiple growth scenarios that emphasize different approaches to directing growth throughout the Denver region, DRCOG has consistently shown the value of a polycentric development pattern that is connected by a robust multimodal transportation network. The most recent scenario analysis done for the 2050 regional transportation plan illustrates these findings. The "Centers + Transit" scenario consistently outperformed other scenarios, showing a 24 percent reduction in vehicle miles traveled, three times as many walk and bicycle trips and six times as many transit trips.

\subsection{TOOLS AND STRATEGIES OF THE REGIONAL TRANSPORTATION DISTRICT (RTD) TRANSIT AGENCY}

Metro Denver's transit agency, the Regional Transportation District (RTD) serves an eight-county area comparable in area to Delaware and in population to Utah. Paired with a deference to municipal support for station-area development, these density demographics introduce unique challenges and opportunities for promoting TOD, connecting communities with multimodal transit services, managing or contributing to local and regional planning studies, and redeveloping agency property for transitsupportive joint development.

It is important to frame RTD's authority relative to its partners. RTD's cousin in regional governance, the Denver Region Council of Governments (DRCOG), serves as the region's MPO, positioning it to leverage federal funding to support a number of transportation investments intended to achieve the agency's laudable goals for growth management and densification in defined urban centers. Municipal partners, most significantly the City and County of Denver dictate land-use regulations and tax 
incentives to encourage or require preferred development, including TOD, and control right-of-way. RTD operates within these partners' regimes: it manages or otherwise participates in DRCOG-funded, station-area master planning studies; it tailors service to benefit transit-supportive development patterns; and it travels on public streets.

Although RTD transit service benefits and encourages polycentric development, it does not dictate far-reaching TOD as regional and municipal partners do. However, without RTD service, TOD would not be a viable growth pattern in Metro Denver.

The following sections describe RTD's work to complement and evaluate partners' TOD initiatives.

\subsubsection{Capital Transit Improvements}

In 1994, RTD opened its first train line between Denver's Five Points neighborhood and the intersection of I-25 and Broadway, including 14 stations along 5.3 miles. The agency subsequently opened train lines southwest (2000, 5 stations, 8.7 miles), north central (2002, 4 stations, 1.8 miles), and southeast (2006, 11 stations, 19.1 miles).

In 2004, voters approved a $\$ 0.004$ sales tax to support FasTracks, the largest transit expansion program in the nation at that time, including 122 miles of light-rail and commuter-rail service and 18 miles of bus rapid transit (BRT) service on eight lines, 57 train and BRT stations, and 31 park-and-ride facilities with 21,000 parking spaces (Figure 10.2). FasTracks prompted capital transit improvements throughout the region for approximately 15 years; RTD will open its final funded service in September 2020. 


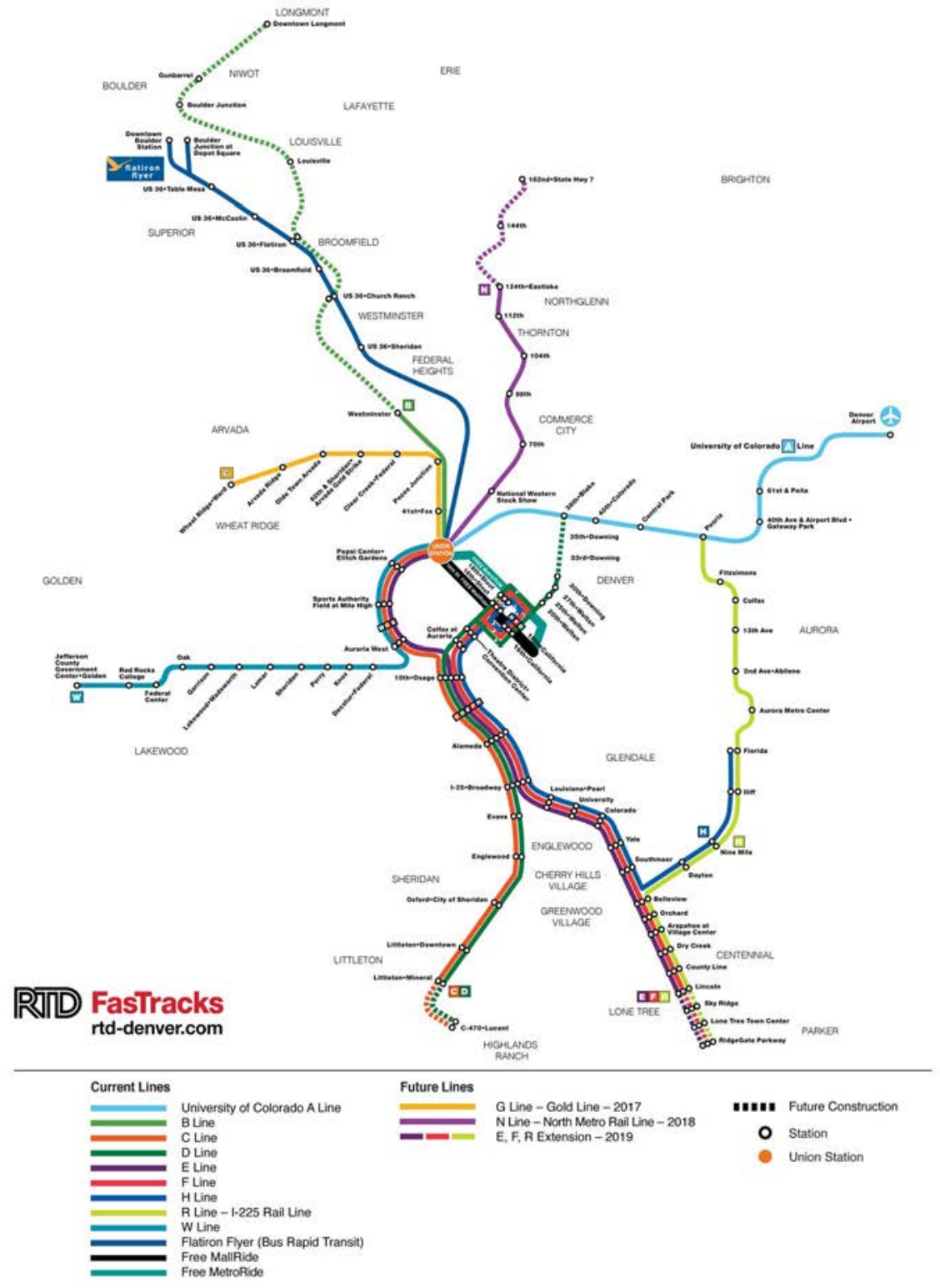

Figure 10.2: Map of Funded and Planned FasTracks Projects, Source: FasTracks

With funded portions of FasTracks complete, RTD's attention has turned to partnering with municipalities to construct first- and last-mile improvements to make existing transit stations more accessible to multimodal passengers. Completed in 2019, RTD's Firstand Last-Mile Strategic Plan identified five typologies, categorized six overlays, and recommended six strategies for municipal partners to adapt to local contexts (see Figure 10.3). 


\begin{tabular}{|c|c|c|c|c|c|}
\hline & $\begin{array}{l}\text { Reuse of Existing } \\
\text { Infrastructure }\end{array}$ & $\begin{array}{l}\text { New } \\
\text { Infrastructure }\end{array}$ & $\begin{array}{l}\text { FLM General } \\
\text { Guidance }\end{array}$ & TDM & $\begin{array}{l}\text { Transportation } \\
\text { Service }\end{array}$ \\
\hline Description & $\begin{array}{l}\text { Improvements to, } \\
\text { or leverage of, } \\
\text { existing assets to } \\
\text { increase transit } \\
\text { access }\end{array}$ & $\begin{array}{l}\text { Construction of } \\
\text { new infrastructure } \\
\text { (at stations/stops) }\end{array}$ & $\begin{array}{l}\text { Guidance on } \\
\text { infrastructure types } \\
\text { that improve FLM } \\
\text { access }\end{array}$ & $\begin{array}{l}\text { Programs that } \\
\text { incentivize transit } \\
\text { use or encourage } \\
\text { walking or biking }\end{array}$ & $\begin{array}{l}\text { Services that } \\
\text { complement } \\
\text { traditional transit }\end{array}$ \\
\hline $\begin{array}{l}\text { Strategy } \\
\text { Examples }\end{array}$ & $\begin{array}{l}\text { - Curbside } \\
\text { management } \\
\text { - Car share } \\
\text { parking } \\
\text { - Charging } \\
\text { stations }\end{array}$ & $\begin{array}{l}\text { - Bike and } \\
\text { micromobility } \\
\text { parking } \\
\text { - Bike repair } \\
\text { stations } \\
\text { - Wayfinding }\end{array}$ & $\begin{array}{l}\text { - Bicycle and } \\
\text { micromobility } \\
\text { infrastructure } \\
\text { improvements } \\
\text { - Pedestrian- } \\
\text { scaled lighting }\end{array}$ & $\begin{array}{l}\text { - Transit pass } \\
\text { promotion } \\
\text { - Bike commuter } \\
\text { education } \\
\text { - Dynamic } \\
\text { carpooling to } \\
\text { transit } \\
\end{array}$ & $\begin{array}{l}\text { - Shuttle services } \\
\text { - Micromobility } \\
\text { services } \\
\text { - Car share }\end{array}$ \\
\hline $\begin{array}{l}\text { Most } \\
\text { Applicable to... }\end{array}$ & $\begin{array}{l}\text { - Urban Core } \\
\text { - Urban } \\
\text { - Suburban-Mixed }\end{array}$ & $\begin{array}{l}\text { - Urban Core } \\
\text { - Urban } \\
\text { - Suburban-Mixed }\end{array}$ & $\begin{array}{l}\text { - Urban Core } \\
\text { - Urban } \\
\text { - Suburban-Mixed } \\
\text { - Suburban- } \\
\text { Residential }\end{array}$ & - Suburban-Mixed & $\begin{array}{l}\text { - Urban } \\
\text { - Suburban-Mixed } \\
\text { - Suburban- } \\
\text { Residential }\end{array}$ \\
\hline $\begin{array}{l}\text { Implementing } \\
\text { Agencies }\end{array}$ & $\begin{array}{l}\text { RTD, local } \\
\text { governments, } \\
\text { partnership with } \\
\text { other agencies }\end{array}$ & $\begin{array}{l}\text { RTD, in partnership } \\
\text { with other } \\
\text { agencies }\end{array}$ & $\begin{array}{l}\text { Local } \\
\text { governments, } \\
\text { developers, and } \\
\text { businesses }\end{array}$ & $\begin{array}{l}\text { TMAs, local } \\
\text { agencies, and } \\
\text { employers }\end{array}$ & $\begin{array}{l}\text { RTD, local } \\
\text { governments, and } \\
\text { private companies }\end{array}$ \\
\hline
\end{tabular}

Figure 10.3: First- and Last-Mile Strategies, Source: RTD First and Last Mile Strategic Plan

Recognizing the need to expand service on a limited budget, in 2019 RTD completed a preliminary study of prospective BRT corridors across the region, based in part on residential and employment densities as a proxy for potential ridership. The Regional BRT Network Feasibility Study ultimately recommended 21 corridors for further evaluation (see Figure 10.4). 


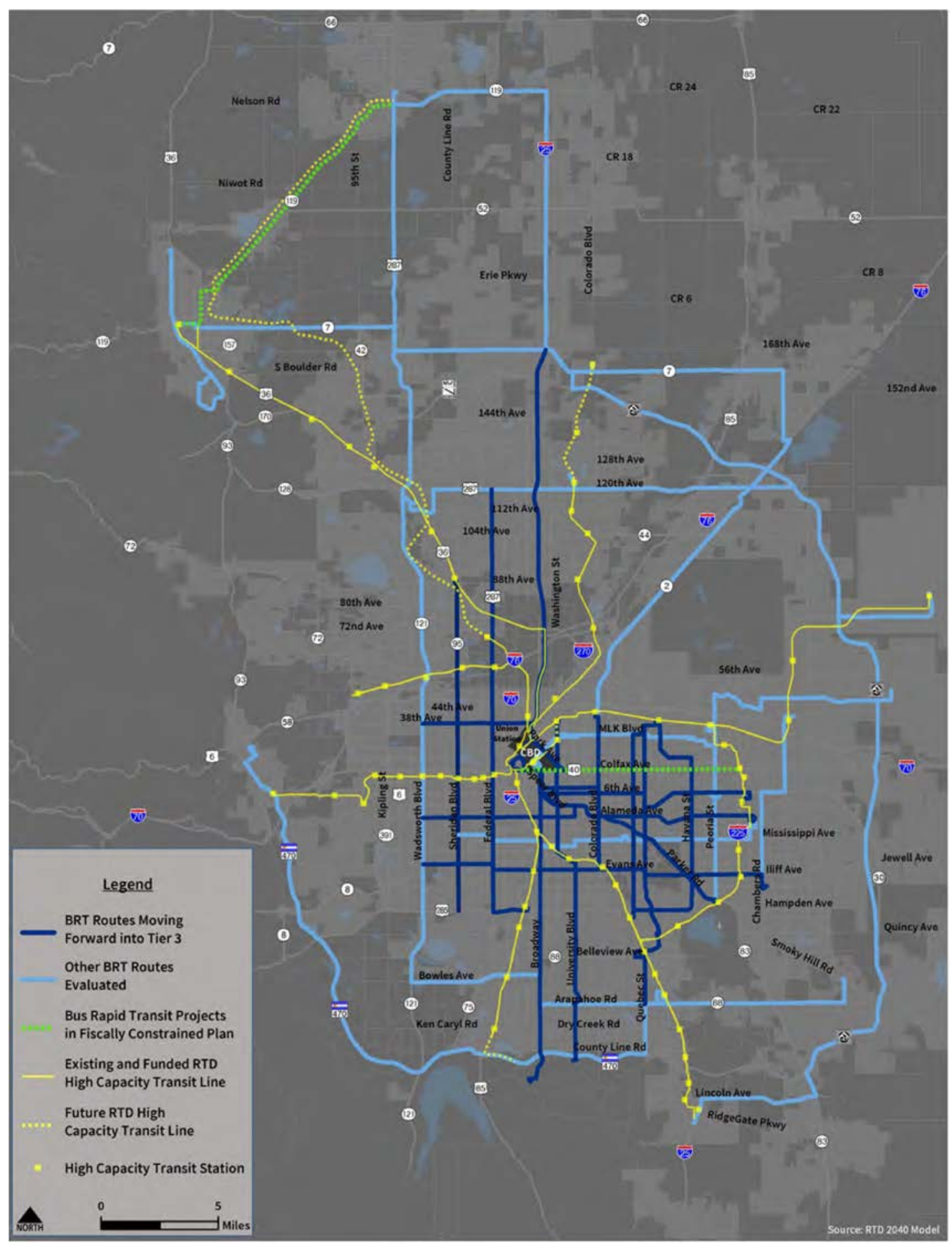

Figure 10.4: Proposed Regional BRT Network (Implemented By 2040), Source: RTD Regional BRT Network Feasibility Study 


\subsubsection{TOD Planning and Evaluation}

Although RTD defers to municipal authority to dictate development, the transit agency has documented its preference for and the benefits of TOD as a signal to municipal and regional partners across the region for a decade. Recently, RTD has evaluated the impact of municipal and regional planning on tangible development in several station areas. This section details those plans and evaluations.

Since voters approved FasTracks in 2004, RTD has partnered with DRCOG to inform TOD planning through selection of and participation on station-area master planning (STAMP) projects. RTD advises DRCOG's selection of STAMP applicants and then, as a direct recipient of federal transportation funding, works with award sub-recipients in an administrative function to ensure compliance with federal regulations and on project management teams to inform planning outcomes. Since 2007, RTD has participated in more than 80 STAMPs across Metro Denver.

First published in 2006 and most recently updated in 2010, the FasTracks Strategic Plan for Transit-Oriented Development outlines RTD's roles and responsibilities in promoting TOD in partnership with local government, private developers, and state and regional stakeholders, including DRCOG (Figure 10.5). The document positions RTD as a partner to private and municipal interests in TOD and its subset joint development, inviting but not necessarily initiating redevelopment of park-and-ride facilities and deferring development programming to others as markets and/or regulations dictate.

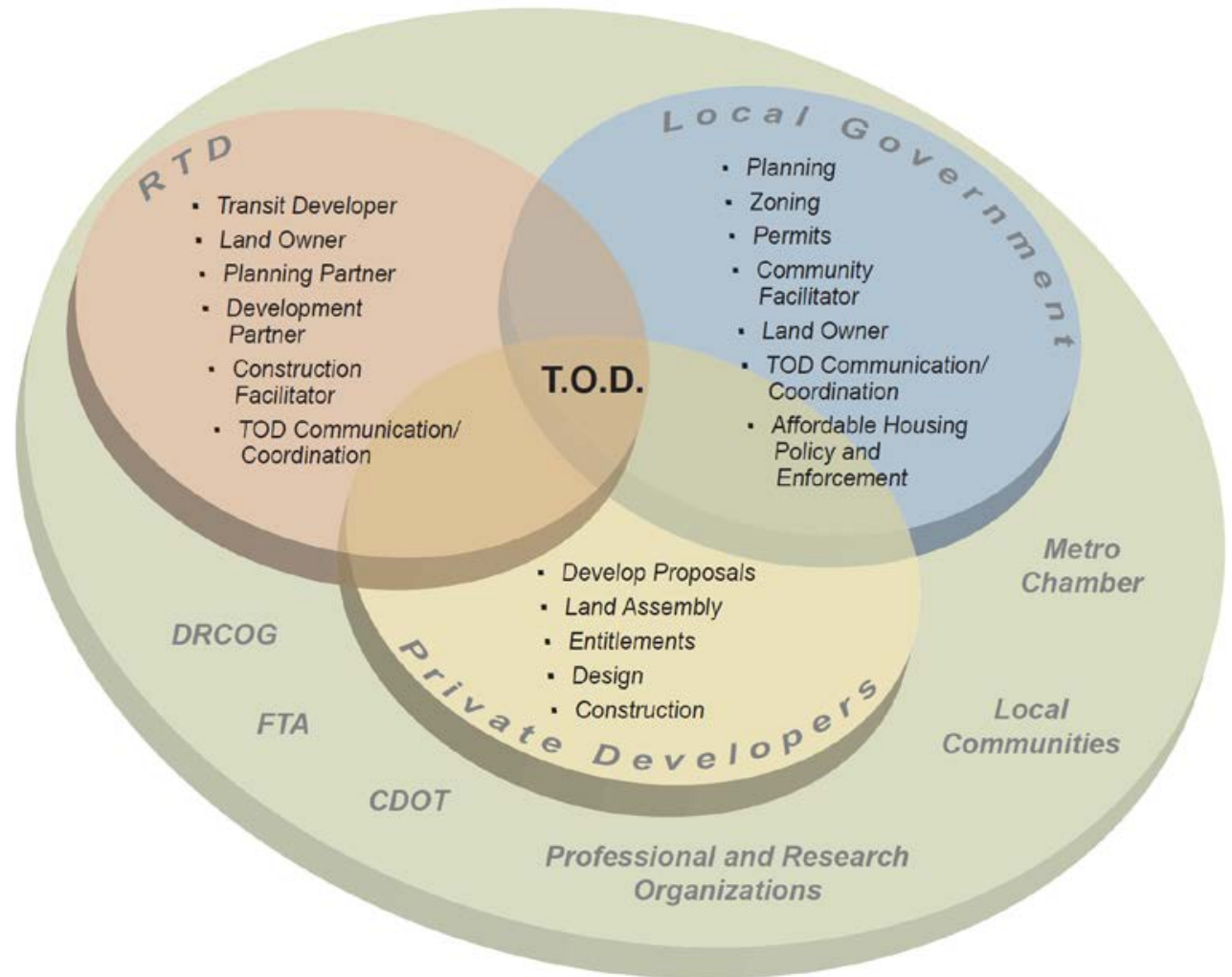

Figure 10.5: Roles in the TOD Process, Source: RTD FasTracks Strategic Plan for TOD 
Having set guidelines for RTD's involvement in TOD, in 2011 RTD prioritized four station areas for piloting TOD principles, including coordination with local government and private developers, and advanced residential development at two Denver station areas on opposite ends of the agency's first transit line and at a third station area in a northwestern suburb, where train service started in 2019. Together, these projects ultimately will create 661 homes.

The 2012 TOD Design Criteria soon followed the pilot designations in order to define and memorialize key TOD concepts, principles, standards, and guidelines that distinguish effective station-area development. The document's eight principles advise;

1. Organize \& Orient the TOD Site Based on the Transit Station Configuration;

2. Design for Compact and Mixed-Use Development;

3. Create a High-Quality Pedestrian-Oriented Environment;

4. Utilize the Street Grid to Connect and Provide Access;

5. Strategically Manage Parking;

6. Support Jurisdictional Policies for Mixed-Income Housing;

7. Demonstrate Successful TOD at all Development Phases; and

8. Exhibit Jurisdictional Support and Partnerships.

Metro Denver rebounded from the Great Recession with renewed interest in developing around an increasingly expansive transit system, and RTD responded by establishing and later clarifying a procedure for evaluating unsolicited proposals for joint development. (RTD typically does not solicit proposals, instead preferring to respond to external inquiries.) The 2018 TOD Evaluation Guidelines document outlines six requisite value principles that protect and promote the agency's financial interests, capital assets, and commitments to safety and municipal partnership before noting criteria against which the agency will evaluate development proposals (see Figure 10.6).

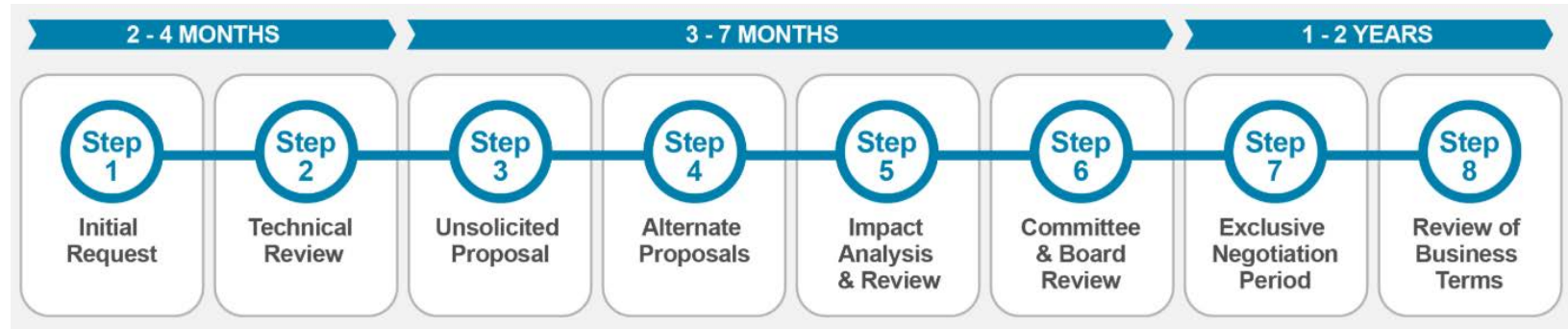

Figure 10.6: Unsolicited Proposal Timeline, Source: RTD Unsolicited Proposal Procedure for Joint Development

RTD's long-standing effort to promote TOD across Metro Denver has delivered significant results. According to the 2019 RTD TOD Status Report, which evaluates large-scale commercial and residential projects built in Metro Denver since 2005, 25 percent of the region's multi-family development and 31 percent of the region's office development (excluding intensive growth in downtown Denver and downtown Boulder) has located in only 0.6 percent of the region - the area within a 10-minute walk of a BRT or train station. The report shows that 2019 accounted for the most multifamily 
deliveries ever in the region. RTD is encouraged that its extensive and expansive FasTracks investment in regional transit is leveraging unprecedented TOD (see Figure 10.7).

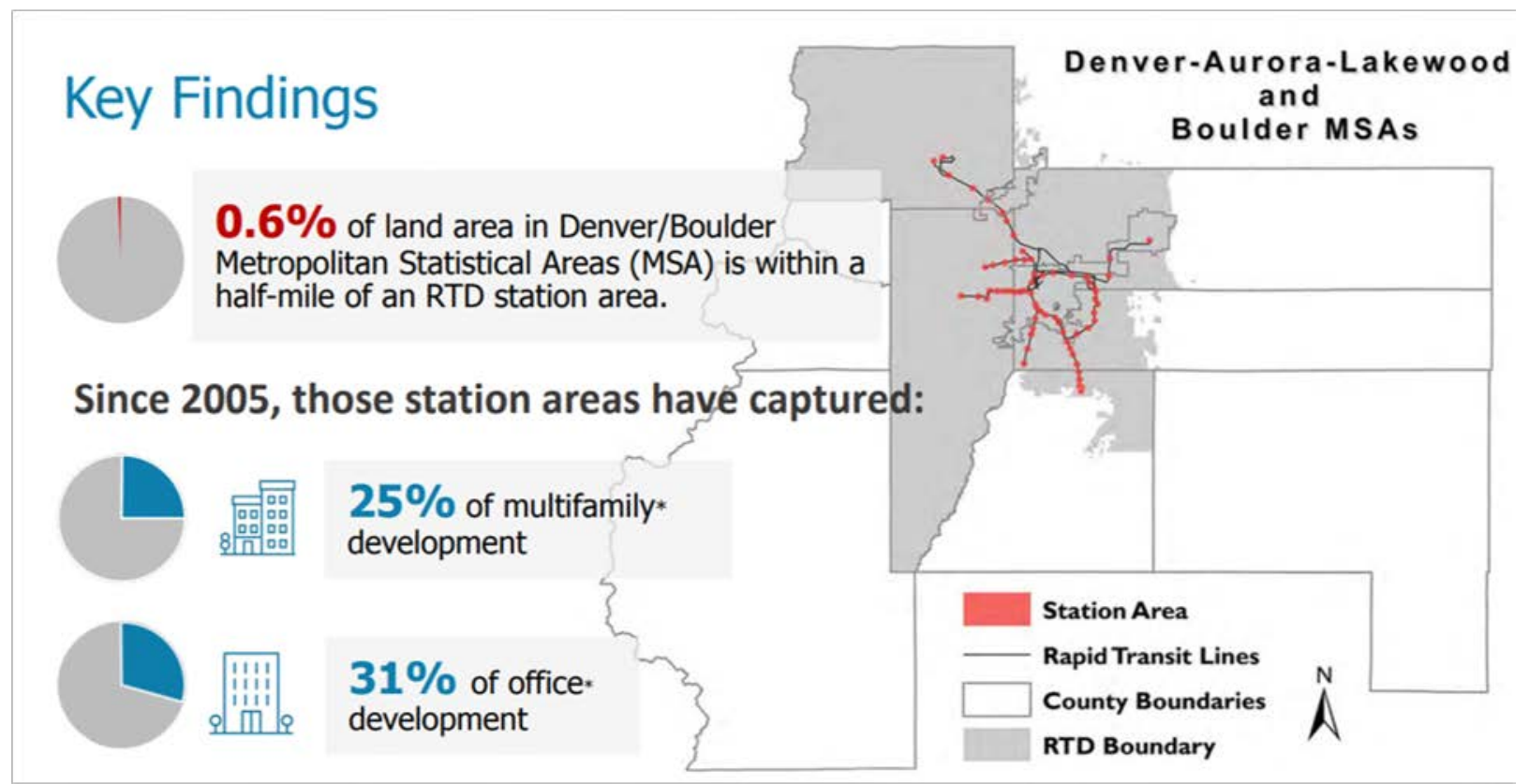

Figure 10.7: 2019 TOD Status Report Key Findings, Source: RTD TOD Status Report

\subsubsection{Future RTD TOD Policies}

Over the past few years, RTD has studied TOD resident demographics, transit use, and parking demand in order to inform not only agency policy for joint development but also municipal regulations and developer objectives to promote transit-supportive development.

The 2017 and 2018 TOD Resident Ridership Survey received 1,340 responses from residents of multifamily apartments within a 10-minute walk of a BRT and train station and found that residents of income-restricted apartments use transit significantly more than affluent neighbors. Among households in income-restricted apartments, 63 percent ride the bus and 57 percent ride the train once a week or more; among households in market-rate apartments, 88 percent ride the bus and 73 percent ride the train once a week or less.

In 2020, RTD surveyed managers of approximately 100 multifamily apartment buildings within a 10-minute walk of a BRT or train station about property characteristics and transportation policy, including parking availability and alternative-transportation programming. In addition, RTD counted peak-demand parking utilization at these properties to assess right-sized parking supply at residential TODs. Taken together, the Residential Property Parking Survey \& Count found only 60 percent utilization across all properties, with higher utilization at market-rate properties and lower utilization at mixedincome and income-restricted properties. This suggests that multifamily apartment 
buildings in transit-rich neighborhoods could include significantly less parking, thus reducing development cost, housing cost, and residents' cost of living.

Findings from the TOD Resident Ridership Survey and Residential Property Parking Survey \& Count serve to suggest that ridership and attendant farebox revenue would increase if RTD and municipal partners encouraged or required affordable housing in station areas. To that end, the City and County of Denver adopted an inclusionary zoning overlay district around the $38^{\text {th }}$ \& Blake Station designed to exchange additional density for affordable housing and/or enhanced project design. In addition, similar to peer agencies on the West Coast and elsewhere, RTD is advancing a policy for equitable TOD that would encourage or require affordable housing in residential jointdevelopment transactions and hopes to approve a policy in December 2020.

\subsection{TOOLS AND STRATEGIES OF THE CITY OF DENVER}

\subsubsection{Comprehensive Plan 2040 and Blueprint Denver}

The City and County of Denver's "Comprehensive Plan 2040" and its land use and transportation component, "Blueprint Denver," is the fundamental document guiding and identifying the city's vision. The plans were approved by the Denver City Council in April 2019 and provide a holistic and sustainable vision to guide the future of Denver in the next 20 years. The comprehensive plan emphasizes creating a more inclusive, connected and healthier Mile High City through the realization of its six vision elements developed with extensive community input. Blueprint Denver, as a supplement to Comprehensive Plan 2040, is a citywide land use and transportation plan for the next 20 years. It calls for an equitable city of complete neighborhoods connected by a complete multimodal transportation network and strategic growth management by directing new jobs and housing to key centers and corridors. For the first time in a citywide land-use plan, Blueprint Denver accounts for socioeconomic factors like vulnerability to displacement - allowing Denver to tailor programs and policies to the needs of each neighborhood.

Both plans were part of Denveright, a larger citywide planning effort, that included an update to the city's parks and recreation master plan and two new modal plans for transit and pedestrians. This coordinated, multidepartment effort was unprecedented for Denver and had over 25,000 touchpoints with the public. This collaborative approach resulted in a suite of plans that work together to establish both the city's highlevel vision and programmatic implementation.

\subsubsection{Role of Centers in Visions, Goals, and Strategies}

Together, Comprehensive Plan 2040 and Blueprint Denver express the City's approach to the strategic and intentional development of regional and community centers to manage expected growth while having more Denverites live in neighborhoods with convenient, equitable access to jobs, housing, recreation, education and retail opportunities. 


\subsubsection{Comprehensive Plan 2040}

Denver's Comprehensive Plan 2040 works as the overarching plan that other citywide plans are nested under. The plan's policies are organized by six vision elements and a "Denver and the Region" chapter (see Figure 10.8). At just 75 pages, the plan provides only high-level policy recommendations that create the framework for these other plans to provide greater detail on specific subjects including economic development, housing, climate, land use and transportation. Thus, Comprehensive Plan 2040 only touches on the City's growth strategy and leaves more detailed policies to Blueprint Denver.

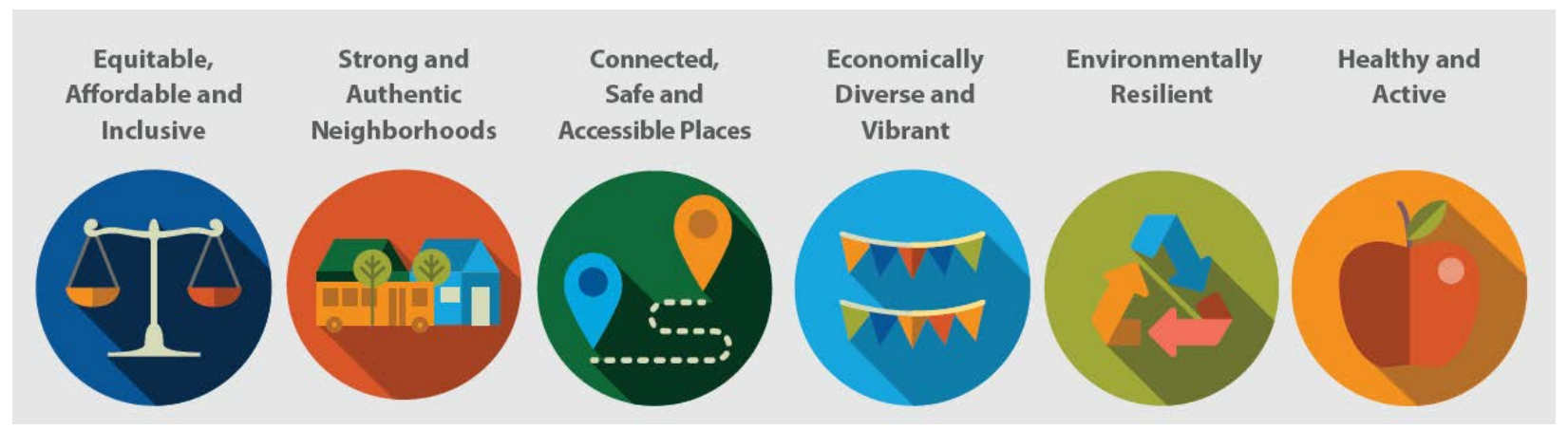

Figure 10.8: Comprehensive Plan 2040 Vision Elements

Comprehensive Plan polices that address the role of centers include:

\section{Equitable, Affordable and Inclusive Vision Element}

Goal 1: Ensure all Denver residents have safe, convenient and affordable access to basic services and a variety of amenities.

Strategy A: Increase development of housing units close to transit and mixed-use developments.

This strategy calls for increasing density in mixed-use areas (expressed in Blueprint Denver as centers and corridors) with close proximity to high-quality, high-frequency transit options to ensure all Denver residents have safe, convenient and affordable access to basic services and a variety of amenities.

\section{Strong and Connected Neighborhoods Vision Element}

Goal 1: Create a city of complete neighborhoods.

Strategy A. Build a network of well-connected, vibrant, mixed-use centers and corridors. 
This goal and strategy speak to how mixed-use centers with multimodal connections play an important role in strengthening Denver's neighborhoods.

\section{Connected, Safe and Accessible Places Vision Element}

Goal 8: Strengthen multimodal connections in mixed-use centers and focus growth near transit.

Strategy A. Improve multimodal connections within and between mixeduse centers including downtown, Denver International Airport and major urban centers.

Strategy B. Promote transit-oriented development and encourage higherdensity development, including affordable housing, near transit to support ridership.

This goal and accompanying strategies establish the desire to increase the multimodal connectivity and development density in the city's mixed-use centers and transit-oriented developments.

\section{Denver and the Region Chapter}

Goal 1: Be a regional leader in smart growth.

Strategy B. Monitor increases in population and employment annually to ensure Blueprint Denver has appropriate policies and strategies to manage expected future growth.

Strategy C. Develop a strategic implementation plan and program for regional centers and other key growth areas in Denver.

Goal 2: Embrace Denver's role as the center of regional growth.

Strategy A. Direct significant growth to regional centers and community centers and corridors with strong transit connections.

Strategy B. Establish growth targets for specific regional centers to help the region achieve its goals for directing growth to designated urban centers.

Strategy C. Add a significant amount of jobs and housing in downtown.

The Denver and the Region chapter of Comprehensive Plan 2040 provides the most specifics about the city's approach to developing centers as a key part of its growth strategy. These strategies not only establish policies to direct growth to regional centers and corridors, but also to development implementation efforts, establish specific growth targets for centers and continually measure the success of these policies in managing growth. 
Comprehensive Plan 2040 does tie metrics to each vision element in order to track the success of the plan's policies. Several metrics directly relate to monitoring the implementation of a polycentric land use pattern and connecting the city's centers through multiple modes other than single-occupancy vehicles.

Notable metrics include:

Reduce the Amount of Cost-burdened households: This metric uses the nationally recognized Housing + Transportation Index to measure the percentage of Denver households spending 45 percent or more on housing and transportation costs.

Increase the number of neighborhoods with convenient access to transit, jobs and retail: This metric measures the number of neighborhoods where at least 50 percent of households have access to quality transit, jobs and retail in walking and rolling distance. Denver's strategy to direct most jobs and housing to high-growth areas such as regional centers will directly impact its ability to meet this metric goal.

Reduce dependence on driving alone: This metric measures the percentage of Denver commuters who drive to work in single-occupancy vehicles (SOV). To achieve the goal of 50 percent of SOV use by 2030, Denver will both need to direct growth to high-density centers and built-out transit, bike and pedestrian infrastructure to support utilization of these modes.

\subsubsection{Blueprint Denver}

\section{Growth Strategy Approach}

As Denver's land use and transportation vision, Blueprint Denver takes the high-level policies established in Comprehensive Plan 2040 and establishes a detailed 20-year growth strategy. The original Blueprint Denver plan, adopted in 2002, took a binary approach to growth management, directing growth to "Areas of Change" and preserving the existing character of neighborhoods by designating them as "Areas of Stability." The new Blueprint Denver has evolved the growth strategy into a more nuanced, placebased approach using the plan's future places map, which illustrates how the city and neighborhoods are comprised of various types of centers, corridors, residential areas and districts (see Figures 10.9-10.11). The plan has future place descriptions that lay out the expectations for any specific location of the city in terms of land use, built form, mobility and quality-of-life infrastructure (green infrastructure, parks, open space, etc). Three different scales of centers are described and illustrated in the plan: regional centers, community centers and local centers. The plan then provides more detailed descriptions of these centers, including expected building height ranges and intensity of uses in the plan's neighborhood context chapter. This hierarchy of neighborhood contexts and future place types provides the policy basis for rezoning recommendations. 


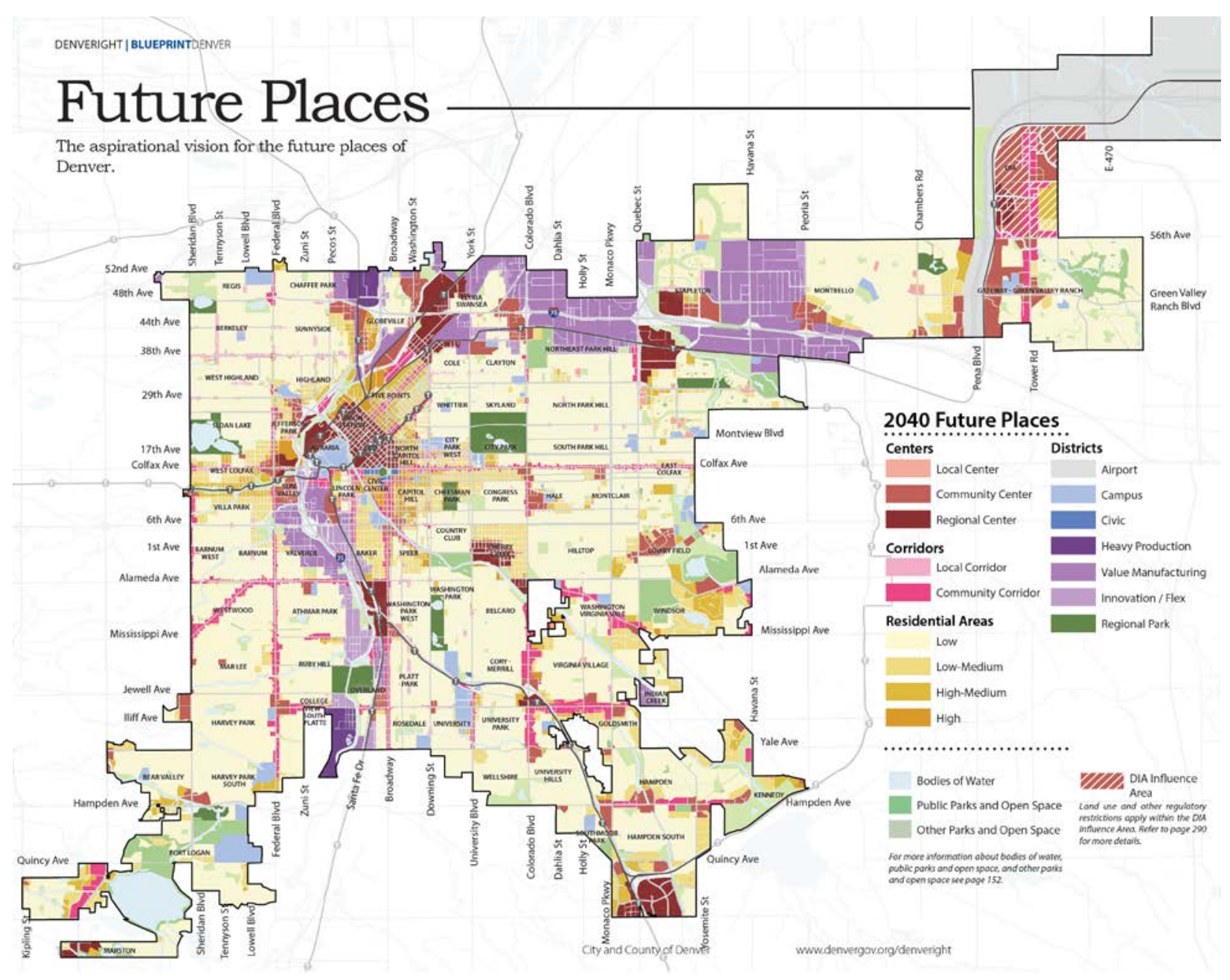

Figure 10.9: Denver's Vision for Future Places, Source: Blueprint Denver, 2019 


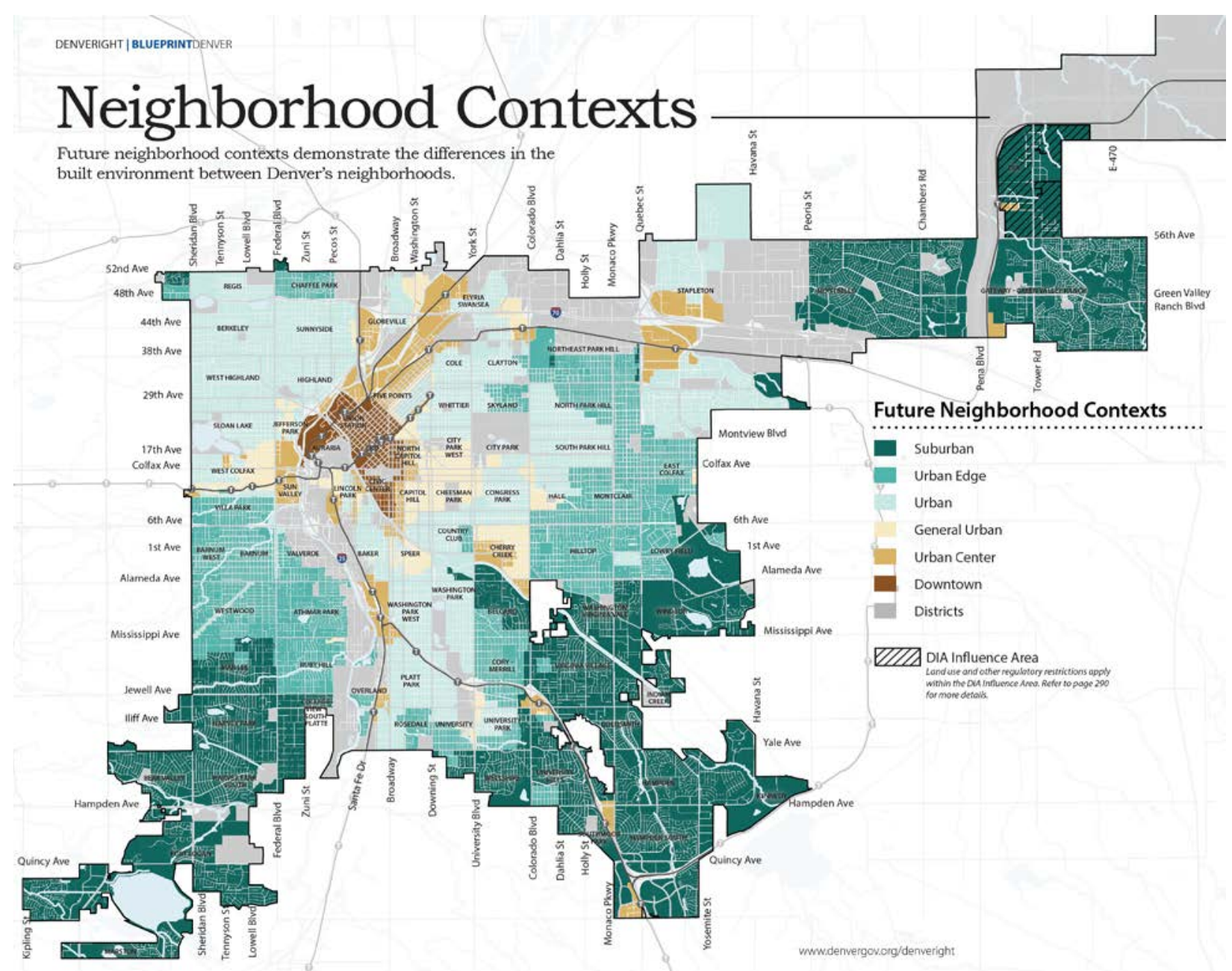

Figure 10.10: Denver's Neighborhood Contexts, Source: Blueprint Denver, 2019

The core of the growth strategy approach is to guide much of the city's new housing and employment to vibrant, mixed-use regional centers and community centers that have significant infill redevelopment sites. Many of these centers are rail station areas in RTD's transit system, but others are smaller to mid-sized centers located along future transit capital investment corridors identified in Denver Moves: Transit and will require coordinated transit supportive development. The placed-based growth strategy approach frames how the development of mixed-use, transit-rich centers throughout the city helps to achieve citywide equity goals, increases access to opportunities and serves as a benefit to all residents. 


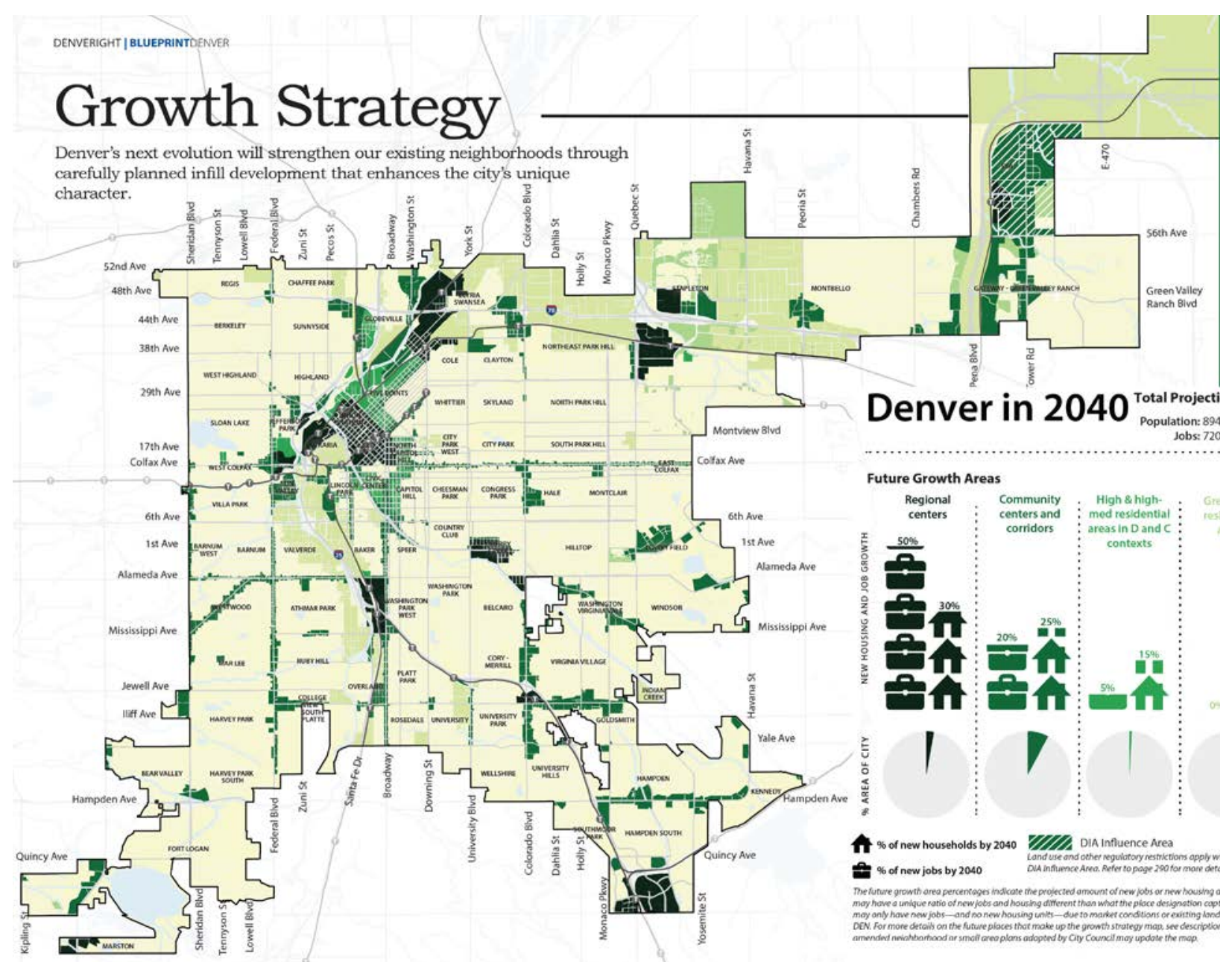

Figure 10.11: Denver's Growth Strategy, Source: Blueprint Denver, 2019

Denver illustrates its polycentric development approach through its growth strategy map that highlights the strategic and intentional direction of growth to key centers, corridors, and high-density residential areas by improving access to transportation options to achieve citywide equity goals. The map is paired with a detailed legend that associates specific job and housing targets to the various growth areas. For example, 50 percent of all new jobs and 30 percent of all new housing is expected to occur in Denver's regional centers.

Focusing growth in centers and corridors helps to provide a variety of housing, jobs, and entertainment options within a comfortable walking distance to all Denverites and is a crucial element of building complete neighborhoods throughout Denver. Blueprint Denver provides a nuanced way to handle growth and development, maintaining the most cherished characteristics while directing growth to key centers, corridors, and high-density residential areas with robust transportation options to help the city achieve its vision and goals. 
Blueprint Denver polices that address the role of centers include:

\section{Land Use and Built Form - General}

Policy 1: Promote and anticipate planned growth in major centers and corridors and key residential areas connected by rail service and transit-priority streets.

Strategy B: Implement regulatory land use changes in coordination with transit investments. For example, rezonings to support transit-oriented development should be closely timed with the implementation of transit priority streets.

Strategy D: Develop a citywide strategic plan to address implementation needs, including infrastructure investments, in regional and/or community centers.

Policy 2: Incentivize or require efficient development of land, especially in transitrich areas.

Strategy A: In regional centers, urban center community centers and urban center community corridors, study and implement requirements or incentives for density. An example of a tool to implement this could include establishing minimum building heights.

Blueprint Denver not only promotes density in centers, but explicitly directs the city to focus on the rezoning, infrastructure investments and incentives needed to achieve greater densities in transit-rich areas. These policies and strategies seek to expand on already successful incentive-based tools that have been piloted in recent years, such as incentive overlay zoning districts that allow greater density in exchange for a greater commitment to affordable housing at the $38^{\text {th }}$ and Blake station area (See Denver Zoning Code Section 9.4.6)

\section{Land Use and Built Form - Housing}

Policy 8: Capture 80 percent of new housing growth in regional centers, community centers and corridors, high-intensity residential areas, greenfield residential areas, innovation flex districts and university campus districts.

Strategy A: Align high-density residential areas near regional centers to support housing growth near major job centers with access to transit priority streets.

Strategy C: Ensure land use regulations, small area plans and major transit investments support desired growth areas.

Blueprint Denver has a specific growth goal to direct 80 percent of new housing to high-growth areas, with a significant amount of the 90,000 expected new units located in regional centers (27,000 units) and community centers and corridors 
$(22,500)$. To direct the growth into these areas, the plan looks to expand the footprint of regional centers by placing high-density residential areas adjacent to major job centers and align land use regulations with major transit investments that would promote a walkable, mixed-use environment that reduces singleoccupancy vehicle trips.

\section{Land Use and Built Form - Economics}

Policy 1: Capture 90 percent of job growth in regional centers, community centers and corridors, certain districts and high-intensity residential areas in downtown and urban center contexts. Of the 90 percent job growth, focus 30 percent downtown.

Strategy A: Encourage and preserve opportunity for office development within regional centers by allowing high-density employment. Study and implement requirements and/or incentives for high-density development in regional centers including vacant and underutilized land in downtown.

Strategy B: Promote the development and redevelopment of regional centers, including downtown, to meet the land use and transportation needs of targeted industries. This means encouraging regional centers to have strong connections to transportation options, especially passenger rail and transit priority streets, and fostering the mix of uses needed to attract businesses with a wide variety of jobs.

Policy 2: Improve equitable access to employment areas throughout the city to ensure all residents can connect to employment opportunities.

Strategy A: Invest in transit-priority streets to connect all Denver residents to the city's regional, community centers and community corridors.

Strategy B: Promote and incentivize the development of affordable and family-friendly housing, as well as a full range of job opportunities, in and near regional centers, community centers and community corridors.

Similar to the housing policies, Blueprint Denver's economic policies place a target of capturing 90 percent of all jobs in high-growth areas, including 50 percent of jobs $(68,000)$ in regional centers and 20 percent of jobs $(27,200)$ in community centers and corridors. The plan outlines strategies that incentivize high-density development to preserve the opportunity for office development (as opposed to allowing too much residential use in centers resulting in lower internal trip capture). These policies also acknowledge the need to plan for equitable access to these high-density employment areas so all Denverites benefit from having multiple centers across the city. 


\section{Land Use and Built Form - Design Quality and Preservation}

Policy 3: Create exceptional design outcomes in key centers and corridors.

Strategy A: In high-profile areas of the city where a large share of growth is expected, such as downtown and regional centers, use a tool such as area-specific design standards and guidelines to be administered by a design review board.

Strategy B: In other centers and corridors citywide, especially those that anticipate significant growth, study and implement a design review process guided by design standards and guidelines. This could include administrative design review by city staff with the potential for projects of a certain threshold or type to be reviewed by a board.

Policy 4: Ensure an active and pedestrian-friendly environment that provides a true mixed-use character in centers and corridors.

Strategy B: Study and implement stronger street-level active use requirements for community and regional centers and community corridors. Tools could include regulations on floor-to-floor heights for the first story to facilitate conversion to commercial uses and reconsideration of appropriate street-level uses.

The plan acknowledges that directing growth to existing and future centers is not enough to achieve Blueprint Denver's inclusive vision. Denver has multiple design tools already in place, especially in key existing centers such as downtown Denver and Cherry Creek. The plan calls for expanding the design tools to ensure a high-quality pedestrian realm in centers and use administrative design review or a design review board to guide development in centers.

\section{Mobility}

Policy 1: Encourage mode shift - more trips by walking and rolling, biking and transit - through efficient land use and infrastructure improvements.

Strategy A: Implement the bicycle, pedestrian and transit networks in Denver Moves plans.

Strategy B: Improve multimodal access to downtown by implementing updates to the downtown multimodal access study (Denver Moves: Downtown).

Blueprint Denver provides the adopted policy direction on transportation issues due to the city's modal plans, known as the "Denver Moves" plans, not being adopted by City Council. The Denveright coordination effort enabled the cross- 
pollination of plan policies and carries the weight of adoption from City Council. Blueprint Denver's mobility policies set the groundwork for key implementation efforts by the Department of Transportation and Infrastructure to continue the shift to more bicycle and pedestrian trips to and from the city's multiple centers.

Policy 2: Align the impacts of private development with transportation infrastructure and promote development that creates walkable, transit-friendly communities.

Strategy C: For centers and corridors downtown and in the urban center contexts, where access to transit is high, study and implement maximums for off-street parking in private development to encourage the use of alternative modes of transportation.

Denver zoning regulations already limit surface parking near rail stations in certain contexts through parking maximums (see Denver Zoning Code Section 10.4.4.4). Blueprint Denver directs staff to evaluate expanding the limit on parking to all off-street parking in downtown and the urban center context, a common zoning context for rail stations and regional centers.

Policy 3: On all streets, prioritize people walking and rolling over other modes of transportation.

Strategy B: Develop access management policies — especially in centers and corridors in the downtown, urban center and general urban contexts

- to reduce conflicts between driveways/garages and pedestrians and cyclists.

Strategy C: Ensure that café seating in the public right-of-way provides ample and high-quality space for pedestrians and streetscaping, especially in areas with high pedestrian volumes.

This policy establishes the primacy of pedestrians over all modes when designing streets in Denver. The pedestrian-enhanced area map (page 170-171) goes even further, designating areas, typically aligned with the centers on the future places map, where street design should deliver an even higher level of pedestrian comfort and amenities.

Policy 8: Connect centers and corridors across the city through a variety of modal choices.

Blueprint Denver's "Complete Networks" concept, which aims to connect Denver's neighborhoods with modal choices, is embodied in this policy. It acknowledges the greater intensity of uses and residential densities that can be achieved in centers and that neighborhoods are more complete with the amenities and services provided in these areas.

\section{Quality-of-Life Infrastructure}


Policy 1: Expand tools and regulations to ensure high-quality parks and outdoor public spaces keep pace with Denver's growth.

Strategy B: Evaluate the need to increase requirements and/or create incentives for publicly accessible outdoor space for mid- and large-scale developments in centers, corridors and districts.

Policy 10: Work with public and private partners to improve access to shops, restaurants, entertainment, civic uses, services and a variety of daily needs for all Denver residents.

Strategy A: Prioritize street and trail improvements and connections leading to and through existing and future centers and corridors.

Strategy B: Develop incentives to promote human-scaled, accessible and inclusive mixed-use centers and corridors.

Blueprint Denver's vision for a city of complete neighborhoods and complete networks looks to improve the public realm in the city's centers by increasing the amount and quality of parks and outdoor spaces in these high-density areas. As part of the Denveright process, the Denver Parks and Recreation master plan (Game Plan) called for new funding sources for park and open space acquisition and improvement. Denver voters recently approved a new parks and open space sales tax that is estimated to generate $\$ 37$ million annually to achieve the policies outlined in the Denveright plans.

\subsubsection{Zoning}

Blueprint Denver provides the primary plan guidance of all rezoning (known as zoning map amendments) applications. One of the most significant policy recommendations of the previous iteration of Blueprint Denver in 2002 called for a complete overhaul of the Denver Zoning Code which dated from the 1950s. A five-year process cumulated in a new citywide form and context-based Denver Zoning Code being adopted in 2010 and 80 percent of the city was rezoned into this new code (exceptions being parcels with complicated customized zoning districts) that serves as the city's primary regulatory tool. A critical element of the new code is the use of neighborhood contexts that place all areas of the city along a planning transect from more to less intense reflects Denver's different neighborhoods built over a century of urbanization. The new Blueprint Denver took the neighborhood contexts from the zoning code and developed the city's first forward-looking future neighborhood context map. This organizational structure of providing land use and built form, mobility and quality-of-life infrastructure guidance by a property's desired future neighborhood context and future place type (centers, corridors, residential areas and districts) allows for significant nuance and detail in plan guidance for rezonings. For example, a property that has a community center future place type and is located in an urban center neighborhood context has plan guidance for greater 
intensity of uses and building heights than a community center in the suburban context. The Denver Zoning Code then has corresponding zone districts that align with these Blueprint Denver designations.

\subsubsection{Transit-Oriented Denver: Denver's TOD Strategic Plan}

Blueprint Denver recommends efficient land development, especially in the transit-rich Transit-Oriented Development Strategic Plan.

The Transit-Oriented Development (TOD) Strategic Plan identifies the actions needed to promote TODs in Denver. This plan aims to integrate the policies, goals, and strategies addressed through multiple city departments in planning and promoting TODs. The strategic plan plays a vital role in different steps of TOD implementation, including providing a foundation to guide public and private investment at rail stations. Denver's Station Typology classifies each station area based on five characteristics: "land use mix," "street and block pattern," "building placement and location," "building heights," and "mobility." The plan distinguishes five place types: "Downtown," "Urban Center," "General Urban," "Urban," and "Suburban" typologies. Urban centers are provided with robust transit and designed as pedestrian-friendly environments. Urban centers have a mix of mid- to high-rise multifamily residential integrated with commercial buildings to intensify their roles as regional employment hubs.

Twenty-eight of Denver's rail stations were quantitively evaluated by their market potential and readiness for development and placed into three categories along a TOD continuum. Strategize stations still require additional planning and visioning. Catalyze stations have strong market potential but are lacking in infrastructure or amenities to realize significant TOD. Energize stations have both strong market potential and are ready for TOD development. By organizing these 28 rail stations into these categories, Denver was able to highlight what city investments could result in the greatest return on public investment and catalyze the most development in these critical centers to promote a polycentric development pattern throughout Denver.

\subsection{CONCLUSION}

The Denver region case study shows clear coordination of regional planning that utilizes multiple levels of government to enact a shared vision of urban centers that results in a polycentric development pattern. The various policies and tools used at both the regional and local levels of government support the growth of new centers and the intensification of existing centers, especially when located on RTD's expanding regional rail transportation system.

Opposed to other metropolitan regions, DRCOG employs a bottom-up approach to growth management that relies heavily on voluntary compliance from its member jurisdictions. This effort has been most successful when the region's MPO, transit authority and local jurisdictions work together to align resources to plan and develop connected urban centers. The RTD investments in the regional transit system and DRCOG funding of station area and urban center planning have been critical drivers in 
the Denver region's success in establishing a metropolitan area with multiple connected urban centers. The City and County of Denver's policies illustrates the critical role individual jurisdictions play in the region's strategy to guide growth sustainably.

As the region's primary city, Denver illustrates this collaborative approach to being strategic and intentional about where and how growth should be accommodated in the region. Denver has the most urban neighborhoods in the region with some of the largest infill development sites suited for high-density, mixed-use centers. Denver's Comprehensive Plan 2040 and Blueprint Denver continue the city's commitment to compact development patterns and striving to create great places at strategic locations tied closely with reliable, frequent, high-quality transit options.

\subsection{DOCUMENTS REVIEWED IN THIS CHAPTER}

- Blueprint Denver (2019). Retrieved from https://www.denvergov.org/media/denvergov/cpd/blueprintdenver/Blueprint_Denver.pdf

- Comprehensive Plan 2040: Denver's Plan for the Future (2019). Retrieved from https://www.denvergov.org/content/dam/denvergov/Portals/Denveright/documents/compplan/Denver_Comprehensive_Plan_2040_city_council_draft.pdf

- Denver Transit-Oriented Development Strategic Plan. (2014) Retrieved from https://www.denvergov.org/content/dam/denvergov/Portals/193/documents/TOD_Plan/TOD _Strategic_Plan_FINAL.pdf

- Denver Zoning Code (2010). Retrieved from https://www.denvergov.org/content/dam/denvergov/Portals/646/documents/Zoning/DZC/Co mplete_Denver_Zoning_Code.pdf

- DRCOG 2012-2017 Transportation Improvement Program. Retrieved from http://www3.drcog.org/documents/archive/Amended\%202012-2017\%20TIP\%20Policy\%20\%20Amended\%20May\%202013.pdf

- DRCOG 2020-2023 Transportation Improvement Program. Retreived from https://drcog.org/sites/default/files/resources/Adopted\%202020-2023\%20TIP\%20Policy.pdf

- DRCOG 2040 Metro Vision Regional Transportation Plan (2017). Retrieved from https://drcog.org/sites/drcog/files/resources/FINAL\%20-\%202040\%20MVRTP\%20\%20April\%202017.pdf

- DRCOG 2050 Metro Vision Regional Transportation Plan Draft 2050 Scenario Outcome Results (2020). Retrieved from https://drcog.org/sites/default/files/eventmaterials/REVISED\%20Attachment\%20D\%20Presentation\%20Scenario\%20results\%20for\%20March\%2023\%2C\%202020\%20TAC.pdf

- DRCOG Community Mobility Planning and Implementation (2019). Set-Aside FY 2020 and FY 2021 Projects Eligibility Rules and Selection Process. Retrieved from https://drcog.org/sites/default/files/CMPI_Eligibility_Rules_and_Selection_Process_Final.pdf

- DRCOG Metro Vision 2020 (1995). Vision Framework for the Denver Metropolitan Region. Retrieved from https://drcog.org/sites/drcog/files/resources/1995\%20MV\%20Framework\%201b.pdf 
- DRCOG Metro Vision 2040 (2017) https://indd.adobe.com/view/8bb0b608-d82e-44da-8303e379416c7e5a

- DRCOG Metro Vision Idea Exchange. Retrieved from https://metrovision.drcog.org/in_practice/idea_exchanges/

- DRCOG Perspective on Transit in the Denver Region (2016). Retrieved from https://drcog.org/sites/default/files/resources/RPD-RP-WHOTOD-18-10-31-V15.pdf

- RTD FasTracks Commitment in Principle http://www3.drcog.org/documents/archive/DRCOG\%20FasTracks\%20Review\%20and\%20D etermination\%20Report\%20-\%20April\%2023.pdf

- RTD FasTracks Strategic Plan for TOD (2010). Retrieved from https://www.rtddenver.com/sites/default/files/files/2019-08/rtd-tod-fastracks-strategic-plan-2010.pdf

- RTD First and Last Mile Strategic Plan (2019). Retrieved from https://www.rtddenver.com/sites/default/files/files/2019-07/FLM-Strategic-Plan_06-10-19.pdf

- RTD First and Last Mile Strategic Plan (2019). Retrieved from https://www.rtddenver.com/sites/default/files/files/2019-07/FLM-Strategic-Plan_06-10-19.pdf

- RTD Regional BRT Network Feasibility Study (2019). Retrieved from https://www.rtddenver.com/sites/default/files/files/2020-03/RTD-regional-BRT-feasibility-study.pdf

- RTD TOD Evaluation Guidelines (2018). Retrieved from https://www.rtddenver.com/sites/default/files/files/2018-08/tod-evaluation-guidelines-2018.pdf

- RTD TOD Status Report (2019). https://www.rtd-denver.com/sites/default/files/files/202005/2019-TOD-status-report.pdf

- RTD Transit-Oriented Development Design Criteria (2012). RTD FasTracks. Retrieved from https://www.rtd-denver.com/sites/default/files/files/2018-08/tod-design-criteria-rtd-final.pdf

\subsection{CASE STUDY OF POLYCENTRIC DEVELOPMENT STRATEGIES IN SEATTLE, WA}




\subsection{INTRODUCTION}

Although less renowned than its neighbor to the South, Portland, OR, in terms of innovative planning practice, Seattle, WA, is also unique in its regional planning history. Similar to the history of Portland and LUTRAQ, Washington adopted the Washington State Growth Management Act (GMA) in 1990. This legislation sought to facilitate coordination between varying levels of government to restrain uncontrolled growth. Principally, GMA works by requiring counties of a certain size or growth rate to develop comprehensive plans and regulations that are aligned with specific goals mandated by the GMA. Cities within these counties are also required to produce comprehensive plans that are in accordance with the county plans. The GMA contains 14 explicit goals, the first three of which are most pertinent to the focus of this research. These include: 1 ) focusing growth in existing urban areas, 2) reducing low-density sprawling development, and 3) encouraging efficient multimodal transportation. The acknowledgement of these priorities within the GMA indicates that officials were considering the basic principles of polycentric development, hoping to facilitate this style over the conventional sprawling development patterns that dominated the period in which the legislation was passed.

An important aspect of the GMA is the framework that it designates for shared responsibility in planning between multiple levels of government. This shared responsibility, or collaboration, is depicted in the Washington State Planning Framework, which is modeled below in Figure 11.1.

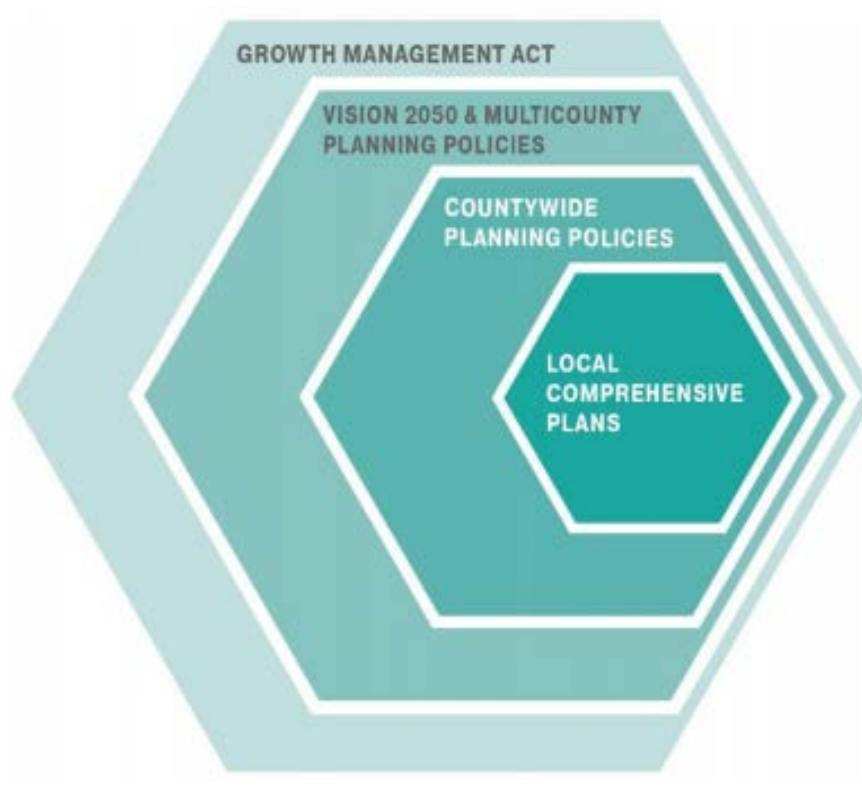

Figure 11.1: Washington State Planning Framework

In this case study we use interviews coupled with review of policy and legal documents to identify tools for facilitating polycentric development in the Seattle region. We interviewed representatives from the region's transit agency, the City of Seattle, and the 
metropolitan planning organization. Interviewees outlined the ways that their organizations promote polycentric development using explicit policies, funding mechanisms, and programs. We dive deeper into these tools through analysis of supporting documents to complete the picture of agency facilitation of polycentric development patterns. Below, we enumerate our efforts interviewing and reviewing documents for this case study.

Table 11.1: Number of officials interviewed and documents reviewed

\begin{tabular}{lcc}
\hline Organization & Officials Interviewed & Documents Reviewed \\
\hline City of Seattle & One & Three \\
\hline Puget Sound Regional Council & One & Two \\
\hline Sound Transit & One & One \\
\hline
\end{tabular}

\subsection{PUGET SOUND REGIONAL COUNCIL}

\subsubsection{Vision 2050}

Vision 2050 is the draft regional planning document that outlines a plan for growth for the four most populous counties in the state of Washington. Per the requirements of the Washington Growth Management Act (GMA), the plan provides a framework for where and how development should occur in the region. Puget Sound Regional Council (PSRC) employed contemporary visioning practices like listening sessions and focus groups, surveys, and data analysis to produce a vision that reflects empirical need as well as the wishes of the public.

The context for Vision 2050 includes dramatic growth in population and employment. The plan predicts growth in population of 1.8 million people from now to 2050, and 1.2 million new jobs over this time. They expect that the population will be older, on average, and more diverse, with families living in smaller homes than is typical today. To accommodate this growth, the Vision provides a framework for how and where development should occur, focusing the majority of this growth in centers. This necessitates both land use and transportation considerations that also acknowledge economic development exigencies. The Vision explicitly focuses growth within designated growth centers and transit station areas. More specifically, the Vision sets a goal of attracting $65 \%$ percent of all growth within centers and transit station areas. This is achieved by many specific policies that we will discuss below. The prominence of the concept of centers within the Vision can be easily illuminated with a simple quantitative measurement: The 184-page document references centers 205 times.

\subsubsection{Regional Centers Framework}

The designation of centers for allocating growth is a foundational policy tool for facilitating polycentric development. The PSRC outlines the purpose of centers in its Vision 2050 (2019) planning document as well as in its Regional Centers Framework (2018). These documents explain how the use of centers allows for appropriately 
allocating growth. The inextricable nature of centers to the type of regional planning done by PSRC is evident as it opens the Regional Centers Framework:

"Centers are the hallmark of VISION 2040 and the Regional Growth Strategy. They guide regional growth allocations, advance local planning, inform transit service planning, and represent priority areas for PSRC's federal transportation funding."

At the time of our interview with a representative from PSRC, the region had 29 regional growth centers and 10 industrial centers. Regional centers are designated by the PSRC Executive Board using specific criteria to ensure consistency and conformity with the regional vision. Centers' designation is based on four criteria. The first is local commitment; PSRC must see evidence that the potential center is a local priority and the sponsoring municipality or county has provided commitment in the form of investment for a walkable, livable center. The second is the completion of a center plan that is in accordance with regional guidance. The third is the location within a citythere are exceptions to this stipulation, however. Finally, certain existing conditions must also be present. These include existing infrastructure to support center growth, such as housing, employment density or potential for these conditions in the near future.

The Regional Centers Framework designates a hierarchy of centers with quantitative criteria, similar to other leading polycentric regions. Below, Figure 11.2 depicts the hierarchy and criteria, created by the author but adapted from the Regional Centers Framework.

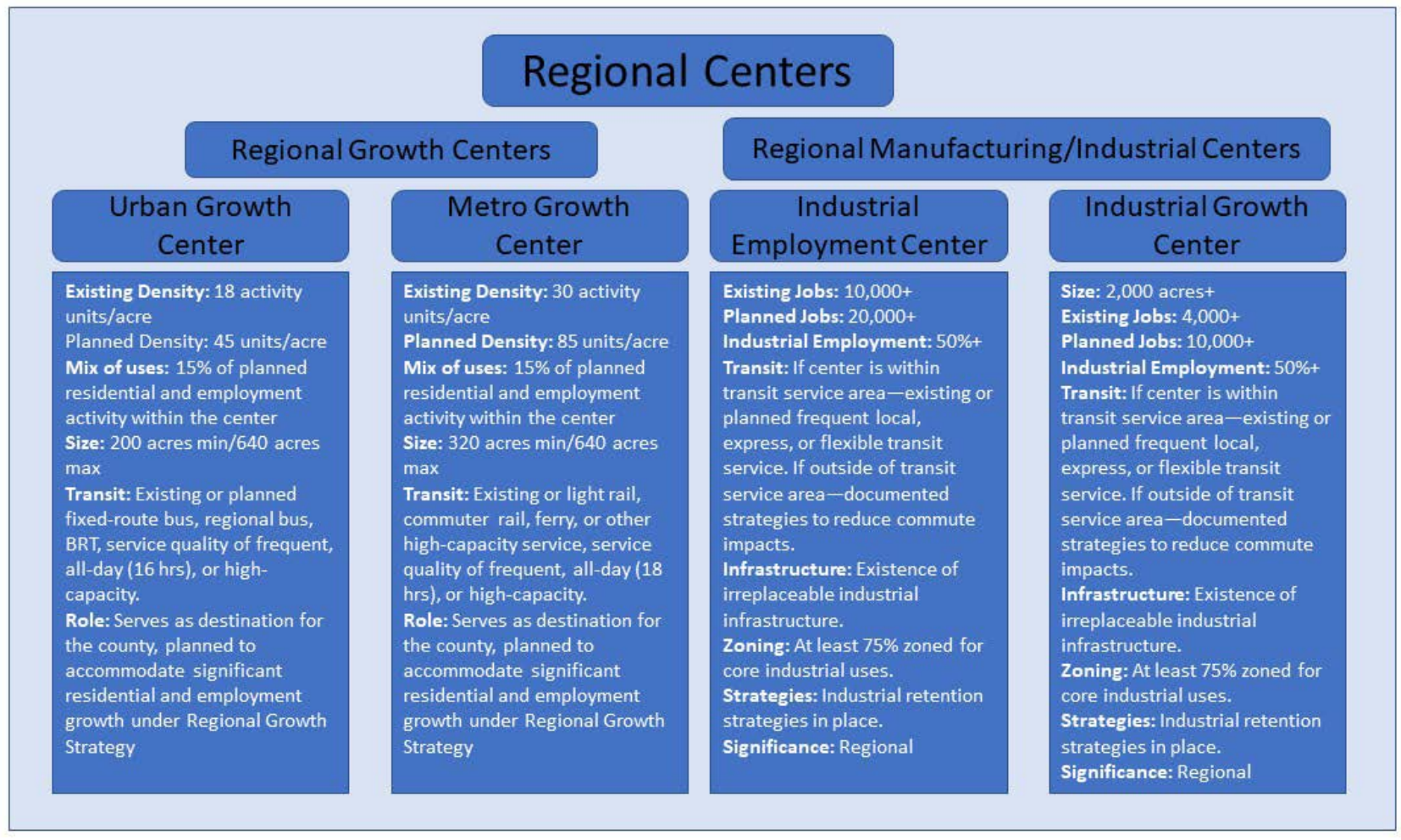

Figure 11.2: Regional centers hierarchy and criteria 
We see in Figure 11.2 that the Regional Centers Framework identifies two broad categories of regional centers: regional growth centers and regional manufacturing/industrial centers. The broad regional growth center category is then broken into urban growth centers and metro growth centers. These are distinguished mostly by higher activity density, larger size, and greater transit access for metro growth centers. The regional manufacturing/industrial center category is separated into industrial employment centers and industrial growth centers. Industrial employment centers are defined by a higher number of jobs while industrial growth centers are defined by a larger area.

The Regional Centers Framework also describes two types of county-wide centers, although the designation of these centers is outside the purview of PSRC. Similar to regional centers, the framework separates county-wide centers into county-wide growth centers and county-wide industrial centers. The distinction between these two types of centers follows from what we see of regional centers and there are additional criteria that the framework elaborates on. Finally, the framework calls for the designation of local centers throughout the region. The framework does this, however, without prescribing characteristics of local centers, acknowledging that they should be contextspecific and include input from local citizens and officials. Below, Figure 11.3 depicts the map of regional growth and industrial centers in the Seattle region. 


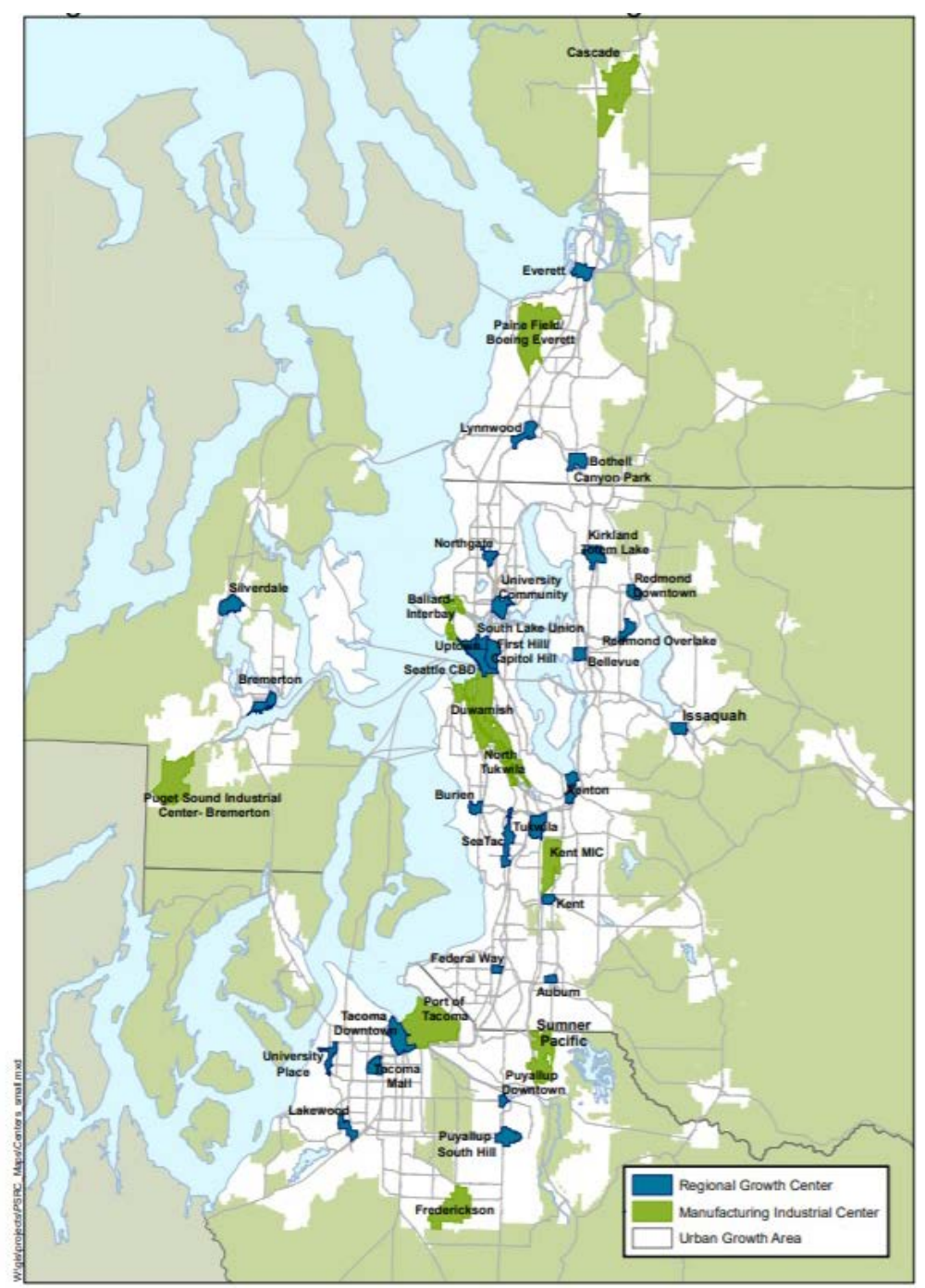

Figure 11.3: Regional growth and industrial centers map

\subsubsection{Funding Strategies}

PSRC, using policies set in the Vision 2050 plan, the Regional Centers Framework, and the Regional Growth Strategy (discussed next), uses funding as a lever for affecting centered development. Our interviewee described centers as, "The entire basis for the way we do our funding here-it is at the heart of the region's plan overall." This is to say that priority, in terms of federal transportation funding from the MPO, is given to projects, technical support, and infrastructure that is within a designated regional growth center. The explicit policy (MPP-DP-7) from the Vision 2040 plan is as follows:

"Give funding priority - both for transportation infrastructure and for economic development - to support designated regional growth centers consistent with the regional vision. Regional funds are prioritized to regional growth centers. 
County-level and local funding are also appropriate to prioritize regional growth centers."

Beyond directly funding centers, the Regional Centers Framework provides that PSRC staff will help to research and identify other potential funding sources to support development in centers. As is the expectation of all MPOs, PSRC also uses its Regional Transportation Plan (RTP) as a tool for exercising funding priorities in accordance with its polycentric vision.

\subsubsection{Concurrency}

Concurrency is a centering tool that forces development to be located where there is existing infrastructure capable of handling the transportation impacts of that growth. Concurrency is a tool that is explicitly cited by the GMA to direct growth in appropriate areas (i.e., centers). The Vision 2050 plan explains this in further detail below.

"Under the Growth Management Act, part of the concurrency requirement is the establishment of level-of-service standards for arterials, transit service, and other facilities. These standards are used to determine whether a proposed development can be served with available facilities, or whether mitigation of some sort may be required. The law requires cities and counties to have a reassessment strategy in the event of a service deficiency or shortfall. Such a strategy allows a jurisdiction to consider: (1) other sources of funding to provide the service, (2) changing the level-of-service standard that was established, and/or (3) reconsidering the land use assumptions."

Some researchers have found that concurrency standards are often used to exact concessions from developers such as impact fees or other design elements that would not otherwise be considered (Knaap et al., 2001). This policy, however, is written in a way that makes its motivation apparent: funneling growth to dense areas that can most efficiently accommodate it. The suggestion that jurisdictions consider funding additional service, which by design is more easily acquired in centers, is ample evidence of this motivation. The other two suggestions of the policy, that level-of-service standards and land use assumptions be reconsidered, also provide indication of the centering premise of this policy.

\subsubsection{Regional Growth Strategy}

The Regional Growth Strategy (RGS) is an important component of the Vision 2050 plan, creating a framework for collaboration and between different entities responsible for handling the region's growth and development goals. The stated goal of the Strategy is as follows:

"The region accommodates growth in urban areas, focused in designated centers and near transit stations, to create healthy, equitable, vibrant communities wellserved by infrastructure and services. Rural and resource lands continue to be 
vital parts of the region that retain important cultural, economic, and rural lifestyle opportunities over the long term."

The RGS has eight components that focus growth in areas it deems most appropriate: centers. First, the RGS recommends the maintenance of a stable urban growth area. This means not expanding the urban growth boundary unless necessary, thus incentivizing more dense, centered development. Thinking of the region as a whole, the RGS recommends that the majority of new population and employment growth be allocated within the designated growth area. To minimize the need for regional travel and facilitate centered development, the RGS provides for a better balance of jobs and housing across the region. Importantly, it also explicitly states a focusing of growth within the region's cities, further concentrating city growth within centers. Finally, the RGS promotes transit-oriented development coupled with an attempt to use existing infrastructure as efficiently as possible.

\subsubsection{Urban Growth Area}

A paramount legacy of the Growth Management Act was the establishment of the urban growth area (UGA). Like Portland's urban growth boundary, the UGA functions to limit the extent of land in which urban or suburban development can even be considered. Our interviewee suggested that this is an important component of regional planning for PSRC, and the fact that there is a process that requires the area's boundaries be changed by legislation makes doing so difficult. The official asserted that the growth area contains a large portion of the region's jobs and population, and that the majority of growth is planned to occur within the UGA. In fact, the Vision 2050 plan states that a measure of success for the MPO and regional collaborators would be the ability to accommodate growth through 2050 without having to modify the existing UGA boundary.

\subsection{CITY OF SEATTLE}

\subsubsection{Comprehensive Plan}

As could be expected, our City of Seattle representative referred to the 2035 Comprehensive Plan first when asked about policies and programs the City was using to affect polycentric development. We were informed by our interviewee of the importance of the 1990 Comprehensive Plan, which was referred to as a "seminal document that established the concept of urban villages, putting forth a polycentric vision for the City." Like the original seminal document, the 2035 Comprehensive Plan has numerous strategies that were developed to promote polycentricity that we will detail below.

\subsubsection{Urban Village Strategy}

Arguably the most important component of the 2035 Comprehensive Plan for facilitating a polycentric development pattern is the urban village strategy (UVS). Put most simply, in the words of the comprehensive plan, "The urban village strategy is Seattle's growth 
strategy." The strategy outlines different designations of centers, namely urban centers and urban villages. It also details specific targets for each designation, which we will elaborate on shortly. The UVS utilizes existing or historic commercial centers for increased residential development, creating mixed-use centers that will continue to serve commercial purposes while also accommodating the growing need for population density. This strategy, it should seem, will also help to improve jobs/housing balance for the region by allowing for colocation of employment and housing opportunities. The UVS designates four types of centers:

- Urban Centers: The densest neighborhoods in Seattle, acting as regional centers and local neighborhoods. They are meant to provide the broadest diversity of uses, housing, and employment opportunities.

- Hub Urban Villages: Villages that are less dense than urban centers but still offer a similar level of diversity in land use, housing, and employment options.

- Residential Urban Villages: Areas of residential development at reduced density than can be expected in urban centers or hub urban villages. These villages offer less in terms of employment opportunities while still supplying adequate goods and services for residents.

- Manufacturing/Industrial Centers: The centers for business and industry. These areas are important regional resources that are meant to attract and retain jobs and are essential for maintaining a diverse regional economy.

The above designated center types are intended to see the most change in the coming decades. The comprehensive plan states that while other parts of the City will receive adequate attention from planners, the centers are where most of the City's efforts will be focused. This admission is proof of Seattle's commitment to polycentric development.

\subsubsection{Growth Strategy}

In tandem with the UVS, the 2035 Comprehensive Plan outlines a Growth Strategy that provides additional details about the mechanics of the centers' designations as well as other goals and policies for targeted development within the City. The Growth Strategy includes four overarching goals and countless policies, some of which are pertinent to polycentric development. We include the pertinent goals and policies below.

Growth Strategy Goal 1: "Keep Seattle as a city of unique, vibrant, and livable urban neighborhoods, with concentrations of development where all residents can have access to employment, transit, and retail services that can meet their daily needs."

GS 1.1 - Designate places as urban centers, urban villages, or manufacturing/industrial centers based on the functions they can perform and the densities they can support.

GS 1.2 - Encourage investments and activities in urban centers and urban villages that will enable those areas to flourish as compact mixed-use 
neighborhoods designed to accommodate the majority of the city's new jobs and housing.

GS 1.3 - Establish boundaries for urban centers, urban villages, and manufacturing/ industrial centers that reflect existing development patterns; potential access to services, including transit; intended community characteristics; and recognized neighborhood areas.

GS 1.4 - Coordinate planning for transportation, utilities, parks and recreation, libraries, and other public services to meet the anticipated growth and increased density in urban centers and villages.

GS 1.5 - Encourage infill development in underused sites, particularly in urban centers and villages.

GS 1.6 - Plan for development in urban centers and urban villages in ways that will provide all Seattle households, particularly marginalized populations, with better access to services, transit, and educational and employment opportunities.

GS 1.7 - Promote levels of density, mixed uses, and transit improvements in urban centers and villages that will support walking, biking, and use of public transportation.

GS 1.10 - Establish urban centers and urban villages using the guidelines described in [the Urban Center and Urban Village Guidelines].

The plan continues, describing specific guidelines with respect to geographic area, accessibility standards, zoning and land uses, and growth targets for the different center types. The plan also includes policies for growth outside of centers and villages, although these areas receive about as much attention within the plan as the proportion of growth they are supposed to receive.

Growth Strategy Goal 2: "Accommodate a majority of the city's expected household growth in urban centers and urban villages and a majority of employment growth in urban centers."

GS 2.1 - Plan for a variety of uses and the highest densities of both housing and employment in Seattle's urban centers, consistent with their role in the regional growth strategy.

GS 2.2 - Base 20-year growth estimates for each urban center and manufacturing/ industrial center on [specified] criteria.

GS 2.3 - Accommodate a substantial portion of the city's growth in hub and residential urban villages.

GS 2.6 - Work with communities where growth is slower than anticipated to identify barriers to growth and strategies to overcome those barriers. 
The 2035 Strategic Plan and attendant Growth Strategy outline very specific policies and guidelines for directing growth to centers in the City of Seattle. While we have not found quantitative evidence to be able to determine with certainty that these centering policies are having the intended effects, we did hear encouraging claims from our interviewee. We were told that the City has envisioned $80-85 \%$ of its population growth within urban villages and the actual observed growth trends have very closely matched the planners' expectations. They continued that this assertion does not mean that every village has grown exactly as expected, but rather the balance of growth has gone proportionally to urban villages as hoped.

\subsubsection{Maps}

Like other leading U.S. regions, Seattle relies heavily on maps as a planning tool for conceptualizing and directing growth in a polycentric pattern. In conjunction with the policies stated in the 2035 Strategic Plan, the plan also includes a map of the centers designated in the Growth Strategy. We present the Growth Strategy Centers Map below (Figure 11.4). 


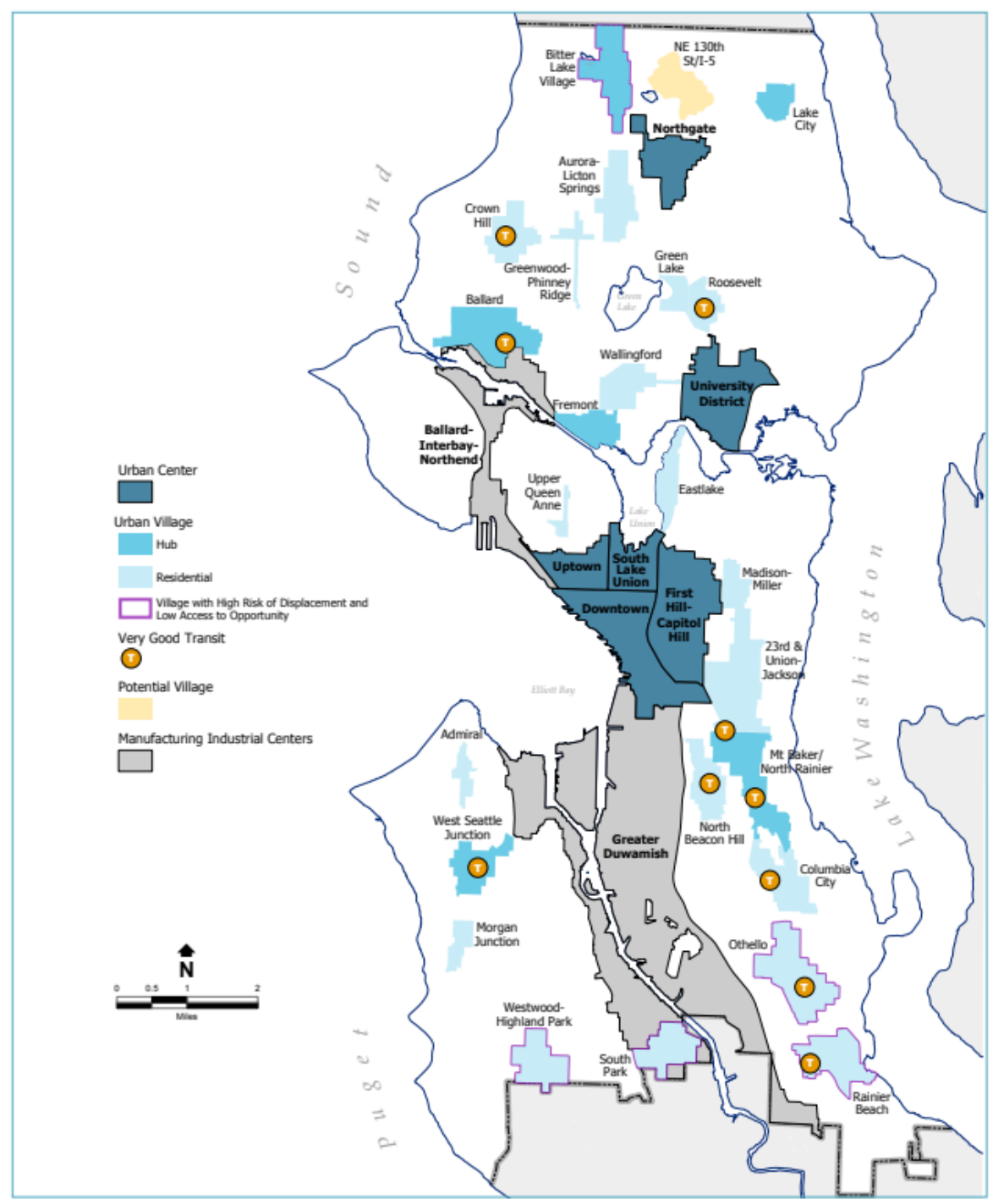

Figure 11.4: Growth Strategy Centers Map

The Growth Strategy Centers Map depicts in dark blue the densest urban centers planned for a contiguous section in the central part of downtown Seattle, and two separated urban centers to their north. In the medium shade of blue, hub urban villages are shown spread relatively evenly throughout the land area of Seattle. In the lightest shade of blue, residential urban villages are also spread evenly throughout the city. Areas of high transit service density are marked on the map, and one can observe centers aligned with these transit-dense areas. This is an excellent example of coordinated land use and transportation planning that is both polycentric and multimodal. The map also comports with what we learned in interviews. Our interviewee told us that they have planned and observed lots of development around bus rapid transit corridors. These areas of high levels of transit service, or corridors as our interviewee referred to them, are set to continue to be areas of focused growth.

With a finer grain of detail, but to similar effect, the Future Land Use Map (Figure 11.5) specifies the 2035 Comprehensive Plan's vision for land use for Seattle in the coming 
decades. Again, like the centers map, we see dense urban center development in the central downtown portion of the city, with another dense urban center allowed just to its north. One thing that is made clearer by this map, however, is the persistence of singlefamily residential areas. The planners we interviewed admitted to us the political and practical challenges associated with planning any kind of zoning changes to singlefamily residential areas. In fact, we learned, planning for centers is a convenient and expedient way to assuage the concerns of single-family neighborhoods. It is clear that without focusing development pressure within centers, and thus allowing a more geographically even distribution of development, single-family residential zoning would not be feasible in a context like Seattle with such a limited supply of undeveloped land.

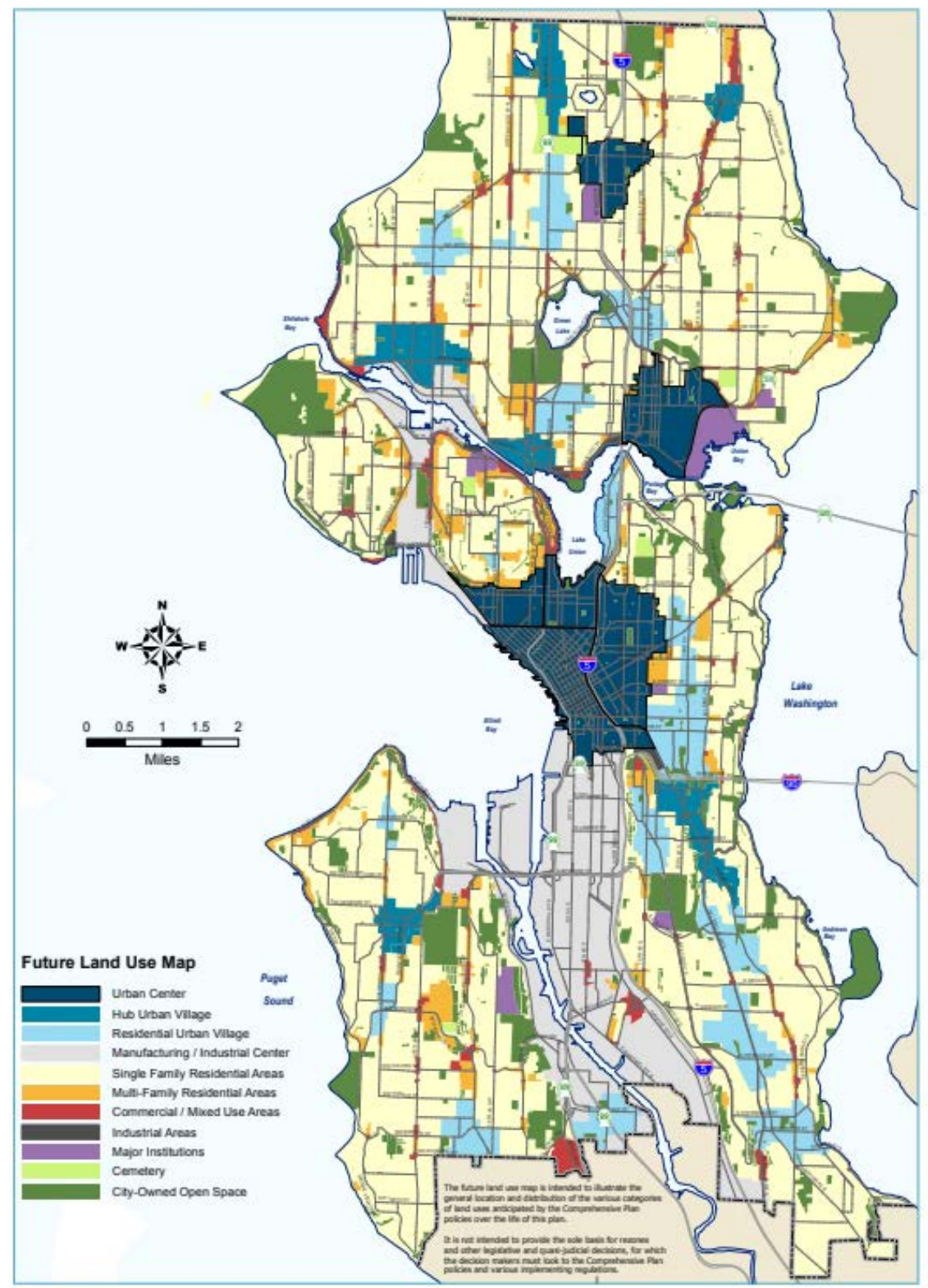

Figure 11.5: Future Land Use Map 


\subsection{SOUND TRANSIT - SEATTLE REGION'S HIGH-CAPACITY TRANSIT PROVIDER}

When asked a question about policies and programs the agency is administering to support polycentric development, our Sound Transit respondent simply told us, "Well, this is kind of a chicken and egg issue, isn't it?" More to the point, however, they went on to say that Sound Transit is "building the bones of a polycentric type of regional development." Sound Transit, being the regional transit authority, is currently tasked with planning and building an expanding regional, high-capacity transit system. The existing system consists of light rail, heavy rail and express bus service, with a huge amount of additional service planned. The current Seattle region's transit system is commensurate with what one might expect in a large U.S. city, but what is planned will make the transit system rival large legacy systems like New York and Washington, D.C. Figure 11.6 shows the Sound Transit 3 Plan Map depicting proposed and current service.

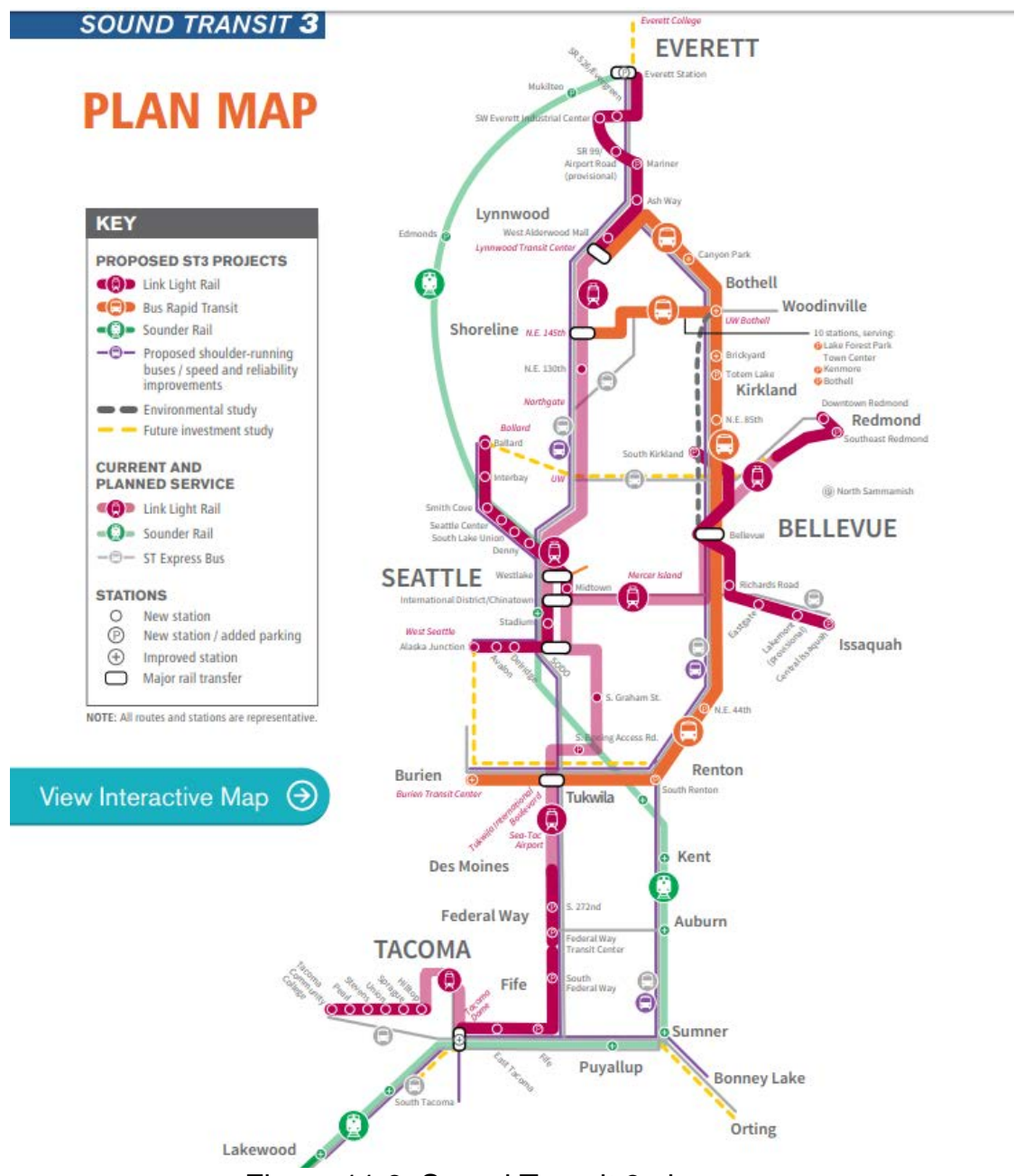

Figure 11.6: Sound Transit 3 plan map 


\subsubsection{Sound Transit 3 - The Regional Transit System Plan}

An integral part of Seattle's regional growth plan includes a major expansion of the transit system. The level of growth that the region predicts, even with impeccable regional land use planning, would cause crippling stress to the transportation system. An essential way to ameliorate that problem is to drastically increase the capacity of the transit system. The Sound Transit 3 plan does just that with increases to existing service and investment in capital projects unlike any U.S. transit system plans to or has undergone in decades. For context, the Sound Transit 3 plan, as written, is estimated to cost $\$ 53.85$ billion in capital and operating investments. Figure 11.7 illustrates the agency's estimated allocation of those funds.

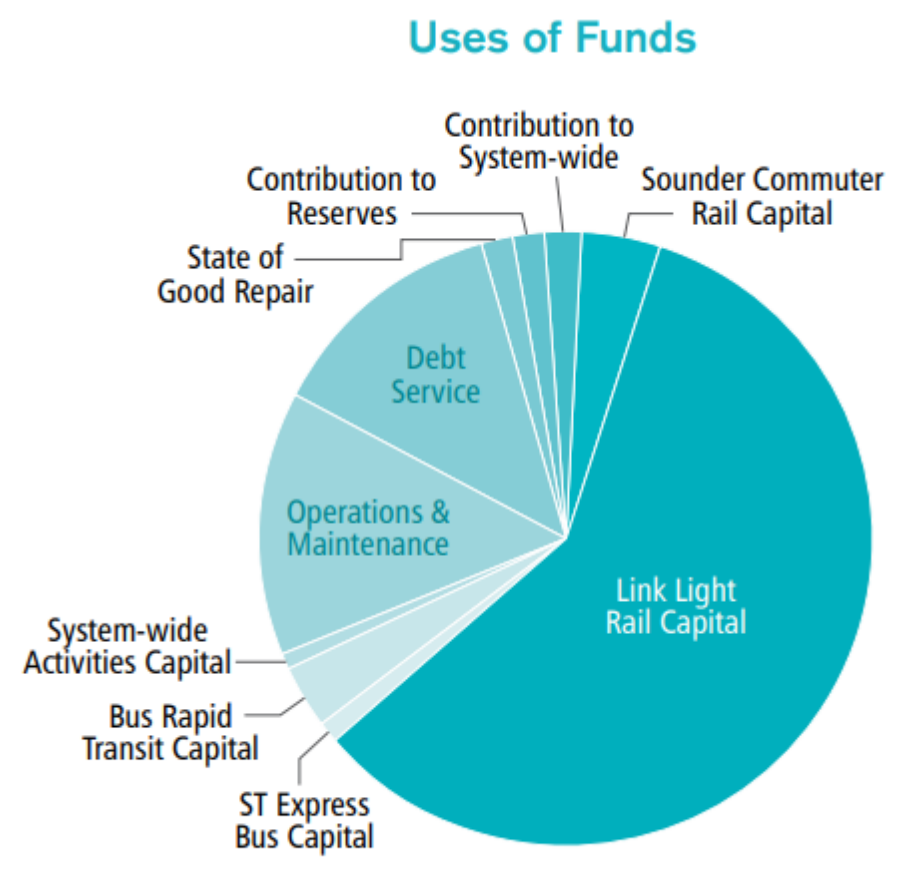

Figure 11.7: Sound Transit 3 expansion planned fund expenditure

The most striking takeaway from Figure 11.7 is the proportion of funds estimated to be allocated to light rail capital investment. Our interviewee proudly shared that the plan allows for the construction of 115 new miles of light rail. While this type of investment in transit infrastructure is unprecedented in contemporary American planning, it is necessary for the region to be able to achieve its goals of polycentric development without adding similar levels of highway capacity.

\subsubsection{System Access Plan}

For such astonishing levels of capital investment to be seamlessly tied to the existing multimodal transportation network, the Sound Transit 3 plan contains what it calls a System Access Plan. The System Access Plan (SAP) is a series of programs and policies to facilitate access to the transit system such that it is accessible by active 
transportation modes, supports transit-oriented development, includes innovative practices, and is sustainable. Essentially, the SAP is an acknowledgement that the proposed transit system will not be successful without intentional multimodal access. A critical element of the SAP is dedicated funding, included in the total budget outlined above, for multimodal access to the system. Funding for access is dependent on the context of planned stations; funding levels will reflect the type of stations being planned, and access orientation will depend on the surrounding land uses. Funding is dedicated for project-level planning where bus-rail integration allowances will provide for construction that permits convenient passenger transfers between bus and rail modes. Access allowances will provide funds that facilitate the development of safe and direct walking and bicycling routes to neighborhoods surrounding station areas. Dedicating funding to system access will strengthen the region's ability to create polycentric development because concentrations of development in centers will require mode shifts away from auto travel. Furthermore, a well-designed and multimodally integrated transit system is paramount to achieving such a shift.

\subsubsection{Transit-Oriented Development}

TOD is the best example of fine-grained development that utilizes existing or planned infrastructure in a way that promotes a polycentric development pattern. In fact, the modern paradigm of land use and transportation planning has been described by Ewing and Bartholemew (2018) as centered development connected by high-quality transit service. TOD exemplifies this practice at a small scale, and promoting this style of development is crucial for advancing a polycentric development pattern. Like the System Access Plan, the Sound Transit 3 plan contributes dedicated funds for TOD planning activities for areas within the system expansion that are expected to maintain surplus land. The plan includes a TOD Fund of \$20 million to include TOD considerations during the process of land acquisition. This is to ensure that there is adequate surplus property for Sound Transit to meaningfully support TOD development as the system becomes operable.

\subsection{CONCLUSION}

The Seattle region is another excellent example of coordinated regional planning that utilizes multiple levels of government to enact a shared vision of polycentric development. Similar to the Portland, OR case study, the Seattle MPO has additional authority beyond what is typically afforded to an MPO. This allows PSRC to facilitate a regional agenda of centered development through overarching policy like the Regional Centers Framework, the Regional Growth Strategy, and the Growth Boundary. Unlike most MPOs where such policies would be more like voluntary guidance, in this case the MPO has the ability to enforce these policies through their ability to approve or demand changes to comprehensive plans. This process allows PSRC to ensure that municipalities within the region are in line with their regional goals, like centered development. 
Additionally, the City of Seattle and Sound Transit share this goal for a polycentric region. The City is contributing to centered development with many policies that explicitly work to that end. Specifically, the City of Seattle employs a hierarchy of centers for focusing growth in areas that can best accommodate it. The City also has its own Growth Strategy for achieving centered development in a way that is in line with the regional approach but also incorporates the City's unique context. An essential component for directing growth within the Seattle region is also the expansion of important transportation infrastructure. Sound Transit exists as a regional transportation authority that is charged with developing this infrastructure to facilitate polycentric development. The region is planning the largest public transit expansion in the US, and Sound Transit is carefully coordinating with other regional actors like the MPO and City to ensure that capital investment is made in a way that promotes the goals of responsible, centered development.

\subsection{DOCUMENTS REVIEWED IN THIS CHAPTER}

- Puget Sound Regional Council (2019). Draft Vision 2050 Plan. Retrieved from https://www.psrc.org/sites/default/files/draft-vision2050-plan.pdf

- Puget Sound Regional Council. Part II: Regional Growth Strategy. Retrieved from https://www.psrc.org/sites/default/files/part_ii_regional_growth_strategy.pdf

- Puget Sound Regional Council (2018). Regional Centers Framework Update. Retrieved from https://www.psrc.org/sites/default/files/final_regional_centers_framework_march_22 _ver

- Knaap, G., Ding, C., \& Hopkins, L. D. (2001). Managing urban growth for the efficient use of public infrastructure: toward a theory of concurrency. International Regional Science Review, 24(3), 328-343.

- Laschever, E. S. (1998). An Overview of Washington's Growth Management Act. Paific Rim Law \& Policy Journal, 7, 657.

- The City of Seattle (2016). Seattle 2035 Comprehensive Plan. Retrieved from comprehensivePlan/CouncilAdopted2019.pdf

- Sound Transit (2016). Sound Transit 3 The Regional Transit System Plan for Central Puget Sound. Retrieved from https://st32.blob.core.windows.net/media/Default/Document\%20Library\%20Featured $18-2$ 


\subsection{CONCLUSION: RECOMMENDATIONS FOR WASATCH FRONT}

\subsection{SUMMARY}

This project aims at helping Salt Lake County, WFRC, MAG, and UTA make informed decisions about future growth patterns, set realistic-yet visionary-goals, and improve the overall health of residents and communities. The report first explored academic literature and empirical evidence on polycentric development (Chapter 2); analyzed more than 100 regional transportation plans on their definition and qualification of various types of centers (Chapter 3 ); reviewed scenario planning projects in other regions to see how polycentric plans perform (Chapter 4); identified centers in 28 U.S. regions as CBDs and subcenters (Chapter 5); analyzed transportation benefits of centers using comprehensive household travel survey datasets (Chapters 6 and 7); and conducted in-depth case studies of policy strategies aimed at polycentricity (Chapters 8 through 11). In this concluding chapter, we summarize our findings and provide policy suggestions for the Wasatch Front region in Utah.

A polycentric region consists of a network of compact developments connected with each other through high-quality transportation options. Rather than continuing the expanse of low-density development radiating from an urban core, investments can be concentrated on central nodes and transit connections. Central to this shift is the increased influence of agglomeration economies and activity clusters on population and employment distribution and, thus, spatial development. As the antidote to sprawling suburbs, compact centers could encourage all the things sprawl discourages: public health, environmental sustainability, social cohesion, and economic diversity (European Commission, 1999; Hamidi et al., 2015; Meijers and Burger, 2010).

A comprehensive review of 126 regional transportation plans across the nation shows that the term "center" is used in connection with various geographic scales-region, city, sub-region, town, community, and village. Alternatively, center is also used to signify clusters of certain activities or functions-an area with a single concentrated use, such as an employment center, transit center, residential center, or entertainment center. Generally, a center is described as the densest part of an area, characterized by compact, mixed-use development, multiple transit options, and employment opportunities.

Only 25 of the 126 regional transportation plans we reviewed included any type of quantitative criteria for designating centers, and some of these indicators are overly broad. The quantitative criteria found in these 25 RTPs can be classified into four main areas-employment density, residential density, total population or employment, and area size. Other areas covered in only a few plans include land use mix, building design (e.g., floor area ratio), transit service, and street density. Synthesizing the quantitative criteria found in the 25 RTPs and the qualitative criteria found in all 126 plans, we 
articulated general guidelines for identifying five of the most common types of centersregional centers, urban centers, activity centers, town centers, and employment centers.

In Chapter 5, the identification of centers in selected regions was done in two steps. First, we identified the location of central business districts (CBDs) in 28 U.S. regions using local spatial autocorrelation techniques. These techniques enabled us to identify the highest local peaks in terms of employment density as potential CBDs. Second, having identified CBDs, the location of potential employment subcenters was identified using Geographically Weighted Regression (GWR). Then, multistep criteria were applied to exclude unqualified candidates and find the final location of subcenters. As a result, a total of 23 centers as either CBDs or local density peaks were identified in the Wasatch Front region. The sites range in size from 78.6 acres to 956.4 acres. The locations of centers were validated against the centers designated in Wasatch Choice 2050. In the whole 28 regions, a total of 589 centers were identified (an average of 21 per region). Out of 79,670 households included in the travel surveys, 1,506 households live within centers and 78,164 households live outside centers.

Then, we compared travel outcomes between center households and non-center households. On average, households living in centers tend to make fewer and shorter automobile trips, take transit more, walk more, and bike less. After matching households having similar socio-demographic status using the propensity score matching method, center households tend to drive less ( 24.6 vs. 29.8 miles per day) and walk more (0.99 vs. 0.78 walk trips per day) than their counterparts outside centers. When a household in a suburban area moves into an existing center, or a center is newly developed, the average household is expected to have significantly shorter auto trips and more walk trips.

Using a non-linear regression model-GAM, we tried to find optimal values maximizing transportation benefits of polycentric developments. By exploring the GAM plots, we could reach to recommendations for optimal built environment characteristics of centers (Table 8.1). For successful centers, we recommend 10,000-25,000 activity density (1640 per acre; may vary by center types); a minimum of 150 intersections/square mile; over $60 \%$ of four-way intersections; over 60 transit stops/square mile; and a minimum $30 \%$ of regional job accessibility within 30 minutes by transit.

Finally, as a best practice in polycentric planning and development efforts, we conducted case studies of four regions with more or less polycentric policies. The strongest case study is the Portland region in Oregon. From interviews and document reviews for the City of Portland, Portland Metro (Portland's MPO), and TriMet (Portland's transit agency), we identified strategies that these entities are using to promote polycentric development. Many of the findings from the case study are incorporated into our recommendations for the Wasatch Front, discussed in the next section. 


\subsection{RECOMMENDATIONS FOR THE WASATCH FRONT}

Based on our literature review, center identification and analysis, and case studies, we present WFRC, MAG, UTA, and counties and municipalities within the region with recommendations for achieving polycentricity.

Salt Lake County is in a unique position to develop and invest in centers; several centers within the county have already begun to form organically. The MPO for the northern portion of the region, the Wasatch Front Regional Council, has been planning for polycentric development since the Wasatch Choice for 2040 Vision was released in 2010. Context-specific strategies could help the region strategically develop centers within its communities that would help the county reach its goals of economic growth, community preservation, environmental sustainability, connected transportation networks, air-quality improvement, and homelessness minimization.

Centers can vary in scale-for example rural areas have small town centers, metropolitan areas house regional centers and multiple city centers-but each would provide public services, housing, employment opportunities, and recreational experiences for the surrounding population, and each would be functionally connected to the other centers, creating a true polycentric transit network.

Below we provide built environment criteria for three center types in the Wasatch Choice 2050-metropolitan center, urban center, and city center. Our recommendations are based on findings from three previous analyses in this report-current built environment condition of centers in our region, RTP review (Chapter 3), and GAM analysis (Chapter 6). Tables 12.1 to 12.3 show those three results and Table 12.4 shows our final recommendations.

Table 12.1: Current built environment condition of $D$ variables of 20 centers in the Wasatch Front, classified by the WC 2050 center designation (note: four centers were dropped because they don't overlap with any center in the WC 2050 map; see Appendix for more information)

\begin{tabular}{llll}
\hline Variable & $\begin{array}{l}\text { Metropolitan center } \\
(\mathbf{n = 1})\end{array}$ & $\begin{array}{l}\text { Urban center } \\
(\mathbf{n}=\mathbf{8})\end{array}$ & $\begin{array}{l}\text { City center } \\
(\mathbf{n = 9})\end{array}$ \\
\hline Actden & 25,649 & 15,475 & 9,160 \\
\hline Jobpop & 0.10 & 0.13 & 0.22 \\
\hline Entropy & 0.99 & 0.85 & 0.63 \\
\hline Intden & 163.12 & 131.96 & 106.62 \\
\hline Pct4way & 52.28 & 35.49 & 32.90 \\
\hline Transitden & 51.17 & 52.71 & 21.33 \\
\hline Pctemp10a & 20.57 & 13.48 & 5.50 \\
\hline Pctemp30t & 36.09 & 16.60 & 6.54 \\
\hline
\end{tabular}

Table 12.2: Recommendations for optimal built environment characteristics of centers from GAM analysis in Chapter 6

Built environment variables
Activity density ((pop + emp)/sq.mi.)
Job-pop balance
Entropy index

Recommendations 10,000-25,000 (according to a center type) No recommendation No recommendation 


\begin{tabular}{ll}
\hline Intersection density (\# intersection/sq.mi.) & Minimum 150 \\
\hline Percentage of four-way intersections & Minimum 60\% \\
\hline Transit stop density (\# stops/sq.mi.) & Minimum 60 (recommended: $60-100)$ \\
\hline $\begin{array}{l}\text { Percentage of regional employment within } \mathbf{1 0} \\
\text { minutes by car }\end{array}$ & No recommendation \\
\hline $\begin{array}{l}\text { Percentage of regional employment within } \mathbf{3 0} \\
\text { minutes by transit }\end{array}$ & Minimum 30\% \\
\hline
\end{tabular}

Table 12.3: Density criteria by different centers types from other RTPs (see Chapter 3)

\begin{tabular}{|c|c|c|c|}
\hline Variable & $\begin{array}{l}\text { Metropolitan } \\
\text { center }\end{array}$ & Urban center & City center \\
\hline $\begin{array}{l}\text { Activity density } \\
\text { ((pop+jobs)/sq.mi.) }\end{array}$ & $\begin{array}{l}\text { - 48,000 (Austin, } \\
\text { regional center) }\end{array}$ & $\begin{array}{l}\text { - } 28,800 \text { (Austin; town } \\
\text { center) }\end{array}$ & $\begin{array}{l}\text { - 16,000 (Austin; } \\
\text { community center) }\end{array}$ \\
\hline $\begin{array}{l}\text { Employment density } \\
\text { (jobs/sq.mi.) }\end{array}$ & $\begin{array}{l}\text { - 19,200 (Baltimore; } \\
\text { employment center) } \\
\text { - 73,000 (Orlando; } \\
\text { downtown) } \\
\text { - 15,400 (Knoxville; } \\
\text { regional commercial } \\
\text { center) } \\
\text { - 5,120 (Sacramento; } \\
\text { regional job center) } \\
\text { - 32,000 (Anchorage; } \\
\text { major employment } \\
\text { centers) }\end{array}$ & $\begin{array}{l}\text { - 16,000 (Baltimore; } \\
\text { mixed-use center) } \\
\text { - 32,600 \& 58,000 } \\
\text { (Orlando; Corridors \& } \\
\text { Primary TOD) }\end{array}$ & $\begin{array}{l}\text { - 6,400 (Baltimore; } \\
\text { suburban center) } \\
\text { - 5,800 (Orlando; } \\
\text { special district) } \\
\text { - 8,200 (Knoxville; } \\
\text { community center) }\end{array}$ \\
\hline $\begin{array}{l}\text { Residential density }{ }^{1} \\
\text { (pop/sq.mi.) }\end{array}$ & $\begin{array}{l}\text { - 146,000 (Orlando; } \\
\text { downtown) } \\
\text { - 32,000 (Flagstaff; } \\
\text { regional center) } \\
\text { - 25,600-256,000 } \\
\text { (Wasatch Front; } \\
\text { metropolitan center) } \\
\text { - 64,000 (Minneapolis; } \\
\text { urban center with rail) }\end{array}$ & $\begin{array}{l}\text { - 57,600 \& 116,500 } \\
\text { (Orlando; Corridors \& } \\
\text { Primary TOD) } \\
\text { - 32,000 (Flagstaff; } \\
\text { community center) } \\
\text { - 25,600-128,000 } \\
\text { (Wasatch Front; urban } \\
\text { center) } \\
\text { - 19,200 - 32,000 } \\
\text { (Minneapolis; urban } \\
\text { center with BRT) } \\
\text { - 12,400-51,200 } \\
\text { (Anchorage; town } \\
\text { center) } \\
\text { - 25,600 (Murrietta; } \\
\text { town center) }\end{array}$ & $\begin{array}{l}\text { - 44,800 (Orlando; } \\
\text { special district) } \\
\text { - 20,500 \& 15,400 } \\
\text { (Flagstaff; district } \\
\text { center \& neighborhood } \\
\text { center) } \\
\text { - 12,800-64,000 } \\
\text { (Wasatch Front; town } \\
\text { center) } \\
\text { - 12,800 (Minneapolis; } \\
\text { urban center with bus) } \\
\text { - 9,000-76,800 } \\
\text { (Burlington; center } \\
\text { planning areas) } \\
\text { - 12,800 (Baltimore; } \\
\text { mixed-use centers) } \\
\text { - 17,000 (Knoxville; } \\
\text { mixed-use } \\
\text { center/corridor) }\end{array}$ \\
\hline
\end{tabular}

1. We assumed 2 persons per household or dwelling unit.

Table 12.4: Our recommendations on built environment characteristics by center type for the Wasatch Front

$\begin{array}{lll}\text { Metropolitan } & \text { Urban center } & \text { City center } \\ \text { center }\end{array}$




\begin{tabular}{llll}
\hline $\begin{array}{l}\text { Activity density } \\
(\text { (pop + emp)/sq.mi.) }\end{array}$ & Minimum 25,000 & $\begin{array}{l}\text { Minimum 15,000 } \\
\text { (Target: 20,000-25,000) }\end{array}$ & $\begin{array}{l}\text { Minimum 10,000 } \\
\text { (Target: 15,000-20,000) }\end{array}$ \\
\hline $\begin{array}{l}\text { Intersection density } \\
\text { (\# intersection/sq.mi.) }\end{array}$ & Minimum 150 & Minimum 150 & $\begin{array}{l}\text { Minimum 120 } \\
\text { (Target: 150) }\end{array}$ \\
\hline $\begin{array}{l}\text { Percentage of four- } \\
\text { way intersections }\end{array}$ & Minimum 60 & Minimum 50 & $\begin{array}{l}\text { Minimum 40 } \\
\text { (Target: 50-60\%) }\end{array}$ \\
\hline $\begin{array}{l}\text { Transit stop density } \\
\text { (\# stops/sq.mi.) }\end{array}$ & Minimum 60 & (Target: 60\%) & Minimum 30 \\
Percentage of & Minimum 40\% & Minimum 60 & Minimum 10\% \\
$\begin{array}{l}\text { regional employment } \\
\text { within 30 minutes by } \\
\text { transit }\end{array}$ & & Minimum 20\% & (Target: 20\%) \\
\hline
\end{tabular}

\subsubsection{Strategies for WFRC/MAG/Salt Lake County}

The Vision Plan needs to dictate where growth should be concentrated, emphasizing centers and maximizing the efficient use of space. Strategies need to establish urban design principles to achieve polycentric development, identifying the hierarchy of centers as the typologies for polycentric development.

A functional plan, like Portland's Urban Growth Management Functional Plan, can provide guidance to municipalities and coordinate policy that can collectively achieve regional growth goals. Some guidelines can recommend changes to ordinances and comprehensive plans. The plan can also create requirements for consideration of regional funds and investment in centers. In order to be eligible for regional investment in a center, a city or county must establish a boundary for the center and perform a comprehensive assessment of the center including a market analysis, assessment of regulatory barriers to mixed use, pedestrian friendly and transit supportive development, and an analysis of the development code with respect to each of the above. By calling for minimum housing densities and allowing for accessory dwelling units, the functional plan can affect housing capacity.

Quantitative indicators help to monitor and encourage polycentric policy goals. WFRC/MAG may generate a report (e.g., the State of the Centers report in Portland) quantifying the progress being made in the region to concentrate growth in centers, which describes in detail how the designated centers have changed over time. Such a report will help to measure progress in creating the type of centers envisioned in the Wasatch Choice 2050 and to illustrate the features that contribute to a successful center such as demographics, employment, mode share, housing, and business activity.

Planning and development grants can provide funding to local governments to plan for development in a manner that is aligned with the Wasatch Choice 2050 vision. The WFRC already has its TLC program, but the program could be expanded to include infrastructure funding (as well as planning and technical assistance) and could have set asides for designated centers, those specifically identified in the Wasatch Choice for 2050 plan. Cities that have center plans in place (perhaps funded by TLC) would be eligible for additional funding for infrastructure. 


\subsubsection{Strategies for UTA}

Metro's TOD program in Portland has many implications for UTA as well as WFRC/MAG. The program aims to provide grants for projects near transit to incentivize denser development than would otherwise be built by developers. When transitadjacent projects qualify, the TOD program provides funding and support to increase the density of these projects. Funding amounts may be based on the projected increase that such density would have on transit ridership. UTA could also consider appropriate land acquisition around transit stations with the intention of promoting TOD in the future. This practice of land banking allows UTA and MPOs to hold onto land and prevent lower utilization to occur prior to the point in time when the market will support more intensive TOD development. UTA's park-and-ride lots can be considered land banks for future development.

Polycentric development requires high-quality transit connections between centers. Coordinated efforts between UTA, WFRC/MAG, and municipal governments will help to manifest the region's polycentric growth. This coordination may include the development of new capital projects and fixed-guideway transit lines, the concentration of resources to specifically designated corridors in the form of high-frequency service, and the acquisition and retention of important real estate. For example, TriMet's Southwest Service Enhancement Plan (SWEP) brings together municipalities, counties, business groups, and residents of the area to help design light rail lines as well as other service improvements and active transportation amenities to help improve the livability of the corridors.

An essential element for maintaining transit ridership is creating an environment that is safe and convenient for other active transportation modes, as transit trips often start with walking and bicycling. In the Wasatch Front region, spatially extensive growth in population and employment has created problems with congestion and unsafe conditions for active transportation users. Priorities in an active transportation plan may include safe crossings for pedestrians and bike riders near transit stations, shortened crossing distances, bus stop improvements such as landing pads, and adequate bike parking. UTA would need to urge cities and counties to extend the reach of transit by creating more walkable and bikeable environments that connect well to transit lines in the first and last miles of trips. UTA already has a program for bus stop improvements (pads, benches, and shelters), and these could be targeted for centers designated in WC 2050.

\subsubsection{Strategies for Municipalities}

General plans of municipalities are critical to achieve polycentric development as a planning guide for defining future land uses and development. A general plan may first identify different scales of centers - central city, regional center, town center, etc.within its jurisdiction boundary. Then, specific policy areas could include housing, investment, government services, arts and culture, accessibility, connections, and green infrastructure in and between centers. 
Zoning is the preeminent tool to direct development patterns through general plans and planning practice. A zoning map can designate a variety of mixed-use, commercial, and residential zones that allow adequate density to guide development intensity into centers. The majority of land use designations need to allow for dense, multifamily, residential development, mixed-use development, and high-intensity commercial development. Providing zones with high allowances for intensity gives planners the ability to direct growth into already designated centers, limiting sprawl and consumptive development patterns.

Transportation demand management (TDM) plans could mandate new developments to implement and operate TDM programs in order to be permitted and advance to construction. The mandate of such programs can ensure that new development will have limited impacts on congestion and vehicle trip generation through the facilitation of alternative modes of transportation.

Parking can also be an effective tool for planners to manage the impacts of changes to the built environment on transportation systems. The goal of parking policies would be primarily to reduce demand, and secondarily to reduce the supply of parking in an effort to increase the attractiveness of alternative modes of transportation. Parking management is a strategy that tries to reduce demand and manage supply to improve the viability of alternative modes, increase neighborhood livability, subsequently decrease automobile dependency, and improve air quality. Parking policies can also promote the use of market-based parking pricing systems in which parking prices accurately represent demand spatially and temporally. A comprehensive plan may refer to limited development of new parking structures (with consideration of proximity to transit) or redevelopment of surface parking lots within centers in order to achieve higher densities.

As the MRC found in the recent Orem Parking Study, parking tends to be oversupplied in residential and commercial developments alike. Revised parking standards were recommended by the MRC in the WFRC-funded Point-of-the-Mountain Parking Generation Study. These standards could be promoted throughout the region by WFRC and MAG. 


\subsection{REFERENCES}

- Anas, A., Arnott, R., \& Small, K.A. (1998). Urban spatial structure. Journal of Economic Literature, 36, 1426-1464.

- Anderson, Nathan B., and William T. Bogart. 2003. "The Structure of Sprawl: Identifying and Characterizing Employment Centers in Polycentric Metropolitan Areas." American Journal of Economics and Sociology 60 (1): 147-69. https://doi.org/10.1111/1536-7150.00058.

- Atkinson, J. L., Sallis, J. F., Saelens, B. E., Cain, K. L., \& Black, J. B. (2005). Recreational environments with physical activity. American Journal of Health Promotion, 19, 304-309.

- Austin, P. C. (2009). Some methods of propensity-score matching had superior performance to others: results of an empirical investigation and Monte Carlo simulations. Biometrical Journal: Journal of Mathematical Methods in Biosciences, 51(1), 171-184.

- Austin, P. C. (2011). Optimal caliper widths for propensity-score matching when estimating differences in means and differences in proportions in observational studies. Pharmaceutical statistics, 10(2), 150-161.

- Baily, N., \& Turok, I. (2001). Central Scotland as a polycentric urban region: Useful planning concept or chimera? Urban Studies, 38(4), 697-715.

- Bhat, C.R., Koppelman, F.S., 1999. Activity-based modeling of travel demand. In: Hall, R.W. (Ed.), Handbook of Transportation Science. Kluwer, Norwell, MA, pp. 3965.

- Bingham, N., \& Fry, J. (2010). Regression: Linear models in statistics. London, UK: Springer Undergraduate Mathematics Series.

- Boer, R., Zheng, Y., Overton, A., Ridgeway, G. K., \& Cohen, D. A. (2007). Neighborhood design and walking trips in ten US metropolitan areas. American journal of preventive medicine, 32(4), 298-304.

- Bowman, J.L., Ben-Akiva, M.E., 2001. Activity-based disaggregate travel demand model system with activity schedules. Transp. Res. Part A: Policy Pract. 35 (1), 128.

- Bradley, M., Bowman, J.L., Griesenbeck, B. (2009), Activity-based model for a medium-sized city: Sacramento. Traffic Eng. Control 50 (2), 73-79. 
- Brown, A. L., Khattak, A. J., \& Rodriguez, D. A. (2008). Neighbourhood types, travel and body mass: A study of new urbanist and suburban neighbourhoods in the US. Urban Studies, 45, 963-988.

- Brown, B. B., \& Cropper, V. L. (2001). New urban and standard suburban subdivisions: Evaluating psychological and social goals. Journal of the American Planning Association, 67, 402-419.

- Burger, M. J., De Goei, B., van der Laan, L., \& Huisman, F. M. J. (2011). Heterogeneous development of metropolitan spatial structure: Evidence from commuting patterns in English and Welsh city-regions. Cities, 28(2), 160-170.

- Burger, Martijn, and Evert Meijers. 2012. "Form Follows Function? Linking Morphological and Functional Polycentricity." Urban Studies 49 (5): 1127-49. https://doi.org/10.1177/0042098011407095.

- Caliendo, M., \& Kopeinig, S. (2008). Some practical guidance for the implementation of PSM. Journal of economic surveys, 22(1), 31-72.

- Cao, X. J., \& Schoner, J. (2014). The influence of light rail transit on transit use: An exploration of station area residents along the Hiawatha line in Minneapolis. Transportation Research Part A: Policy and Practice, 59, 134-143.

- Cao, X. J., Xu, Z., \& Fan, Y. (2010). Exploring the connections among residential location, self-selection, and driving: Propensity score matching with multiple treatments. Transportation research part A: policy and practice, 44(10), 797-805.

- Cao, X., \& Fan, Y. (2012). Exploring the influences of density on travel behavior using propensity score matching. Environment and Planning B: Planning and Design, 39(3), 459-470.

- Cao, X., Handy, S. L., \& Mokhtarian, P. L. (2006). The influences of the built environment and residential self-selection on pedestrian behavior: Evidence from Austin, TX. Transportation, 33, 1-20.

- Cervero, R, and K-L Wu. 1997. "Polycentrism, Commuting, and Residential Location in the San Francisco Bay Area." Environment and Planning A: Economy and Space 29 (5): 865-86. https://doi.org/10.1068/a290865.

- Cervero, R. (1989). America's suburban centers: The land use-transportation link, Boston: Unwin Hyman.

- Cervero, R. (2001). Walk-and-ride: Factors influencing pedestrian access to transit. Journal of Public Transportation, 7(3), 1-23. 
- Cervero, R., \& Duncan, M. (2003). Walking, bicycling, and urban landscapes: Evidence from the San Francisco Bay Area. American Journal of Public Health, 93(9), 1478-1483.

- Cervero, R., \& Kockelman, K. (1997). Travel demand and the 3Ds: density, diversity, and design. Transportation Research Part D: Transport and Environment, 2(3), 199219.

- Cervero, Robert, and Kang-Li Wu. 1998. "Sub-Centring and Commuting: Evidence from the San Francisco Bay Area, 1980-90." Urban Studies 35 (7): 1059-76. https://doi.org/10.1080/0042098984484.

- Cervero, Robert. 1991. "Land Uses and Travel at Suburban Activity Centers," October. https://escholarship.org/uc/item/0d08h1bz.

- Champion, A. G. (2001). A changing demographic regime and evolving poly centric urban regions: Consequences for the size, composition and distribution of city populations. Urban Studies, 38(4), 657-677.

- Cohen, J (1988). Statistical power analysis for the behavioral sciences (2nd ed.). Hillsdale, NJ: Erlbaum.

- Colquhoun, I. (2004). Design out crime: Creating safe and sustainable communities. Crime Prevention and Community Safety, 6, 57-70.

- Commission of European Community (CEC) (1999) 6th Periodic report on Social and Economic Situation and Development of Regions in the EU. Brussels: European Commission.

- Daisy, N.S., Millward, H., Liu, L. (2018), Trip chaining and tour mode choice of nonworkers grouped by daily activity patterns, Journal of Transport Geography, 69 (150162), https://doi.org/10.1016/j.jtrangeo.2018.04.016.

- Davoudi, S. (2003). European Briefing: Polycentricity in European spatial planning: From an analytical tool to a normative agenda. European Planning Studies, 11(8), 979-999.

- De Bourdeaudhuij, I. D., Sallis, J. F., \& Saelens, B. E. (2003). Environmental correlates of physical activity in a sample of Belgian adults. American Journal of Health Promotion, 18, 83-92. Retrieved from http://www.ncbi.nlm.nih.gov/pubmed/13677966.

- de Nazelle, A., Morton, B.J., Jerrett, M., Crawford-Brown, D. (2010). Short trips: an opportunity for reducing mobile-source emissions? Transp. Res. Part D: Transp. Environ. 15 (8), 451-457. 
- Dehejia, R. H., \& Wahba, S. (2002). Propensity score-matching methods for nonexperimental causal studies. Review of Economics and statistics, 84(1), 151161.

- Dieleman, F.M., \& Faludi, A. (1998). Polynucleated metropolitan regions in northwest Europe: Theme of the special issue. European Planning Studies, 6(4), pp. 365377.

- Doyle, S., \& Kelly-Schwartz, A. (2006). Active community environments and health: The relationship of walkable and safe communities to individual health. Journal of the American Planning Association, 72, 37-41.

- Dubin, Robin. 1991. "Commuting Patterns and Firm Decentralization." Land Economics 67 (1): 15-29. https://doi.org/10.2307/3146482.

- Dumbaugh, E., \& Rae, R. (2009). Safe urban form: Revisiting the relationship between community design and traffic safety. Journal of the American Planning Association, 75, 309-329.

- Durand, C. P., Andalib, M., Dunton, G. F., Wolch, J., \& Pentz, M. A. (2011). A systematic review of built environment factors related to physical activity and obesity risk: Implications for smart growth urban planning. Obesity Reviews, 12, e173-e182.

- European Commission (EC), “ESDP - European Spatial Development Perspective: Towards a Balanced and Sustainable Development of the Territory of the European Union". Luxembourg: Office to the Official Publications of the European Community, 1999.

- Ewing, R. (1997). Is Los Angeles-style sprawl desirable?. Journal of the American planning association, 63(1), 107-126.

- Ewing, R. (1997). Transportation \& Land Use Innovations-When You Can't Pave Your Way Out of Congestion. Chicago, IL: APA Planners Press.

- Ewing, R., \& Cervero, R. (2001). Travel and the built environment. Transportation Research Record, 1780, 87-114.

- Ewing, R., \& Cervero, R. (2010). Travel and the built environment: a meta-analysis. Journal of the American planning association, 76(3), 265-294.

- Ewing, R., \& Hamidi, S. (2014). Measuring urban sprawl and validating sprawl measures. National Institutes of Health and Smart Growth America.

- Ewing, R., \& Hamidi, S. (2015). Compactness versus sprawl: A review of recent evidence from the United States. Journal of Planning Literature. Published online first. DOI: $10.1177 / 0885412215595439$ 
- Ewing, R., \& Rong, F. (2008). The impact of urban form on US residential energy use. Housing Policy Debate, 19(1), 1-30.

- Ewing, R., Greenwald, M. J., Zhang, M., Walters, J., Feldman, M., Cervero, R., ... Thomas, J. (2009). Measuring the impact of urban form and transit access on mixed use site trip generation rates-Portland pilot study. Washington, DC: U.S. Environmental Protection Agency.

- Ewing, R., Greenwald, M., Zhang, M., Walters, J., Feldman, M., Cervero, R., Frank, L., \&Thomas, J., 2010. Traffic generated by mixed-use developments-Six-region study using consistent built environmental measures. Journal of Urban Planning and Development, 137(3), 248-261.

- Ewing, R., Haliyur, P., \& Page, G.W. (1994). Getting around a traditional city, a suburban planned unit development (PUD), and everything in-between. Transportation Research Record: Journal of the Transportation Research Board, 1466, 53-62.

- Ewing, R., Hamidi, S., \& Grace, J. B. (2016a). Urban sprawl as a risk factor in motor vehicle crashes. Urban Studies, 53(2), 247-266.

- Ewing, R., Hamidi, S., Grace, J. \& Wei, D. (2016b). Does sprawl hold down upward mobility? Landscape and Urban Planning, 148, 80-88.

- Ewing, R., Meakins, G., Hamidi, S., \& Nelson, A. C. (2014b). Relationship between urban sprawl and physical activity, obesity, and morbidity: Update and refinement. Health \& Place, 26, 118-126.

- Ewing, R., Pendall, R., \& Chen, D. (2002). Measuring sprawl and its impact. Smart Growth America.

- Ewing, R., Tian, G., Goates, J. P., Zhang, M., Greenwald, M. J., Joyce, A., ... \& Greene, W. (2015). Varying influences of the built environment on household travel in 15 diverse regions of the United States. Urban Studies, 52(13), 2330-2348.

- Fagerland, M.W. (2012), t-tests, non-parametric tests, and large studies-a paradox of statistical practice?. BMC Med Res Methodol 12, 78. doi:10.1186/1471-2288-1278

- Forsyth, A., Hearst, M., Oakes, J. M., \& Schmitz, K. H. (2008). Design and destinations: Factors influencing walking and total physical activity. Urban Studies, 45, 1973-1996.

- Frank, L. D., \& Pivo, G. (1994). Impacts of mixed use and density on utilization of three modes of travel: Single-occupant vehicle, transit, and walking. Transportation Research Record, 1466, 44-52. 
- Frank, L. D., Schmid, T. L., Sallis, J. F., Chapman, J. E., \& Saelens, B. E. (2005). Linking objectively measured physical activity with objectively measured urban form: Findings from SMARTRAQ. American Journal of Preventive Medicine, 28, 117-125.

- Frank, L., Bradley, M., Kavage, S. et al. (2008), Urban form, travel time, and cost relationships with tour complexity and mode choice. Transportation 35, 37-54, doi:10.1007/s11116-007-9136-6

- Freeman, L., \& Rohe, W. (2000). Subsidized housing and neighborhood racial transition: An empirical investigation. Housing Policy Debate, 11(1), 67-89.

- Fujita, Masahisa, and Hideaki Ogawa. 1982. "Multiple Equilibria and Structural Transition of Non-Monocentric Urban Configurations." Regional Science and Urban Economics 12 (2): 161-96. https://doi.org/10.1016/0166-0462(82)90031-X.

- Gallimore, J. M., Brown, B. B., \& Werner, C. M. (2011). Walking routes to school in new urban and suburban neighborhoods: An environmental walkability analysis of blocks and routes. Journal of Environmental Psychology, 31, 184-191.

- Garcia-López, M. À., \& Muñiz, I. (2010). Employment decentralisation: Polycentricity or scatteration? The case of Barcelona. Urban Studies, 47, 3035-3056.

- Garreau, J. (2011). Edge City: Life on the New Frontier. Anchor.

- Geppert, A. (2009). Polycentricity: Can we make it happen? From a concept to its implementation. Urban Research \& Practice, 2(3), 251-268.

- Geppert, Anna. 2009. "Polycentricity: Can We Make It Happen? From a Concept to Its Implementation." Urban Research \& Practice 2 (3): 251-68. https://doi.org/10.1080/17535060903319145.

- Ghosh, D., \& Vogt, A. (2012, July). Outliers: An evaluation of methodologies. In Joint statistical meetings (pp. 3455-3460). San Diego, CA: American Statistical Association.

- Giuliano, G., Agarwal, A., Redfearn, C., Traveled, V. M., \& Consumption, E. (2008). Metropolitan spatial trends in employment and housing. Transportation Research Board, 29.

- Giuliano, Genevieve, and Kenneth A. Small. 1991. "Subcenters in the Los Angeles Region." Regional Science and Urban Economics 21 (2): 163-82. https://doi.org/10.1016/0166-0462(91)90032-I.

- Gordon, P., Richardson, H.W., \& Wong, H. (1986). The distribution of population and employment in a polycentric city: the case of Los Angeles, Environment and Planning A, 18, 161-173. 
- Gottman, J. (1961). Megalopolis. Twentieth Century Fund.

- Green, N. (2007). Functional polycentricity: A formal definition in terms of social network analysis. Urban Studies, 44(11), 2077-2103.

- Hague, C., \& Kirk, K. (2003). Polycentricity scoping study. London: Office of the Deputy Prime Minister.

- Hall, P. \& Pain, K. (Eds) (2006). The Polycentric Metropolis: Learning from MegaCity Regions in Europe (London: Earthscan).

- Hall, Sir Peter, and Kathy Pain. 2009. The Polycentric Metropolis: Learning from Mega-City Regions in Europe. 1 edition. London; Sterling, VA: Routledge.

- Hamidi, S., \& Ewing, R. (2014). A longitudinal study of changes in urban sprawl between 2000 and 2010 in the United States. Landscape and Urban Planning, 128, $72-82$.

- Hamidi, S., \& Ewing, R. (2015). Is sprawl affordable for Americans? Exploring the association between sprawl and housing + transportation affordability. Transportation Research Record, 2500, 75-79.

- Hamidi, S., \& Zandiatashbar, A. (2018). Does urban form matter for innovation productivity? A national multi-level study of the association between neighbourhood innovation capacity and urban sprawl. Urban Studies, 0042098018767002.

- Hamidi, S., Ewing, R., Preuss, I., \& Dodds, A. (2015). Measuring sprawl and its impacts: An update. Journal of Planning Education and Research, 35(1), 35-50.

- Hamidi, S., Ewing, R., Tatalovich, Z., Grace, J. B., \& Berrigan, D. (2018). Associations between Urban Sprawl and Life Expectancy in the United States. International journal of environmental research and public health, 15(5).

- Hamidi, S., Zandiatashbar, A., \& Bonakdar, A. (2018). The relationship between regional compactness and regional innovation capacity (RIC): Empirical evidence from a national study. Technological Forecasting and Social Change.

- Handy S., Sallis J., Weber D., Maibach E., \& Hollander M. (2008). Is support for traditionally designed communities growing? Evidence from two national surveys. Journal of the American Planning Association, 74(2), 209-221.

- Harding, C., Miller, E.J., Patterson, Z., Axhausen, K.W. (2015), Multiple purpose tours and efficient trip chaining: an analysis of the effects of land use and transit on travel behavior in Switzerland. Presented at the 94th Annual Meeting of the Transportation Research Board, Washington D.C.

- Hillier, B. (2004). Can streets be made safe? Urban Design International, 9, 3-45. 
- Ho, C.Q., Mulley, C. (2013), Multiple purposes at a single destination: a key to a better understanding of the relationship between tour complexity and mode choice. Transportation Research Part A, 49: 206-219.

- Hu, Lingqian, Tieshan Sun, and Lanlan Wang. 2018. "Evolving Urban Spatial Structure and Commuting Patterns: A Case Study of Beijing, China." Transportation Research Part D: Transport and Environment 59 (March): 11-22. https://doi.org/10.1016/j.trd.2017.12.007.

- Humpel, N., Owen, N., Iverson, D., Leslie, E., \& Bauman, A. (2004). Perceived environment attributes, residential location, and walking for particular purposes. American Journal of Preventive Medicine, 26, 119-125.

- Jaume Masip-Tresserra. 2016. "Polycentricity, Performance and Planning; Concepts, Evidence and Policy in Barcelona, Catalonia." A+BE\&58; Architecture and the Built Environment 6 (7): 1-348. https://doi.org/10.7480/abe.2016.6.

- Kim, Chansung. 2008. "Commuting Time Stability: A Test of a Co-Location Hypothesis." Transportation Research Part A: Policy and Practice 42 (3): 524-44. https://doi.org/10.1016/j.tra.2008.01.001.

- Kim, J. (2007). Perceiving and valuing sense of community in a New Urbanist development: A case study of Kentlands. Journal of Urban Design, 12, 203-230.

- Kim, J., \& Kaplan, R. (2004). Physical and psychological factors in sense of community: New Urbanist Kentlands and nearby Orchard Village. Environment and Behavior, 36, 313-340.

- Kloosterman, R.C., \& Musterd, S. (2001). The polycentric urban region: Towards a research agenda. Urban Studies, 38(4), pp. 623-633.

- Kloosterman, Robert C., and Sako Musterd. 2001. "The Polycentric Urban Region: Towards a Research Agenda." Urban Studies 38 (4): 623-33. https://doi.org/10.1080/00420980120035259.

- Knaap, G., Ding, C., \& Hopkins, L. D. (2001). Managing urban growth for the efficient use of public infrastructure: toward a theory of concurrency. International Regional Science Review, 24(3), 328-343.

- Kotrlik, JW and Williams, HA (2003). The incorporation of effect size in information technology, learning, and performance research. Information Techology, Learning, and Performance Journal 21(1) 1-7.

- Krugman, P. (1991). Geography and Trade. Cambridge, MA: MIT Press.

- Krugman, Paul R. 1993. Geography and Trade. MIT Press. 
- Landman, K. (2009). Boundaries, bars, and barricades: Reconsidering two approaches to crime prevention in the built environment. Journal of Architectural and Planning Research, 26, 213-228.

- Laschever, E. S. (1998). An Overview of Washington's Growth Management Act. Paific Rim Law \& Policy Journal, 7, 657.

- Levine, Jonathan C. 1992. "Decentralization of Jobs and Emerging Suburban Commute." Transportation Research Record, no. 1364. https://trid.trb.org/view/371484.

- Leyden, K. M. (2003). Social capital and the built environment: The importance of walkable neighborhoods. American Journal of Public Health, 93, 1546-1551.

- Lund, H. (2002). Pedestrian environments and sense of community. Journal of Planning Education and Research, 21(3), 301-312.

- Lund, H. (2003). Testing the claims of new urbanism: Local access, pedestrian travel, and neighboring behaviors. Journal of the American Planning Association, 69, 414-429.

- MacDonald, J. M., Stokes, R. J., Cohen, D. A., Kofner, A., \& Ridgeway, G. K. (2010). The effect of light rail transit on body mass index and physical activity. American Journal of Preventive Medicine, 39, 105-112.

- Marshall, W. E., \& Garrick, N. W. (2010). Street network types and road safety: A study of 24 California cities. Urban Design International, 15, 133-147.

- Masip-Tresserra, J. (2016). Polycentricity, performance and planning: Concepts, evidence and policy in Barcelona, Catalonia (Doctoral dissertation, TU Delft, Delft University of Technology).

- McCormack, G. R., Giles-Corti, B., \& Bulsara, M. (2008). The relationship between destination proximity, destination mix and physical activity behaviors. Preventive Medicine, 46, 33-40.

- McDonald, John F. 1987. "The Identification of Urban Employment Subcenters." Journal of Urban Economics 21 (2): 242-58. https://doi.org/10.1016/00941190(87)90017-9.

- McMillen, D. P. (2001). Nonparametric employment subcenter identification. Journal of Urban economics, 50(3), 448-473.

- McMillen, Daniel P., and Stefani C. Smith. 2003. "The Number of Subcenters in Large Urban Areas." Journal of Urban Economics 53 (3): 321-38. https://doi.org/10.1016/S0094-1190(03)00026-3. 
- Meeteren, M.V., Poorthuis, A., Derudder, B., \& Witlox, F. (2016). Pacifying Babel's Tower: A scientometric analysis of polycentricity in urban research. Urban Studies, 53(6), 1278-1298.

- Meijers, E. \& Burger, M. (2010). Spatial structure and productivity in US metropolitan areas. Environment and Planning A, 42(6), 1383-1402.

- Meijers, E. (2007). Clones or complements? The division of labour between the main cities of the Randstad, the Flemish diamond and the RheinRuhr area. Regional Studies, 41, 889-900.

- Mishra, G. S., Clewlow, R. R., Mokhtarian, P. L., \& Widaman, K. F. (2015). The effect of carsharing on vehicle holdings and travel behavior: a propensity score and causal mediation analysis of the San Francisco Bay Area. Research in Transportation Economics, 52, 46-55.

- Moudon, A. V., \& Lee, C. (2003). Walking and bicycling: An evaluation of environmental audit instruments. American Journal of Health Promotion, 18, 21-37.

- Nasri, A., Carrion, C., Zhang, L., \& Baghaei, B. (2018). Using propensity score matching technique to address self-selection in transit-oriented development (TOD) areas. Transportation, 1-13.

- Noland, R. B., \& Thomas. J. V. (2007). Multivariate analysis of trip-chaining behavior. Environment and Planning B: Planning and Design, 34, 953.

- Park, K., Ewing, R., Scheer, B. C., \& Ara Khan, S. S. (2017). Travel Behavior in TODs vs. Non-TODs: Using Cluster Analysis and Propensity Score Matching. Transportation Research Record, 0361198118774159.

- Parr, J. B. (2004). The polycentric urban region: A closer inspection. Regional Studies, 38(3), 231-240.

- Pendyala, R.M., Ye, X. (2005), Contributions to understanding joint relationship among activity and travel variables. In: Progress in Activity-based Analysis. Elsevier, The Netherlands, pp. 1-24.

- Perdomo-Calvo, J. A., Mendoza, C. A., Baquero-Ruiz, A. F., \& Mendieta-Lopez, J. C. (2007). Study of the effect of the transmilenio mass transit project on the value of properties in Bogotá, Colombia.

- Pessoa, R. P. P. (2009). Towards a definition of urban polycentrism for Brazilian metropolises. In Proceedings of the 4th International Conference of the International Forum on Urbanism (IFoU), The New Urban Question-Urbanism beyond NeoLiberalism (pp. 1003-1014). 
- Pitt, D. (2013). Assessing energy use and greenhouse gas emission savings from compact housing: A small-town case study. Local Environment: The International Journal of Justice and Sustainability, 18(8), 904-920.

- Podobnik, B. (2011). Assessing the social and environmental achievements of New Urbanism: Evidence from Portland, Oregon. Journal of Urbanism, 4, 105-126.

- Porter, M.E. (1990). The Competitive Advantage of Nations. London: Free Press.

- Porter, Michael E. 2011. Competitive Advantage of Nations: Creating and Sustaining Superior Performance. Simon and Schuster.

- Primerano, F., Taylor, M.A., Pitaksringkarn, L., Tisato, P. (2008), Defining and understanding trip chaining behavior, Journal of Transportation, 35 (55-72).

- Puget Sound Regional Council (2018). Regional Centers Framework Update. Retrieved from https://www.psrc.org/sites/default/files/final_regional_centers_framework_march_22 _ver

- Puget Sound Regional Council (2019). Draft Vision 2050 Plan. Retrieved from https://www.psrc.org/sites/default/files/draft-vision2050-plan.pdf

- Puget Sound Regional Council. Part II: Regional Growth Strategy. Retrieved from https://www.psrc.org/sites/default/files/part_ii_regional_growth_strategy.pdf

- Roberts, M., Lloyd-Jones, T., Erickson, B., \& Nice, S. (1999). Place and space in the networked city: Conceptualizing the integrated metropolis. Journal of Urban Design, 4(1), 51-66.

- Rogers, S. H., Halstead, J. M., Gardner, K. H., \& Carlson, C. H. (2011). Examining walkability and social capital as indicators of quality of life at the municipal and neighborhood scales. Applied Research in Quality of Life, 6, 201-213.

- Rosenbaum, P. R., \& Rubin, D. B. (1985). Constructing a control group using multivariate matched sampling methods that incorporate the propensity score. The American Statistician, 39(1), 33-38.

- Rubin, D. B., \& Thomas, N. (2000). Combining PSM with additional adjustments for prognostic covariates. Journal of the American Statistical Association, 95(450), 573585.

- Rundle, A., Diez Roux, A. V., Free, L. M., Miller, D., Neckerman, K. M., \& Weiss, C. C. (2007). The urban built environment and obesity in New York City: A multilevel analysis. American Journal of Health Promotion, 21, 326-334. 
- Saelens, B. E., Sallis, J. F., Black, J. B., \& Chen, D. (2003). Neighborhood-based differences in physical activity: An environment scale evaluation. American Journal of Public Health, 93(9), 1552-1558.

- Schwanen, Tim, Frans M Dieleman, and Martin Dijst. 2001. "Travel Behaviour in Dutch Monocentric and Policentric Urban Systems." Journal of Transport Geography, Mobility and Spatial Dynamics, 9 (3): 173-86. https://doi.org/10.1016/S0966-6923(01)00009-6.

- Schwanen, Tim, Frans M. Dieleman, and Martin Dijst. 2004. "The Impact of Metropolitan Structure on Commute Behavior in the Netherlands: A Multilevel Approach." Growth and Change 35 (3): 304-33. https://doi.org/10.1111/j.14682257.2004.00251.x.

- Scott, A.J. (1988). Metropolis: From the Division of Labour to Urban Form. Berkeley, CA: University of California Press.

- Shiftan, Y., Ben-Akiva, M., Proussaloglou, K., De Jong, G., Yasasvi, P., Kasturirangan, K., Bekhor, S. (2003), Activity-based modeling as a tool for better understanding travel behaviour. Paper Presented at the10th Conference of the International Association of Travel Behavior Research, Lucerne, Switzerland.

- Social Sciences. Multivariate Behavioral Research, 46, 90-118.

- Sound Transit (2016). Sound Transit 3 The Regional Transit System Plan for Central Puget Sound. Retrieved from https://st32.blob.core.windows.net/media/Default/Document\%20Library\%20Featured /8-2

- Strathman, J.G., Dueker, K.J. (1990), Understanding trip chaining (Chapter 1) In: Special Reports on Trip and Vehicle Attributes-IN, 3 NPTS special reports.

- Stuart, E. A. (2010). Matching methods for causal inference: A review and a look forward. Statistical Science, 25, 1-21.

- Susilo, Y.O., Kitamura, R. (2008), Structural changes in commuters' daily travel: The case of auto and transit commuters in the Osaka metropolitan area of Japan, 19802000, Transportation Research Part A: Policy and Practice, Volume 42, Issue 1, Pages 95-115, https://doi.org/10.1016/j.tra.2007.06.009.

- Sutton, S. A. (2014). Are bids good for business? The impact of bids on neighborhood retailers in New York City. Journal of Planning Education and Research, 34(3), 309-324.

- Thoemmes, F., \& Kim, E. S. (2011). A Systematic Review of Propensity Score Methods in the 
- Trowbridge, M. J., M. J. Gurka, and R. O'Connor. 2009. "Urban Sprawl and Delayed Ambulance Arrival in the United States." American Journal of Preventive Medicine 37 (5): 428-32.

- Tyndall, J. (2018). Bus quality improvements and local commuter mode share. Transportation Research Part A: Policy and Practice, 113, 173-183.

- Vasanen, A. (2012). Functional polycentricity: Examining metropolitan spatial structure through the connectivity of urban sub-centres. Urban studies, 49(16), 36273644.

- Wang, R. (2014). The stops made by commuters: evidence from the 2009 US National Household Travel Survey. Journal of Transport Geography, 47, 109-118.

- Wasatch Front Regional Council (2015). Regional Transportation Plan: 2015-2040. Retrieved from http://www.wfrc.org/publications/RTPpublications/RTP_2015_FINAL.pdf.

- Waterhout, B., Zonneveld, W., \& Meijers, E. (2005). Polycentric development policies in Europe: Overview and debate. Built Environment, 31, 163-173.

- Wilkerson, A., Carlson, N.E., Yen, I.H., \& Michael, Y.L. (2012). Neighborhood physical features and relationships with neighbors: Does positive physical environment increase neighborliness? Environment and Behavior, 44(5), 595-615.

- Wood, L., Frank, L. D., \& Giles-Corti, B. (2010). Sense of community and its relationship with walking and neighborhood design. Social Science \& Medicine, 70, 1381-1390.

- Wood, L., Shannon, T., Bulsara, M., Pikora, T., McCormack, G., \& Giles-Corti, B. (2008). The anatomy of the safe and social suburb: An exploratory study of the built environment, social capital and residents' perceptions of safety. Health Place, 14, 15-31.

- Yang Liu, Wang Yuanqing, Bai Qiang, and Han Sunsheng. 2018. "Urban Form and Travel Patterns by Commuters: Comparative Case Study of Wuhan and Xi'an, China." Journal of Urban Planning and Development 144 (1): 05017014. https://doi.org/10.1061/(ASCE)UP.1943-5444.0000417.

- Yang, J., Xie, M., \& Goh, T. N. (2011). Outlier identification and robust parameter estimation in a zero-inflated Poisson model. Journal of Applied Statistics, 38(2), 421430.

- Yang, M., Wang, W., Ren, G., Fan, R., Qi, B., \& Chen, X. (2010). Structural equation model to analyze socio-demographics, activity participation, and trip chaining between household heads. Transportation Research Record, 2157, 38-45. 


\section{APPENDIX}


Table 0.1: Built environment measures (D Variables) of 22 centers in the Wasatch Front

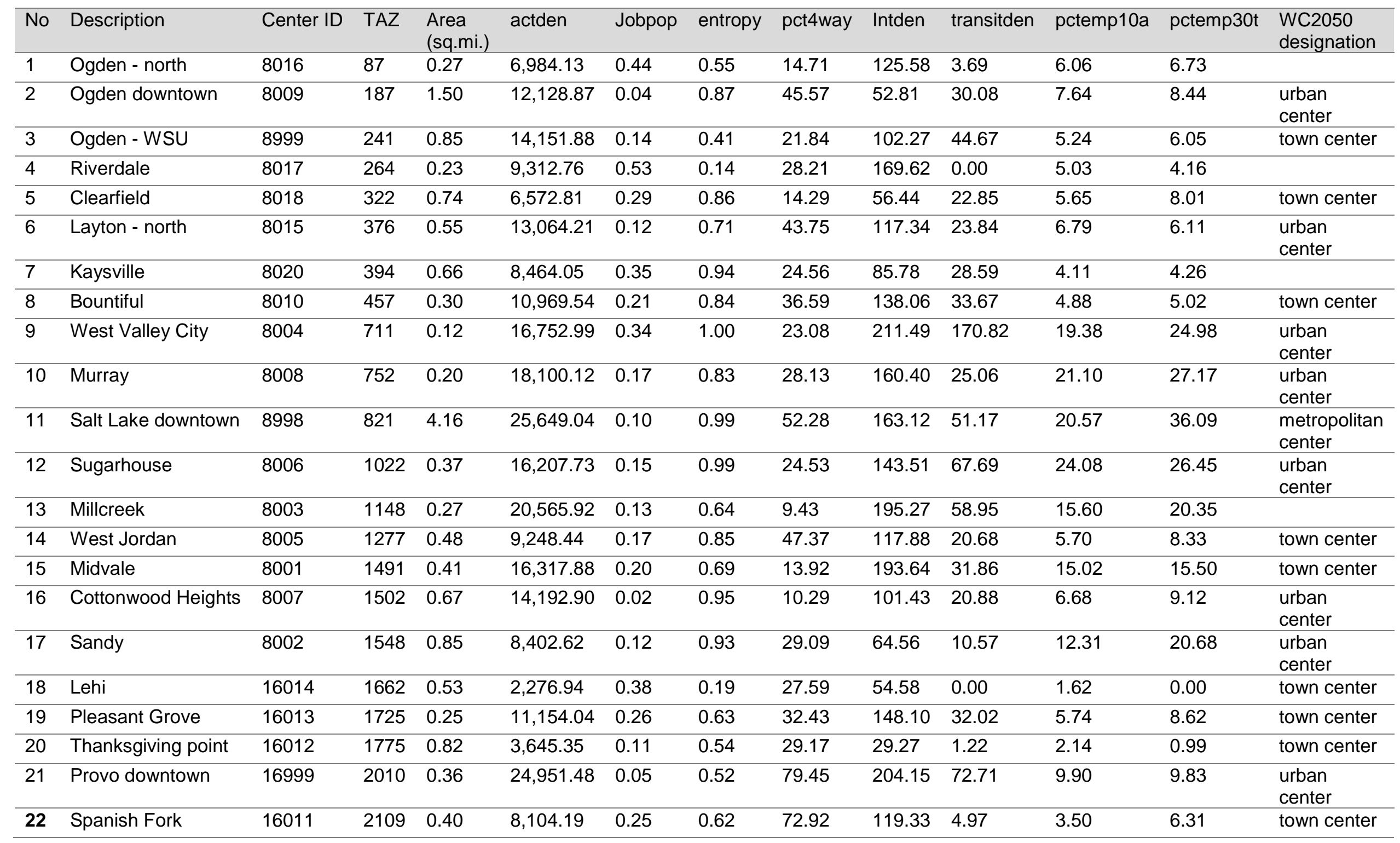




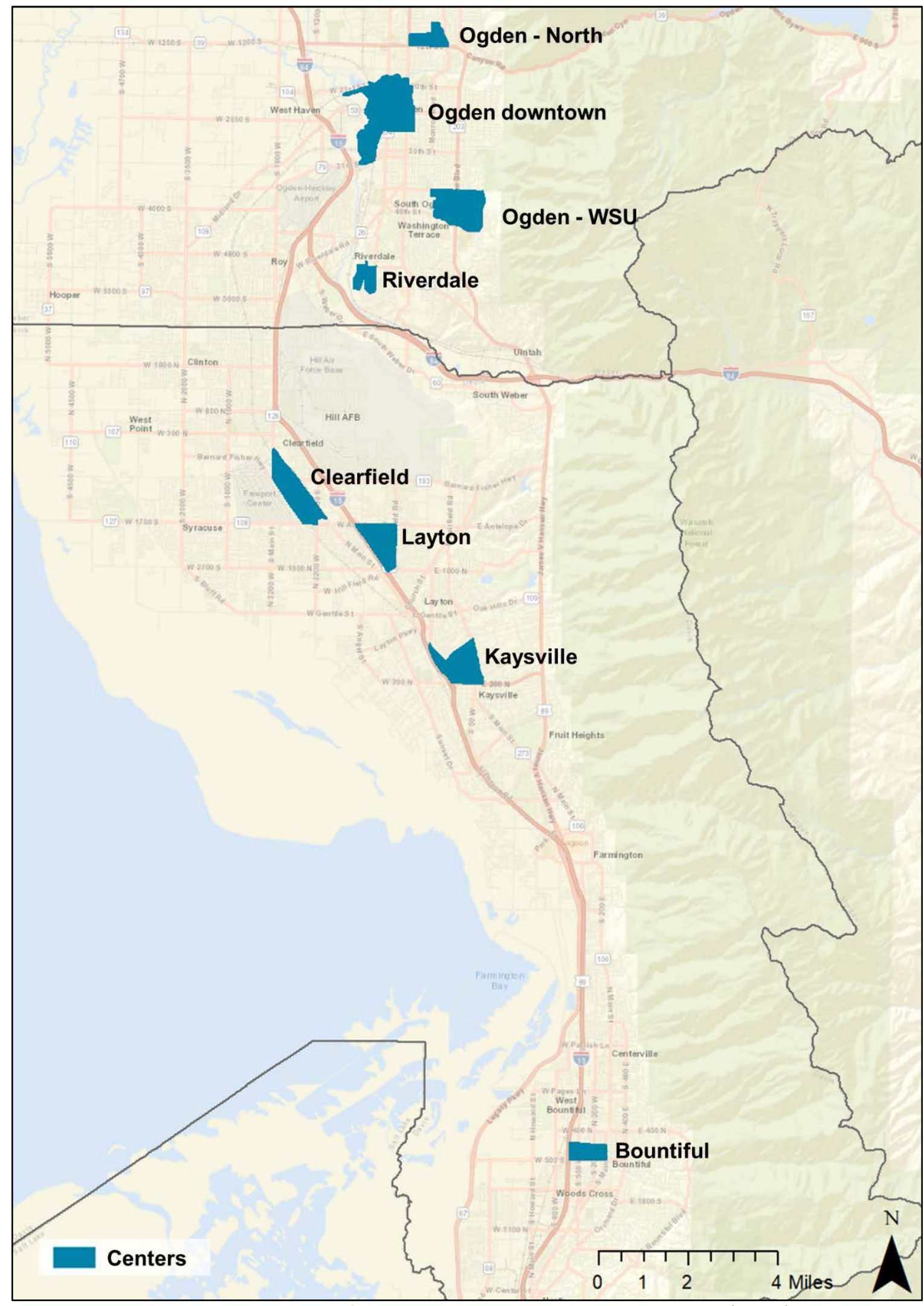

Figure A.1: Location of 22 centers in the Wasatch Front region (Part I) 


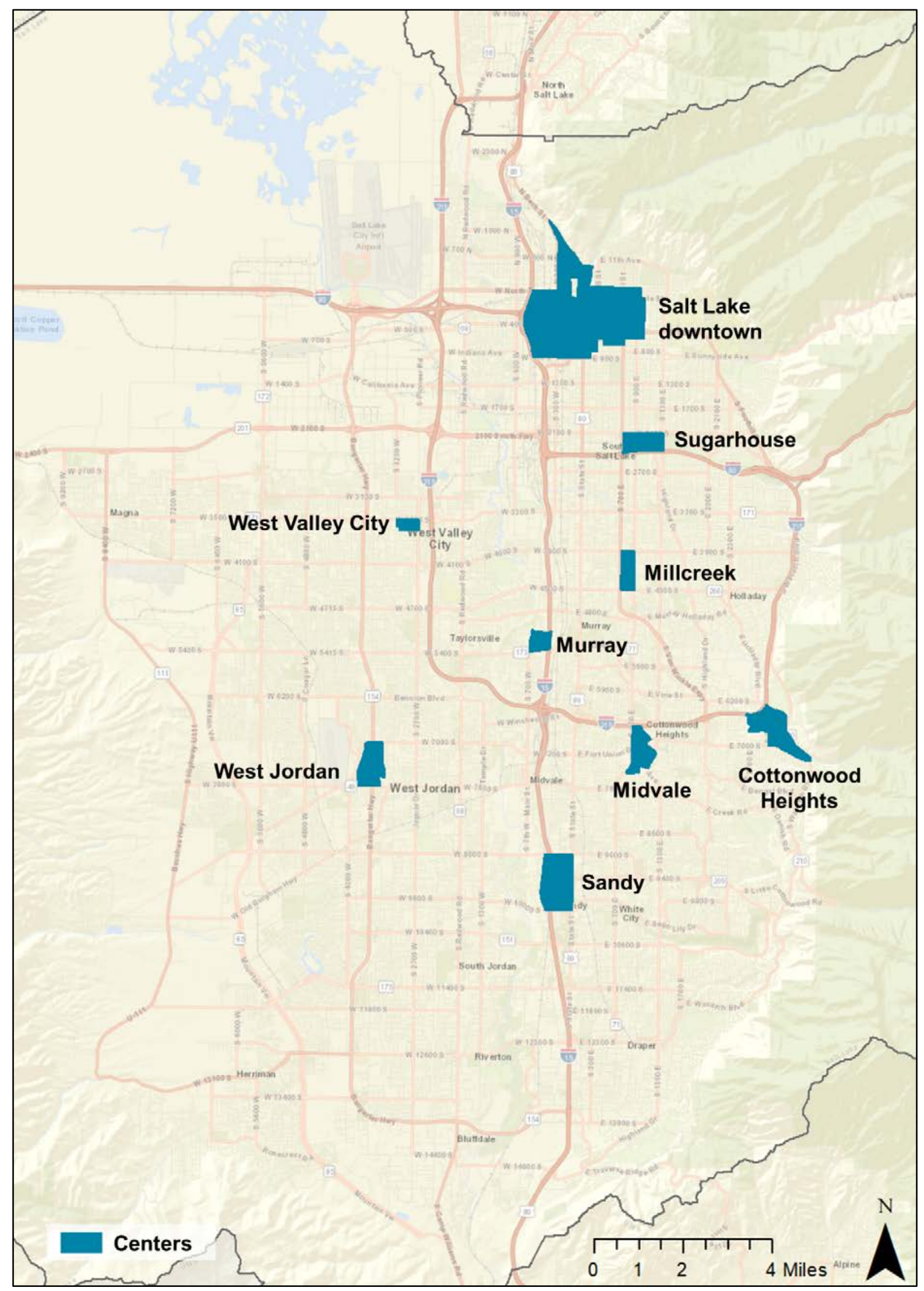

Figure A.2: Location of 22 centers in the Wasatch Front region (Part II) 


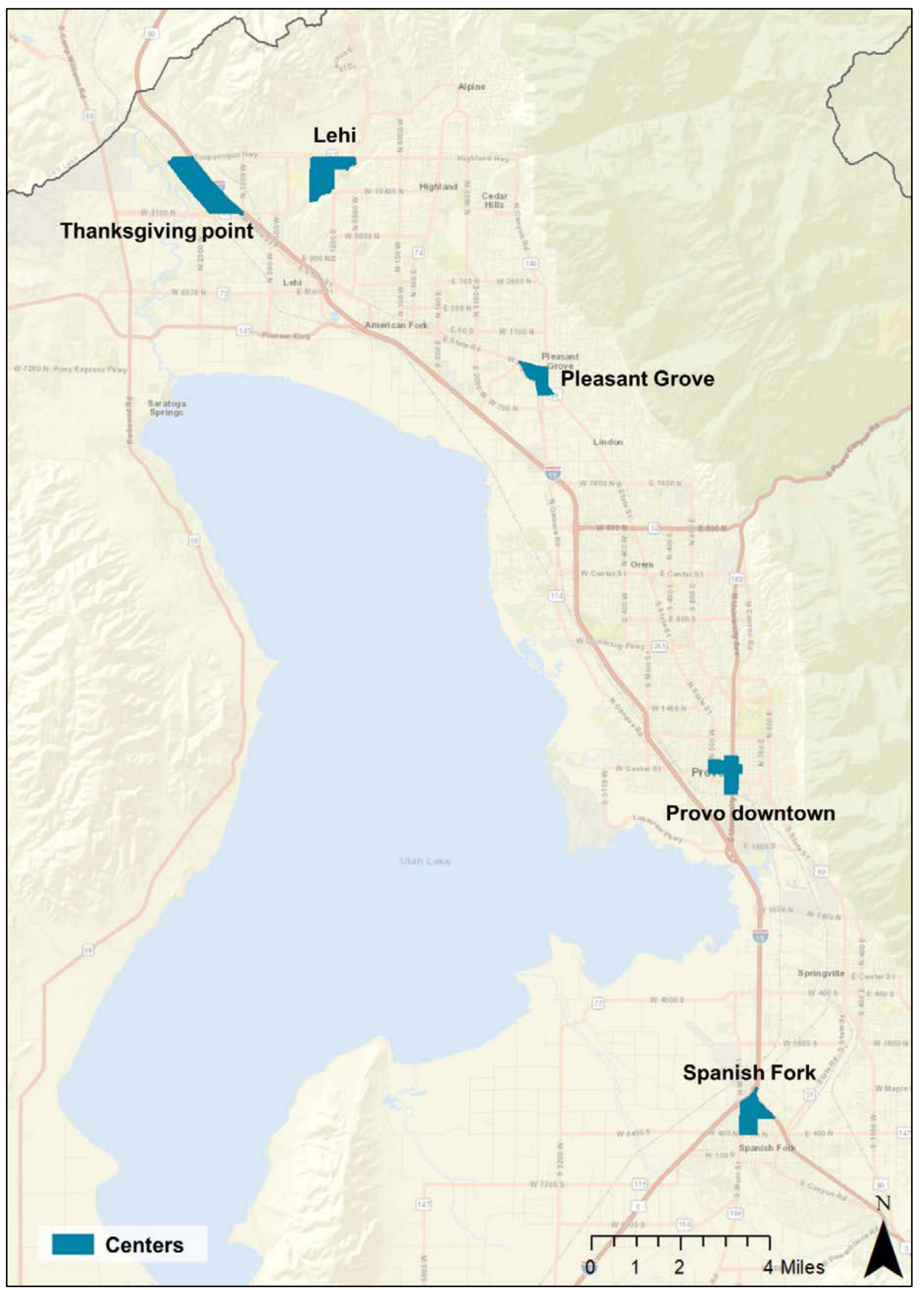

Figure A.3: Location of 22 centers in the Wasatch Front region (Part III) 